Pastor Willy Gonzales Taco

\title{
REDES NEURAIS ARTIFICIAIS APLICADAS NA MODELAGEM INDIVIDUAL DE PADRÕES DE VIAGENS ENCADEADAS A PÉ
}

Tese apresentada à Escola de Engenharia de São Carlos da Universidade de São Paulo, como parte dos requisitos para obtenção do título de Doutor em Engenharia de Transportes.

Orientador: Prof. Dr. Eiji Kawamoto

São Carlos

Julho 25

2003 


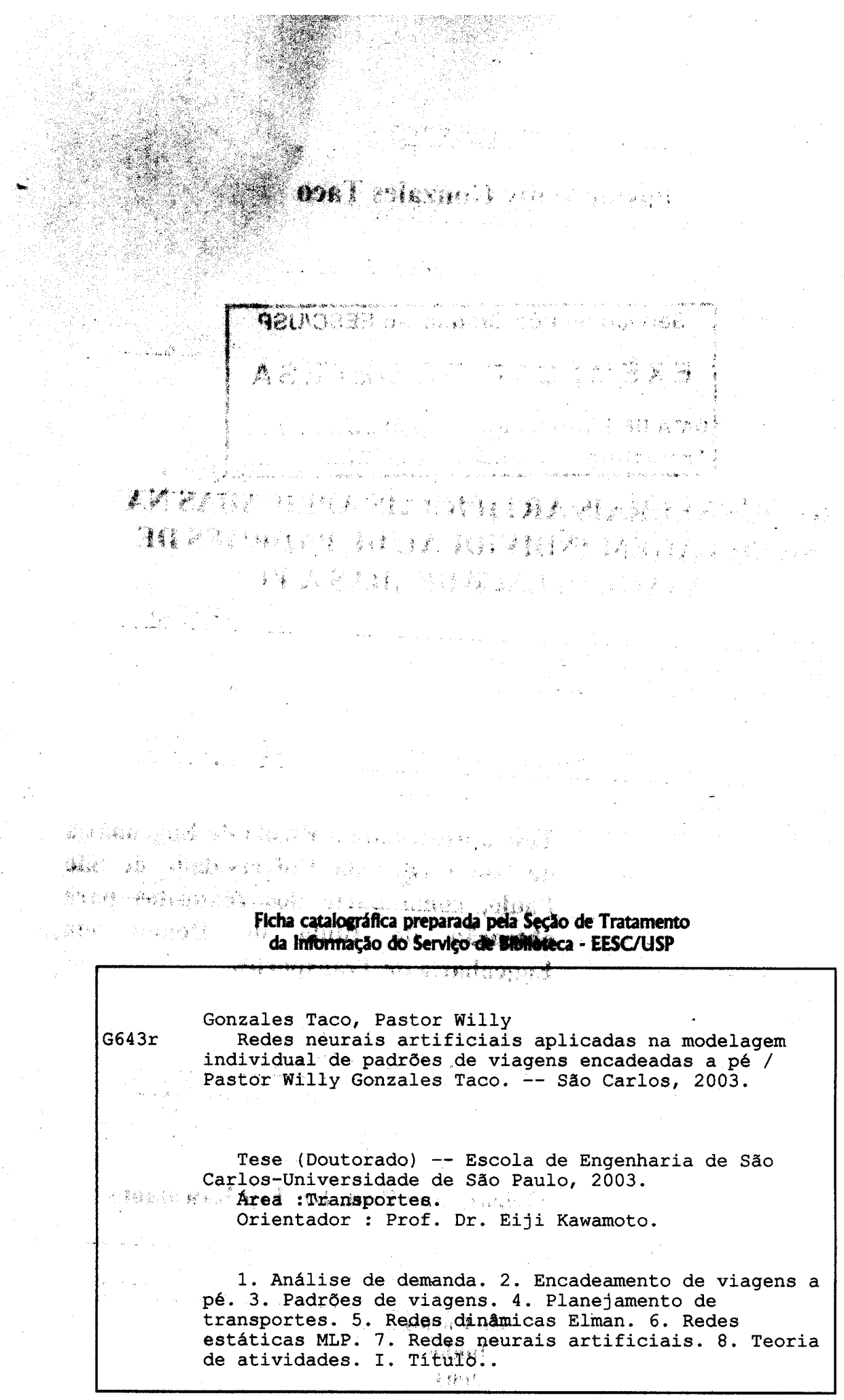


FOLHA DE JULGAMENTO

Candidato: Engenheiro: PASTOR WILLY GONZALES TACO

Tese defendida e julgada em 25-07-2 603 perante a Comissão Julgadora:

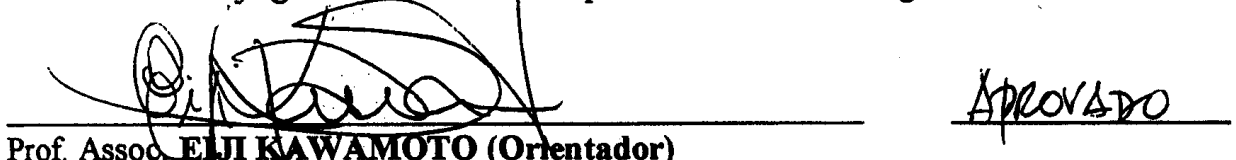

(Escola de Engenharia de São Carlos/USP)

\begin{tabular}{|c|c|}
\hline sue srancher & $\triangle P R O V A D O$ \\
\hline $\begin{array}{l}\text { Profa. Dra. SUEL DA PENHA SANCHES } \\
\text { (Universidade Federal de São Carlos/UFSCar) }\end{array}$ & \\
\hline wre An $_{1}$. Sonativi & APROVADO \\
\hline
\end{tabular}

Prof. Dr. JOSÉ APARECIDO SORRATINI

(Universidade Federal de Uberlândia/UFU)

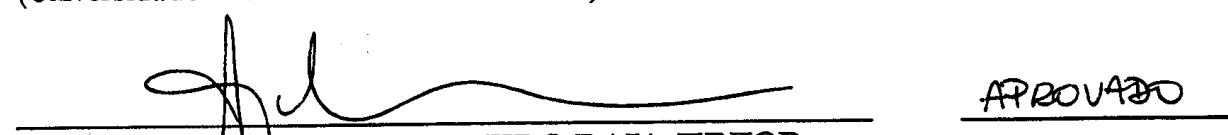

Prof. Dr. AROHIMEDES AZEVEDO RAIA JUNIOR

(Universidade Federal de São Carlos/UFSCar)

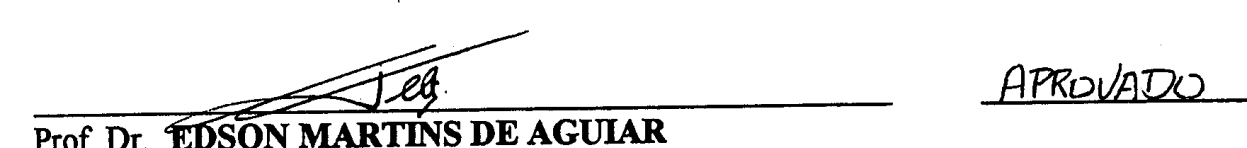

Prof. Dr. EDSON MARTINS DE AGUIAR

(Escola de Engenharia dę̧São Carlos/USP)

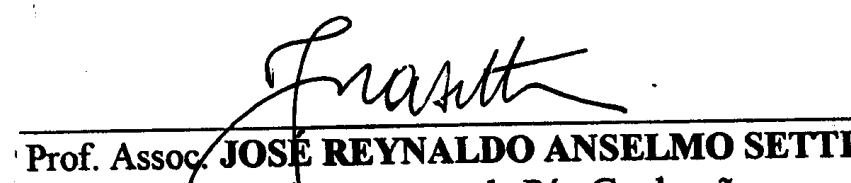

Coordehador do Programa de Pós-Graduação em

Engenharia de Transportes

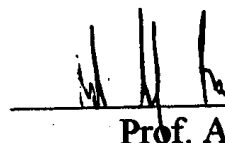

Prof. Assoc. MURILO ARAUJO ROMERO

Vice-Presidente da Comissão de Pós-Graduação da EESC, em exercício 
Com todo o amor que dia após dia têm mostrado para mim, dedico este trabalho: Aos meus pais Benito e Natividad, aos meus irmãos e irmãs Jorge, Edgard (in memoriam) e Wilberth, Rosa, Madeleine e Glenda, as minhas cunhadas Bertha e Josefina ao meu cunhado Carlos e aos meus sobrinhos e sobrinhas David, Karol,Gabriel, Fernando, Poldar e Victória, e a todos os meus familiares. 


\section{AGRADECIMENTOS}

Para a Luz Crucificada, a Rocha Eterna, o Verbo da Vida, o Manancial de Águas Eternas, a Verdade e $O$ Caminho, $O$ Espírito todo inclusivo que agora mora em mim: Jesus Cristo a Quem sirvo, ofereço meu louvor por ter-me concedido o privilégio de estar aqui no Brasil, de conhecer o significado da Vida, de experiênciar a riqueza de um povo hospitaleiro, e entre outras oportunidades a de poder escrever esta tese.

Ao Professor Eiji Kawamoto minha eterna gratidão pela sua orientação e acima de tudo pela amizade demonstrada ao longo do desenvolvimento da presente pesquisa.

À Professora Suely da Penha Sanchez e ao Professor Archimedes Raia Jr., pelas sugerencias indicadas no exame de qualificação, sem as quais não teria sido possível a culminação desta pesquisa.

À Professora Yaeko Yamashita pela motivação para continuar estudos de Doutorado, e pelo incentivo permanente, e ao Professor Márcio Muniz de Farias e ao jovem Jonas.

Aos Professores da Universidade de Brasília José Matsuo, Joaquim G. de Aragão, Maria Alice Prudêncio J., José Alex, Paulo César, José Augusto, pela motivação e amizade.

Ao Professor André Soares Dantas e a sua esposa a Doutora Karisa Ribeiro Dantas, pela amizade e pelo compartilhar das suas novas descobertas e vitórias.

Aos Professores do Departamento de Transportes da EESC-USP, pelo ensino recebido e pela amizade mostrada durante estes tempos de pós-graduação.

Ao Professor Guilherme de Alencar da Universidade Federal do Ceará pelos conselhos recebidos com os programas de Matlab.

A todos os amigos do Departamento de Transportes da EESC/USP, aqueles que encontrei ao chegar, aqueles que já foram e ainda aqueles que estão chegando. A todos vocês minha eterna gratidão pelos tempos vividos, a amizade que compartilhamos será levada como um tesouro inesgotável, que poderei compartilhar com outras pessoas, onde quer que eu esteja. Acho necessário citar os seus nomes, mas se acontecer que esqueça de outros, me perdoem. Quero agradecer ao Fábio Wermersch, ao Delfos e família, Renatinho, Ricardinho, Cida, Mario e o Diogo, Charlie, Sandra Rodgher, Coutinho, Cira, Juliana, Sandrinha, Márcia Lika, Cíntia Egami, Mauro Kenji, Cíntia Lotti, Scarlett, Gloria, Marta, Giovani, Rogério, Helio Marcus, Helio Arita, Gauchinha, Fernanda Biroli, Célio, Fernanda, Andrea Kaneko, Andrea Hora, Topó, Rômulo, Mario Herba, Profa. Marilda, Cláudio, Ari, João Mota, Fabiana, Carolina, Renato, Josiane e Mariana, Marcelo, Pablo, Shirley, Ana, Giseli, Antonio, Olympio. Aos amigos de 
Mensuração: Ûchoa, Tule, Genival, Maurício, Rodrigo, Antonio Sergio, Ana Paula, Marisa, Simone, Mônica Kofler, Mauro Menzori, Zé Maria, Geraldo. Para todos vocês "muchas bendiciones"...

Aos funcionários do Departamento: Carlos (Toco), Beth, Heloísa, Lílian, Magali, Sueli, Gigante, Paulinho, Vicente e Dom Ângelo.

À Norma pela amizade e a Fé compartilhada.

Aos amigos peruanos, o clube dos "pirulitos", Juan, Alex, César, Waldo, Lizbeth e Jorge. Aos amigos(a) cubanos, salvadorenhos, colombianos, africanos: Felipe, Marta, Edwin, William, Marlon, Mamadú, entre outros.

Ao Netanias, o meu caro amigo, pela sabedoria brindada nos momentos que mais precisava e por mostrar-me a praticidade da vida na presença do Senhor.

À Dennise pelo apoio e as orações, pela amizade e mais do que tudo por não desistir de apreender espanhol.

À Jaqueline pelo aconchego nas suas mensagens.

À Gissele Zandini pela simplicidade da nossa amizade.

Aos amigos da xerox do CAASO: Ricardo, Patrícia Freitas, Patrícia Duarte e Alexandra. Meu muito obrigado por tudo.

Ao Célio, ao Rodrigo Chalub torcedor inigualável do Santos FBC!

Ao Richard Martines parceiro na esperança de uma nova terra e novos céus!

Aos amigos da Guarda Universitária do PCASC.

Ao Pedro, irmão na Fé, na perseverança, na luta, na firme promessa de um novo amanha.

Ao Inerves e Família, obrigado por ter me mostrado $O$ Caminho.

Ao pessoal da Polícia Federal de Ribeirão Preto e Araraquara.

A Sayumy, a personagem do meu primeiro livro. "Gracias" por inspirar-me a descoberta de novas virtudes, pois como tenho apreendido: só basta darmos uma oportunidade e o fluir da vida ninguém segura.

Aos santos das igrejas no Perú, no Brasil e no mundo; a edificação do Corpo avança de dia em dia, e muito em breve a volta do Cordeiro fará surgir a cidade de ouro transparente, com colunas de pérolas vivas... Maran-ata... 
Aos irmãos e irmãs da Igreja em São Carlos, pelas orações e por acima de tudo terem sido minha família, uma única e universal família; ao César e família, Cidinho e família, Zezinho e família, Osório e família, Martins e família, Jurandir e família, Dona Antonieta, Robson e família, Christian e Kelly; João e Família, Eder e família, Daniel e Família, Patracón e Família, Silvio Luporini e família, Leda e Família, André e família, Mauriza, Álvaro, Josias; e em especial ao Carlos, Iara e Heitor por ter-me providenciado a proteção e as bênçãos da sua casa, nos momentos em que as águas bravias e os ventos fortes arremetiam. Obrigado santos, pois aprendi que os ventos fortes, quando direcionados, produzem energia; e que as águas bravias nos ensinam a encarar a vida de uma forma diferente!

Aos santos do Projeto "Entendendo a Bíblia nas Universidades" EESC-USP: Fabiano, Natanael, Bangui, Patrícia, Rebeca, Matias, Daniel, Gessner.

A Dom Ivan, Dona Silvia, Ayla e Aline, pela força mostrada durante estes oito anos de vida fora de terras peruanas.

À Dona Valdineris, ao Renato e esposa; Dona Tereza Moura e família, pela acolhida e amizade compartilhada.

Aos redimidos para dentro de um novo Corpo nestes tempos de pós-graduação: Julio, Scarlett, Elmer, Bina, José Luis, Eduardo e família. Um ano a mais não foi em vão!

À Coordenadoria de Aperfeiçoamento de Pessoal de Nível Superior - CAPES, pela bolsa de estudos concedida.

E muito em especial, ao cidadão Brasileiro, que cada dia tem-me mostrado a sua férrea vontade de ser amistoso e hospitaleiro, e para quem peço a Deus derrame toda as suas bênçãos. 
"Bendito o homem que confia no SENHOR e cuja esperança é o SENHOR.

Porque ele é como a árvore plantada junto às águas, que estende as suas raízes para o ribeiro e não receia quando vem o calor, mas a sua folha fica verde; e no ano de sequidão, não se perturba, nem deixa de dar fruto". 


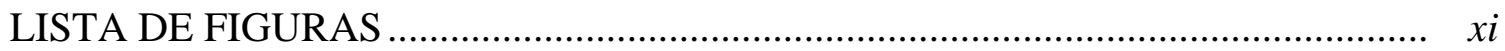

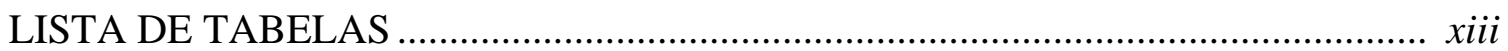

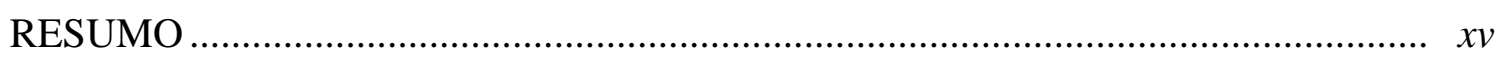

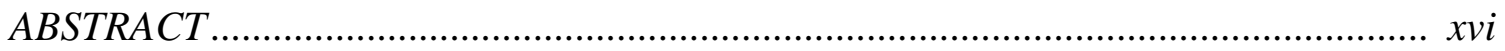

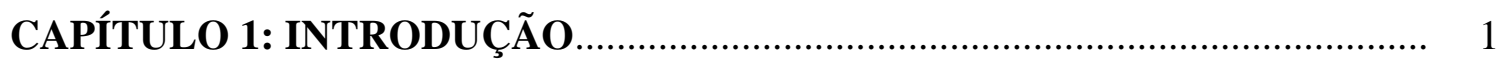

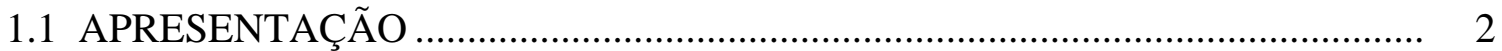

1.2 CONTEXTO DA TESE: ENCADEAMENTO DE VIAGENS E MUDANÇAS DE PARADIGMAS NA MODELAGEM EM TRANSPORTES .......................... 3

1.3 RELEVÂNCIA DO TRABALHO E QUESTIONAMENTOS A SEREM RESOLVIDOS .......................................................................................... 6

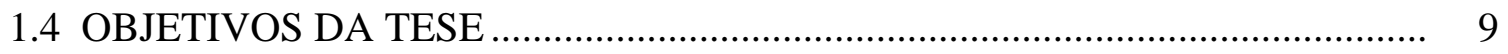

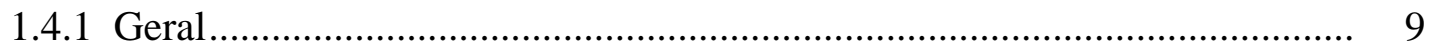

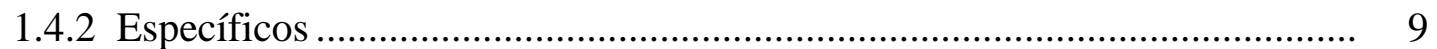

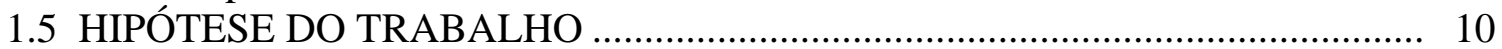

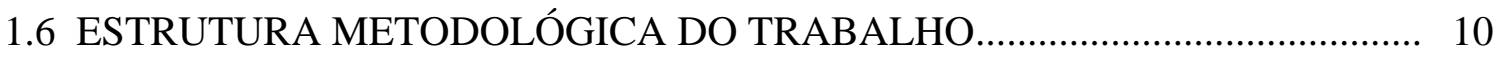

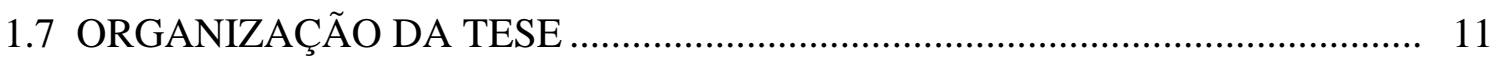

CAPÍTULO 2: COMPORTAMENTO DE VIAGENS BASEADAS EM ATIVIDADES E VIAGENS ENCADEADAS .................................................... 13

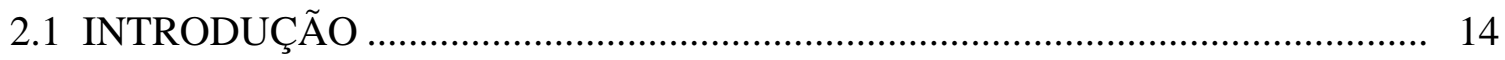

2.2 PLANEJAMENTO DE TRANSPORTE E VIAGENS ENCADEADAS .............. 15

2.3 PLANEJAMENTO DE TRANSPORTE E VIAGENS A PÉ................................ 16

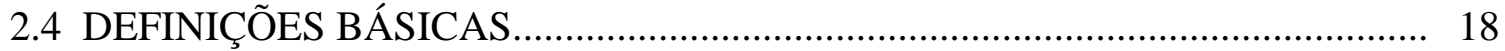

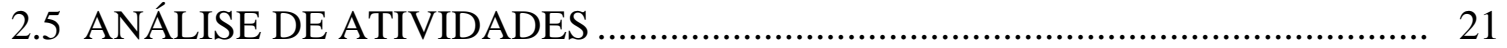

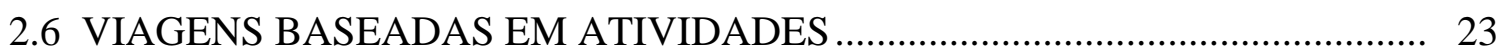

2.7 ANÁLISE DE VIAGENS ENCADEADAS ....................................................... 25

2.8 MODELOS DE ATIVIDADES E VIAGENS ENCADEADAS .............................. 26

2.8.1 Classificações Baseadas em Atividades................................................... 27

2.8.2 Modelos Básicos ..................................................................................... $\quad 30$

2.9 VARIÁVEIS UTILIZADAS NOS MODELOS DE VIAGENS ENCADEADAS . 33

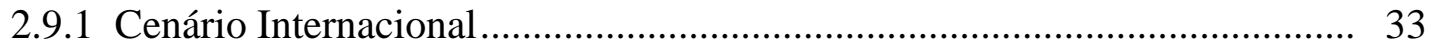

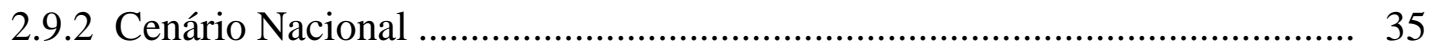

2.9.3 Variáveis Condicionantes .................................................................... 36 
3.1 INTRODUÇÃO

3.2 MODELAGEM COM REDES NEURAIS ARTIFICIAIS ...................................... 40

3.2.1 Redes Neurais Artificiais Estáticas ............................................................. 41

3.3 PROCESSAMENTO TEMPORAL ATRAVÉS DAS REDES NEURAIS ARTIFICIAIS

3.3.1 Redes Neurais Temporais .......................................................................... 44

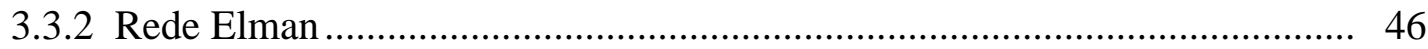

3.4 MODELAGEM EM TRANSPORTES FAZENDO USO DE REDES NEURAIS ARTIFICIAIS

3.5 TÓPICOS CONCLUSIVOS ................................................................................ 52

CAPÍTULO 4: MODELO NEURAL DE ENCADEAMENTO DE VIAGENS ..... 53

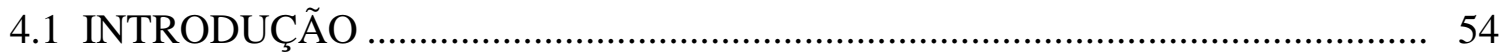

4.2 SUPOSIÇÕES TEÓRICAS PARA CONCEPÇÃO DO MODELO NEURAL DE

ENCADEAMENTO DE VIAGENS.

4.3 DEFINIÇÕES BÁSICAS PARA CONCEPÇÃO DO MODELO NEURAL DE ENCADEAMENTO DE VIAGENS................................................................ 58

4.3.1 Restrições da Modelagem............................................................................. 65

4.4 FORMULAÇÃO NEURAL DO MODELO DE ENCADEAMENTO DE VIAGENS

4.4.1 Formulação da Arquitetura de Rede Neural no Modelo ................................ 67

4.4.2 Formulação do Algoritmo de Treinamento da Rede Neural no Modelo ...... 69

4.5 TÓPICOS CONCLUSIVOS ........................................................................... 71

CAPÍTULO 5: MÉTODO PARA VERIFICAÇÃO DA MODELAGEM DE PADRÕES DE ENCADEAMENTO DE VIAGENS A PÉ....................................... 72

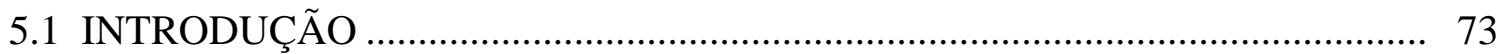

5.2 FASE 1: DEFINIÇÃO E SISTEMATIZAÇÃO DO MODELO ………………….... 74

5.3 FASE 2: COLETA, ANÁLISE E SELEÇÃ̃O DE DADOS........................................ 75

5.3.1 Filtragem e Seleção de Dados.................................................................... 76

5.3.2 Definição das Variáveis de Entrada .............................................................. 77

5.3.3 Definição das Variáveis de Saída ............................................................... 79

5.3.4 Definição da Amostra ............................................................................. 80

5.4 FASE 3: PRÉ-PROCESSAMENTO DOS DADOS PARA MODELAGEM ......... 81

5.4.1 Codificação ………………………………………………………..... 81

5.4.2 Normalização …………………………………………………………. 83

5.4.2 Partições ............................................................................................. 85

5.5 FASE 4: SIMULAÇÃO DAS RNAs MLP e ELMAN ………………………….... 86

5.5.1 Programa de Simulação …………………………………………………... 86 
5.5.2 Seleção da Topologia das RNAs

5.5.3 Processo de Treinamento Validação e Teste ............................................... 89

5.6 FASE 5: PÓS-PROCESSAMENTO DOS ATRIBUTOS DE SAÍDA DAS

RNAs.

5.6.1 Desnormalização dos Atributos de Saída ................................................ 91

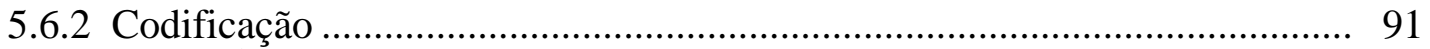

5.7 FASE 6: ANÁLISE DE RESULTADOS …..................................................... 91

5.7.1 Tabulação, Análise e Interpretação......................................................... 92

5.7.2 Desempenho da Rede Neural .................................................................... 93

\section{CAPÍTULO 6: APLICAÇÃO DO MODELO NEURAL DE ENCADEAMENTO} DE VIAGENS A PÉ NA REGIÃO METROPOLITANA DE SÃO PAULO 198795

6.1 INTRODUÇÃO

6.2 COLETA, SELEÇÃO E ANÁLISE DOS DADOS DA REGIÃO METROPOLITANA DE SÃO PAULO 1987 .................................................. 96

6.2.1 Dados da Pesquisa Domiciliar Origem-Destino da RMSP 1987 ................. 97

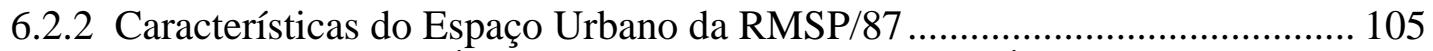

6.3 DEFINIÇÃO DAS VARIÁVEIS DE ENTRADA E DE SAÍDA …........................ 109

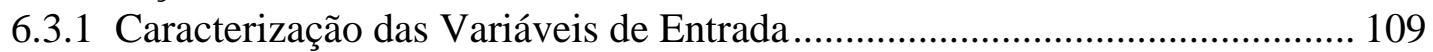

6.4 APLICAÇÃO DO MODELO NEURAL DE ENCADEAMENTO DE

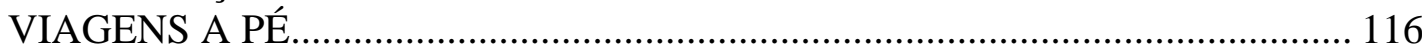

6.4.1 Modelagem do Vetor dos Padrões de Duração e Tipo de Atividade das Viagens Encadeadas a Pé .......................................................................... 117

CAPÍTULO 7: ANÁLISE DE RESULTADOS.

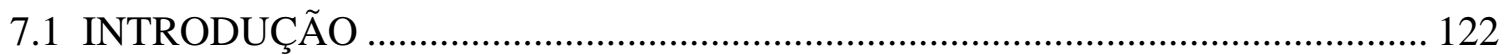

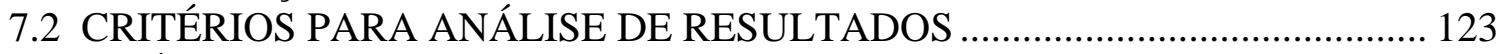

7.3 ANÁLISE DA MODELAGEM GERAL DAS VIAGENS ENCADEADAS ........ 125

7.3.1 Análise dos Resultados dos Conjuntos de Teste das Redes M12g e E3b .... 129

7.4 ANÁLISE DA MODELAGEM PARA DUAS VIAGENS ENCADEADAS ........ 139

7.4.1 Análise da Classificação dos Padrões de VEP por Topologia de Rede para

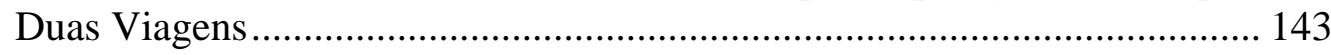

7.4.2 Análise da Classificação por Cadeia de Viagem para Duas Viagens:

Duração - Atividade.

7.4.3 Análise da Classificação por Padrão de Encadeamento para Duas Viagens 147

7.5 ANÁLISE DA MODELAGEM PARA TRÊS VIAGENS ENCADEADAS ........ 149

7.5.1 Análise da Classificação dos Padrões de VEP por Topologia de Rede para Três Viagens....

7.5.2 Análise de Classificação por Cadeia de Viagem para Três Viagens:

Duração - Atividade

7.5.3 Análise da Classificação por Padrão de Encadeamento para Três Viagens . 156

7.6 ANÁLISE DA MODELAGEM PARA QUATRO VIAGENS ENCADEADAS . 158

7.6.1 Análise da Classificação dos Padrões de VEP por Topologia de Rede para Quatro Viagens 
7.6.2 Análise da Classificação por Cadeia de Viagem para Quatro Viagens:

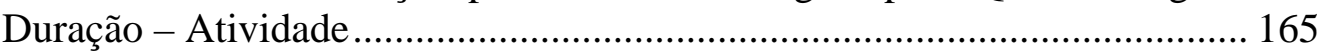

7.6.3 Análise da Classificação por Padrão de Encadeamento para Quatro Viagens

8.1 INTRODUÇÃO

8.3 RECOMENDAÇÕES 184

REFERÊNCIAS BIBLIOGRÁFICAS 


\section{LISTA DE FIGURAS}

Figura 1.1: Estrutura Metodológica

Figura 2.1: Conceitos de tour e encadeamento de viagem

Figura 2.2: Desenvolvimento dos modelos baseados em atividades (BOWMAN e

BEN-AKIVA, 1997; BOWMAN, 1998).

Figura 3.1: Modelo estático de neurônio artificial

Figura 3.2: Processamento Temporal (a) usando atrasos no tempo (HAYKIN, 1999),

(b) utilizando rede recorrente (HERTZ et al. 1991)....

Figura 3.3: Rede completamente recorrente - Rede Elman.

Figura 4.1: Estrutura das decisões de viagens e desenvolvimento urbano .................... 55

Figura 4.2: Mudanças na demanda por transportes pela redefinição na estrutura familiar

Figura 4.3: Estrutura de abordagem de viagens encadeadas baseado em atividades..... 57

Figura 4.4: Elementos do sistema de comportamento dinâmico da modelagem do encadeamento de viagens

Figura 4.5: Formulação espaço-tempo do encadeamento de viagens .....

Figura 4.6: Estados da viagem começando e finalizando no domicílio num Período de tempo compreendido entre as 0hrs. até as $24 \mathrm{hrs}$.

Figura 4.7: Continuidade Temporal do encadeamento de viagens ............................. 66

Figura 4.8: Continuidade Espacial do encadeamento de viagens ................................ 66

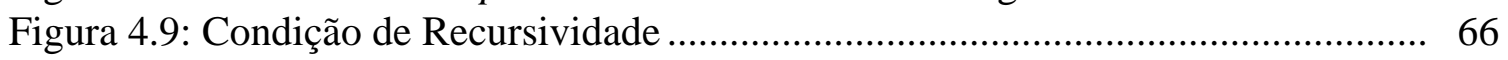

Figura 4.10: Condição de Linearidade ................................................................ 67

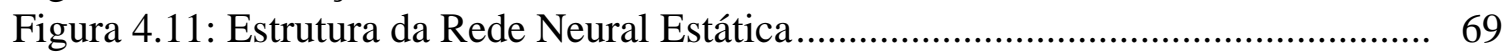

Figura 4.12: Estrutura da Rede Neural Recorrente .......................................................69

Figura 5.1: Estrutura do método proposto ............................................................... 74

Figura 5.2: Estrutura da seleção e pré-processamento de dados.................................. 80

Figura 5.3: Codificação dos padrões das cadeias de viagens a pé ................................. 82

Figura 6.1: Porcentual de indivíduos que fazem viagens a pé por IDADE - RMSP/87 101

Figura 6.2: Porcentual de indivíduos que fazem viagens a pé por classe de SMED -

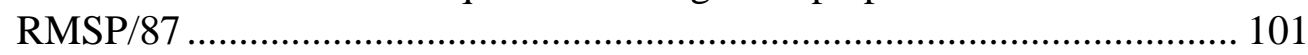

Figura 6.3: Porcentual de indivíduos por tempo médio de viagem - RMSP/87 ............ 104

Figura 6.4: Divisão da RMSP/87 em zonas de tráfego .................................................... 106

Figura 6.5: Mapa temático de acessibilidade por distância média entre zonas da RMSP/87

Figura 6.6: Mapa temático do índice normalizado de atratividade por empregos da RMSP/87

Figura 6.7: Mapa temático do índice normalizado de atratividade por matrículas da RMSP87 
Figura 6.8: Exemplos de padrões de VEP baseadas em atividades

Figura 6.9: Estrutura do Modelo de Viagens Encadeadas a Pé - RMSP87

Figura 6.10: Freqüência relativa de padrões de VEP para a amostra de DUAS viagens.

Figura 6.11: Freqüência relativa de padrões de VEP para a amostra de TRÊS viagens 120

Figura 6.12: Freqüência relativa de padrões de VEP para a amostra de QUATRO viagens.

Figura 7.1: Classificação dos padrões observados e previstos de viagens encadeadas a pé do conjunto de teste da rede $\mathbf{M 1 2 g}$.....

Figura 7.2: Freqüência relativa de características socioeconômicas e espaciais para o conjunto de indivíduos que fazem os padrões de VEP 11S e 22S

Figura 7.3: Classificação dos padrões observados e previstos de viagens encadeadas a pé do conjunto de teste da rede $\mathbf{E} 3 \mathbf{b}$.

Figura 7.4: Freqüência média de classificação das redes MLP e Elman para DUAS viagens encadeadas a pé

Figura 7.5: Classificação de atividades por topologia de redes MLP e Elman para DUAS viagens encadeadas a pé

Figura 7.6: Classificação de padrões de VEP por topologia de redes MLP e Elman para DUAS viagens encadeadas a pé

Figura 7.7: Freqüência média de classificação das redes MLP e Elman para TRÊS viagens encadeadas a pé

Figura 7.8: Classificação de atividades por topologia de redes MLP para TRÊS viagens encadeadas a pé

Figura 7.9: Classificação de atividades por topologia de redes Elman para TRÊS viagens encadeadas a pé.

Figura 7.10: Classificação de padrões de VEP por topologia de redes MLP e Elman para TRÊS viagens encadeadas a pé....

Figura 7.11: Freqüência média de classificação das redes MLP e Elman para QUATRO viagens encadeadas a pé

Figura 7.12: Classificação de atividades por topologia de redes MLP para QUATRO viagens encadeadas a pé

Figura 7.13: Classificação de atividades por topologia de redes Elman para QUATRO viagens encadeadas a pé....

Figura 7.14: Classificação de PVE por topologia de redes MLP e Elman para QUATRO viagens encadeadas a pé. 


\section{LISTA DE TABELAS}

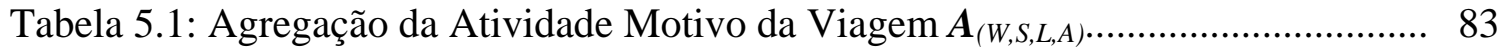

Tabela 5.2: Agregação do Período da Viagem $P_{(1,2,, N)}$. ……………………………... 83

Tabela 5.3: Equações típicas de normalização (ZHAN, PATUWO e HU. 1998)......... 84

Tabela 5.4: Codificação do dado calculado $\boldsymbol{x}_{\mathbf{0}}$............................................................. 91

Tabela 5.5: Medidas de desempenho da rede ............................................................. 93

Tabela 6.1: Freqüência das Variáveis Individuais e Domiciliares - RMSP87 .............. 100

Tabela 6.2: Agregação da Atividade (Motivo da Viagem) ............................................. 102

Tabela 6.3: Características das viagens encadeadas a pé ................................................ 103

Tabela 6.4: Normalização do Vetor dos Dados Socioeconômicos Individuais e

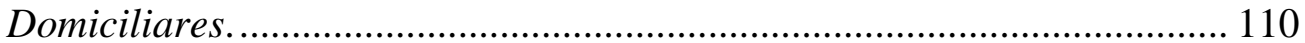

Tabela 6.5: Codificação dos tempos de duração de cada viagem.................................... 111

Tabela 6.6: Freqüência dos padrões de duração da viagem............................................. 112

Tabela 6.7: Codificação das atividades por cada viagem .............................................. 113

Tabela 6.8: Padrões das atividades por viagem ............................................................. 113

Tabela 6.9: Padrões de VEP da duração de viagem e do tipo de atividade ..................... 115

Tabela 6.10: Normalização do vetor dos dados de saída ............................................... 116

Tabela 7.1: Acerto de classificação médio de padrões de VEP para as redes MLP e Elman ............................................................................................. 127

Tabela 7.2: Acerto de classificação médio de padrões de VEP para a rede MLP .......... 128

Tabela 7.3: Acerto de classificação médio de padrões de VEP para a rede Elman ........ 129

Tabela 7.4: Acerto de classificação por topologia da rede MLP para DUAS viagens encadeadas a pé.

Tabela 7.5: Acerto de classificação por topologia da rede Elman para DUAS viagens encadeadas a pé

Tabela 7.6: Erro quadrático médio (EQM) de classificação por topologia da rede MLP para DUAS viagens encadeadas a pé................................................ 142

Tabela 7.7: Erro quadrático médio (EQM) de classificação por topologia da rede Elman para DUAS viagens encadeadas a pé.

Tabela 7.8: Acerto de classificação por topologia da rede MLP para TRÊS viagens encadeadas a pé

Tabela 7.9: Acerto de classificação por topologia da rede Elman para DUAS viagens encadeadas a pé

Tabela 7.10: Erro quadrático médio $(\boldsymbol{E Q M})$ de classificação por topologia da rede MLP para TRÊS viagens encadeadas a pé.

Tabela 7.11: Erro quadrático médio $(\boldsymbol{E} \boldsymbol{Q M})$ de classificação por topologia da rede Elman para TRÊS viagens encadeadas a pé

Tabela 7.12: Acerto de classificação por topologia da rede MLP para QUATRO viagens encadeadas a pé 
Tabela 7.12: Acerto de classificação por topologia da rede MLP para QUATRO viagens encadeadas a pé (Continuação)

Tabela 7.13: Acerto de classificação por topologia da rede Elman para QUATRO viagens encadeadas a pé.

Tabela 7.13: Acerto de classificação por topologia da rede Elman para QUATRO viagens encadeadas a pé (Continuação)

Tabela 7.14: Erro quadrático médio (EQM) de classificação por topologia da rede MLP para QUATRO viagens encadeadas a pé.

Tabela 7.15: Erro quadrático médio (EQM) de classificação por topologia da rede Elman para QUATRO viagens encadeadas a pé..... 


\section{RESUMO}

GONZALES TACO, P. W. (2003). Redes neurais artificiais aplicadas na modelagem individual de padrões de viagens encadeadas a pé. São Carlos, 2003. 209p. Tese (Doutorado) - Escola de Engenharia de São Carlos, Universidade de São Paulo.

O objetivo deste trabalho foi desenvolver um modelo para reconhecer e reproduzir padrões de viagens encadeadas a pé. O processo de modelagem foi conduzido através da aplicação das técnicas das Redes Neurais Artificiais (RNAs), utilizando-se de uma rede estática MLP e de rede dinâmica Elman. A análise do desempenho do modelo foi baseada nos dados de uma pesquisa de Origem-Destino realizada, em 1987, pelo METRÔ-SP na Região Metropolitana de São Paulo. Na modelagem foi fixado o modo de viagem a pé, e, na abordagem seqüencial, padrões de viagens individuais foram representados em termos de dois componentes: duração da viagem e tipo de atividades. A análise foi realizada partindo da classificação geral e específica para cada segmento do encadeamento de viagens, o que permitiu a comparação dos resultados entre padrões de viagens observados e os reproduzidos pelas redes. Na classificação geral, cinco dos padrões previstos com maior freqüência pelas RNAs representaram em média 58,9\% dos indivíduos no conjunto de dados usado para testar o desempenho do modelo. Para o vetor de duas e quatro viagens, as redes neurais reproduziram $50 \%$ das durações de viagem e $90 \%$ das atividades, tais como Trabalho e Escola. Embora esses resultados não pareçam muito robustos, não significa que eles estejam errados. As porcentagens acima representam a probabilidade de uma pessoa realizar viagens com aquelas durações ou tipo de atividades.

Palavras-chave: análise de demanda; encadeamento de viagens a pé; padrões de viagens; planejamento de transportes; redes dinâmicas Elman; redes estáticas MLP; redes neurais artificiais; teoria de atividades. 


\begin{abstract}
GONZALES TACO, P. W. (2003). Artificial neural networks applied in individual modeling of trip-chaining patterns by walk. São Carlos, 2003. 209p. Doctoral Thesis. Escola de Engenharia de São Carlos, Universidade de São Paulo.
\end{abstract}

The main objective of this work was to develop a model for recognizing and reproduzing trip-chaining patterns by walk. The process of modeling was conducted applying the techniques of Artificial Neural Networks (ANNs), by using one of the static networks MLP and the Elman dynamic network. The analysis of the performance of the model was based on the origin-destination home-interview survey carried out by METRÔ-SP in São Paulo Metropolitan Area in 1987. The mode of trip by walk was fixed in the model, and, in the sequential approach, individual travel patterns were represented in terms of two components: trip duration and activity type. The analysis was accomplished starting from the general and specific classifications for each segment of the chained trips, which allowed the comparison of the results between the observed travel patterns and reproduced ones through ANNs. In general classification, 5 of the patterns most frequently predicted by the ANNs represented $58.9 \%$ of the individuals in the dataset used for testing the model performance. For the vectors of two and four trips, the neural networks reproduced $50 \%$ of trip durations and $90 \%$ of the activities, such as work and school. Although those results seem not so robust, it does not mean that they are wrong. The percentages above represent the probability of a person making trips with those durations or type of activities.

Keywords: demand analysis, trip-chaining by walk, travel patterns, transport planning, dynamic network Elman, static network MLP, artificial neural networks, activity based theory. 


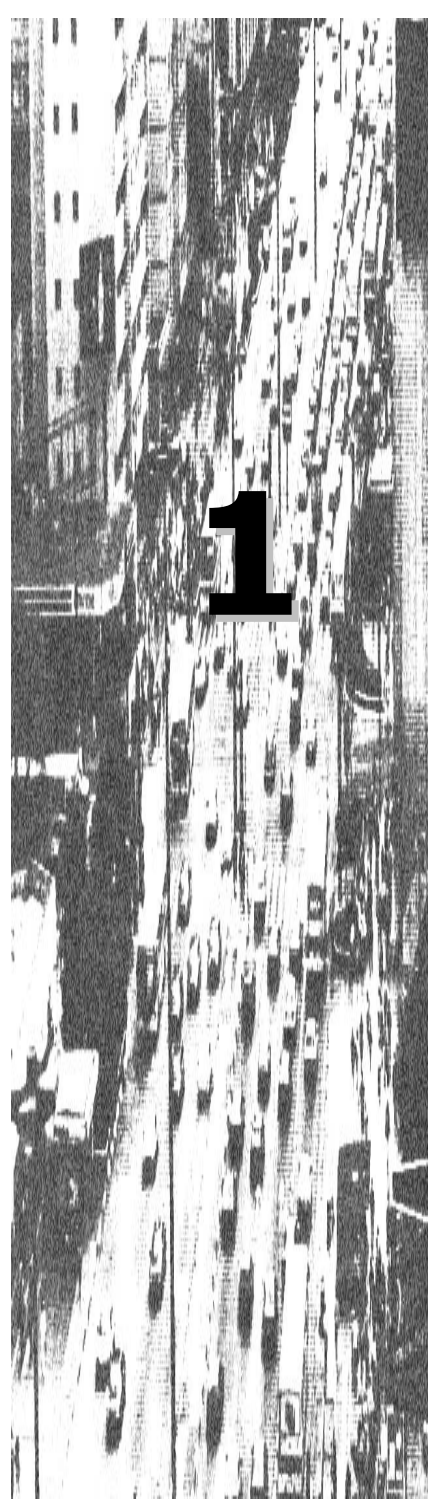

\section{Introdução}

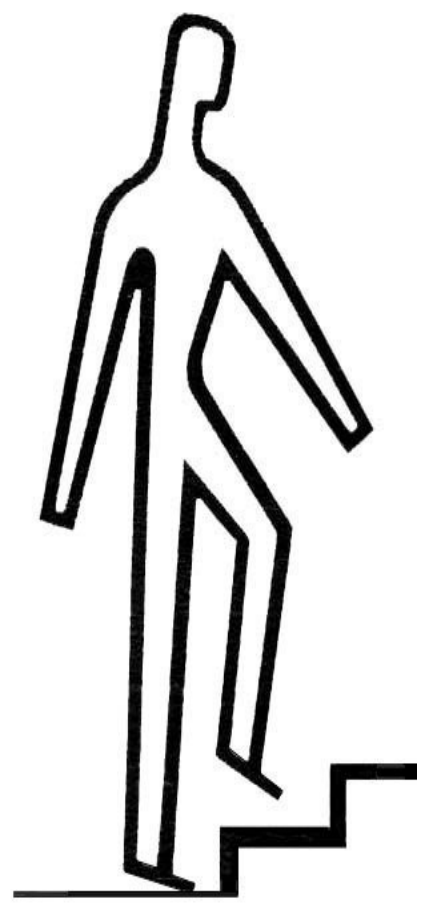

mas o Senhor lhe dirige os passos" 


\section{INTRODUÇÃO}

\subsection{APRESENTAÇÃO}

O encadeamento de viagens é a face visível de uma série de decisões tomadas por pessoas ao longo de uma unidade de tempo. A análise de cadeias de viagens é uma forma de compreender as motivações e as restrições que propiciam a formação de seqüência de viagens. Tradicionalmente, para modelar viagens encadeadas, utiliza-se uma abordagem seqüencial gerando padrões de atividades individuais dentro de vários componentes, tais como: tipo de atividades, duração, localização, e, escolha do modo da viagem. Entretanto, na presente tese, apresenta-se o resultado da aplicação de um modelo individual de geração de padrões de viagens encadeadas diárias a pé fazendo uso de Redes Neurais Artificiais (RNAs) que considera as dinâmicas do comportamento individual, as influências domiciliares, e, as restrições espaço-temporal, além de poder ser incorporado em um sistema de modelo de análise e previsão de viagens urbanas. Inspirada pela arquitetura do cérebro humano, as RNAs são ferramentas matemáticas que permitem modelar relações complexas (lineares ou não-lineares) que raramente são atingidas pela modelagem tradicional.

O presente capítulo introdutório está dividido em oito seções. Na primeira seção há uma breve apresentação; na segunda seção são tratados os aspectos que contextualizam a tese, especialmente aqueles relacionados ao comportamento das viagens encadeadas e de mudanças de paradigmas na modelagem; na terceira seção são 
apresentados a relevância da tese e os questionamentos a serem resolvidos; na quarta seção são definidos os objetivos da tese; na quinta seção, é estabelecida a hipótese da tese; na sexta seção apresentam-se as justificativas da aplicação da tese no contexto Brasileiro; na sétima seção é apresentada a estrutura metodológica da tese; e, finalmente, na oitava seção, mostrar-se-á a organização da presente tese.

\subsection{CONTEXTO DA TESE: ENCADEAMENTO DE VIAGENS E MUDANÇAS DE PARADIGMAS NA MODELAGEM EM TRANSPORTES}

Nos últimos 20 anos, pesquisadores e planejadores de transportes têm estudado o comportamento referente às viagens encadeadas. Importantes mudanças nos paradigmas de modelagem na demanda por transportes permitiram significativos avanços e conclusões nesta área (ADLER e BEN-AKIVA, 1979; GOLOB, 1986; GOULIAS, PENDYALA e KITAMURA, 1990; KITAMURA, 1984; NISHII, KONDO e KITAMURA, 1998; SHIFTAN, 1999; STRATHMAN, DUEKER e DAVIS 1994; STRATHMAN e DUEKER, 1995). A primeira mudança está relacionada com a consideração da viagem como uma demanda derivada pela demanda de atividades. Conseqüentemente, o deslocamento por si só não teria mais sentido e o estudo das atividades torna-se-ia mais importante do que o das viagens.

A segunda mudança se baseia no fato de que o contexto em que as atividades humanas se desenvolvem - o tempo, o espaço e o lugar na seqüência de eventos - é crucial ao estudo das viagens de um indivíduo. Assim, a consideração do tempo e o espaço na análise quebram uma longa tradição na área de planejamento de transportes, na medida em que esta analisava viagens individuais, vistas apenas como deslocamentos físicos no espaço (McNALLY, 2000; KITAMURA, 1996; KURANI e LEEGOSSELIN, 1996).

A terceira mudança diz respeito à inclusão das características individuais atreladas as características domiciliares na modelagem. As dinâmicas dos comportamentos e inter-relações entre os indivíduos dentro do domicílio influenciam as decisões de suas atividades, e, conseqüentemente das viagens (McNALLY, 2000; STRATHMAN, 
DUEKER e DAVIS, 1994). Ao considerar o encadeamento das viagens influenciadas pelo encadeamento das atividades, no tempo e no espaço, e pelas dinâmicas domiciliares, quebra-se outra tradição: a de considerar apenas viagens isoladas como processos discretos de decisão.

A incorporação destes avanços das mudanças dos paradigmas de modelagem na demanda por transportes levou a ganhos significativos observados no atual estado da prática da modelagem. No estágio mais básico, os modelos baseados na viagem como unidade de análise (trip-based) são estimados como um sistema integrado de modelo de escolha discreta, incluindo variáveis de acessibilidade. As ligações das viagens reproduzidas através dos modelos introduzem uma representação parcial das restrições do tempo-espaço e das interações domiciliares. Ao modelar as decisões de viagens separadamente, omitem-se algumas restrições naturais de tempo-espaço. Geralmente exclui-se da modelagem a duração da viagem e o período do dia em que ela ocorreu (BOWMAN e BEN-AKIVA, 2001).

Já no estágio mais avançado, os modelos baseados em tour agrupam as viagens em tours motivados pelo fato de que todas as viagens podem ser vistas como viagens de ida-e-volta com base no domicílio. Cada tour é adotado de acordo com uma atividade e destino primário, e as atividades são as principais motivações da viagem. A modelagem das decisões em tour fornece uma melhoria sobre os sistemas de modelos baseados na viagem, incorporando uma representação das restrições temporais e espaciais entre as paradas das atividades dentro de um tour. Entretanto, na abordagem baseada em tour, falta uma conexão entre os múltiplos tours realizados no mesmo dia, falhando assim em capturar os efeitos e restrições do tempo-espaço de inter-tour (BOWMAN e BENAKIVA, 2001).

Apesar dos avanços e das tentativas dos pesquisadores de transportes em desenvolver modelos que permitam capturar os padrões básicos do comportamento das viagens encadeadas - baseadas em atividades -, poucos modelos completos e simples puderam ser desenvolvidos (BOWMAN e BEN-AKIVA, 2001). A maioria dos modelos de viagens encadeadas não tem incorporado as restrições espaço-temporal dentro da 
estrutura de análise qualitativa, e não estão suficientemente preparados para serem ferramentas úteis de previsão.

Paralelamente a essas mudanças e melhorias na modelagem do comportamento de viagens encadeadas, estão surgindo novas técnicas de análise impulsionadas pelos avanços em outros campos do conhecimento como da Inteligência Artificial. Esse novo cenário vem estimulando o aumento e aprimoramento de técnicas mais detalhadas e eficientes na análise dos problemas na área de transportes (DOUGHERTY, 1995; FAGHRI e HUA, 1992; FAGHRI e SANDEEP, 1998).

Uma das técnicas atualmente muito explorada para modelagem nesta área é Redes Neurais Artificiais (RNA), cujas características principais são: o reconhecimento de padrões; a capacidade de representar relações não-lineares para modelar qualquer relação entre as variáveis, evidenciadas num conjunto de dados; a capacidade de reproduzir eventos temporais e não somente estáticos; e, a capacidade de generalização. Além disso, existe a vantagem de modelar sem a complicação de ter que formalizar todas as complexidades causais das variáveis e suas relações que outros tipos de modelos requerem (DOUGHERTY, 1995; RODRIGUE, 1997; SHMUELI, SALOMON e SHEFER. 1996; SHMUELI, SALOMON e SHEFER, 1998).

Com base nas premissas anteriores, esta tese apresenta um modelo individual de geração de padrões de viagens encadeadas diárias a pé usando Redes Neurais Artificiais que pode ser incorporado em um sistema de modelo de análise e previsão de viagens urbanas. Através do uso das técnicas das Redes Neurais Artificiais procura-se entender e reproduzir a representação dos aspectos temporais e espaciais do comportamento das viagens encadeadas a pé. Além disso, acredita-se que o conhecimento e experiência, adquiridos com a aplicação das RNAs, possam se construir novas teorias e conceitos que possibilitem definir e criar modelos de geração de viagens encadeadas que sejam os mais genéricos possíveis (incluindo por exemplo outros modos de transporte) e simples de serem utilizados na sua aplicação. 


\subsection{RELEVÂNCIA DO TRABALHO E QUESTIONAMENTOS A SEREM RESOLVIDOS}

Uma das tendências mais significativas nas três décadas passadas foi a mudança na ordem social, econômica e tecnológica mundial. De modo que é importante que os efeitos dessas mudanças no comportamento dos indivíduos possam ser incorporadas na modelagem da previsão da demanda de viagens no planejamento dos transportes (McGUCKIN e MURAKAMI, 1999).

$\mathrm{Na}$ modelagem da previsão da demanda de viagens, a abordagem baseada em atividades é cada vez mais a base teórica para analisar o comportamento das viagens individuais. Ao contrário das abordagens tradicionais que enfocam as viagens como centro da análise, a abordagem baseada em atividades analisa os indivíduos em termos de padrões de uso do tempo, de comportamento de participação em atividades, e de comportamento associado à viagem (KITAMURA, 1996).

Considera-se que indivíduos buscam com mais freqüência oportunidades para minimizar a quantidade de viagens requeridas para cumprir um programa de atividades. Como levantado por Godwin (1981), um indivíduo utiliza o máximo tempo disponível para realizar suas atividades. A procura por formas de cumprir mais atividades com menor número de viagens e com menores extensões de deslocamento produziram alterações no comportamento da viagem, uma das quais são precisamente o aumento das viagens encadeadas (STRATHMAN, DUKER e DAVIS, 1994). Em decorrência, acredita-se que o encadeamento da viagem seja um comportamento individual ou social em constante desenvolvimento na procura do cumprimento de atividades através da viagem.

Por outro lado, paralelamente ao desenvolvimento das viagens encadeadas, tem sido observado o prevalecer das cadeias formadas exclusivamente pelas viagens a pé. Segundo dados da Pesquisa Origem/Destino da Região Metropolitana de São Paulo (RMSP) ${ }^{1}$, no ano de 1997, dos 31,4 milhões de viagens por dia, 34,4\% foram realizadas especificamente a pé. Se considerados todos os trechos percorridos pelas pessoas,

\footnotetext{
${ }^{1}$ Dados da Pesquisa Origem Destino da Região Metropolitana de São Paulo 1997.
} 
ocorreram 64 milhões de deslocamentos por dia, sendo que os deslocamentos a pé assumem a liderança com $62 \%$ do total (VASCONCELOS, 2002). Além disso, D’Agosto e Balassiano (2002) afirmam que as viagens a pé poderiam ser mais bem exploradas e estimuladas, considerando que estas são realizadas principalmente por camadas da população de baixa renda. Adicionalmente as viagens a pé não consomem combustíveis fósseis e não são poluentes.

Entretanto, as mudanças nas atividades e nas condições da viagem podem induzir a ajustes similares na modelagem da demanda por transporte envolvendo componentes da viagem e padrões de atividades. Em forma mais específica, o entendimento e inclusão no modelo das variáveis que influenciam o comportamento das viagens encadeadas a pé podem ser úteis em várias aplicações, tais como: previsão de impactos da adoção de medidas e programas de Gerenciamento da Demanda de Viagens (Travel Demand Managment - TDM); na utilização de instrumentos econômicos e de regulamentação (para incentivar ou desestimular determinado comportamento dos usuários do sistema de transporte público ou privado); e, nas políticas de planejamento referentes ao uso do solo. Indiretamente, possibilitaram aos planejadores contribuir na diminuição da lacuna existente entre o comportamento do usuário e a adoção de políticas na área de transporte, e a aumentar a compreensão do encadeamento da viagem como um possível condicionante nas políticas de planejamento e suas conseqüências no comportamento dos usuários do sistema de transporte público e privado.

Considerando os apontamentos dados acima, é necessário desenvolver um modelo de encadeamento de viagens que possibilite representar e examinar os movimentos físicos diários dos indivíduos por modos específicos de transporte (motorizado/nãomotorizado, público/privado), por período e duração de viagem, por motivo de viagem (trabalho, não-trabalho), pela rota e sua localização num espaço geográfico (zonas de tráfego), e pela distância das viagens que ligam as atividades. Com tais informações, os pesquisadores de transportes e planejadores urbanos podem gerenciar tanto a infraestrutura de transporte existente como os novos sistemas de transporte e novas tecnologias. Ademais, acrescentar-se-iam procedimentos e técnicas de análise e previsão na modelagem da demanda por transportes baseada em atividades (especificamente no 
encadeamento de viagens a pé) que considerem as tendências das dinâmicas do comportamento individual, as influências domiciliares e as restrições espaço-temporal e financeiro. Isto permitirá, entre outros ganhos, identificar a influência que exercem as características socioeconômicas (individuais e domiciliares) e do contexto urbano sobre o indivíduo para empreender cadeias de viagens com vários graus de simplicidade e/ou complexidade.

Contudo, pela quantidade e diversidade de variáveis envolvidas afetando o encadeamento de viagens, e sendo que o uso das RNAs permite extrair a essência da relação entre tais variáveis, surgem questionamentos básicos para serem respondidos pela presente abordagem de modelagem de viagens encadeadas fazendo uso das Redes Neurais Artificiais:

- O encadeamento de viagens depende de quais variáveis (socioeconômicas e demográficas, domiciliares, individuais, por tipo de atividades, de variáveis urbanas como acessibilidade e uso do solo etc.)?

- Através da identificação das variáveis que influenciam o encadeamento das viagens, de que forma será possível representá-las na modelagem fazendo uso das técnicas das RNAs?

- Como podem ser utilizadas as técnicas das RNAs para melhorar o entendimento e reproduzir os aspectos temporal e espacial do comportamento das viagens encadeadas a pé?.

Para responder a estes questionamentos levantados, a seguir são estabelecidos os objetivos geral e específicos da presente tese.

\subsection{OBJETIVOS DA TESE}

Nesta seção são apresentados o objetivo geral e os objetivos específicos estabelecidos na presente Tese. 


\subsubsection{Geral}

Desenvolver a modelagem através do uso das técnicas das Redes Neurais Artificiais (RNA) para reconhecer e reproduzir padrões de comportamento individual de encadeamento de viagens, especificamente padrões de viagens encadeadas a pé, e assim acrescentar procedimentos e técnicas de análise e previsão na modelagem da demanda por transportes que considerem fundamentalmente as dinâmicas do comportamento individual juntamente com as influências domiciliares e as restrições espaço-temporal.

\subsubsection{Específicos}

- Elaborar um modelo individual de encadeamento de viagens baseado em atividades usando RNAs que permita representar padrões de viagens encadeadas a pé.

- Testar e avaliar o uso das RNAs como uma ferramenta de reconhecimento de padrões dinâmicos para modelagem de padrões de viagens encadeadas a pé.

- Considerando a existência de uma base de dados confiáveis, aplicar-se-á o modelo individual em um estudo de caso aos dados da Pesquisa Domiciliar Origem/Destino da Região Metropolitana de São Paulo de 1987.

\subsection{HIPÓTESE DO TRABALHO}

Através da utilização das técnicas das $R N A$, é possível reproduzir espacial e temporalmente padrões individuais de encadeamento de viagens. Com isto, é possível modelar os padrões de deslocamentos diários dos indivíduos por modos específicos de transporte, no caso pelo modo a pé. 


\subsection{ESTRUTURA METODOLOGICA DO TRABALHO}

Segundo o observado até a presente seção, existem três componentes conceituais básicos que norteiam este trabalho e que explicam os fluxos individuais que caracterizam o comportamento das viagens encadeadas. Estes três principais componentes são: as Atividades (A), o Espaço-Tempo (E-T), e o Indivíduo-Domicílio (ID), e por serem determinantes nos fatores relacionados ao encadeamento de viagens afetando estes fluxos, são definidos para formar a estrutura metodológica de trabalho nesta abordagem (Figura 1.1).

As inter-relações desses três componentes permitem determinar os padrões de atividades dos indivíduos com base no domicílio; os padrões de atividades e sua localização, o período de tempo em que são executados, os tempos de duração; e as dinâmicas de comportamento individual-domiciliar, sua caracterização e localização. A forma como estes três componentes se inter-relacionam permite a análise do comportamento das viagens encadeadas. Isto permite definir a forma como as viagens encadeadas podem ser modeladas, as quais no presente trabalho serão analisadas no contexto da previsão da demanda de viagens baseada em atividades (cap. 2).

Um outro componente está relacionado com a técnica que possibilitará representar e reproduzir o comportamento das viagens encadeadas. Esta técnica das Redes Neurais Artificiais, constitui-se (juntamente com os outros três componentes) o quarto componente base do trabalho (cap. 3). Com esta base teórica, é desenvolvido, no cap. 4, o Modelo Neural de Encadeamento de Viagens a Pé (MONEVPE), definindo-se as suposições teóricas do modelo, os conceitos base do modelo e a formulação neural do modelo.

Uma vez desenvolvido o Modelo Neural de Encadeamento de Viagens a Pé (MONEVPE), é definido o método utilizado para aplicação do modelo, e, deste modo, representar e reproduzir o comportamento de padrões de viagens encadeadas individuais diárias a pé (cap 5). Seguidamente no cap. 6, o MONEVPE foi aplicado em um estudo 
de caso com dados da Pesquisa Domiciliar da Região Metropolitana de São Paulo. No cap. 7, é avaliado o desempenho do modelo.

\subsection{ORGANIZAÇÃO DA TESE}

O trabalho está organizado como segue: como base do trabalho, no capítulo 2 são apresentadas a revisão bibliográfica sobre previsão da demanda de viagens e viagens encadeadas baseadas em atividades, estudos recentes, seu uso, e modelos desenvolvidos. Ainda neste capítulo são avaliadas as variáveis condicionantes utilizadas atualmente na modelagem, assim como o planejamento dos transportes e as viagens a pé. No capítulo 3 é realizada uma breve análise a respeito da aplicação das técnicas das RNA na modelagem comportamental de viagens em transportes. No capítulo 4 é proposto o Modelo Neural de Encadeamento de Viagens a Pé (MONEVPE) junto das formulações matemáticas da estrutura do modelo, restrições, e definição de parâmetros do modelo. No cap. 5 são definidas as fases do método para aplicação do modelo. A viabilidade da aplicação do MONEVPE é demonstrado no cap. 6, através de um estudo de caso, utilizando dados da Região Metropolitana de São Paulo. O processo de aprendizado e processamento temporal das características dos indivíduos que realizam as viagens encadeadas a pé será efetivado fazendo uso de um tipo de rede neural estática MLP e um tipo de rede recorrente Elman. Os resultados da modelagem e sua análise são registrados no cap. 7. Por fim, no cap. 8, são apresentadas as conclusões e recomendações. 


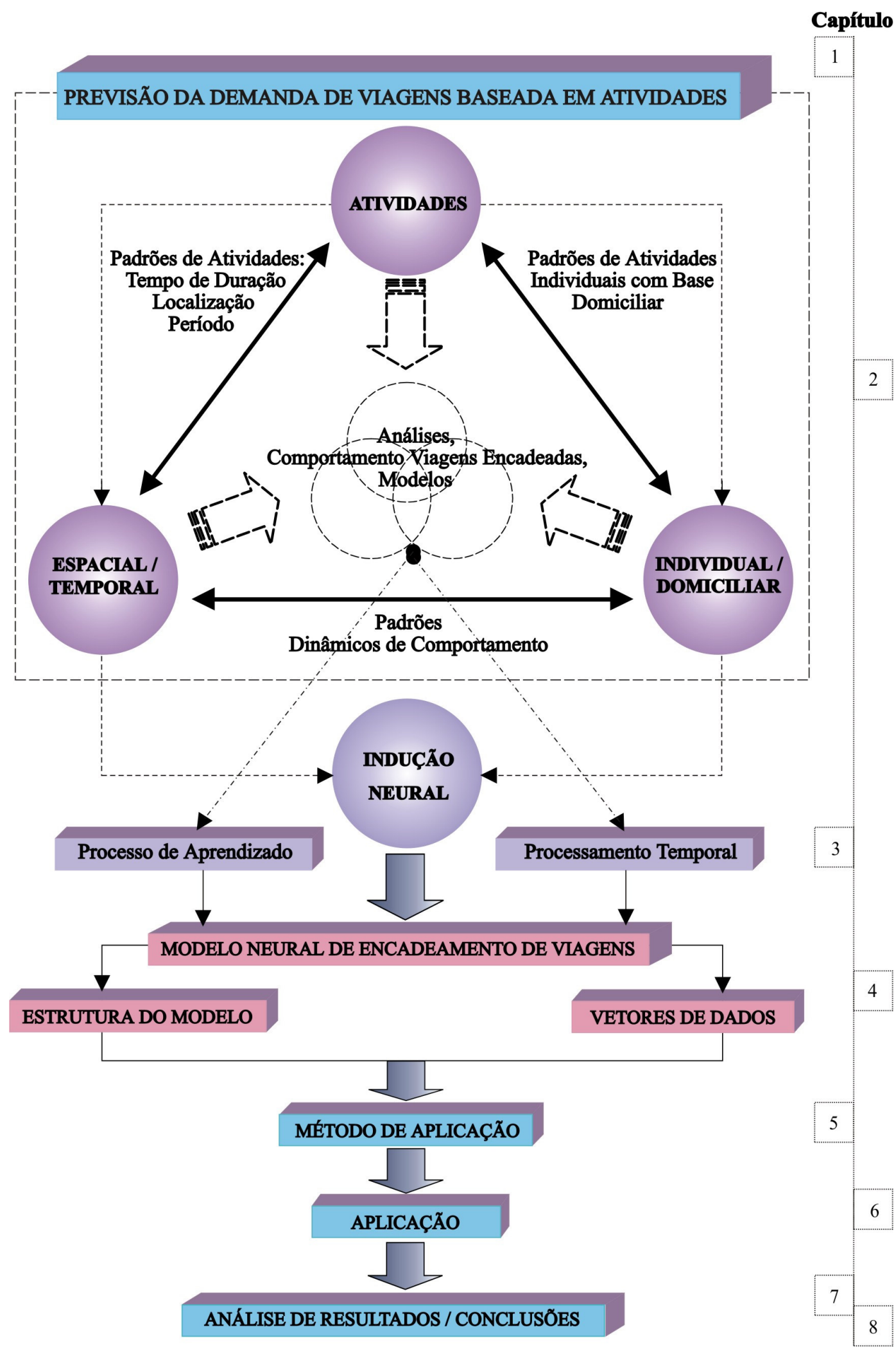

Figura 1.1: Estrutura Metodológica 


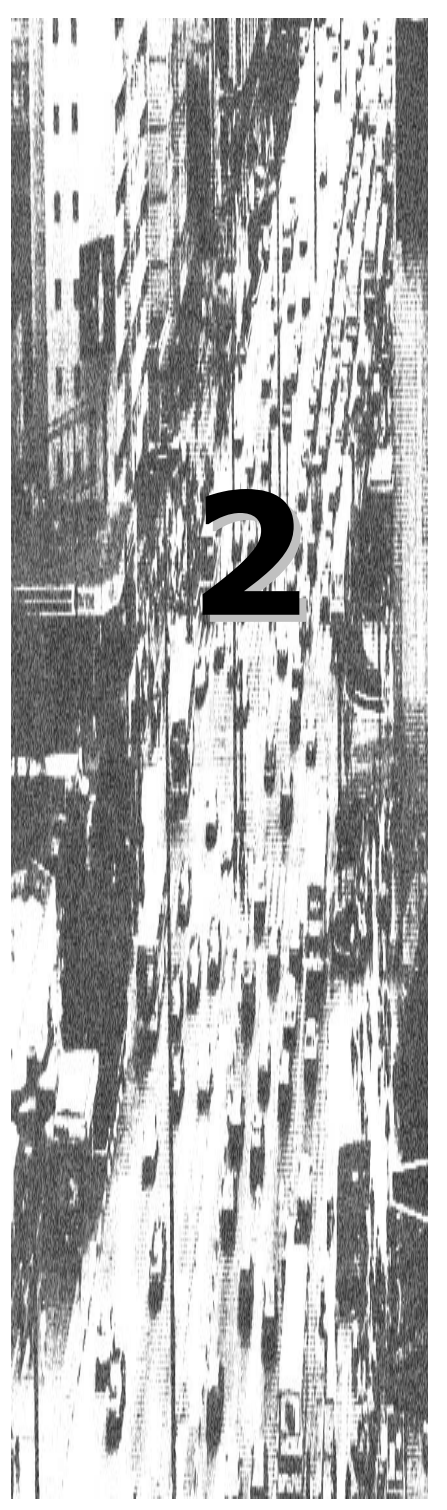

\section{Comportamento de viagens baseadas em atividades e viagens encadeadas}

"We find our individual freedom by choosing not a destination but a direction"

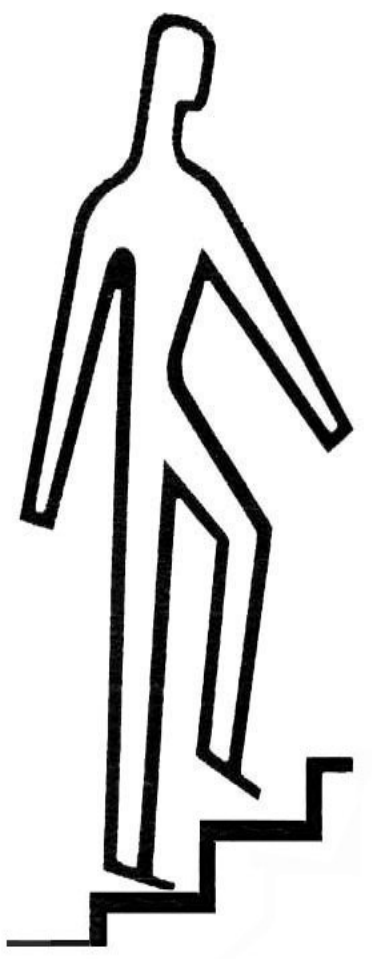




\section{COMPORTAMENTO DE VIAGENS BASEADAS EM ATIVIDADES E VIAGENS ENCADEADAS}

\subsection{INTRODUÇÃO}

No final da década dos anos 80, os modelos existentes a respeito de comportamento de viagens encadeadas eram classificados em quatro grupos. $\mathrm{O}$ primeiro era constituído pelos modelos Markovianos, aplicados ao encadeamento da viagem dentro do contexto das viagens representando as ligações entre os propósitos ou as facilidades no fim das viagens. O segundo grupo continha os modelos baseados em atividades, que na atualidade está contribuindo significativamente para analisar o comportamento de encadeamento de viagens. O terceiro grupo é constituído por modelos desagregados de maximização da utilidade, nos quais as decisões subjacentes ao comportamento referentes às viagens diárias são decompostas, e modelos de escolha discreta são aplicados as parcelas resultantes. O quarto grupo está constituído de modelos de simulação de encadeamento de viagens (NISHII, KONDO e KITAMURA 1988).

Baseados na classificação do comportamento de viagens encadeadas acima, e em função dos recentes desenvolvimentos que procuram introduzir o conceito de encadeamento de viagem dentro de Modelos de Demanda de Viagens Baseados em Atividades (Activity-Based Models of Travel Demand), no presente capítulo são apresentadas idéias básicas emergentes dentro dos paradigmas de análises de viagens 
baseadas em atividades e suas aplicações para previsão de viagens encadeadas baseadas em atividades.

Primeiramente, na seção 2.2, apresentam-se os fundamentos subjacentes à relação existente entre o planejamento dos transportes e encadeamento de viagens e, na seção 2.3, as noções básicas sobre planejamento de transportes e viagens a pé. Na seção 2.4 são estabelecidas as definições básicas relacionadas com as atividades e as viagens encadeadas. Em seguida, na seção 2.5 definem-se as características da análise de atividades, e na seção 2.6 a análise de viagens baseadas em atividades, suas características, e representação das viagens baseadas em atividades. Na seção 2.7 os diferentes enfoques para tratar o encadeamento de viagens são apresentados sob a perspectiva do comportamento de viagens baseados em atividades. Na seção 2.8 analisam-se os modelos baseados em atividades que incorporam o encadeamento de viagem. Na seção 2.9, em função dos estudos disponíveis sobre análise e modelagem de comportamento de encadeamento de viagens, são analisadas as variáveis utilizadas nessa modelagem. Finalmente, na seção 2.10, os tópicos conclusivos do presente capítulo são apresentados.

\subsection{PLANEJAMENTO DE TRANSPORTE E VIAGENS ENCADEADAS}

O transporte é um componente vital do sistema socioeconômico. O planejamento seguro, eficiente, e efetivo dos sistemas de transportes é importante para o funcionamento da sociedade e da economia. Tal planejamento pode ser adequadamente executado sobre a base de um bom entendimento do comportamento da viagem e a habilidade para predizer a resposta dos indivíduos a mudanças no transporte ou subsistemas de atividades e mudanças no ambiente socioeconômico e demográfico. A viagem é inerentemente um fenômeno comportamental complexo. Essa complexidade deriva de relações entre viagem e participação em atividades e das inter-relações entre viagens individuais.

Adicionalmente, o comportamento de participação em atividades responde a complexas necessidades e desejos dos indivíduos e sua interação com os domicílios. 
Todas essas complexidades dos elementos do comportamento da viagem são reconhecidas conceitualmente e estão sendo analisadas através do comportamento da viagem baseada em atividades. A análise de viagem baseada em atividades é conceituada e formulada para examinar a viagem a partir de uma perspectiva geral que considera a demanda para participação em atividades e motivações e inter-relações entre as viagens. Essa perspectiva inclui a programação de atividades no tempo e no espaço, as restrições espacial-temporal e interpessoal sobre a viagem e escolha de atividades, e, a estrutura do domicílio e o papel dos indivíduos e do domicílio.

O objetivo da abordagem baseada em atividades é a previsão da demanda de viagem em função de um completo entendimento do processo de decisão do comportamento da viagem subjacente. Esta abordagem é fundamentalmente diferente da abordagem tradicional de quatro etapas (Urban Transportation Planning System UTPS) onde associações estatísticas, em lugar de relações de comportamento, dirigem o desenvolvimento do modelo. Na abordagem tradicional, a hipótese adotada é a de que cada viagem é independente daquelas realizadas antes e depois da mesma, desconsiderando que tanto as atividades como as viagens programadas em um dia são unidas uma a outra, de modo que elas não podem ser analisadas separadamente, e sim como uma seqüência de atividades/viagens.

\subsection{PLANEJAMENTO DE TRANSPORTE E VIAGENS A PÉ}

As necessidades dos usuários dos modos de transporte não motorizado, isto é, pedestres e ciclistas, devem ser preocupação constante das políticas de transporte urbano. O potencial dos deslocamentos a pé e de bicicleta atinge as camadas mais pobres da população e pode ser estimulado e melhor explorado assegurando-se medidas de segurança e disponibilidade de espaço físico (MMA-IBAMA-IPEA, 2002).

Para Gondim (2001), a participação das viagens a pé nas pesquisas sobre modais de transportes nem sempre é contabilizada por não ser considerada importante pela política de transportes que privilegia apenas trajetos de longa distância. A promoção dos 
sistemas sustentáveis de transporte, no meio urbano, pode propiciar melhores condições ambientais para a população.

Segundo D’Agosto e Balassiano (2002), os modos de transporte a pé e por bicicleta deveriam ser privilegiados pelo baixo consumo de energia primária. Consequientemente, as ações e políticas para influenciar mudanças da demanda por transportes, baseados em regulamentação, fomento e investimento, deveriam considerar medidas para incentivar esses modos não motorizados, entendidos como as duas formas de deslocamento de menor consumo energético. Esta prática, no entanto, se aplica a uma faixa limitada de extensões de deslocamentos e depende da existência de fatores favoráveis que influenciam na opção pelos modos de transporte não motorizados, entre outros aspectos. Embora diferentes cidades da Europa e dos EUA estejam testando há algum tempo maneiras de gerenciar a mobilidade urbana, por meio do incentivo à utilização de alternativas ao carro, como o uso mais intensivo de bicicletas, a caminhada e o transporte público, não se conhecem, no Brasil, ações semelhantes.

O transporte a pé é o mais importante modo de transporte urbano utilizado atualmente em São Paulo. Segundo a Companhia do Metropolitano de São Paulo na pesquisa Origem Destino de 1997, sobre a distribuição modal das viagens diárias, $34,4 \%$ das viagens diárias realizadas foram a pé, dos quais 58,8\% correspondem a viagens com motivo educação e 24,6\% correspondem a viagens com motivo trabalho. Na Região Metropolitana de Fortaleza, em 1997, os percursos a pé chegaram a $40 \%$ do total, em quantidade maior que as viagens por ônibus e o triplo da realizada por automóvel (GONDIM, 2001).

Com relação a distância de viagem para percursos a pé, estudos do Federal Highway Administration (FHWA) (1992) identificaram que pode ser percorrida a pé, em cerca de 30 a 40 minutos, uma distância aproximada de 3,0 km, como limite aceitável para caminhadas diárias. Dependendo das características socioeconômicas e da localização das residências em relação ao centro da cidade, a distância máxima de caminhada admitida para indivíduos que não possuem automóveis, varia entre 1,3 e 2,5 km. (THAMIZ et al., 1996). Arruda (2000) constatou que, para uma cidade brasileira de 
porte médio, a distribuição de viagens por modo a pé em relação ao comprimento da viagem $(\mathrm{km}), 49 \%$ das pessoas entrevistadas percorrem menos do que $0,5 \mathrm{~km}$; que $27,1 \%$ percorrem distâncias entre 0,5 e 1,0 km.; $10,4 \%$ entre 1,0 e 1,5 km.; 4,8\% entre 1,5 e 2,0 km; 4,0\% entre 2 e 2,5 km; 2,4 entre 2,5 e $3 \mathrm{~km}$; e 2,4 acima de 3,0 km.

Observa-se na prática que geralmente o planejamento urbano e de transportes, prioriza a circulação de longo percurso, favorecendo desse modo o transporte motorizado em detrimento das rotas de pedestres e ciclistas. Para Arruda (2000), é necessária a utilização de modelos que sejam sensíveis aos efeitos dos fatores que influenciam a opção dos viajantes pelos modos não motorizados, para assim analisar efetivamente uma grande variedade de medidas e políticas de transporte, desde alternativas de uso do solo até incentivos à redução do número de viagens motorizadas.

Uma abordagem que considere o potencial dos modos não motorizados, especificamente das viagens a pé, nos modelos de planejamento de transportes, torna-se necessário. Modelos baseados em atividades representam uma alternativa na representação do comportamento de viagem individual e na representação do encadeamento de viagens a pé.

\subsection{DEFINIÇÕES BÁSICAS}

Segundo Adler e Ben-Akiva (1979), Sojourn (estada curta) é a principal unidade de atividade da viagem definida como sendo a visita a um lugar distante do domicílio. A atividade que um indivíduo procura durante um sojourn pode ser para trabalhar ou qualquer dos outros motivos que não seja trabalho. Múltiplas atividades podem ser realizadas juntamente em um simples sojourn.

Os mesmos autores (ADLER e BEN-AKIVA, 1979), definem também os três elementos básicos que influenciam na geração de viagens:

- O domicílio é definido como uma unidade residencial onde um ou mais indivíduos moram e tomam conjuntamente decisões econômicas. Enquanto cada 
componente dos padrões de viagens do domicílio é resultante da ação de um ou mais indivíduos, a viagem é assumida como sendo motivada por necessidades (atividades) que são alocadas em nível domiciliar entre os indivíduos. Assim, o domicílio é visto como a unidade ao redor da qual as decisões relacionadas às viagens são organizadas, e como tal é referida como uma unidade de decisão (com relação à viagem);

- O sistema de transporte é descrito em termos de atributos de nível de serviço. Cada ligação da viagem tem um nível de serviço que é uma função do tempo, custo, conforto, e outros atributos do modo usado e da rota adotada; e,

- O terceiro componente da viagem é o sistema de atividades, que descreve os padrões de atividades econômicas e sociais desenvolvidas em um espaço urbano. Assume-se que no destino da viagem existem todas as oportunidades de atividades, e que estas podem ser acessadas sem a necessidade de uma viagem adicional.

Bowman et al. (1998) e Mcguckin e Murakami (1999) estabelecem as condições existentes como parte de uma cadeia de viagem e suas características. Por exemplo, na Figura 2.1, as seguintes configurações podem ser consideradas:

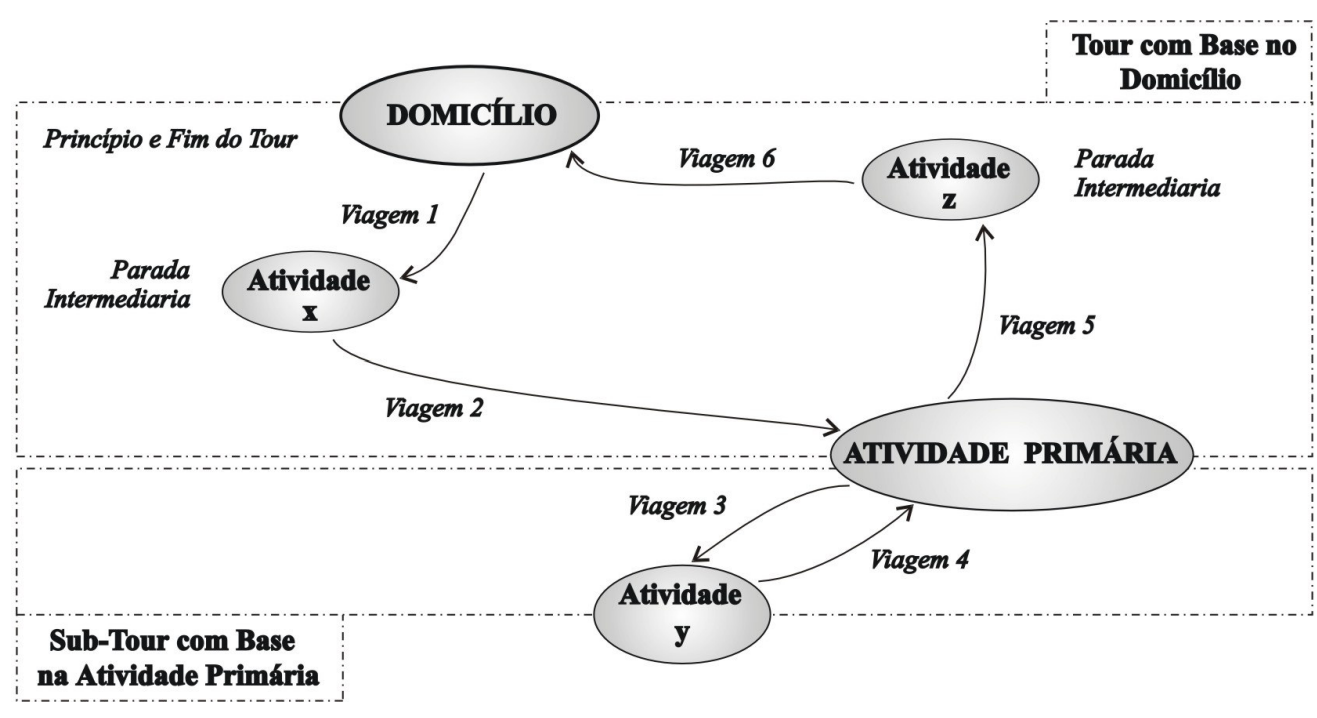

Figura 2.1: Conceitos de tour e encadeamento de viagem 
- Trip corresponde a um segmento de viagem isolada em uma direção entre uma origem e um destino.

- Tour é chamado assim o conjunto de viagens consecutivas em que a origem da primeira viagem corresponde ao destino da última viagem (ADLER e BEN-AKIVA, 1979; BOWMAN et al., 1998; SHIFTAN, 1999). Para Srinivasan (2000), um tour é um conjunto de cadeias de viagens que inclui uma ou mais atividades diferentes.

- Tipo de tour é definido pelas âncoras primarias. Na Figura 2.1 podem ser observadas seis viagens simples (Viagem 1, Viagem 2, ..., Viagem 5, Viagem 6). Duas viagens em cadeias, do domicílio para a atividade primária e outras duas, da atividade primaria para o domicílio, criando-se assim um tour com base no domicílio (Home Based - HB). As outras duas viagens (Viagem 3 e Viagem 4), ida-e-volta da atividade primária para uma qualquer atividade $\mathbf{y}$, constituindo um sub-tour com base na atividade primária. $\mathrm{Na}$ maioria das análises de viagens encadeadas, nas âncoras primarias são geralmente considerados o domicílio (Home - H) e o trabalho (Work - W), surgindo assim cadeias do domicílio ao trabalho ou do trabalho ao domicílio.

- Parada são os finais das viagens entre as âncoras de domicílio e a atividade primária. Por exemplo, se uma pessoa parte do domicílio, e vai para uma atividade $\mathbf{x}$ (exemplo: visita a uma creche) e continua para a atividade primária.

- Viagens em cadeia ou viagens encadeadas é a união de vários segmentos de viagens ou deslocamentos realizados com o objetivo de realizar diversas atividades. Exemplificando, se uma pessoa parte do domicílio e realiza uma parada numa atividade $\mathbf{x}$, e faz uma outra parada na atividade $\mathbf{y}$, e volta para o domicílio, isso constitui uma cadeia. Nessa análise preliminar, quando o segmento da viagem é composto de um único destino que não seja o domicílio, a viagem em cadeia é chamada de simples; e, quando envolve vários destinos que não sejam o domicílio, é chamada de complexa.

Como definido por Bowman et al. (1998), cada tour apresenta um número de paradas, classificadas por três tipos de propósitos ou motivos: de subsistência (trabalho 
ou escola), de manutenção, e lazer. Cada tour tem um destino primário. Na Figura 2.1 o destino primário pode ser o trabalho. Para outros tours um conjunto de regras baseadas na combinação de propósitos e duração das atividades determinará o destino primário. A porção de tour do domicílio para o destino primário é denominada médio tour, e a porção de tour do destino primário para o domicílio é a outra metade do tour.

Na definição de Bowman et al. (1998) e na Figura 2.1 todas as outras paradas entre o domicílio e o destino primário são denominadas paradas intermediárias. Uma ou mais atividades podem ser realizadas em cada localização da parada, assim a duração da parada pode ser bastante longa, embora seja usualmente menor que o tempo gasto no destino primário. Tours de manutenção podem ter sub-tour com base no trabalho (ou baseados na escola). Um tour com base no trabalho é definido como uma sequiência de segmentos de viagens que começam e terminam no trabalho.

Finalmente, segundo Adler e Ben-Akiva (1979), o termo padrão de viagem é usado para referenciar o conjunto de tours realizados por um indivíduo dentro de um período de tempo fixo (geralmente 24 horas), considerando atributos de viagem como modo de transporte, tempo de viagem etc.

\subsection{ANÁLISE DE ATIVIDADES}

Para Shmueli, Salomon e Shefer (1998), a realização de uma "atividade" implica o deslocamento de uma pessoa desde uma origem até um destino para cumprir um certo propósito, o qual pode ser trabalho, estudo, compras, lazer etc. A decisão da pessoa de viajar através de diversos meios a fim de realizar uma certa atividade depende de vários fatores tais como o propósito da atividade, a distância entre a origem e o destino, a existência de um veículo à disposição no domicílio, a disponibilidade de um sistema de transporte público.

Para Jones ${ }^{1}$ et al. (1990) apud Kitamura (1996) a análise de atividades é definida como a "estrutura em que a viagem é analisada como padrões de comportamento diário ou multi-diário, relacionados e derivados de diferenças no estilo de vida e participação

\footnotetext{
${ }^{1}$ Jones, P. M. et al. (1990). Activity analysis: state-of-the-art and future durections. In P. Jones (ed.) Developments in Dynamic and Activity-Based Approaches to travel Analysis, Gower Publishing, Aldershot. apud Kitamura (1996).
} 
de atividades entre a população". Kurani e Lee-Gosselin (1996) acrescentam que a análise de atividades delimita um conjunto de problemas para estudo. Este conjunto inclui, embora que não restrito, o estudo da forma como são programadas as atividades nos domicílios, como se esboçam as atividades no tempo e espaço examinando as ligações entre as pessoas e a função que elas exercem dentro dos domicílios e outros grupos sociais a que pertencem.

O conteúdo da análise de atividades é distinto de outros paradigmas de pesquisa em transportes por várias características. Jones ${ }^{1}$ et al. (1990) apud Kitamura (1996) identificam sete características emergentes na análise de atividades:

- A viagem é derivada da demanda por participação em atividades. A viagem é empreendida para se engajar em uma atividade em algum outro local (e tempo futuro).

- Foca no comportamento referente ao seqüênciamento de atividades e viagens, e não de viagens discretas. O encadeamento de viagens é um exemplo de como as seqüências de viagens foram analisadas. A análise de cadeias de viagens é um passo intermediário entre o estudo das viagens simples e o estudo dos padrões de atividades. Quanto a aplicação dos conceitos de viagem em cadeia, recentes esforços são despendidos procurando desenvolver modelos de atividades programadas.

- Analisa os domicílios como as unidades onde se toma decisão. Empregar o domicílio e esquemas de classificação de indivíduos como variáveis para segmentar e analisar as atividades programadas ou de viagem.

- Examina detalhadamente o tempo e duração das atividades e a viagem. Existem distintos ciclos metodológicos desenvolvidos no tratamento da duração da atividade. Recentemente, esforços estão sendo desenvolvidos na análise da duração da atividade sob o enfoque de modelos de escolha discreta e modelos comportamentais de maximização da utilidade.

- Incorpora restrições espaciais, temporais, e interpessoais; 
- Reconhece a interdependência entre eventos separados no espaço e tempo; e,

- Usa esquemas de classificação do domicílio e da pessoa com base nas diferenças de atividades necessárias, compromissos e restrições. Os esquemas de classificação devem ser baseados nas diferenças derivadas da participação em atividades. Classificações do domicílio baseadas no "ciclo de vida" ou "estágio de vida" usam variáveis socioeconômicas para representar essas diferenças.

Kitamura (1996), reconhecendo a importância de análises dinâmicas e da necessidade de examinar as atividades sobre múltiplos períodos de tempo, adiciona as seguintes características:

- Analisar a atividade e a viagem dentro das estruturas longitudinais dinâmicas. Abordagens baseadas em atividades preocupam-se com a análise do desdobramento de eventos no tempo, e freqüentemente o desdobramento sobre diferentes, porém entrelaçadas, escalas de tempo. A classificação do domicílio e indivíduo pode mudar, com os domicílios adaptando-se às condições de mudanças do meio ambiente.

As características citadas acima, derivadas das relações existentes entre a viagem e a participação de atividades e das inter-relacões entre as viagens individuais, permitiram desenvolver a abordagem da análise de viagens baseadas em atividades.

\subsection{VIAGENS BASEADAS EM ATIVIDADES}

No consenso de todos os especialistas em transportes, a demanda por viagens é derivada da necessidade ou desejo de participar em atividades espacialmente distribuídas sobre um ambiente geográfico. Para Bowman et al. (1998) a demanda por atividades e viagens é vista como uma escolha entre todas as possíveis combinações de atividades e viagens no curso de um dia. Recker (1995) afirma que a abordagem tradicional para previsão da demanda por transporte que examina cada viagem isoladamente, permite a obtenção de um nível limitado de informação a respeito da viagem. No entanto, para Spear (1996), a maioria de pesquisas sobre o comportamento 
dos viajantes conclui que a decisão para se fazer uma viagem é realmente derivada de uma complexa série de decisões. Geralmente ignoram-se tanto as informações que precedem as viagens como o futuro que se segue, e virtualmente não são obtidas informações sobre o impacto derivado das decisões de uma viagem particular sobre outras decisões de viagem. Isso gerou uma longa procura por desenvolvimento e operacionalização das análises de demanda de viagens baseados em atividades.

Para Bowman (1995) são quatro os fundamentos básicos na teoria de viagens baseada em atividades. O primeiro define que a demanda por viagens é derivada da demanda por atividades que requerem viagens; o segundo estabelece que o comportamento humano está restrito pelo tempo e espaço; o terceiro confere que o domicílio afeta significativamente as atividades do indivíduo e as decisões referentes às viagens; e, por fim, o quarto atesta que as atividades e as decisões referentes às viagens acontecem dinamicamente. Mcnally (1996) adiciona um outro fundamento, indicando que as sequiências de padrões de comportamento - e não as viagens individuais - são as unidades de análise relevantes.

A abordagem baseada em atividade toma como unidade básica de análise o padrão de viagem/atividade, definida como o padrão de comportamento representado pela viagem e atividade (ambos domiciliares e não domiciliares) num período de tempo específico (freqüentemente um dia). Estes padrões viagens/atividades são referidos como padrões de atividades domiciliares e surgem da programação e execução de programas de atividades domiciliares. Alguns modelos baseados em atividades usam tours ou cadeias equivalentes de viagens como unidade básica de análise (McNALLY, 1996).

Como foi constatado nos recentes desenvolvimentos teóricos e nos procedimentos da previsão da demanda de viagens baseada em atividades, inclui-se o conceito de encadeamento de viagem. Nesse desenvolvimento, novas estruturas analíticas estão sendo propostas, além de que novas características de comportamento sejam identificadas. Nessas análises e modelos são consideradas as limitações e restrições espacial-temporais impostas sobre o comportamento de viagem encadeada. 


\subsection{ANÁLISE DE VIAGENS ENCADEADAS}

A importância de incorporar aspectos de comportamento da viagem na análise de viagens encadeadas torna-se evidente quando se considera que a distribuição espacial e temporal de viagens pode variar dependendo da forma como o indivíduo organiza as atividades diárias, de como desenvolve os itinerários e da forma como encadeia as viagens.

Para Goulias, Pendyala e Kitamura (1990), as ligações entre as atividades que conduzem às ligações entre as viagens, motivaram o surgimento da abordagem do encadeamento de viagens. A vantagem desta visão está em oferecer uma estrutura para rigorosas investigações de possíveis inter-relações entre as características das viagens e das atividades. Assim, a relação entre os diferentes tipos de atividades procuradas, o tempo utilizado nestas atividades e as características das viagens realizadas podem ser estudadas adequadamente.

Embora esses conceitos não tenham sido aplicados a muitos casos, a necessidade dos modelos de viagens encadeadas tem sido discutida na literatura da demanda de viagens desde o final da década de 70 (ADLER e BEN-AKIVA, 1979; BEN-AKIVA, SHERMAN e KULLMAN, 1978b; BOWMAN, 1995; BOWMAN e BEN-AKIVA, 1997; BOWMAN e BEN-AKIVA, 2001; GOLOB, 1986; GOULIAS, PENDYALA e KITAMURA, 1990; KITAMURA, 1984; KOSTYNIUK e KITAMURA, 1986a; NISHII, KONDO e KITAMURA, 1988; RECKER, McNALLY e ROOT, 1986a; SHIFTAN, 1999; STRATHMAN, DUEKER e DAVIS, 1994; STRATHMAN e DUEKER, 1995).

A base teórica das propriedades que governam a formação de viagens encadeadas foi desenvolvida por Adler e Ben-Akiva (1979), e Kitamura (1984) recomenda que o desenvolvimento de um modelo útil e prático de viagens encadeadas requer, entre outras, a identificação das relações existentes entre o comportamento de viagem encadeada e Uso do Solo (US), da Rede de Transporte $(R T)$ e outras variáveis explicativas tais como as Características Domiciliares $(C D)$ e as Características Individuais $(C I)$. 
Segundo Kitamura (1984), no passado foi comum assumir que viagens baseadas no domicílio e não baseadas no domicilio poderiam ser tratadas separadamente na geração de viagens e independentemente da distribuição de viagens. As análises de distribuição de viagens ou escolha do destino foram baseadas na suposição de que cada viagem pode ser analisada de forma separada e independente sem considerar as interrelações que possam existir entre as escolhas realizadas por um indivíduo para uma série de viagens. Portanto, houve um conjunto de suposições conflitantes entre a análise tradicional e o comportamento das viagens encadeadas.

Para Srinivasan (2000), o uso de dados de atividades de viagens pelos engenheiros de transportes e planejadores foi majoritariamente na previsão do modo e principalmente no comportamento da escolha do modo. $\mathrm{O}$ processo de modelagem usualmente envolve a identificação de uma estrutura de decisão, um processo de escolha e os dados desagregados. Esse processo não trata o encadeamento da viagem dentro da estrutura de modelagem de forma a saber como a cadeia se produz.

Segundo Arentze et al. (2001), estruturas de modelos aninhados foram propostas para modelar o encadeamento de viagens como uma série de escolha de atividades/destino. Adicionalmente, estas extensões consideraram a escolha de viagens inserida na escolha de padrões de atividades completa. Embora exista um claro potencial para tais modelos, a adoção de mais variáveis endógenas produz um considerável incremento na complexidade, ou seja, não somente para coletar os dados requeridos, mas também para calibrar os modelos. Logo, complexas estruturas de modelos de atividades e viagens encadeadas são também requeridas para representar oportunidades e restrições do meio ambiente, espaço-tempo e interações entre dimensões de escolha.

\subsection{MODELOS DE ATIVIDADES E VIAGENS ENCADEADAS}

O desenvolvimento de modelos baseados em viagens encadeadas, formalmente expressos, tem sido um dos objetivos das pesquisas na área de demanda por transportes. Diferentes abordagens deram lugar ao aparecimento de modelos com características 
específicas. Essas diferentes abordagens não possibilitam uma classificação exclusiva dos modelos. Assim, a seguir serão descritos os diferentes modelos existentes que apresentam similaridade com o enfoque central da presente tese.

\subsubsection{Classificações Baseadas em Atividades}

Bowman e Ben-Akiva (1997) classificam em quatro grupos os modelos baseados em atividades. No primeiro grupo os modelos econométricos e modelos de simulação híbridos; no segundo, os modelos são classificados pela unidade de decisão em domiciliares e individuais; no terceiro grupo, estão classificados pela operação, em modelos sintéticos e modelos balanceados; no quarto grupo, a classificação é feita de acordo com a natureza probabilística ou determinística.

Para Kitamura (1996) existem dois grandes grupos em que são divididos os modelos baseados em atividades. O primeiro é um sistema de equações estruturadas de medidas de mobilidade e participação em atividades, e, o segundo grupo é um sistema de modelos de micro-simulação do comportamento de indivíduos e os seus compromissos de atividades e viagem.

Para Bowman et al. (1998), a evolução e desenvolvimento de modelos baseados em atividades podem ser divididos em três passos (Figura 2.2). O primeiro, integrando modelos de escolha desagregados baseados na viagem usando ligações através dos modelos, providenciando uma representação parcial das restrições de espaço-tempo e interações domiciliares (Figura 2.2(a)); o segundo passo toma lugar com a introdução de modelos baseados em tour - capturando os efeitos do encadeamento de viagem pelo uso do tour como unidade básica da decisão, isto é, todas as atividades e viagens acontecem entre a saída do domicílio e subseqüentes retornos (Figura 2.2(b)); o terceiro passo introduz uma maior integração do modelo, representando a escolha individual de atividades e viagens por um dia inteiro (atividades programadas, ou atividades de curto prazo), denominado-os de modelos de comportamento de atividades programadas (Figura 2.2(c) e (d)). 

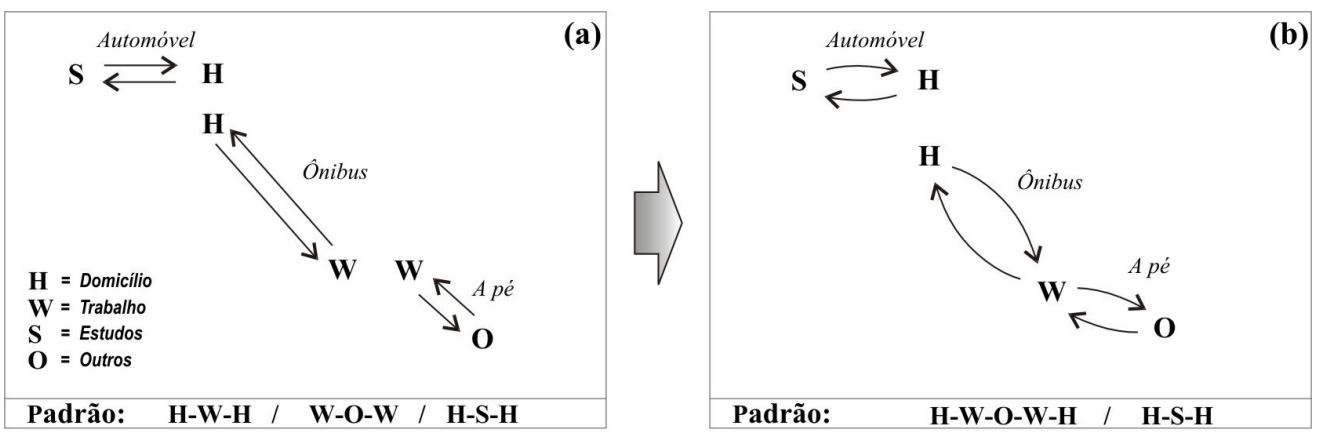

b)
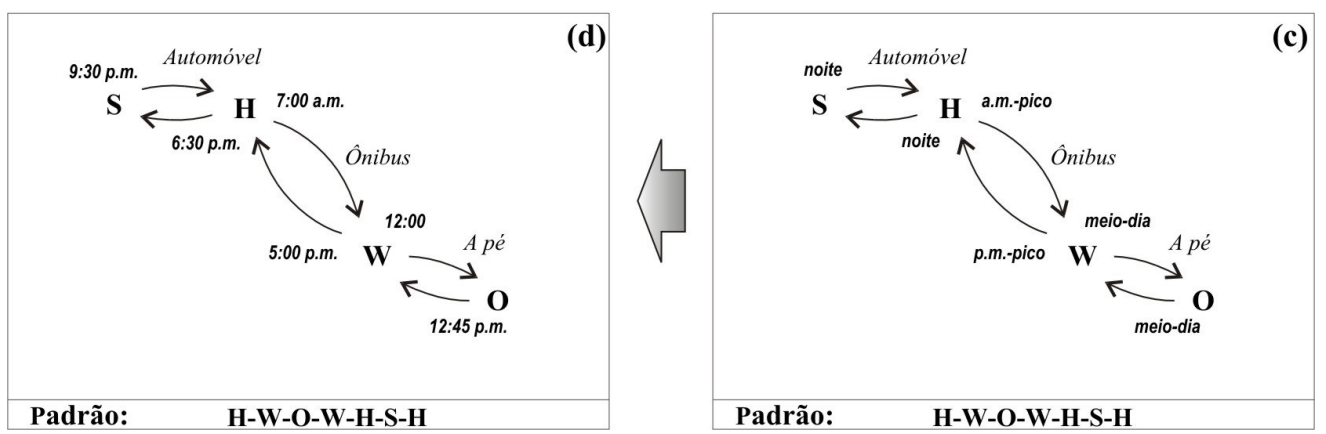

Figura 2.2: Desenvolvimento dos modelos baseados em atividades (BOWMAN e BENAKIVA, 1997; BOWMAN, 1998).

Segundo Bowman e Ben-Akiva (2001), os processos de escolha que os modelos representam foram bem compreendidos nas pesquisas sobre a natureza de atividades individuais e decisões de viagens. Os mais avançados sistemas operacionais desses modelos, baseados em tours, capturam as decisões inter-relacionadas que um indivíduo faz com respeito à viagem do domicilio para um ou mais locais de atividades e o retorno para o domicílio. Adicionam algumas complexidades tais como encadeamento de viagens, mas ignoram as restrições e oportunidades associadas com atividades programadas que podem incluir atividades no domicílio e múltiplos tours.

Para Timmermans (2002), modelos comportamentais de atividades programadas são parte dos modelos de demanda de viagens baseadas em atividades que prevêem quais atividades serão realizadas, onde, quando, quão distantes estão e a previsão da seqüência em que as atividades serão realizadas durante um dia. Assim, os modelos comportamentais de atividades programadas e demanda de viagens podem ser classificados em modelos simultâneos e modelos seqüenciais. 
Modelos Simultâneos: os padrões de atividade-viagem são descritos em termos de diversos atributos da viagem incorporados no modelo, e são previstos pelo uso de uma estrutura de maximização da utilidade. Descritores de padrões de atividade e sóciodemográficos constituem as variáveis explanatórias usadas para considerar a variação dos padrões atividade-viagem. Em termos comportamentais, estes modelos são freqüentemente baseados nas rigorosas suposições de comportamento de maximização da utilidade. Assume-se que os indivíduos programam suas atividades de forma que sua utilidade seja maximizada sujeita a um conjunto de restrições. Recentes modelos de maximização da utilidade de padrões de atividade-viagem prevêem a escolha entre completos padrões atividade-viagem usando modelos logit multinomial. Com a popularização do modelo logit aninhado, este se tornou mais aplicado na modelagem baseada em atividade na demanda de transporte (TIMMERMANS, 2002).

Entre os modelos Simultâneos distingue-se os modelos baseados na maximização da utilidade, entre os quais encontram-se o modelo desenvolvido por Adler e Ben-Akiva (1979), o STARCHILD desenvolvido por Recker, McNally e Root (1986a, 1986b), o modelo de atividades programadas diárias (Daily Activity Schedule Model) proposto por Ben-Akiva $^{2}$ et al. (1994) apud Ben-Akiva, Bowman e Gopinath (1996), e posteriormente elaborado em uma série de projetos por Bowman e Ben-Akiva (1997, 2001), Bowman et al. (1998). E os modelos de programação matemática, entre os quais encontram-se o modelo Household Activity Pattern Problem - HAPP desenvolvido por RECKER (1995), o modelo baseado no prisma de tempo-espaço (Prism-Constrained Activity Travel Simulator - PCATS) desenvolvido por Kitamura ${ }^{3}$ e Fuji (1998) apud Timmermans (2002).

Modelos Seqüenciais: representam uma tentativa de modelagem do processo de programação. Nos modelos simultâneos, o processo pelo qual os indivíduos chegam a suas escolhas não é explicitamente modelado. Diferem uns dos outros pela representação das regras do processo de programação de atividades. Alguns usam sistemas de produção de regras, árvores de decisão, redes neurais, entre outros.

\footnotetext{
${ }^{2}$ Ben-Akiva et al. (1994). Combining revealed ans stated preference data. Forthcoming in a special issue of marketing letters. apud Ben-Akiva, Bowman e Gopinath (1996).

${ }^{3}$ Kitamura e Fuji (1998). Two computational process models of activity-travel choice. In T. Gärling, T. Laitila and K. Westin (eds.): Theoretical Foundations of Travel Choice Modelling, Elsevier, Oxford, 251-279. apud Timmermans (2002).
} 
Os modelos Seqüenciais dividem-se em modelos de processo computacional e modelos baseados em utilidade. Os primeiros partem da concepção de que indivíduos não necessariamente chegam a uma escolha ótima, mas que usam alguma heurística dependente do contexto. Assim, a abordagem da modelagem assume que os padrões de atividades podem ser representados em termos de uma seqüência de pares estado-acão $(E-A)$, onde $E$ representa um possível estado do indivíduo e do contexto onde se toma a decisão, enquanto $A$ representa a decisão tomada nesse estado. Entre esses modelos está o SCHEDULER desenvolvido por Garling, Kwan e Golledge, (1994), GISICAS, AMOS (RDC, 1995), SMASH, CHASE, ALBATROSS. Dentre os baseados no conceito da utilidade, pode-se destacar o Agent for Utility-Driven Rescheduling Of Routinized Activities - AURORA (TIMMERMANS, 2002).

\subsubsection{Modelos Básicos}

Adler ${ }^{4}$ apud Ben-Akiva, Sherman e Kullman (1978a) estima um modelo de escolha desagregado em que o conjunto de escolhas consiste de alternativas de viagens encadeadas com dois ou mais ligações. A utilidade de cada alternativa é caracterizada pelo nível de serviço total do tour e as oportunidades espaciais para os destinos incluídos no tour.

Numa visão integradora, Goulias, Pendyala e Kitamura, (1990) integram conceitos da análise baseada em atividades e conceitos de encadeamento de viagens para formular um modelo que ligue geração de viagens e encadeamento de viagens. Nessa abordagem o "encadeamento da viagem" (trip chaining) é definido como a ligação entre as viagens, enquanto que "viagem em cadeia" (trip chain) é definida como uma série de viagens conectadas que iniciam e finalizam no domicílio.

Um modelo recursivo de geração de viagem e viagem encadeada desenvolvido por Goulias, Pendyala e Kitamura, (1990) reproduz o mecanismo seqüencial de quem realiza a decisão. Inicialmente é gerada uma taxa de geração de viagens por motivo em função da relação existente entre as diversas atividades. Em seguida, o número de

${ }^{4}$ Adler, T.J. (1979). Modelling non-work travel patterns. Transportation Systems Division, Department of Civil Engineering, Massachusetts Institute of Technology, Cambridge, PhD Thesis. apud Ben-Akiva, Sherman e Kullman, (1978a). 
viagens encadeadas é expresso como uma função da frequiência de viagens por tipo de atividade. Taxas de geração de viagens baseadas no domicílio e não baseadas no domicílio podem ser obtidas pelo modelo. As atividades são divididas em duas categorias: as compulsórias, tais como trabalho e escola; e, as facultativas que são aquelas para as quais a decisão de vincular a localização, tempo e duração envolvem alguma flexibilidade.

Strathman, Dueker e Davis, (1994) desenvolveram um modelo logit para analisar o encadeamento de viagens. Para isto, ocorre a escolha hipotética entre as alternativas de viagens ao trabalho, que podem incluir viagens para satisfazer necessidades e obrigações não relacionadas com o trabalho. Supõe-se que essa escolha é afetada pela composição domiciliar, pelo nível de atividade da viagem, pelos fatores locais, pelo modo da viagem e pelas condições de tráfego. Em geral a forma do modelo é especificada como segue:

$\log \left(\mathrm{P}_{\mathrm{c}} /\left(1-\mathrm{P}_{\mathrm{c}}\right)\right)=f(\mathrm{M}, \mathrm{G}, L, \mathrm{D}, \mathrm{C}, \mathrm{NWT}, H S, \mathrm{Y})$

$\mathrm{P}_{\mathrm{c}}=\mathrm{a}$ probabilidade de um indivíduo inserir-se numa viagem complexa ida e volta ao trabalho;

$\mathrm{M}=$ modo da viagem;

$\mathrm{G}=\operatorname{sexo}$

$L=$ vetor de variáveis representando a localização residencial e o local do emprego;

$\mathrm{D}$ = distância entre a residência e o local de emprego;

$\mathrm{C}=$ congestionamento do tráfego;

NWT = total de viagens não trabalho realizadas pelo domicílio;

$H S$ = vetor de variáveis da estrutura domiciliar;

$\mathrm{Y}=$ renda domiciliar.

Bowman e Ben-Akiva (2001) desenvolveram um modelo desagregado de demanda de viagens baseado em atividades com programação de atividades. O sistema de modelos representa a escolha das atividades de um indivíduo e a viagem é associada a um padrão de atividade baseado em um conjunto de tours. O padrão de atividades 
consiste de decisões importantes que fornecem a estrutura global para as atividades diárias e, conseqüentemente, para viagens. Dentro do protótipo dos padrões de atividades incluem-se: $i$ ) a atividade primária - a mais importante - do dia, com uma alternativa de permanecer no domicílio para todas as atividades do dia; ii) o tipo de tour da atividade primária, incluindo informações do número, propósito e seqüência de atividades nas paradas; e iii) o número e propósito de tours secundários - adicionais -. Os modelos de tour incluem a escolha do período do dia, o destino e o modo da viagem, estando condicionados pela escolha do padrão de atividades que é influenciado pela máxima utilidade esperada, avaliada a partir de tours alternativos.

O modelo desenvolvido por Bowman e Ben-Akiva (2001) estabelece como inerente à definição de padrão a noção de atividade prioritária ou importante, supondo que os indivíduos utilizam um processo de decisão baseado em prioridade. Duas características importantes no sistema de modelos podem ser observadas. A primeira inclui o período do dia das decisões tanto como a escolha dos tempos de saída de e para a atividade, providenciando uma categorização do período da viagem no dia e implicitamente a duração da atividade. A segunda característica especifica que as restrições espacial-temporal que os indivíduos enfrentam podem ser capturadas pela restrição de escolhas pré-determinadas.

No modelo desenvolvido por Bowman e Ben-Akiva (2001), a decisão do tour é condicionada pela escolha do padrão de atividades. A forma selecionada para representar as decisões define que a probabilidade de uma particular atividade programada " $p$ (schedule)" é expressa no modelo como o produto da probabilidade marginal de um padrão " $p$ (pattern)" e a probabilidade condicional dos tours " $p$ (tours|pattern)":

$$
p(\text { schedule })=p(\text { pattern }) p(\text { tours } \mid \text { pattern })
$$

Onde a probabilidade do padrão marginal "p(pattern)" é a probabilidade de um padrão particular de atividade ser escolhido. A probabilidade condicional dos tours " $p$ (tourslpattern)" é a probabilidade de um conjunto particular de tours, dado a escolha do padrão. 
A escolha do padrão não é independente de decisões condicionais dos tours, embora as atratividades relativas - ou utilidades - de um padrão dependam do máximo valor esperado da utilidade dos tours associados. Através da utilidade esperada, a probabilidade de escolha de padrões é uma função de atributos de todas alternativas avaliáveis de tours. Esta relação captura a sensibilidade da escolha do padrão para características espaciais e nível de serviço do sistema de transporte, sendo a característica mais importante do sistema de modelo proposto.

\subsection{VARIÁVEIS UTILIZADAS NOS MODELOS DE VIAGENS ENCADEADAS}

Os estudos disponíveis sobre análise e modelagem de comportamento de encadeamento de viagens fornecem uma visão ampla das variáveis utilizadas. As conclusões a respeito da importância de uma ou outra variável dependem muito do contexto da análise, do tipo de dados utilizados, sendo aplicáveis somente em situações específicas. No entanto, algumas variáveis podem ser generalizadas e incorporadas ao conjunto de conhecimentos pertinente à modelagem da demanda por transporte. A seguir, podem ser analisadas algumas das mais importantes pesquisas realizadas em países desenvolvidos (cenário internacional), e no contexto do Brasil (cenário nacional).

\subsubsection{Cenário Internacional}

Para Adler e Ben-Akiva (1979), as características socioeconômicas do domicílio afetam as necessidades e preferências das diferentes alternativas das viagens. Um domicílio que não possui automóvel geralmente não tem um carro disponível para uma determinada viagem. Similarmente, a localização da residência afeta a disponibilidade do modo de transporte, sendo menos provável que domicílios com altas rendas sejam sensíveis a custos da viagem como aconteceria com domicílios de baixa renda. Ademais, outros atributos como tamanho do domicílio, grau de educação, ciclo de vida, podem causar preferências que são diferentes das de outros domicílios.

Por outro lado, Golob e Golob (1983), procurando explicar e prognosticar a influência das atividades no comportamento das viagens, sugerem que a abordagem 
baseada em atividades requer um entendimento não só do comportamento individual, mas também das diferentes interações domiciliares. Estabelece também que uma das mais importantes características da abordagem baseada em atividades deve reconhecer explicitamente as restrições do tempo e espaço sobre o comportamento de viagem.

Pas $^{5}$ (1984) apud Strathman, Dueker e Davis, (1994) determina que atributos individuais e domiciliares exercem significativa influência sobre a escolha de atividades e o padrão de viagens encadeadas. Entre os atributos individuais encontram-se o estágio no ciclo de vida do indivíduo, sexo, grau de instrução, renda individual. No relacionado com os atributos domiciliares são considerados a existência de filhos na família, a densidade residencial, o número de pessoas empregadas, a distribuição das tarefas em função do sexo e da idade.

Spear (1996) considera que a decisão de um indivíduo de ocupar-se de uma atividade é uma função da complexa iteração entre o domicílio, o papel e as responsabilidades individuais, as restrições do tempo sobre o indivíduo e a atividade, as opções referentes ao tipo de atividade, localização, duração, opções de transporte, e os benefícios percebidos $\times$ custos da atividade. Assim, muitos dos parâmetros de decisão são conhecidos, isto é, existe uma previsão de horas fixas para a atividade, ou podem ser agrupados em um número controlável de categorias para previsão, como, por exemplo, sendo agrupados segundo características dependentes dos tipos de domicílios.

Através de um modelo de geração de viagens baseado em categorias de grupos homogêneo de indivíduos, Supernak, Talvite e DeJohn (1983) concluíram quão significativos são para os descritores de mobilidade o estado de emprego, idade, e a disponibilidade de carro. Quanto maior o número de pessoas empregadas na família, maior é o acesso dos seus membros aos meios privados de transporte, em número e diversidade das viagens. Da mesma forma, o carro aparece como um dispositivo privilegiado para garantir o encadeamento das viagens, em um nível impossível de ser atingido por outros meios.

\footnotetext{
${ }^{5}$ Pas, E. I. (1984). The effect of selected socio-demographic characteristics on daily travel-activity behavior. Environment and Planning A 16. p. 571-581. apud Strathman, Dueker e Davis (1994).
} 
Solomon e Ben-Akiva ${ }^{6}$ (1983) apud Prasetyo (2001) afirmam que a escolha do "estilo de vida" pode influir na escolha da mobilidade em termos da localização do emprego, localização da residência, tipo de domicílio, e propriedade de automóvel. Consequientemente, estas escolhas podem influenciar o tipo de atividade, duração, local de atividades e modos utilizados na viagem. O estilo de vida é basicamente a escolha referente à constituição da família, à participação na força de trabalho, e a sua orientação para o lazer.

Para Ben-Akiva, Bowman e Gopinath, (1996), a participação do viajante em atividades é fortemente determinada pelo tempo gasto e pelos recursos alocados, e estreitamente ligados a aspectos comportamentais, tais como o "estilo de vida" - sendo que a escolha deste ou de "atividades programadas" depende das características socioeconômicas do indivíduo -, das oportunidades disponíveis para realizar estas atividades, e das características do meio ambiente (entorno) incluído o sistema de transporte.

\subsubsection{Cenário Nacional}

No cenário brasileiro, o primeiro estudo sobre encadeamento de viagens, foi realizado por Ichikawa (2002), que aplica um minerador de dados para obter relações entre padrões de viagens encadeadas e características socioeconômicas de viajantes urbanos. O minerador de dados utilizado é a Árvore de Decisão e Classificação e os dados dos viajantes foram obtidos da pesquisa origem-destino realizada pelo METRÔSP, na Região Metropolitana de São Paulo em 1987. Um dos importantes resultados encontrados é que indivíduos que têm atributos socioeconômicos e de viagem similares não se comportam de maneira similar; pelo contrário, eles fazem diferentes padrões de viagens encadeadas, as quais podem ser descritas em termos de probabilidade ou freqüência associada a cada padrão.

Ichikawa, Pitombo e Kawamoto (2002) determinam que a utilização de variáveis isoladas não é suficiente para determinar o padrão que cada indivíduo exerce. A combinação das principais características socioeconômicas permite avaliar com maior

\footnotetext{
${ }^{6}$ Solomon e Ben-Akiva (1983). The use of the life-style concept in travel demand models. Environment and Planning A 15. p. 623-638. apud Prasetyo (2001).
} 
confiabilidade o padrão de viagem de um indivíduo. Também mostram que as variáveis utilizadas nas análises têm influência no comportamento dos indivíduos. O número de automóveis no domicílio, por exemplo, é uma variável de grande influência quando se consideram os modos de viagens escolhidos.

Pitombo (2003), continuando a abordagem de Ichikawa (2002), analisa o comportamento de grupos homogêneos de indivíduos com relação às viagens encadeadas, usando um minerador de dados. As análises mostram que as principais variáveis que influenciam o padrão de viagem foram: trabalho, estudo, tamanho da família, idade, sexo, situação familiar, número de automóveis no domicílio e salário médio individual.

\subsubsection{Variáveis Condicionantes}

Os diferentes estudos forneceram conclusões sobre os condicionantes e as estratégias de viagem. A partir das teorias comportamentais de atividades e de padrões de viagens pode-se concluir que as variáveis que afetam a programação e comportamento referente às viagens encadeadas podem ser agrupados em variáveis condicionantes internas (endógenas) e variáveis condicionantes externas (exógenas), como descrito a seguir:

\section{Variáveis condicionantes internas:}

- Características comportamentais e socioeconômicas do indivíduo: incluindo renda, seu papel no domicílio, ocupação, situação na estrutura familiar, gênero, situação de emprego, grau de instrução e idade.

- Características socioeconômicas do domicílio: disponibilidade ou posse de automóvel, tamanho do domicílio, estagio no ciclo de vida, e localização da residência, interações domiciliares e renda domiciliar. 


\section{Variáveis condicionantes externas:}

- Oportunidade espacial-temporal e características das atividades: incluindo a distribuição das atividades, características demográficas, restrições de espaço; variações das atividades possíveis de serem realizadas no período do dia, restrições de tempo; tipo de atividade, localização, duração, opções de transporte, benefícios percebidos $\times$ custos da atividade; densidade residencial e atributos do uso do solo.

- Disponibilidade de meios de transporte, distribuição das características do nível de serviço na viagem entre a residência e a localização das atividades por diferentes modos de viagem e por períodos do dia.

\subsection{TÓPICOS CONCLUSIVOS}

O propósito deste capítulo foi revisar o estado da arte da análise de viagens baseadas em atividades e viagens encadeadas. Foram observados tanto aspectos ligados à modelagem, como a evolução e os aspectos relacionados com as variáveis usadas nos modelos.

Nota-se que as atividades são seqüencialmente conectadas dentro de um domínio contínuo de tempo e espaço, e que a unidade de tempo adotada na análise é o dia. No estágio atual modelos seqüenciais de atividades programadas, com base em tours, têm sido os mais comuns para representação dos aspectos comportamentais inerentes às viagens encadeadas. Aspectos como o processo de escolha e restrições tempo-espaço ainda se constituem em restrições que limitam a modelagem de viagens encadeadas.

Quanto as viagens a pé observa-se três fatores de importância: i) é uma modalidade utilizada majoritariamente por uma camada de população de baixa renda; $i$ ) apresenta um baixo consumo de energia; e, iii) é não poluente. Esses três fatores a tornam importante na modelagem do encadeamento de viagens a pé, visando o auxílio às políticas de planejamento dos transportes. 
Quanto às variáveis condicionantes na modelagem, existe uma ligeira diferença em relação às abordagens. Outras variáveis podem ser generalizadas e incorporadas ao conjunto de conhecimentos pertinentes a esta nova forma de modelagem de viagens encadeadas. Observa-se ainda uma grande diversidade de características domiciliares e individuais correlacionadas ao desejo de satisfazer as necessidades de participar de atividades.

Outro importante fato observado sobre a influência das variáveis socioeconômicas nas viagens encadeadas é que não necessariamente indivíduos com os mesmos atributos realizam um mesmo padrão de viagem. É provável que outras características, externas ao indivíduo e ao domicílio, podem estar contribuindo para isso; o que deverá ser considerado ao modelar viagens encadeadas. 


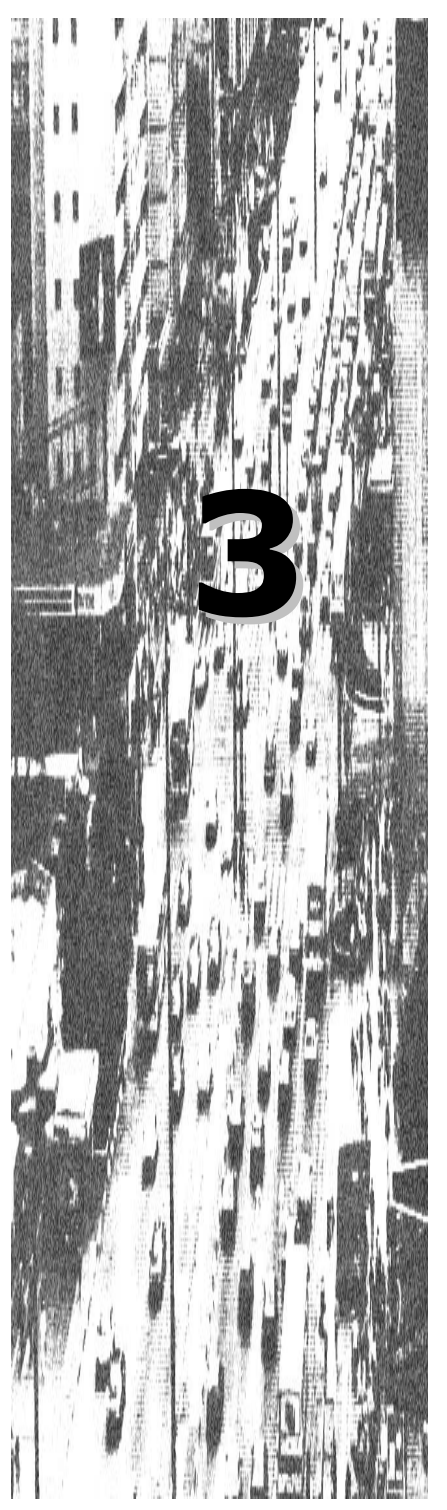

\section{Redes neurais artificiais}

"Respondeu-Ihe Jesus:

Eu sou o caminho, e a verdade, e a vida; ninguém vem ao Pai senão por mim"

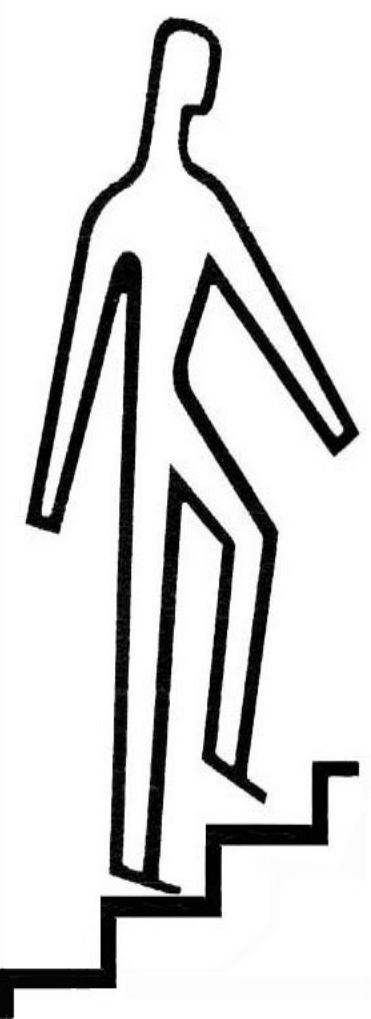




\section{REDES NEURAIS ARTIFICIAIS}

\subsection{INTRODUÇÃO}

Neste capítulo, o objetivo é descrever os princípios básicos da modelagem usando redes neurais, considerando especificamente a modelagem temporal e espacial. Para isso será necessária a apresentação dos conceitos de uma rede neural estática e de uma rede neural dinâmica. Também será apresentada uma breve análise das aplicações de RNA em transportes, especificamente no comportamento de viagens baseadas em atividades.

\subsection{MODELAGEM COM REDES NEURAIS ARTIFICIAIS}

Para Verleysen (1998), modelar é o primeiro objetivo nos domínios científicos, dado que a ciência em si mesma tenta criar e definir modelos que sejam genéricos quanto possíveis, assumindo que existem leis fundamentais que controlam todos os fenômenos físicos. Para isto, supõe-se que tais leis são observáveis. Mesmo que elas não sejam conhecidas, geralmente assume-se que são observáveis através das experiências, e que as experiências podem ser repetidas indefinidamente. Este é um conceito estatístico básico e essencial, pois muitas experiências são necessárias para construir uma nova teoria, isto é, para descobrir um "modelo" e/ou para ajustar seus parâmetros.

Nesse contexto surgem as Redes Neurais Artificiais (RNAs) como estruturas computacionais que tentam imitar habilidades simples do cérebro para modelar 
observações, e não a realidade, pela construção de um modelo que seja tão geral quanto possível, e que inclua parâmetros básicos para atingir os objetivos esperados, tornandose ferramentas úteis em análise de dados e estatística. Do ponto de vista computacional, Haykin (1999) define a rede neural como "um processador compacto distribuído em paralelo composto de unidades de processamento simples que possui uma tendência natural de armazenar conhecimento experimental e torná-lo disponível para uso". Do ponto de vista comportamental, para Shmueli, Salomon e Shefer (1996), as RNAs permitem modelar a intuição ${ }^{1}$, sem a complicação de ter que formalizar todas as complexidades causais das variáveis envolvidas e as relações que outros modelos requerem.

As RNAs diferem das tradicionais técnicas de análise de dados ou técnicas estatísticas pela sua forma de implementação, e não pelos seus objetivos, oferecendo no mínimo as quatro seguintes vantagens: $i$ ) as RNAs são técnicas auto-adaptativas, que aprendem a partir de exemplos e capturam relações funcionais entre dados, mesmo que as relações subjacentes sejam desconhecidas ou de difícil descrição; $i i)$ as RNAs podem generalizar quando a rede aprendeu através dos dados de uma amostra, pode inferir a parte não visível da população, inclusive quando os dados da amostra contém informações com "ruído"; iii) as RNAs são funções universais de aproximação do $\Re^{n}$ para $\Re^{p}$ (acerca disto, vide nota de rodapé ${ }^{2}$ ), podendo aproximar qualquer função contínua, apresentando mais formas funcionais gerais e flexíveis do que os métodos estatísticos tradicionais; iv) as RNAs são não lineares, sendo capazes de realizar modelagem sem conhecimento "a priori" das relações entre as variáveis de entrada e de saída (VERLEYSEN, 1998).

\subsubsection{Redes Neurais Artificiais Estáticas}

Uma RNA está constituída de unidades interconectadas de processamento simples denominados neurônios, onde para cada conexão ou link é atribuído um peso numérico (sináptico). Como observado na Figura 3.1, cada neurônio recebe um sinal de entrada com a "informação" total procedente de outros neurônios ou estímulos externos, sendo processados localmente junto a uma função de ativação ou de transferência produzindo

\footnotetext{
${ }^{1}$ Vocábulo presente no original inglês [“intuition”].

${ }^{2} \Re^{n}$ para $\Re^{p}$ : Conjunto pertencente aos valores reais de $n$ até $p$.
} 
um sinal transformado de saída para outros nós ou saídas externos (RUSSEL e NORVIG, 1996). Cada neurônio individual implementa sua função e efetua um cálculo local, não sendo necessário um controle global.

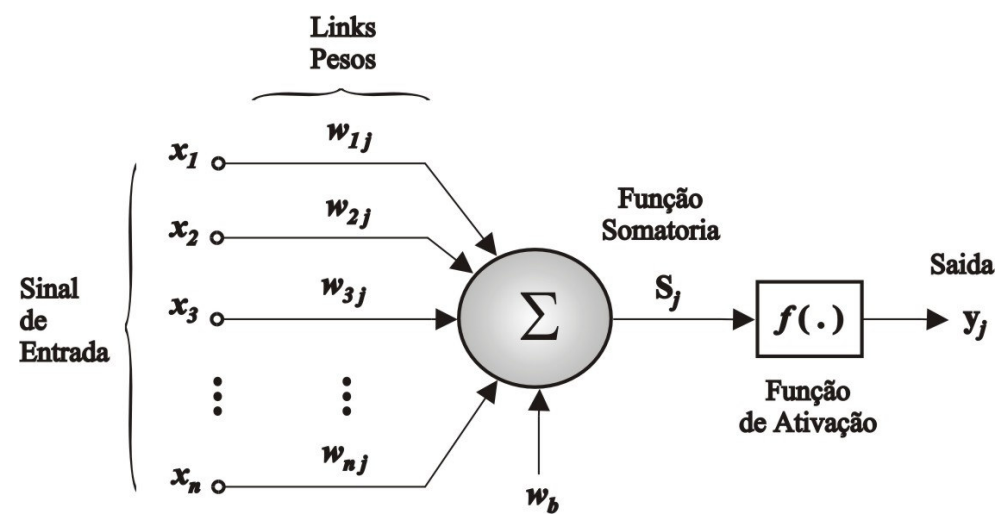

Figura 3.1: Modelo estático de neurônio artificial

Na figura 3.1 cada neurônio $\boldsymbol{j}$ possui vários sinais de entradas $\boldsymbol{x}_{\boldsymbol{i}}$ desde $i=1$ até $n$, que podem ser saídas provenientes de outros neurônios conectados a ele. Cada conexão tem associado um peso sináptico $\boldsymbol{w}_{i j}$. $\mathrm{O}$ neurônio recebe os sinais das conexões de entrada e calcula o novo nível de ativação correspondente que envia através das conexões de saída. O cálculo do nível de ativação está baseado nos valores de cada um dos sinais de entrada que envia o neurônio vizinho, assim como os pesos de cada um aos vínculos de entrada $\left(\boldsymbol{w}_{i j} \boldsymbol{x}_{\boldsymbol{i}}\right)$. O cálculo está dividido em duas componentes: o primeiro é linear, denominado "função de entrada" $S_{j}$, que calcula a soma ponderada dos valores de entrada da unidade; o segundo é não linear conhecido como "função de ativação", $\boldsymbol{f}$, que transforma a soma ponderada no valor final que serve como valor de ativação da unidade, $\boldsymbol{y}_{j}$.

$$
\begin{aligned}
& S_{j}=\sum_{i=1}^{n} w_{i j} x_{i}+w_{b} \\
& y_{j}=f\left(S_{j}\right)
\end{aligned}
$$

Onde, $n$ é o número de entradas do neurônio, $w_{b}$ representa o peso do bias (entrada fixa = "1") que polariza o neurônio. Quando a função de ativação não é linear, a eq. 
(3.2) pode ser avaliada por exemplo como $y=\tanh (S)=\frac{e^{S}-e^{-S}}{e^{S}+e^{-S}}$; no caso em que $f$ é considerada linear tem-se $y=\lambda S$, onde $\lambda=$ constante. Para o caso geral a saída de um j-ésimo neurônio é definida como:

$$
y_{j}=\frac{1}{\left(1+e^{-S_{j}}\right)}
$$

No sentido amplo, a RNA é funcionalmente equivalente a um modelo estatístico de regressão não linear, embora o processamento e a relação funcional entre as variáveis sejam totalmente diferentes da modelagem estatística. Em um problema explanatório ou causal as entradas para a RNA são um conjunto de variáveis independentes $\left(x_{n}\right)$ ou variáveis de previsão, e as variáveis de saída são as dependentes $\left(y_{m}\right)$. Definidos um vetor de entrada de variáveis independentes $\vec{X}=\left[x_{0}, x_{1}, x_{2}, \ldots, x_{n}\right]$ e um vetor de saída de variáveis dependentes $\vec{Y}=\left[y_{0}, y_{1}, y_{2}, \ldots, y_{m}\right]$, a relação funcional ou mapeamento estimado pela RNA é $\vec{Y}=\psi(\vec{X}, \vec{W})$ da entrada da primeira camada para a saída da última camada, parametrizado pelo vetor de pesos sinápticos $\vec{W}$.

Como observado, a rede neural resulta da interconexão de vários neurônios básicos em várias configurações. A configuração mais conhecida é a rede "feedforward" multicamada, referida também como Multi-Layer Perceptron (MLP), cuja estrutura consiste em camadas de neurônios na qual a saída de um neurônio de uma camada alimenta todos os neurônios da camada seguinte. Esta estrutura se caracteriza pela não existência de laços de realimentação, os pesos são fixos, o mapeamento é estático e não tem dinamismo. Para superar essas limitações das redes MLP e poder representar fenômenos temporais tem-se desenvolvido o processamento temporal em RNAs.

\subsection{PROCESSAMENTO TEMPORAL ATRAVÉS DAS RNAS}

Fenômenos temporais são fundamentais para atividades diárias dos seres humanos, e, como conseqüência deste fato, o tempo é um parâmetro importante de várias tarefas de reconhecimento de padrões, tais como séries de tempo e até mesmo 
encadeamento de viagens. Nestas tarefas de reconhecimento de padrões dinâmicos são necessárias estruturas capazes de representar o tempo. Muitos dos algoritmos de treinamento das RNA não são capazes de implementar mapeamentos dinâmicos. É o caso do algoritmo backpropagation, que pode apenas aprender mapeamentos estáticos. Para uma RNA ser considerada dinâmica, é preciso que possua memória, isto é, oferecer características dinâmicas ao mapeamento realizado pela rede, tornando-a sensível a sinais que variem com o tempo (BRAGA, CARVALHO e LUDERMIR, 1999). Redes deste tipo são conhecidas como redes neurais temporais.

\subsubsection{Redes Neurais Temporais}

Existem duas maneiras de incorporar memória a uma RNA: $i$ ) incorporando atraso no tempo através de um "mecanismo de janela" que lida com as variações temporais; e, ii) agregando laços de realimentação ou recorrência, das unidades processadoras até suas entradas, arquitetura conhecida como rede recorrente (HAYKIN, 1999). A seguir são apresentados resumidamente estes tipos de redes.

Redes neurais com atrasos no tempo, a idéia básica do processamento espaçotemporal utilizando atrasos no tempo é mostrada na Figura 3.2(a), onde a resposta da rede neural típica feedforward, no tempo $t$, é baseada nas entradas no tempo $(t-1),(t$ $2), \ldots,(t-n)$. Desta forma, considera-se um histórico da seqüência temporal. Geralmente os atrasos são utilizados na camada de entrada, existindo generalizações do método para considerar atrasos também nas camadas ocultas e na de saída. Entre as redes deste tipo estão a TDNN (Time-Delay Neural Network) que consiste de uma rede feedforward cujas unidades intermediárias e de saída são duplicadas ao longo do tempo; e a rede FIR (Finite-response Impulse Response) (BRAGA, CARVALHO e LUDERMIR, 1999).

Redes neurais recorrentes, no segundo tipo de rede neural para processamento temporal estão as que possuem arquitetura recorrente como observado na Figura 3.2(b), com uma ou mais conexões de realimentação, que pode ser "local" se for dada em nível de neurônio ou "global" se a realimentação engloba alguma(s) camada(s) completa(s). Esta recorrência na rede torna a memória flexível, isto é realimenta respostas geradas 
pelos neurônios da rede, para serem utilizadas em iterações futuras. Esta realimentação de respostas armazena, indiretamente, todos os valores previamente apresentados à rede, dentro da memória (BRAGA, CARVALHO e LUDERMIR, 1999).

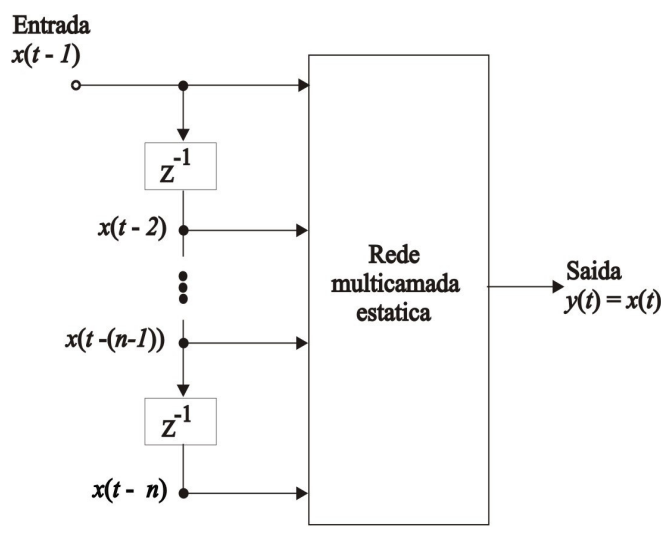

(a)

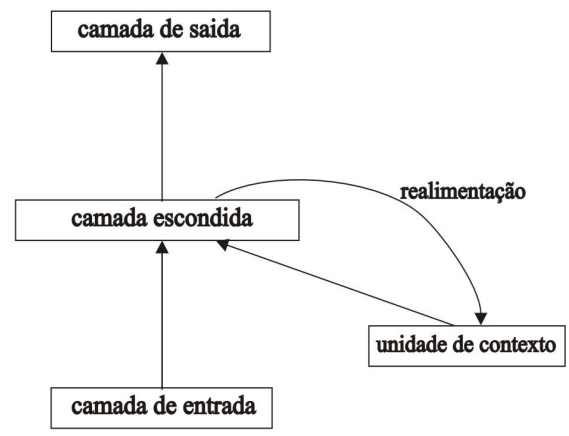

(b)

Figura 3.2: Processamento Temporal (a) usando atrasos no tempo (HAYKIN, 1999), (b) utilizando rede recorrente (HERTZ, KROGH e PALMER 1991).

Para Hertz, Krogh e Palmer (1991) um caminho para reconhecer e muitas vezes reproduzir seqüências é o uso de redes recorrentes (algumas vezes referenciadas como redes seqüenciais). A recorrência permite a rede lembrar informações do passado recente sem tornar complicado o treinamento, sendo que apenas o algoritmo backpropagation pode ser usado facilmente para o treinamento. A atualização é síncrona com uma atualização para todas as unidades a cada passo de tempo.

Na prática há duas maneiras de as redes recorrentes poderem ser utilizadas: $i$ ) para memórias associativas, uma variante de um classificador de padrões, onde as categorias de classificação são apresentadas pelos vetores armazenados na memória (o modelo mais conhecido é a rede Hopfield); e, ii) para mapeamento entrada-saída, onde a conectividade da RNA é estendida para incluir conexões de realimentação das saídas das unidades processadoras até suas entradas, as quais proporcionam comportamento dinâmico (HAYKIN, 1999). Neste tipo de rede a memória é baseada nos estados de ativação passados dos neurônios, como observado na Figura 3.2(b). Entre as RNAs 
deste tipo se encontram as redes Elman, a rede Jordan e a rede NARX (Nonlinear Autoregressive with exogenous Inputs).

No cap. 2, da presente tese, observou-se que uma das limitações da modelagem de viagens encadeadas está relacionada com a representação no sequênciamento das viagens pelas restrições do tempo-espaço. Nesse contexto, a Rede Elman é um tipo de rede temporal que pela sua estrutura, consegue reconhecer e reproduzir sequiências de processos temporais, de forma mais eficiente que uma rede estática do tipo MLP. A seguir são apresentadas as características da rede Elman.

\subsubsection{Rede Elman}

Uma arquitetura mais complexa é obtida quando se utiliza realimentação global, como mostrado na Figura 3.3. Neste caso há realimentações de saída de cada um dos neurônios ocultos para todos os neurônios da camada oculta. O algoritmo de aprendizado utilizado para o treinamento desta rede é o algoritmo de backpropagation. A diferença básica no aprendizado é que a rede Elman no instante $\boldsymbol{k}+\mathbf{1}$ recebe como entradas na camada oculta a(s) entrada(s) externa(s) e os valores de saída da camada escondida do instante anterior $(\boldsymbol{k})$, que representarão as denominadas unidades de contexto e em conjunto, camada de contexto. A rede possui uma memória interna que é capaz de representar a "história" dos efeitos das entradas anteriores, na qual está baseada a resposta da rede ao processo temporal. Esta memória interna também é referida como flexível. Sem esta capacidade de memória interna o uso da rede Elman não teria sentido. A rede Elman tem uma memória infinita, ou limitada ao número de dados disponíveis para a entrada da rede. Por exemplo, considerando somente uma entrada externa, a saída da rede estará determinada pelos pesos sinápticos estimados no treinamento " $\boldsymbol{w}$ ", pela entrada atual da rede $\boldsymbol{x}(\boldsymbol{k})$, e por todas as entradas anteriores que poderiam ser infinitas, como se indica na seguinte expressão:

$$
\mathrm{y}(k)=\mathrm{y}(k \mid \mathrm{w}, x(k), x(k-1), x(k-2), \ldots, x(-\infty))
$$


Como observado na arquitetura da rede Elman (Figura 3.3), a camada de entrada é dividida em duas partes: as unidades de entrada propriamente ditas e as unidades de contexto. As unidades de contexto simplesmente seguram uma cópia das ativações das unidades escondidas do passo anterior de tempo. As conexões modificáveis são todas feedforward e podem ser treinadas através de métodos convencionais de backpropagation. Isto é realizado a cada passo de tempo, no caso das sequiências de entrada, habilitando a rede a reconhecer seqüências e até mesmo produzir prolongamentos curtos de sucessões conhecidas.

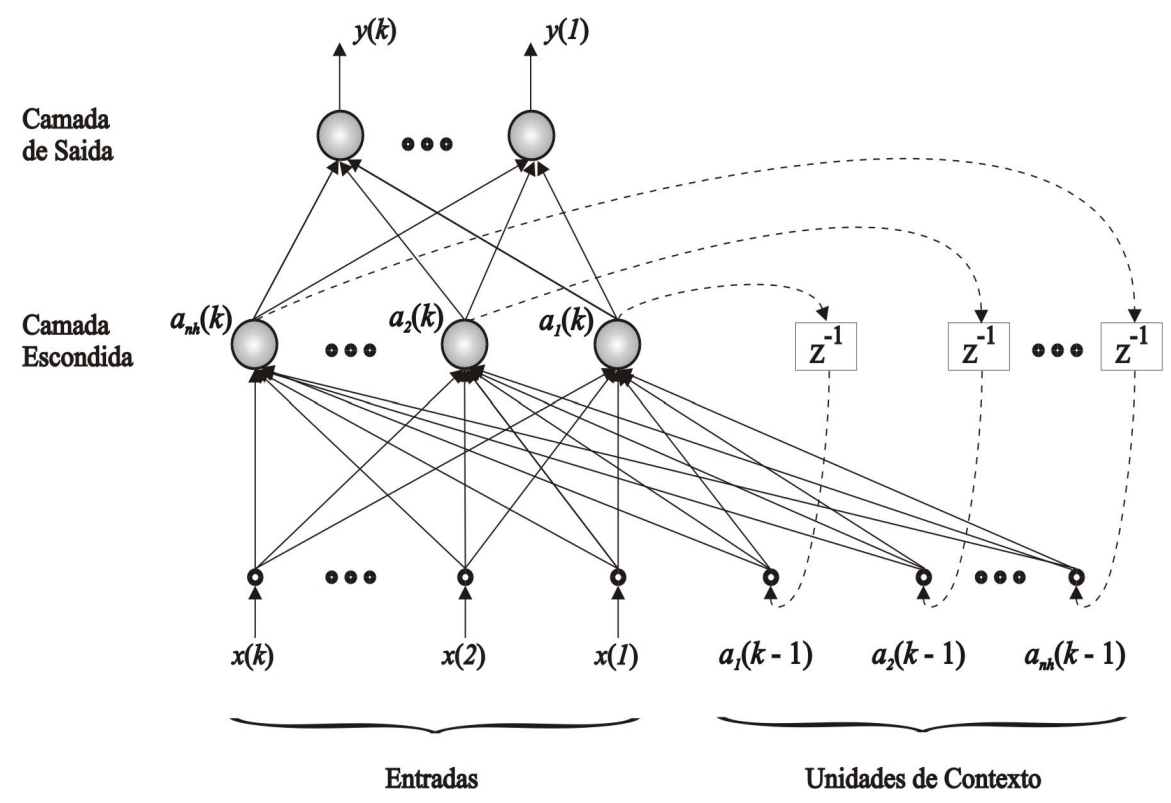

Figura 3.3: Rede completamente recorrente - Rede Elman.

Unidades de Contexto, $C_{i}$, e em conjunto camada de contexto são as que recebem os sinais de ativação da camada oculta. É assumido que a propagação forward acontece rapidamente sem referência ao tempo, enquanto os sinais feedback são cronometrados. Assim, para o tempo $t$, as unidades de contexto têm alguns sinais vindo do estado da rede para o tempo $t-1$, que fixa um contexto para processamento no tempo $t$. As unidades de contexto lembram aspectos do passado, e, assim, o estado da rede inteira, em um momento particular, depende do agregado de estados prévios tanto quanto da entrada atual. Conseqüentemente a rede pode reconhecer seqüências sobre a base deste estado ao término da sequiência. O mais importante desta rede é que as auto-conexões 
proporcionam as unidades de contexto $C_{i}$ alguma memória individual, ou inércia, sendo a regra de atualização função dos estados de tempo e das unidades de saída:

$$
C_{i}(t+1)=\alpha C_{i}(t)+O_{i}(t)
$$

onde $O_{i}$ são as unidades de saída e $\alpha$ é a força das auto-conexões. É necessário que $\alpha<1$. Se as saídas $O_{i}$ fossem fixas, então a $C_{i}$ pode claramente decair exponencialmente para $O_{i} /(1-\alpha)$, esquecendo gradualmente dos seus valores prévios. Para vários estados de tempo, integrando a eq. (3.5) obtém-se:

$$
\begin{gathered}
C_{i}(t+1)=O_{i}(t)+\alpha O_{i}(t-1)+\alpha^{2} O_{i}(t-2)+\cdots \\
C_{i}(t+1)=\sum_{t^{\prime}=0}^{t} \alpha^{t-t^{\prime}} O_{i}\left(t^{\prime}\right)
\end{gathered}
$$

Ou, no limite contínuo,

$$
C_{i}(t)=\int_{0}^{t} e^{-\gamma\left(t-t^{\prime}\right)} O_{i}\left(t^{\prime}\right) d t^{\prime}
$$

onde $\gamma=|\log \alpha|$. Assim, em geral as unidades de contexto acumulam um peso médio trasladado ou o rastro dos valores passados observados, para o $O_{i}$. Se se fizer $\alpha$ próximo a 1, a memória estende um retrocesso adicional para o passado às custas da perda de capacidade de responder a estímulos para o detalhe. Em geral, o valor de $\alpha$ deve ser escolhido de forma que as taxas de decremento igualem às características de escala de tempo da sequiência de entrada.

\subsection{MODELAGEM EM TRANSPORTES FAZENDO USO DE REDES NEURAIS ARTIFICIAIS}

Discussões das potencialidades das aplicações em transportes das RNA podem ser encontradas em Faghri e Hua (1992). Dougherty (1995) realiza um resumo das principais aplicações e dos resultados obtidos em inúmeros trabalhos usando RNA em transportes. Outras aplicações podem ser encontradas em Bocanegra (2002) e Furtado (1998). 
Após um exame detalhado das áreas de aplicação, não foi constatada uma aplicação relacionada especificamente com modelagem de comportamento das viagens encadeadas. Em uma aplicação relativamente próxima à proposta neste trabalho, Shmueli, Salomon e Shefer (1998) aplicam as RNA para previsão de comportamento das viagens como uma necessidade preliminar no planejamento de transportes, enfatizando a investigação das atividades e suas conexões com as características do individuo, o domicílio e a área geográfica, como uma reflexão das necessidades da população, enquanto as viagens e suas características servem como meios para cumprir estas atividades.

Além das descobertas na modelagem de comportamento de viagens fazendo uso das RNAs, Shmueli, Salomon e Shefer (1998) desenvolveram novas técnicas para melhorar o processo de aprendizagem da rede. Incluem medidas comportamentais (psychometric), tentando inserir no modelo as atitudes e as motivações dos indivíduos que possam melhorar o poder de previsão das redes neurais. Afirmam que o comportamento não é determinado exclusivamente por simples variáveis sócioeconômicas e demográficas, mas que, além disso, é afetado por construções psicológicas que podem representar alguma combinação de simples fatores mensuráveis, na forma em que são interpretados pela mente humana.

Shmueli, Salomon e Shefer (1998) criam quatro conceitos de medidas psicométricas com base nas variáveis socioeconômicas e demográficas que são conectados às entradas da rede. Os conceitos atuam como ferramentas e idéias baseadas na intuição, e que, aplicados como "indicadores de regras", podem ser inseridos nas unidades da rede permitindo um processo de aprendizado mais focalizado. Assim os indicadores foram representados na rede, primeiro como unidades de entrada, segundo como unidades de saída, e terceiro mudando a arquitetura da rede pela mudança de conexões. Com estas mudanças representaram bem o número de viagens ao trabalho por sexo. No entanto, outros experimentos não alcançaram sucesso, o que permitiu apontar as deficiências básicas nos tipos de dados coletados, e na necessidade de informação adicional para explicar o comportamento de viagem. 
Numa pesquisa promissora, embora não continuada, a RDC (1995) e Pendyala et al. (1997) desenvolveram novos métodos de aprendizagem indutiva, para modelagem baseada em atividades fazendo uso de RNAs, que são incorporados no modelo AMOS (Activity-Mobility Simulator). O objetivo do método é produzir regras gerais através de exemplos proporcionados externamente, de maneira que o sistema baseado em regras permita localizar e entender os processos de quem toma a decisão. O AMOS usa uma rede neural para modelar o comportamento adaptável dos indivíduos às várias condições. A rede é treinada quanto à maneira como os indivíduos adaptam suas decisões (exemplo: escolha do modo) em resposta a implementações hipotéticas de medidas de controle em transportes (exemplo: pedágio em hora pico).

Rao et al. (1997) realizaram uma avaliação comparativa entre o modelo Logit Multinomial (MNL) e as RNAs na modelagem do comportamento relacionado com a escolha do modo de viagem para acessar o transporte de massa. Devido às relações de não-linearidade que são estabelecidas pela RNAs, seu desempenho superou o MNL tanto na calibração como na previsão. Adicionalmente, ficou demonstrado que a significância relativa das variáveis de entrada pode ser determinada pelo modelo da RNA usando um algoritmo de separação de pesos e cuja validade foi comprovado com os resultados do modelo MNL. Além disso, a elasticidade da demanda pode ser estimada usando os pesos normalizados da camada de saída da RNA. Conclui-se que as RNA tornam-se promissores para futuras aplicações na modelagem de comportamento de viagem.

Faghri e Sandeep (1998) aplicaram o algoritmo backpropagation para modelagem da produção de viagens, como parte do processo de quatro etapas para previsão da demanda de viagens urbanas, focalizaram o estudo na importância da determinação dos valores adequados para treinamento de uma RNA, da "constante momentum" (Momentum Constant - MC) e da "taxa de aprendizagem" (Learning Rate - LR). A seleção de um valor de LR tem um efeito significativo sobre o desempenho da rede. Por sua vez, a constante MC permite diminuir a convergência do tempo e evitar o problema de mínimo local, fazendo a mudança dos pesos correntes. 
Himanem, Järvi-Nykänen e Raitio, (1998) analisaram viagens diárias fazendo uso de mapas auto-organizáveis, também conhecidos como mapas Kohonen ou SelfOrganizing Maps (SOM) de aprendizado não supervisionado competitivo. A tarefa para analisar o comportamento de viagem diária simplifica-se pelo agrupamento de padrões similares de viagens dentro de classes. Com esta nova metodologia consegue-se capturar, intuitivamente, pelo menos algumas das complexas estruturas do comportamento diário de viagens através da classificação do viajante de acordo com vários parâmetros da viagem e do viajante. Ademais, possibilita examinar a correlação entre o comportamento do viajante e de variáveis explanatórias (socioeconômicas) de um modo simples porém eficiente.

Raia Jr. (2000) desenvolveu um processo de modelagem destinada a estimar índices de potenciais de viagens fazendo uso dos Sistemas de Informações Geográficas e das RNAs. Para isso incorporou como variáveis de entrada os valores de acessibilidade, mobilidade e variáveis domiciliares, e como variáveis de saída os valores das viagens realizadas e a distância de deslocamento. As RNAs são utilizadas para avaliar o desempenho das variáveis de entrada e de saída, e assim reformular o modelo e aplicá-lo num estudo de caso na cidade de Bauru-SP.

Embora a aplicação não seja específica em análise de comportamento de viagens baseado em atividades, Dantas (2002) desenvolveu um modelo Neural-Geo-Temporal (NGTM) baseado na integração das RNAs e dos Sistemas de Informações Geográficas. O modelo visa a criação de um instrumento para atividades de planejamento estratégico na modelagem da atração de viagens, considerando as dimensões geográficas e temporais que afetam interações urbanas e conseqüentemente a previsão da demanda de viagens. Numa abordagem inovadora na área de transportes, o modelo usa de uma modelagem recursiva empregando a arquitetura de uma rede neural recorrente do tipo Elman. 


\subsection{TÓPICOS CONCLUSIVOS}

As seções deste cap. 3, permitiram entender os fundamentos teóricos sobre as Redes Neurais Artificiais, como um tipo de inteligência computacional com uma estrutura de processamento parecida com as características de processamento do cérebro humano. Outro aspecto plenamente confirmado é que as RNAs podem ser consideradas ferramentas estatísticas de modelagem não linear e, que além do reconhecimento de padrões, podem também representar seqüências temporais, permitindo criar e reproduzir eventos que dependam do espaço e tempo. Para isto existem diversos tipos de arquiteturas de RNAs, as que estão providas de "memória" na forma de "unidades de contexto", como é o caso da rede Elman. Com isso é incorporada a dimensão temporal na rede, possibilitando a representação do encadeamento de viagens sem a necessidade de formulações matemáticas complicadas.

Das aplicações de RNAs em transportes, pode ser observado que a modelagem do espaço-tempo na representação do comportamento de viagens ainda não foi realizada. Entre algumas das possíveis explicações deste fato pode estar a complexidade inerente ao comportamento dos indivíduos, na seleção e programação das atividades durante um dia. Outro fato observado é que também não foram desenvolvidas aplicações na modelagem de viagens encadeadas para modos não motorizados (especificamente o modo a pé). Isso torna a presente abordagem de modelagem individual de padrões de viagens encadeadas a pé fazendo uso das técnicas das RNAs, uma aplicação promissória no planejamento dos transportes, especificamente no relacionado com o uso de Redes Recorrentes para representação de viagens encadeadas. 


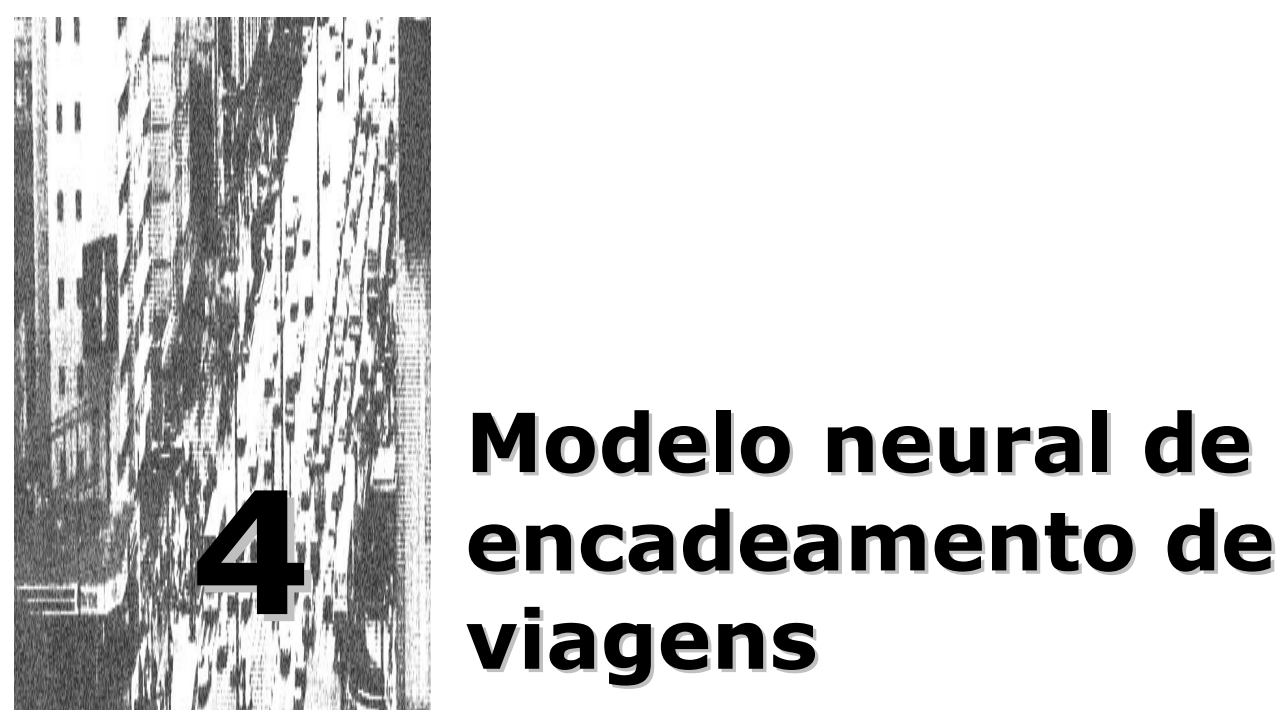

"Porque o Senhor dá a sabedoria, e da sua boca vem a inteligência e o entendimento"

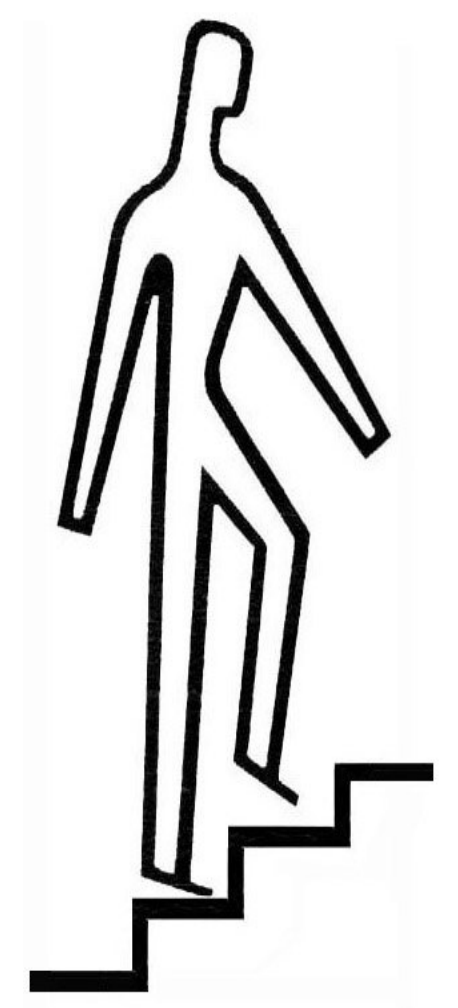




\section{MODELO NEURAL DE ENCADEAMENTO DE}

\section{VIAGENS}

\subsection{INTRODUÇÃO}

A base para modelagem das decisões individuais e domiciliares dentro de uma estrutura de decisão de viagens urbanas é proporcionada pela teoria de viagens baseada em atividades. No tocante às viagens encadeadas, essa teoria é fundamental para modelagem. Como observado no cap. 2, os modelos existentes procuram incorporar nas suas estruturas de decisão, os conceitos de encadeamento de viagens, embora aspectos relacionados com a representação das restrições de tempo-espaço não sejam totalmente garantidas. No cap. 3, observou-se que através da modelagem usando RNAs temporais pode-se inserir e reproduzir as restrições espacial-temporal fundamentais na representação do encadeamento de viagens, sem a necessidade de desenvolvimento de formulações matemáticas sofisticadas e complexas e sem supor relações "a priori" entre as variáveis. Considerando esses critérios, no presente capítulo, em primeiro lugar serão estabelecidas de forma geral as suposições teóricas para a formulação espaço-temporal da modelagem neural de encadeamento de viagens fazendo uso das RNAs. A partir dessa formulação geral da modelagem, será definida especificamente a modelagem individual de padrões de viagens encadeadas a pé. Para isso, na seção 4.2 são feitas as suposições teóricas, fundamentadas na revisão bibliográfica do cap. 2, sobre as quais será baseada a modelagem. Na seção 4.3 são apresentadas as definições básicas para 
formulação do modelo neural de encadeamento de viagens. $O$ modelo neural MONEVPE é descrito na seção 4.4.

\subsection{SUPOSIÇÕES TEÓRICAS PARA CONCEPÇÃO DO MODELO NEURAL DE ENCADEAMENTO DE VIAGENS}

Com base na revisão bibliográfica do cap. 2, a estrutura do modelo a desenvolver segue as suposições teóricas apresentadas a seguir:

- As características da configuração urbana (sistema de atividades, condições de uso do solo) influencia diretamente as decisões individuais e domiciliares. A interrelação altera as decisões individuais que afetam o desempenho do sistema de transporte (BOWMAN, 1995).

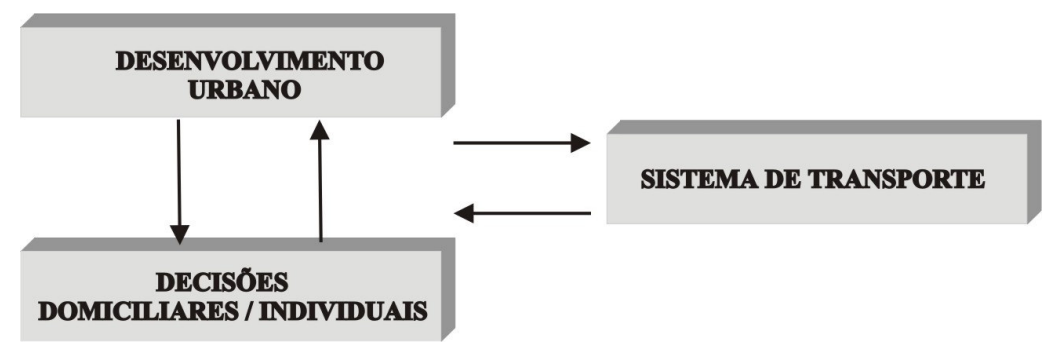

Figura 4.1: Estrutura das decisões de viagens e desenvolvimento urbano.

- Demonstra-se que os "condicionantes da mobilidade, nos países em desenvolvimento, não podem ser reduzidos a medidas simples da quantidade, custo e hora de realização das viagens, pois estes vão além da renda em si; eles estão relacionados aos modos e aos motivos das viagens, à forma da cidade e à localização dos seus equipamentos. Conseqüentemente, a análise de demanda de transportes deve considerar a economia da mobilidade familiar, ou seja, a estratégia familiar de uso do tempo e do espaço, como forma de sobrevivência coletiva" (HENRY e FIGUEROA ${ }^{1}$, 1985 apud VASCONCELOS, 1996).

- O domicílio, como unidade social, é um concentrador da economia, de recursos humanos, é gerador de viagens domiciliares resultantes das atividades que os membros

\footnotetext{
${ }^{1}$ Henry, E. e Figueroa, O. (1985). Transporte y servicios urbanos em América Latina. Quito, INRETS/CIUDAD. apud Vasconcelos (1996).
} 
do domicílio realizam fora do domicílio, individualmente ou em conjunto (KOSTYNIUK e KITAMURA, 1986b).

- A inclusão de variáveis domiciliares altera a significância estatística da modelagem. A redefinição na estrutura familiar através da modificação dos valores e papéis dos indivíduos de ambos os sexos, nos últimos 20 anos, trouxeram para a sociedade contemporânea um novo padrão de comportamento referente a viagens (Figura 4.2), um novo padrão de atividades, um novo padrão de deslocamentos. Por conseguinte alterações na demanda por transportes podem ser diferentes do que era antes, em função das mudanças na sociedade (TANDEL, 1997).

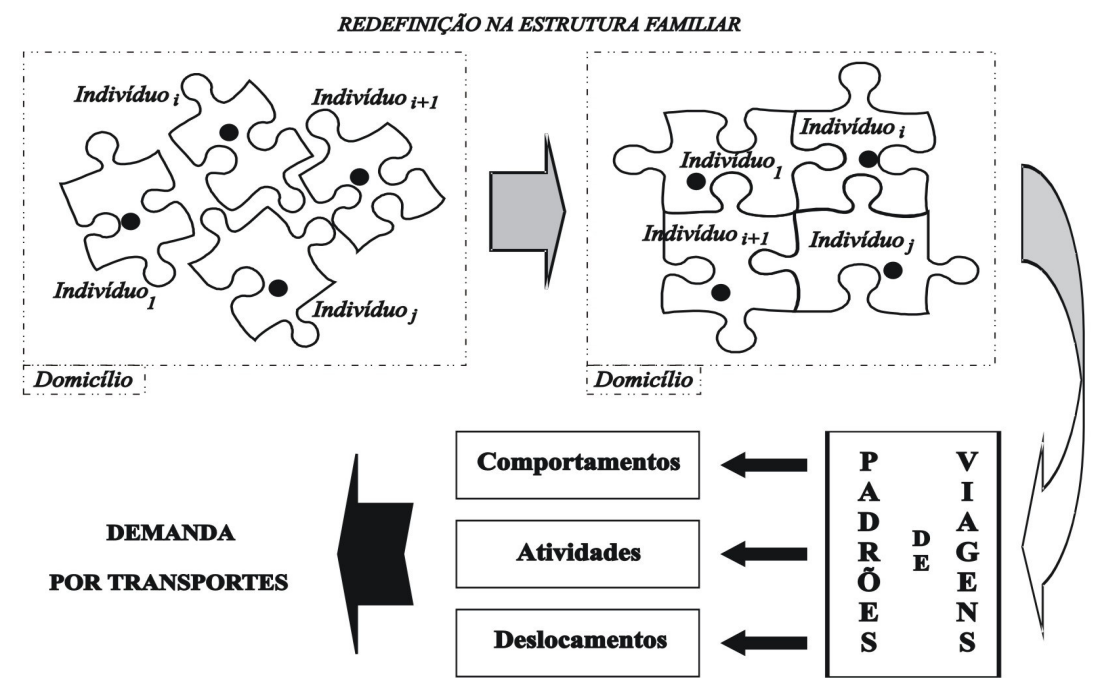

Figura 4.2: Mudanças na demanda por transportes pela redefinição na estrutura familiar.

- A análise da demanda de viagem urbana passou por uma mudança do paradigma principal, da abordagem baseada na viagem para uma abordagem baseada em atividade. A modelagem convencional da demanda de viagem lida com viagens individuais como eventos discretos e sem conexão, freqüentemente agregadas em zonas de tráfego para análise, enquanto a abordagem baseada na atividade coloca a ênfase em padrões de atividade/viagem e na dinâmica de comportamento de viagem individual (JONES ${ }^{2}$ et al. 1990 apud KITAMURA, 1996).

${ }^{2}$ Jones, P. M. et al. (1990). Activity analysis: state-of-the-art and future directions. In P. Jones (ed.) Developments in Dynamic and Activity-Based Approaches to travel Analysis, Gower Publishing, Aldershot. apud Kitamura (1996). 
- Conseqüentemente, o sistema de modelo de viagens encadeado baseado em atividades deve incluir todas as informações sobre a cadeia de atividades de cada individuo do domicílio, desenvolvidas ao longo do dia: o período do dia, a duração da atividade, o tipo de atividade, a localização, o modo da viagem e o tempo de viagem para realização de cada atividade. A estrutura do modelo da Figura 4.3 é desenhada para representar tanto quanto possível um sistema de modelo ideal, como os propostos por Bowman et al. (1998) e Shiftan (1999).

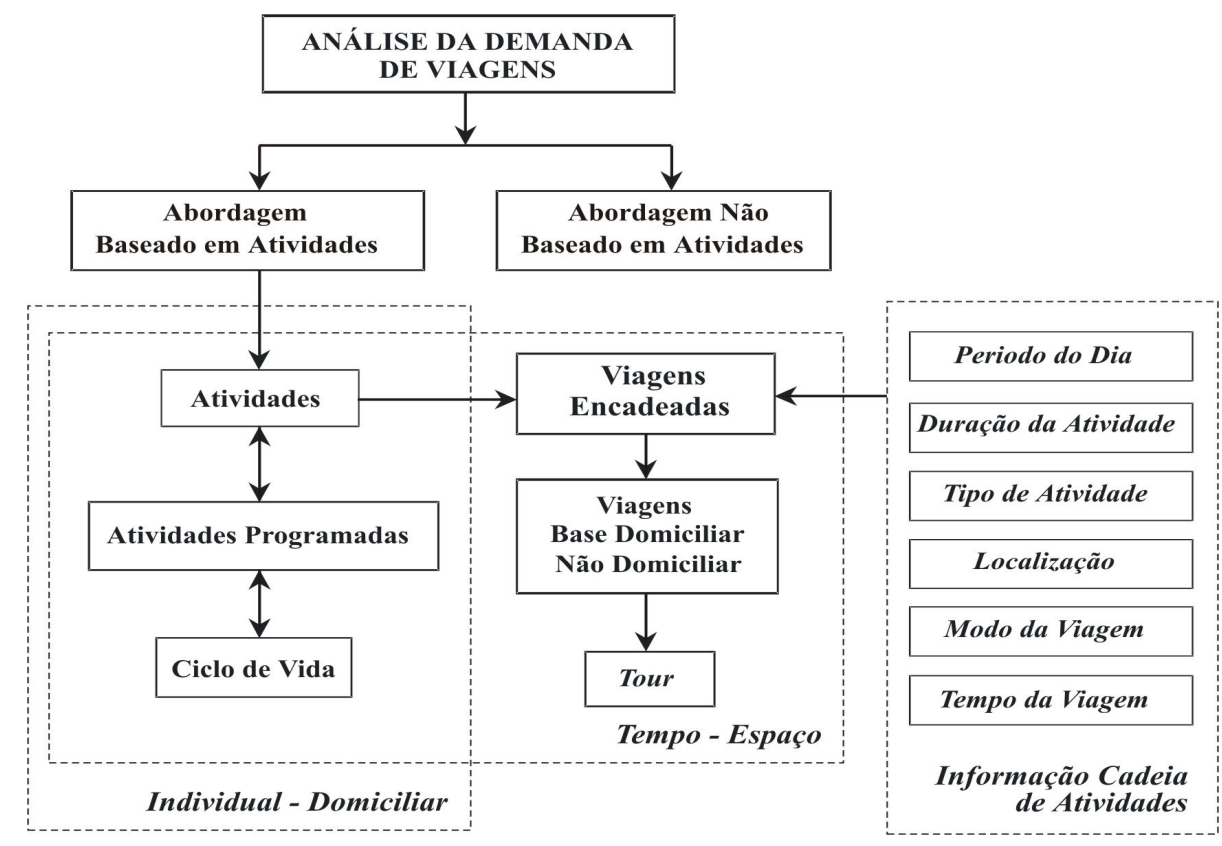

Figura 4.3: Estrutura de abordagem de viagens encadeadas baseado em atividades.

- O comportamento e programação de atividade (Activity Scheduling) consiste de decisões referentes à dimensão temporal (período-no-dia ou duração de atividades), dimensão espacial (local das atividades), e dimensões qualitativas (tipos de atividades, modos de viagem). A abordagem baseada em atividade requer que as viagens sejam tratadas em nível desagregado considerando a interação entre viajante e as atividades. A inclusão das variáveis do espaço-tempo nos dados da modelagem possibilitará analisar padrões de atividade/viagem como comportamento de viagem encadeada e as interações espaço-tempo entre as viagens (KAWAKAMI e ISOBE, 1990). 
- Pelo fato de as atividades representarem vários "objetivos de satisfação de necessidades ligados aos membros do domicílio" estas podem ser agrupadas dentro de várias categorias, tais como trabalho, compras, lazer, ou também agrupadas em opções obrigatórias, flexíveis, e opcionais; e descritas em termos de onde, quando, e quão distante umas de outras, acontecem essas atividades (SPEAR, 1996).

\subsection{DEFINIÇÕES BÁSICAS PARA CONCEPÇÃO DO MODELO NEURAL DE ENCADEAMENTO DE VIAGENS}

A concepção do modelo neural apóia-se nas seguintes definições básicas:

a) Padrões de atividades $\boldsymbol{e}$ viagens: A análise de padrões de atividades pode ser vista como um problema de classificação em que a entrada é um conjunto de medidas que definem movimentos humanos (viagens) e a saída é a classificação destes movimentos dentro de um conjunto de categorias "natural" ou "predeterminada" (RECKER, 1995). No modelo, os padrões de atividades e viagens " $p(a v / v g)$ " estarão constituídos de um conjunto de categorias, em que o começo e final da cadeia da viagem são predeterminados na base do Domicílio - H. O propósito da viagem com base no domicílio pode ser classificado em quatro grupos: Trabalho (W); Escola (S); Lazer (L); e, Outras Atividades (A). Esta classificação do padrão $\boldsymbol{p}(\boldsymbol{a v} / \boldsymbol{v g})$ com base no domicílio poderá ser representada segundo o propósito da atividade principal da viagem, da seguinte forma: ao trabalho $(\mathbf{H W}+\mathbf{H})$, à escola $(\mathbf{H S}+\mathbf{H})$, ao lazer $(\mathbf{H L}+\mathbf{H})$, outras $(\mathbf{H A}+\mathbf{H})$. O “+” representa o acréscimo de pelo menos parada adicional para realização de uma atividade.

b) Encadeamento de viagens: $\mathrm{Na}$ abordagem baseada em atividades o comportamento referente a viagens encadeadas é analisado e representado através do padrão $\boldsymbol{p}(\boldsymbol{a} \boldsymbol{v} / \boldsymbol{v g})$. Com este fundamento será representado e reproduzido o comportamento das viagens encadeadas em função do padrão $\boldsymbol{p}(\boldsymbol{a v} / \mathbf{v g})$.

$$
p(\text { av/vg }) \Rightarrow \text { Encadeamento de Viagens }
$$


c) Comportamento dinâmico: A modelagem do comportamento dinâmico das viagens encadeadas e das interações entre as dimensões espaço-tempo-qualitativas, será representada através de uma função de modelagem dinâmica $\Omega$, que possibilitará expressar de forma realista as inter-relações dinâmicas observadas nas decisões individuais/domiciliares que afetam o desenvolvimento urbano e o sistema de transporte (Figura 4.4). Para isso estabelecem-se o Sistema de Atividades $(\boldsymbol{A})$ o Domicílio $(\boldsymbol{D})$ o Indivíduo (I) e o Espaço Urbano $(\boldsymbol{E})$ em que as atividades são localizadas e desenvolvidas.

$$
\begin{gathered}
\boldsymbol{p}(\boldsymbol{a v} / \boldsymbol{v g})=\Omega\{\operatorname{Indivíduo~}(\boldsymbol{I}), \operatorname{Domicílio~}(\boldsymbol{D}), \text { Sistema de Atividades }(\boldsymbol{A}), \text { Espaço } \\
\operatorname{Urbano}(\boldsymbol{E})\}
\end{gathered}
$$

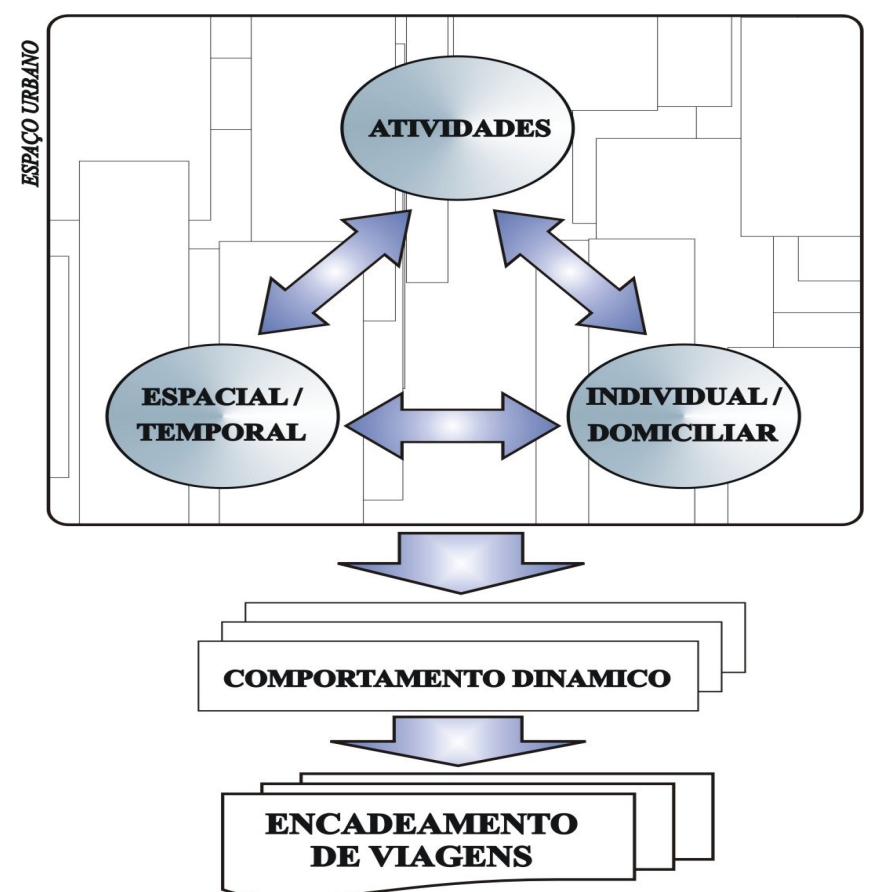

Figura 4.4: Elementos do sistema de comportamento dinâmico $\Omega$ da modelagem do encadeamento de viagens.

d) Características do espaço urbano, domicílio, indivíduo, e do sistema de atividades: Seja o Espaço Urbano $(\boldsymbol{E})$ caracterizado pela sua função urbana, isto é, pelo uso do solo predominante e pelas atividades nele desenvolvidas (Domicílio, Trabalho, Estudos, Lazer, Outras). Para um Espaço Urbano predominantemente Residencial $\left(\boldsymbol{E}_{R}\right)$ 
com $m$ Domicílios $\boldsymbol{D}_{(1,2,3, \ldots, m)}$ localizados naquele espaço urbano, e com $n$ Indivíduos $\boldsymbol{I}_{(i \rightarrow n)}$, (onde $i$ varia de 1 até $n$ ) morando naqueles domicílios, existirão ao menos $m$ domicílios e $n$ indivíduos georeferenciados (localizados geograficamente) no espaço urbano através das suas coordenadas geográficas $Z_{X}$ e $Z_{Y}$. Para tal espaço urbano residencial $\boldsymbol{E}_{R}$ definem-se os seguintes vetores de características:

Vetor das características socioeconômicas do individuo:

$$
\overrightarrow{C I}=\overrightarrow{C I}_{(i \rightarrow n)}
$$

Vetor das características socioeconômicas do domicílio:

$$
\overrightarrow{C D}=\overrightarrow{C D}_{(1,2,3, \ldots, m)}
$$

Vetor das características geográficas do espaço urbano $\boldsymbol{E}_{\boldsymbol{R}}$ :

$$
\overrightarrow{C Z}=\overrightarrow{C Z}_{(X, Y)}
$$

Sejam diversos espaços urbanos caracterizados por não serem especificamente residenciais, denominados $\boldsymbol{E}_{N R}$, e nos quais se desenvolvem Atividades exclusivas tais como Trabalho $(\mathbf{W})$, Estudos $(\mathbf{S})$, Lazer $(\mathbf{L})$ e Outros (A). Para tais $\boldsymbol{E}_{N R}$ definem-se os seguintes vetores de características:

Vetor das características dos tipos de atividades:

$$
\overrightarrow{C A}=\overrightarrow{C A}_{(W, S, L, A)}
$$

Vetor das características geográficas do espaço urbano $\boldsymbol{E}_{N R}$ :

$$
\overrightarrow{C Z}^{\prime}=\overrightarrow{C Z}_{(X, Y)}
$$

e) Características da viagem no espaço-tempo: Para agregar as características da viagem no espaço-tempo e representar o encadeamento, cria-se o termo Estado sendo definido como o conjunto de condições do Espaço Urbano $\left(\boldsymbol{E}_{\boldsymbol{R}}\right.$ ou $\left.\boldsymbol{E}_{N \boldsymbol{R}}\right)$ em que estão situados os indivíduos e suas características, num dado momento da viagem. Tais estados variam desde o início da viagem até a sua finalização (Estado 1, Estado 2,..., Estado $N$, Estado $N+1$ ). Como pode ser observado na Figura 4.5, sejam agregadas as características do espaço urbano $\boldsymbol{E}_{\boldsymbol{R}}$ ou $\boldsymbol{E}_{N R}$, e as características individuais e da viagem 
em tais Estados. Para um individuo $I_{(i \rightarrow n)}$ viajando do espaço urbano $\boldsymbol{E}_{\boldsymbol{R}}$ (Estado 1) em direção a um espaço urbano $\boldsymbol{E}_{N R}($ Estado 2) qualquer, existirá um Período de Tempo do Dia $\boldsymbol{P}_{(1,2, \ldots, N)}$ em que começa e termina a viagem, um Tempo $\boldsymbol{T}_{T}$ da viagem, um Modo $\boldsymbol{M}_{(1,2, \ldots, M)}$ no qual é realizada a viagem, um Tipo de Atividade $\boldsymbol{A}_{(W, S, L, A)}$ no espaço urbano $\boldsymbol{E}_{N \boldsymbol{R}}$ que motiva viagem. Para tais condições, têm-se os seguintes vetores de características:

Vetor das características do individuo e das atividades que motivam a viagem:

$$
\{\overrightarrow{C I}, \overrightarrow{C A}\}=\left\{\overrightarrow{C I}_{(i \rightarrow n)}, \overrightarrow{C A}_{(W, S, L, A)}\right\}
$$

Vetor das características do período durante o dia em que são realizadas as viagens:

$$
\vec{P}_{N}=\overrightarrow{C P}_{(1,2,3, \ldots, N)}
$$

Vetor das características do tempo da viagem:

$$
\vec{T}_{T}=\overrightarrow{C T}_{(1,2,3, \ldots, T)}
$$

Vetor das características do modo da viagem:

$$
\vec{M}_{M}=\vec{M}_{(1,2,3, \ldots, M)}
$$

f) Execução das atividades no espaço-tempo: Para uma dada seqüência de viagens com base no domicílio $\boldsymbol{E}_{\boldsymbol{R}}$, com destinos em espaços urbanos $\boldsymbol{E}_{\boldsymbol{N} \boldsymbol{R}}$ (Figura 4.5) e finalizando a viagem no domicílio, tem-se que as cadeias de viagens atravessam por vários estados (Estado 1, ..., Estado $N$ ), pois acontecem em períodos de tempos diferentes ao longo de um dia. Em cada Estado um indivíduo seleciona um programa de atividades e um caminho específico no espaço e define um tempo para executar as atividades programadas. A estrutura domiciliar, espacial-temporal, as oportunidades e restrições do local onde as atividades são executadas determinam a viabilidade das atividades, e, conseqüentemente, do encadeamento das viagens com base no domicílio $\boldsymbol{E}_{\boldsymbol{R}}$, com destinos em espaços urbanos $\boldsymbol{E}_{\boldsymbol{N} \boldsymbol{R}}$. 


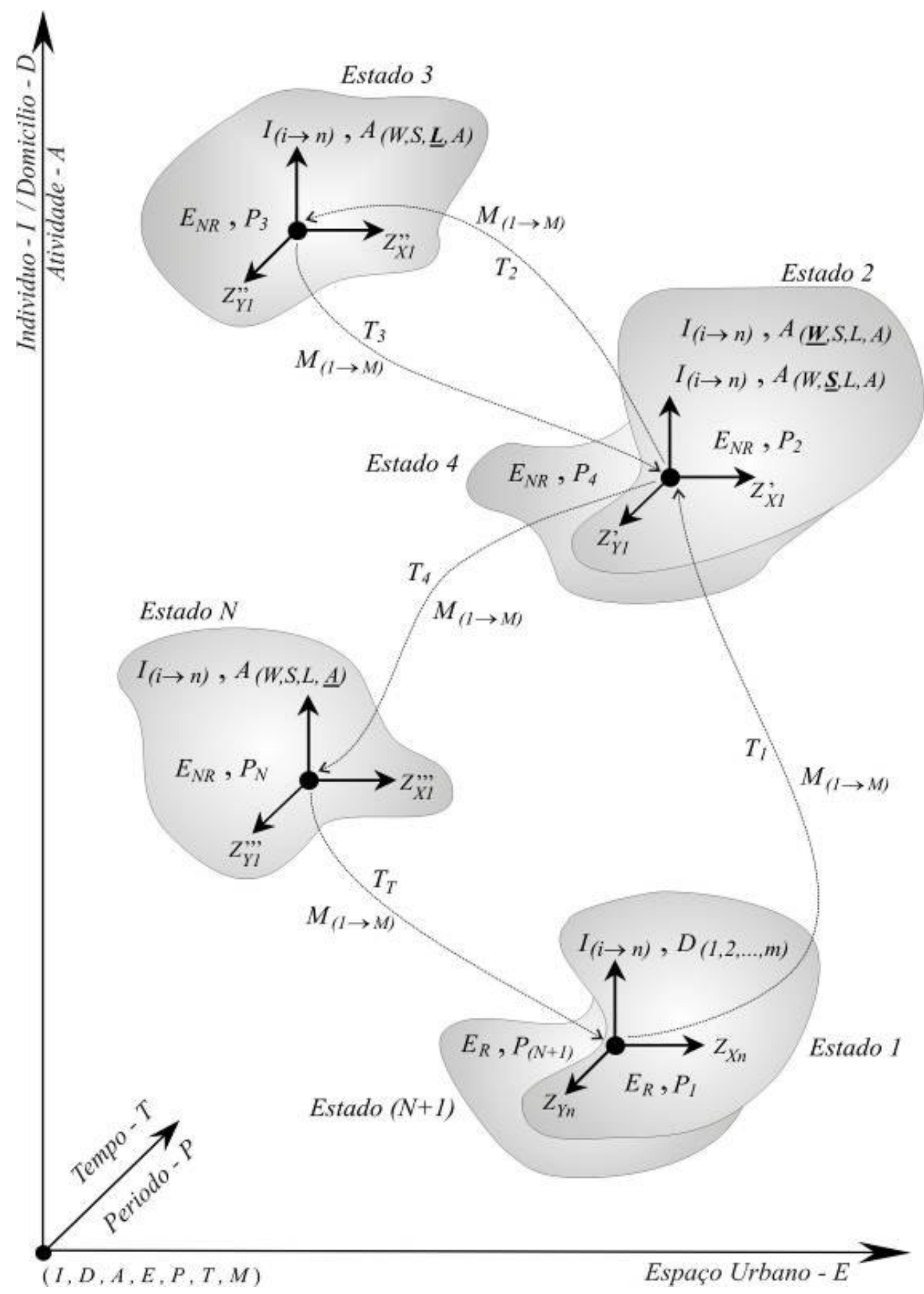

Figura 4.5: Formulação espaço-tempo do encadeamento de viagens. 
g) Medidas de dependência do espaço urbano: A medida da relação de dependência do espaço urbano $\boldsymbol{E}_{\boldsymbol{R}}$ em relação aos espaços urbanos $\boldsymbol{E}_{N \boldsymbol{R}}, f\left(E_{R} / E_{N R}\right)$, estará definida, entre outras, pelas características do sistema de transporte e de desenvolvimento dos espaços urbanos $\boldsymbol{E}_{\boldsymbol{R}}$ e $\boldsymbol{E}_{\boldsymbol{N} \boldsymbol{R}}$. Definindo pontos geográficos nestes espaços para agregar tais características, cria-se um indicador que expresse a medida de dependência de cada espaço urbano com relação aos outros espaços urbanos. São as coordenadas geográficas do centróide dos Estados de Origem $\overrightarrow{C Z}$, e as coordenadas dos Estados de Destino $\overrightarrow{C Z}$ '. O indicador é definido pelo vetor de acessibilidade $\overrightarrow{A S}$ entre o Estado de Origem e o conjunto dos Estados de Destino (distância obtida através da rede viária) e pelo vetor de atratividade $\overrightarrow{A T}$ entre o Estado de Origem e o conjunto dos Estados de Destino (quantidade de empregos, vagas na escola etc.). De modo que, para uma cadeia de viagens " $n v$ ”, a relação $f\left(E_{R} / E_{N R}\right)$ será expressa da seguinte forma:

$$
f\left(E_{R} / E_{N R}\right)=\{\overrightarrow{C Z}, \overrightarrow{C Z}, \overrightarrow{A S}, \overrightarrow{A T}\}^{n v}
$$

h) O encadeamento como função do padrão de atividade viagens: Da seção $4.2 \mathrm{e}$ da Figura 4.4 fica estabelecido que na abordagem baseada na atividade coloca-se a ênfase em padrões $\boldsymbol{p}(\boldsymbol{a v} / \boldsymbol{v g})$ e na dinâmica de comportamento da viagem individual. Esses padrões são estabelecidos pelo espaço urbano domiciliar $\boldsymbol{E}_{\boldsymbol{R}}$ (viagens com base no domicílio - H) e a atividade principal $\boldsymbol{A}_{(\boldsymbol{W}, \boldsymbol{S}, \boldsymbol{L}, \boldsymbol{A})}$ desenvolvida no espaço urbano $\boldsymbol{E}_{\boldsymbol{N} \boldsymbol{R}}$. Logo, o padrão $\boldsymbol{p}(\boldsymbol{a v} / v \boldsymbol{g})$ é definido pela função de modelagem dinâmica $\Omega$ e sua interrelação com as características comportamentais sócio-econômicas individuais, domiciliares, e a relação de dependência do espaço urbano $\boldsymbol{E}_{\boldsymbol{R}}$ em relação aos espaços urbanos $\boldsymbol{E}_{N R}$, isto é $f\left(E_{R} / E_{N R}\right)$, da forma seguinte:

$$
\boldsymbol{p}(\boldsymbol{a v} / \boldsymbol{v g})=\Omega\left\{\overrightarrow{C I}, \overrightarrow{C D}, f\left(E_{R} / E_{N R}\right)\right\}
$$

Assim, substituindo a eq. (4.1) na eq. (4.2) tem-se que o vetor de $\boldsymbol{p}(\boldsymbol{a v} / \boldsymbol{v g})$ para uma cadeia de viagens " $n v$ " estará definido por:

$$
\boldsymbol{p}(\boldsymbol{a v} / v \boldsymbol{g})=\Omega\left\{\{\overrightarrow{C I}, \overrightarrow{C D}\},\{\overrightarrow{C Z}, \overrightarrow{C Z}, \overrightarrow{A S}, \overrightarrow{A T}\}^{n v}\right\}
$$


A eq. 4.3 mostra que um determinado padrão $\boldsymbol{p}(\boldsymbol{a v} / \boldsymbol{v g})$ para um Indivíduo $\boldsymbol{I} \mathrm{em}$ uma cadeia de viagens dependerá das características socioeconômicas (Indivíduo + Domicílio), do espaço urbano (na "origem" e nos “destinos”), da acessibilidade, e da atratividade.

i) Padrão generalizado de atividade viagem: Os componentes do padrão $\boldsymbol{p}(\boldsymbol{a v} / \mathbf{v g})$ definem o movimento. Conseqüentemente, para $n$ Indivíduos $\boldsymbol{I}_{(i \rightarrow n)}$, os componentes são: Tipo de Atividade $\boldsymbol{A}_{(W, S, L, A)}$ que motiva a viagem, um Modo $\boldsymbol{M}_{(1,2, \ldots, M)}$ no qual é realizada a viagem, um Período de Tempo no Dia $\boldsymbol{P}_{(1,2, \ldots, N)}$ em que começa e termina a viagem, um Tempo $\boldsymbol{T}_{T}$ da viagem, o Estado de Origem da viagem (ZO), e o Estado de Destino da viagem $(Z D)$. Portanto, o vetor padrão definindo o movimento para uma cadeia de viagens " $n v$ " estará representado por:

$$
\boldsymbol{p}(\boldsymbol{a v} / \boldsymbol{v g})=\left\{\boldsymbol{A}_{(W, S, L, A)}, \boldsymbol{M}_{(1,2, ., M)}, \boldsymbol{P}_{(1,2, \ldots, N)}, \boldsymbol{T}_{T}, Z O, Z D\right\}^{n v}
$$

Igualando as equações eq. (4.3) e eq. (4.4), obtem-se a equação geral para um padrão de atividade/viagem de encadeamento de viagem:

$$
\left\{\boldsymbol{A}_{(W, S, L, A)}, \boldsymbol{M}_{(1,2,,, M)}, \boldsymbol{P}_{(1,2,,, N)}, \boldsymbol{T}_{T}, Z O, Z D\right\}^{n v}=\Omega\left\{\{\overrightarrow{C I}, \overrightarrow{C D}\},\{\overrightarrow{C Z}, \overrightarrow{C Z}, \overrightarrow{A S}, \overrightarrow{A T}\}^{n v}\right\}
$$

j) Dimensão do padrão generalizado de atividade viagem: A dimensão do vetor $\boldsymbol{p}(\boldsymbol{a v} / v \boldsymbol{g})$ é extensa, como mostra a eq. (4.5), podendo medir informação pouco representativa para classificação eficiente de padrões de atividades. Por exemplo, o padrão de atividade no espaço urbano pode compreender todos os pontos no tempo e espaço que um indivíduo pode alcançar desde pontos de início (Estados 1, ..., Estados $N$ ) arbitrários durante um período contínuo de 24 horas (Figura 4.6). Conseqüentemente, a análise do padrão de atividades pode ser descrita em termos de como encontrar uma regra que divida os padrões do espaço dentro de um conjunto de distintas regiões que tipifiquem certos comportamentos específicos das viagens, tais como o Tipo de Atividade (eq. (4.6)), o Modo (eq. (4.7)), o Período (eq. (4.8) e o Tempo (eq. (4.9)):

$$
\left\{\boldsymbol{A}_{(W, S, L, A)}, Z O, Z D\right\}^{n v}=\Omega_{A}\left\{\{\overrightarrow{C I}, \overrightarrow{C D}\},\{\overrightarrow{C Z}, \overrightarrow{C Z}, \overrightarrow{A S}, \overrightarrow{A T}\}^{n v}\right\}
$$




$$
\begin{aligned}
& \left\{\boldsymbol{M}_{(1,2, \ldots, M)}, Z O, Z D\right\}^{n v}=\Omega_{M}\left\{\{\overrightarrow{C I}, \overrightarrow{C D}\},\{\overrightarrow{C Z}, \overrightarrow{C Z}, \overrightarrow{A S}, \overrightarrow{A T}\}^{n v}\right\} \\
& \left\{\boldsymbol{P}_{(1,2, \ldots, N)}, Z O, Z D\right\}^{n v}=\Omega_{P}\left\{\{\overrightarrow{C I}, \overrightarrow{C D}\},\{\overrightarrow{C Z}, \overrightarrow{C Z}, \overrightarrow{A S}, \overrightarrow{A T}\}^{n v}\right\} \\
& \left\{\boldsymbol{T}_{T}, Z O, Z D\right\}^{n v}=\Omega_{T}\left\{\{\overrightarrow{C I}, \overrightarrow{C D}\},\{\overrightarrow{C Z}, \overrightarrow{C Z}, \overrightarrow{A S}, \overrightarrow{A T}\}^{n v}\right\}
\end{aligned}
$$

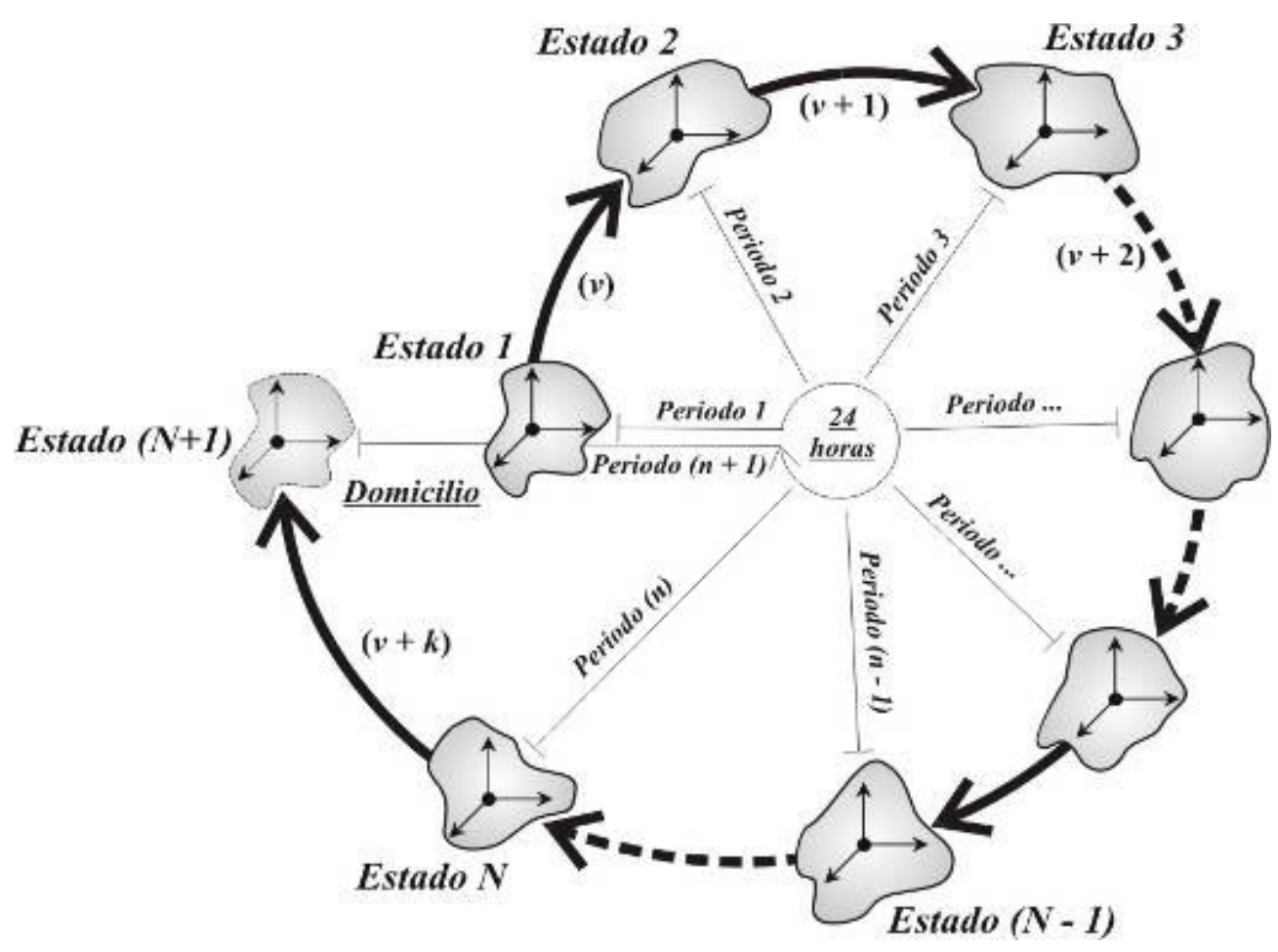

Figura 4.6: Estados da viagem começando e finalizando no domicílio num Período de tempo compreendido entre 0:00 h e 24:00 h.

\subsubsection{Restrições da Modelagem}

Entretanto, como pode ser observado nos vários Estados (Figura 4.5 e Figura 4.6), para poder realizar a representação do encadeamento das viagens para $n$ Indivíduos $\boldsymbol{I}_{(i \rightarrow} \rightarrow$ ${ }_{n}$ ), serão necessárias duas restrições espaço-tempo e o cumprimento de algumas das duas condições em cada um dos Estados: 
a) Deve existir Continuidade Temporal: $T_{o}(v+1)=T_{f}(v)+U$, onde $T_{o}(v+1)$ representa o tempo de começo de viagem $(v+1) . T_{f}(v)$ representa o tempo de fim da viagem $v$, e $U$ é o tempo entre o final da viagem $v$ e o começo da viagem $(v+1)$, sendo maior ou igual a zero (pode ser o tempo na parada ou na atividade).

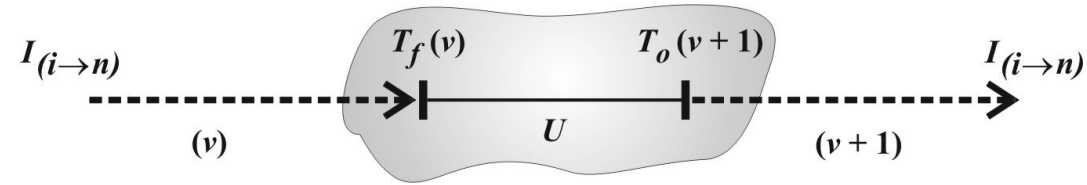

Figura 4.7: Continuidade Temporal do encadeamento de viagens.

b) Continuidade no Espaço: O lugar de destino da viagem (v) se torna o lugar de origem da próxima viagem $(v+1)$. Isto é, $D(v)$ é a $O(v+1)$.

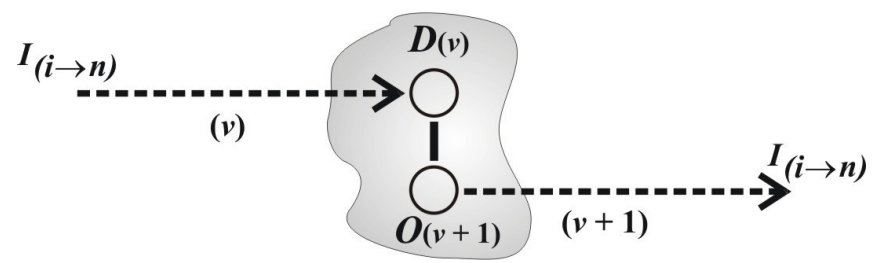

Figura 4.8: Continuidade Espacial do encadeamento de viagens.

c) Condição de Recursividade: As condições do Estado precedente "Estado (N)" influem no Estado seguinte "Estado $(N+1)$ "; e

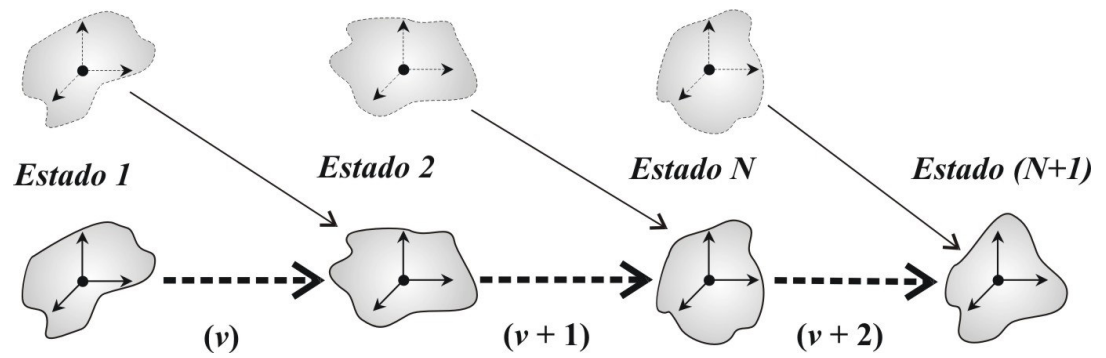

Figura 4.9: Condição de Recursividade 
d) Condição de Linearidade: As condições do Estado seguinte "Estado $(N+1)$ " não são influenciadas pelo estado precedente "Estado $(N)$ ".

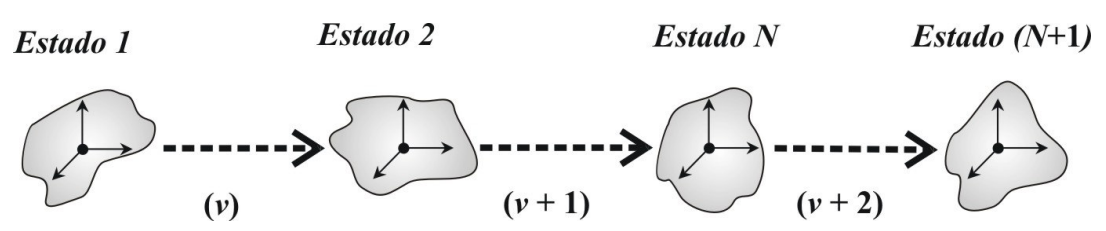

Figura 4.10: Condição de Linearidade

Em decorrência, para a classificação do padrão $\boldsymbol{p}(\boldsymbol{a v} / \boldsymbol{v g})$ será necessário utilizar uma formulação tal que permita representar as restrições Temporal e Espacial, e algumas das condições de Recursividade e Linearidade para representação das características dos Estados. Tal classificação e representação serão mais bem compreendidas, a seguir, na formulação neural do modelo de viagens encadeadas.

\subsection{FORMULAÇÃO NEURAL DO ENCADEAMENTO DE VIAGENS}

Esta seção trata especificamente do tipo de arquitetura de rede neural a ser utilizada na formulação do modelo.

\subsubsection{Formulação da Arquitetura de Rede Neural no Modelo}

$\mathrm{Da}$ eq. (4.5), a função de modelagem dinâmica que permite representar o encadeamento de viagens é $\Omega$, estabelecendo a relação entre os diferentes elementos que condicionam o padrão $\boldsymbol{p}(\boldsymbol{a v} / \boldsymbol{v g})$, através da seguinte relação:

$$
\vec{Y}=\Omega(\vec{W}, \vec{X})
$$

Nas equações $(4.6,4.7,4.8,4.9)$ observa-se que existe uma relação de dependência de $\Omega$ em relação a $\Omega_{A}, \Omega_{M}, \Omega_{P}, \Omega_{T}$. Pela abordagem neural para a representação do encadeamento de viagens fazendo uso das redes neurais, estas funções $\Omega$ podem ser expressas e representadas pelo vetor de pesos $\vec{W}$ que estabelecem as 
relações entre os neurônios de entrada e os neurônios de saída de uma rede neural, e pela composição do vetor das variáveis de entrada que pode ser definido como $\vec{X}$.

$$
\begin{aligned}
& \overrightarrow{Y_{A}}=\Omega_{A}\left(\vec{W}_{A}, \vec{X}\right) \\
& \overrightarrow{Y_{M}}=\Omega_{M}\left(\vec{W}_{M}, \vec{X}\right) \\
& \overrightarrow{Y_{P}}=\Omega_{P}\left(\vec{W}_{P}, \vec{X}\right) \\
& \overrightarrow{Y_{T}}=\Omega_{T}\left(\vec{W}_{T}, \vec{X}\right)
\end{aligned}
$$

Entretanto, falta ainda determinar qual o tipo de rede neural a ser utilizada para representar esta relação. Na seção 4.4.2 foram levantadas duas condições possíveis de representação: uma condição de Linearidade e a outra independente da primeira de Recursividade. Na primeira condição as características da representação ajustam-se a um tipo de arquitetura de rede estática; já no segundo caso, pela necessidade de representar o estado anterior, isto é um tempo (t-1), a estrutura que se ajusta são as das redes do tipo recorrente.

Para selecionar a arquitetura da rede, a composição do vetor de entrada pode ser definido como $\vec{X}$, e o vetor de saída por $\vec{Y}$. Através das equações 4.5 , e 4.10 , pode-se estabelecer a seguinte relação:

$$
\begin{gathered}
\vec{X}=\left\{\{\overrightarrow{C I}, \overrightarrow{C D}\},\{\overrightarrow{C Z}, \overrightarrow{C Z}, \overrightarrow{A S}, \overrightarrow{A T}\}^{n v}\right\} \\
\vec{Y}=\left\{\boldsymbol{A}_{(W, S, L, A)}, \boldsymbol{M}_{(1,2,,, M)}, \boldsymbol{P}_{(1,2,, N)}, \boldsymbol{T}_{T}, Z O, Z D\right\}
\end{gathered}
$$

Na Figura 4.11 e Figura 4.12 podem ser observadas as duas opções em que os vetores de entrada e saída podem ser representados usando a arquitetura de dois tipos de redes, e representando o conceito de Estados $\left(\boldsymbol{E}_{\mathbf{1}}, \boldsymbol{E}_{\mathbf{2}}, \boldsymbol{E}_{\mathbf{3}}, \boldsymbol{E}_{\mathbf{4}}, \boldsymbol{E}_{\mathbf{n}}\right)$. 


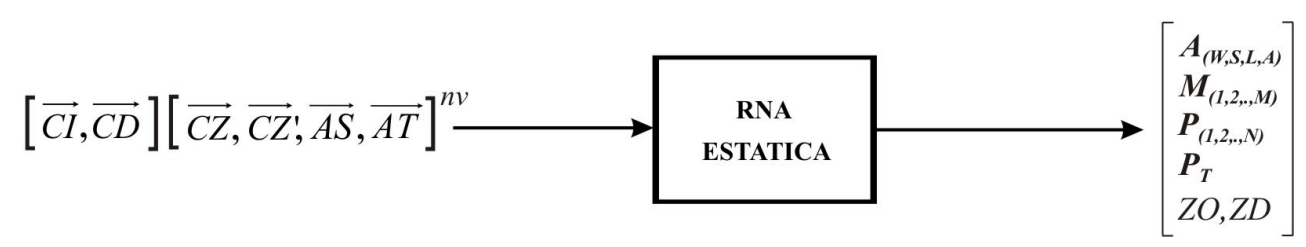

Figura 4.11: Estrutura da Rede Neural Estática.

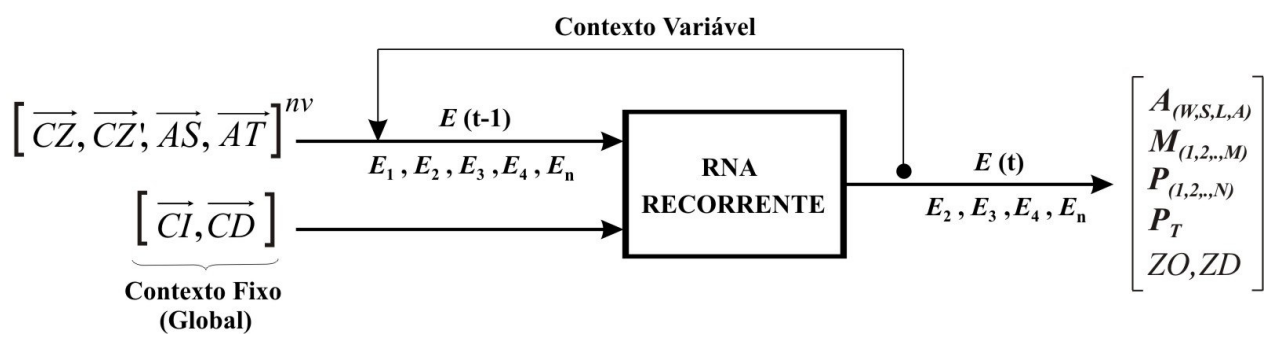

Figura 4.12: Estrutura da Rede Neural Recorrente.

\subsubsection{Formulação do Algoritmo de Treinamento da Rede Neural no Modelo}

Para obtenção da matriz de pesos $\boldsymbol{w}$, um algoritmo de treinamento deve ser selecionado. Para este caso específico no treinamento da rede adota-se o algoritmo de aprendizado supervisionado backpropagation. No treinamento, o erro da informação é passado para trás, da camada de saída até a camada de entrada. Os pesos são ajustados com o método de gradiente descendente. Se a superfície de erro fosse representada graficamente comparando o vetor de pesos, obter-se-ía a inclinação da superfície de menor erro. $\mathrm{O}$ método de gradiente descendente determina a inclinação da superfície de erro e os pesos das conexões são mudados de tal forma que o valor de erro seguinte seja menor que o valor do erro corrente. A regra delta generalizada é geralmente usada como algoritmo de treinamento. A regra delta é definida como segue:

$$
e_{j}=\frac{1}{2} \sum_{j=0}^{n}\left(d_{j}-y_{j}\right)^{2}
$$

Onde $e_{j}=$ erro da $j$-ésima unidade de processamento de saída $; d_{j}=$ saída desejada da $j$-ésima unidade de processamento, e $y_{j}=$ atual saída da $j$-ésima unidade de 
processamento. Para a camada de saída, o gradiente de erro com relação à conexão de pesos é definido como segue:

$$
\frac{\partial\left(e_{j}\right)}{\partial\left(w_{j}\right)}=-\frac{\partial\left(y_{j}\right)}{\partial\left(w_{j}\right)}\left(d_{j}-y_{j}\right)
$$

Para a camada intermediária, os erros são calculados como:

$$
e_{i}^{q}=\frac{\partial\left(f\left(S_{i}^{q}\right)\right)}{\partial\left(w_{i}\right)} \sum_{j=0}^{n}\left(e_{j}^{q+1} w_{i j}^{q+1}\right)
$$

Onde $e_{i}^{q}=$ erro da $i$-ésima unidade de processamento de $q$-ésima camada; $S_{i}^{q}=$ soma de pesos da entrada para o i-ésima unidade de processamento de q-ésima camada; $w_{i j}^{q+1}=$ peso da conexão entre a unidade de processamento $j$ na $(q+1)$-ésima camada e unidade de processamento $i$ no q-ésima camada, e $e_{i}^{q+1}=$ erro da unidade de processamento $j$ na $(q+1)$-ésima camada. Conseqüentemente o ajuste de pesos é determinado pela seguinte equação:

$$
w_{i j}(k+1)=w_{i j}(k)+\left[\Delta w_{i j}(n)+\alpha\left(\Delta w_{i j}(n-1)\right)\right]
$$

Onde $w_{i j}(n)=$ ajuste de pesos para o peso $w_{i j}$ na $n$-ésima iteração; $\alpha=$ constante momentum é,

$$
\Delta w_{i j}=\eta \frac{\partial\left(e_{j}\right)}{\partial\left(w_{j}\right)} y_{j}
$$

Onde $\eta=$ taxa de aprendizagem.

Os dois parâmetros $\alpha$ e $\eta$ nas eq. (4.20 e 4.21) são a constante momentum e a taxa de aprendizagem, respectivamente. Introduzindo o momento constante na regra de atualização de pesos assegura-se que a mudança de pesos se mantém na mesma direção. Isto assegura uma rápida convergência durante o processo de treinamento. A taxa de 
aprendizagem define a proporção de erro a ser usada na corrente iteração para atualização de pesos. O valor final destes parâmetros dependerá de um processo de busca por tentativa e erro.

\subsection{TÓPICOS CONCLUSIVOS}

A partir da formulação geral da seção 4.4 e dos objetivos propostos na presente tese, conclui-se que o Modelo Neural de Viagens Encadeadas a Pé (MONEVPE), que reproduzirá padrões de viagens individuais diárias a pé, estará expresso pela eq. (4.9):

$$
\left\{\boldsymbol{T}_{T}, \boldsymbol{A}_{(W, S, L, A)}, Z O, Z D\right\}^{n v}=\Omega_{T}\left\{\{\overrightarrow{C I}, \overrightarrow{C D}\},\{\overrightarrow{C Z}, \overrightarrow{C Z}, \overrightarrow{A S}, \overrightarrow{A T}\}^{n v}\right\}
$$

E mais especificamente pela eq. (4.11) e (4.14):

$$
\begin{aligned}
& \overrightarrow{Y_{A}}=\Omega_{A}\left(\vec{W}_{A}, \vec{X}\right) \\
& \overrightarrow{Y_{T}}=\Omega_{T}\left(\vec{W}_{T}, \vec{X}\right)
\end{aligned}
$$

Onde o vetor $\overrightarrow{Y_{T}}$ estará representado pelo vetor dos padrões de tempos de viagens de cada indivíduo, e o vetor $\overrightarrow{Y_{A}}$ estará representado pelas atividades destino de cada viagem. Assim da eq. (4.11) e (4.14) o modelo MONEVPE fica definido pela eq. (4.22) que se segue:

$$
\vec{Y}_{(T, A)}=\Omega_{(T, A)}\left(\vec{W}_{(T, A)}, \vec{X}\right)
$$




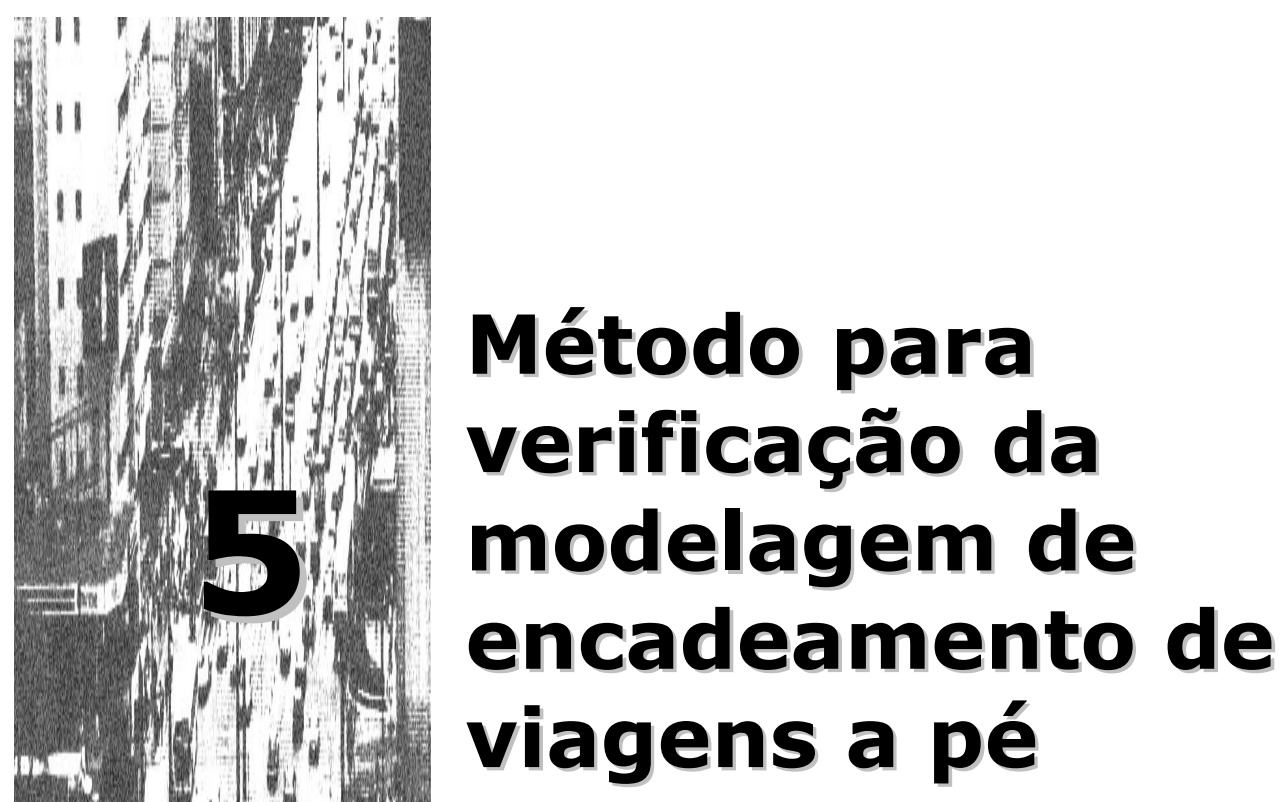

"All men by nature desire to know"

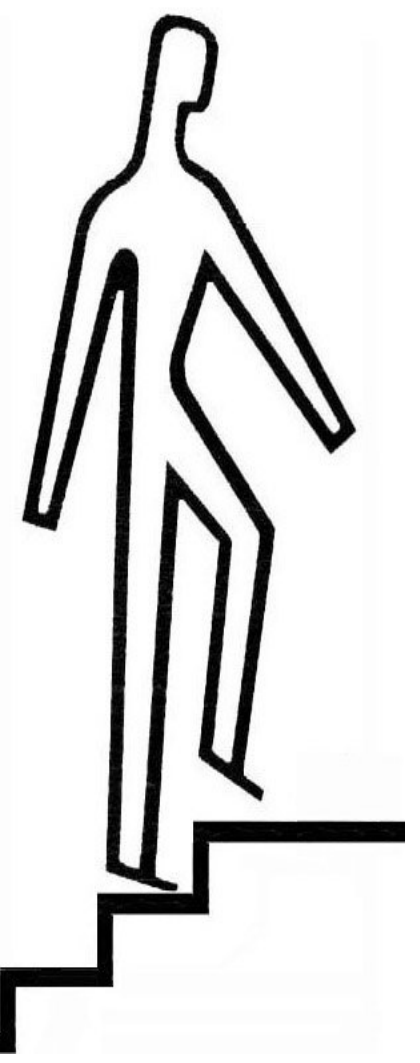




\section{MÉTODO PARA VERIFICAÇÃO DA MODELAGEM DE PADRÕES DE ENCADEAMENTO DE VIAGENS A PÉ}

\subsection{INTRODUÇÃO}

Neste capítulo estão apresentadas, em nove seções, as sete fases de procedimentos que tornam efetiva a modelagem de encadeamento de viagens fazendo uso das RNAs. As sete fases e os procedimentos estão ordenados de maneira a possibilitar a obtenção de informações para atingir os objetivos estabelecidos na presente tese.

A Figura 5.1 mostra a estrutura do método, assim como as seis fases de procedimentos que o constituem. Embora as fases e procedimentos estejam direcionados a uma aplicação específica, na sua descrição e detalhamento procura-se estabelecer os principais fundamentos de cada procedimento, para que sirvam como material auxiliar em outras aplicações de modelagem de encadeamento de viagens bem como para utilização de outras fontes de dados. O objeto é deixar um roteiro do que se precisaria para uma aplicação específica, procurando definir um esquema genérico adaptado a um contexto específico de padrões de viagens encadeadas a pé. A seguir são definidas cada uma das fases. 


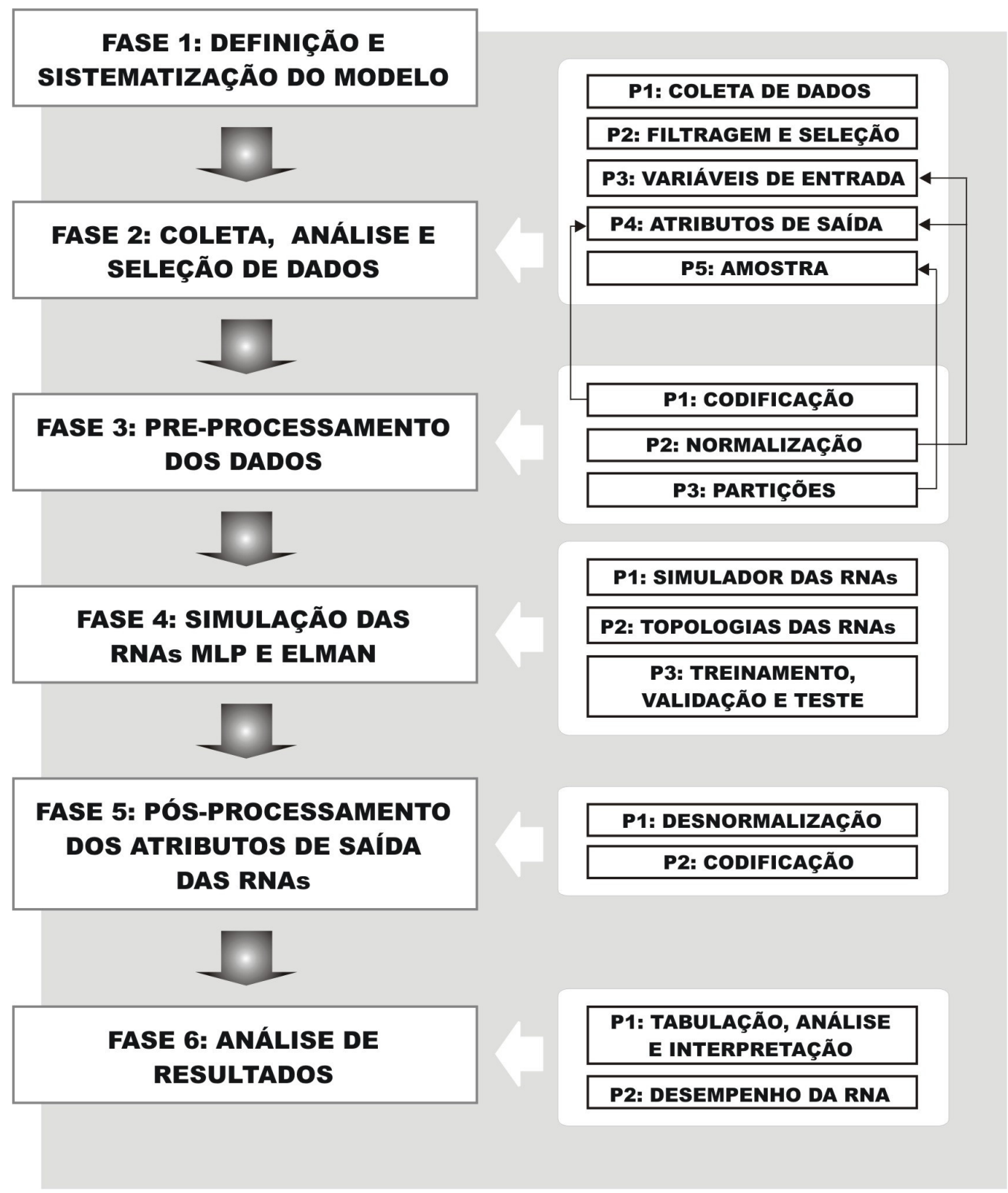

Figura 5.1: Estrutura do método proposto

\subsection{FASE 1: DEFINIÇÃO E SISTEMATIZAÇÃO DO MODELO}

Esta fase, embora tenha sido já desenvolvida no cap 4, visa estabelecer o tipo de abordagem para representação do encadeamento de viagens. Em se tratando da formulação de um modelo, não existe muita clareza a respeito de como nasce ou se gera 
um modelo, mas existem alguns aspectos básicos, chamados aqui de instâncias, que permitem formular um modelo (WILSON ${ }^{1}, 1974$ apud. ORTÚZAR, 2000).

A primeira instância questiona o propósito pelo qual se está formulando o modelo: no caso presente é para representação de padrões de encadeamento de viagens a pé. A segunda instância procura definir as variáveis que deverão ser incluídas no modelo: no caso, as variáveis individuais e domiciliares, variáveis espaciais como atratividade e acessibilidade, e finalmente os padrões codificados dos tempos das viagens encadeadas a pé. A terceira instância observa o nível de agregação a ser utilizado: no caso, em nível individual. A quarta instância está relacionada com $o$ tratamento do tempo: no caso, os dados a utilizar correspondem a uma pesquisa de seção cruzada de viagens diárias. A quinta instância estabelece a teoria que se está representando no modelo: no caso, o encadeamento de viagens baseadas em atividades. A sexta instância busca definir as técnicas estatísticas e matemáticas para construir o modelo: no caso, o uso das redes neurais artificiais, com duas variantes, uma utilizandose de uma rede estática MLP e a outra de uma rede dinâmica Elman. Finalmente, a sétima instância que define os métodos para validar o modelo: no caso, a validação fica fora do alcance da presente tese; entretanto, a análise dos resultados em termos dos erros e acertos dos padrões reproduzidos pelas RNAs, serão os meios pelos quais comprovarse-á a eficiência do modelo. Em função desta sistematização do modelo, a seguinte fase torna-se mais objetiva.

\subsection{FASE 2: COLETA, ANÁLISE E SELEÇÃO DE DADOS}

Em qualquer tipo de modelagem, os dados são os elementos base para representação do fenômeno estudado, podendo viabilizar ou inviabilizar a obtenção do modelo. No caso específico dos sistemas de transporte, uma das formas de se obter dados confiáveis que permitam prever o comportamento dos usuários, é através de pesquisas de seção cruzada e preferência revelada. E, dentro dessa classificação, destacam as pesquisas de entrevista domiciliar origem-destino, que além de possibilitar a identificação do padrão atualizado dos deslocamentos, segundo os diferentes meios de

\footnotetext{
${ }^{1}$ Wilson, A. G. (1974). Urban and Regional Models in Geography and Planning. John Wiley and Sons, Londres. apud Ortúzar, J. de D. (2000).
} 
transporte, motorizados e não-motorizados, permite também a obtenção de dados sobre as características socioeconômicas da população, a localização de empregos e escolas, os padrões de uso do solo, entre outras características das áreas urbanas (ORTÚZAR e WILLUMSEN, 1994). Com este procedimento, as informações coletadas podem ser desagregadas em diferentes recortes espaciais e as variáveis em distintas unidades. A desagregação das características dos indivíduos, das famílias, dos domicílios e das viagens, permite a identificação precisa dos padrões de viagens entre as zonas de origem e destino, e conseqüentemente sua melhor representação na modelagem.

Em geral, os dados considerados básicos para modelagem, devem estar distribuídos em cinco grupos: Dados Gerais (identificadores da zona de tráfego onde foi realizada a pesquisa), Dados do Domicílio (identificadores do domicílio), Dados da Família (identificadores da família, condição de ocupação, número de veículos, características socioeconômicas, entre outros), Dados da Pessoa (identificadores do indivíduo, características socioeconômicas, localização do emprego, localização da escola, entre outras) e, Dados da Viagem (origem, destino, motivo, modo, período, e duração da viagem). Contudo, informações adicionais que possuem características espaciais, como é o caso da origem e destino da viagem podem ser introduzidos em ambiente de Sistemas de Informações Geográficas (SIG), permitindo associar aos mesmos as características de tempo e/ou distâncias envolvidas nos deslocamentos (RAIA JR., 2000). Isso tudo redundará numa melhor representação das variáveis envolvidas e, conseqüentemente, numa maior precisão nos resultados da estrutura da parte seguinte.

\subsubsection{Filtragem e Seleção de Dados}

No conjunto de dados coletados será necessário aplicar um procedimento de limpeza por remoção chamada de filtragem, primeiro com o objetivo de eliminar dados inconsistentes ou incompletos, e, segundo, para descartar dados que sejam irrelevantes à modelagem (STEIN, 1993b). Isso possibilitará uma melhor análise das variáveis envolvidas como também obter uma melhoria na qualidade dos dados fornecidos ao modelo. Com isso, prossegue-se na definição e seleção das informações que sejam 
específicas na modelagem e que possibilitem expressar de forma simplificada as características mais relevantes da situação real estudada e modelada.

Na Figura 5.2 está esquematizada a forma em que a partir da base de dados são selecionados os dados completos e os dados correspondentes as viagens realizadas. De todas as alternativas, a selecionada corresponde às viagens realizadas a pé. Através de uma análise de tabelas de freqüência resultantes da quantidade de indivíduos que realizam uma, duas, três, quatro, cinco, seis, sete, e " $n$ " viagens, foram selecionados os indivíduos que especificamente realizam duas, três e quatro viagens. Esta justificativa será dada mais adiante no item 5.3.4.

\subsubsection{Definição das Variáveis de Entrada}

Conforme foi observado no cap. 2, em se tratando da representação de viagens encadeadas baseadas em atividades, na literatura pesquisada verifica-se que as variáveis de entrada adotadas para modelagem são aquelas cujos atributos representam o comportamento individual, as diferentes interações domiciliares, e as influências do entorno urbano na decisão da viagem. Com isso, a seleção dos atributos das variáveis de entrada segue um processo de tratamento dado pelo próprio simulador da RNA. Isto é, através do ajuste de pesos da própria RNA espera-se que a rede determine a importância e o comportamento destas variáveis e sua influência no modelo. Os atributos das variáveis, como pode ser observado na Figura 5.2, serão agrupados em vetores de características dos dados sócio-econômicos Individuais e Domiciliares $(\overrightarrow{C I}, \overrightarrow{C D})$, e vetores dos dados Espaciais, como acessibilidade e atratividade $(\overrightarrow{A S}, \overrightarrow{A T})$. Quanto aos vetores $\overrightarrow{C I}, \overrightarrow{C D}$, estes são obtidos da própria base de dados. Entretanto, os vetores de $\overrightarrow{A S}, \overrightarrow{A T}$, deverão ser calculados. A seguir será detalhada a forma de se obter o vetor de acessibilidade.

Para Hanson (1995) existem dois tipos de acessibilidade: uma individual e a outra espacial ou por zonas. O primeiro tipo está relacionado com a possibilidade de um indivíduo movimentar-se pelo espaço geográfico em função das oportunidades 
distribuídas no espaço, e, de uma medida de separação do local de domicílio de esses pontos. Essa medida pode ser o tempo de viagem, custo da viagem ou simplesmente distância. O segundo tipo, análogo à definição dada por Joaquim (1999), estabelece que a acessibilidade pode ser entendida como a facilidade com que os destinos desejados são alcançados, ou como a facilidade com que uma separação espacial é transposta. De forma similar, Ingram (1971) estabelece dois tipos de acessibilidade: relativa e integral. O índice de acessibilidade integral é o mais adequado para se comparar os níveis de acessibilidade das várias regiões de uma cidade.

Diversas medidas simplificadas de acessibilidade têm sido propostas, considerando atributos da rede de transporte. Lima (1998), Raia Jr. (2000), Sales Filho (1996), Sanches (1996), desenvolvem uma satisfatória revisão sobre acessibilidade na área de transportes, especificamente para ser empregada no planejamento dos transportes. Considerando as limitações enquanto a disponibilidade de dados e na busca de simplificação do cálculo dos índices de acessibilidade, será escolhido o método proposto por Allen (LIMA, 1998) que é um tipo de indicador de acessibilidade definido por medidas de distância de separação média entre zonas.

$$
A S_{i}=\frac{1}{n-1} \sum_{j=1}^{n} D_{i j}
$$

$$
\begin{aligned}
& A S_{i}=\text { Acessibilidade da zona } i \text { em relação às demais zonas; } \\
& D_{i j}=\text { distância entre as zonas } i \text { e } j, \text { através do sistema viário; } \\
& n=\text { número de zonas de tráfego. }
\end{aligned}
$$

Quanto aos vetores de atratividade $\overrightarrow{A T}$, estes podem ser medidos considerando os efeitos combinados da atratividade de todos os destinos, inclusive a zona de origem, como especificado por Sales Filho (1996). As atratividades dos destinos podem ser representadas pelo total de empregos (na indústria, comércio, serviços e outros), e pelo número de matrículas em educação (primeiro e segundo grau completo, e superior) de cada zona de tráfego. Com tais informações, índices de atratividade para viagens ao trabalho e às escolas podem ser obtidos, da seguinte maneira: 


$$
A T_{(E, M)_{i}}=\frac{1}{n-1} \sum_{j=1}^{n}\left(E_{i j}, M_{i j}\right)
$$

$A T_{(E, M) i}=$ Vetor de atratividade por empregos e matrículas da zona $i$ em relação às demais zonas;

$E_{i j}=$ proporção de empregos na zona de origem $i$ em relação à zona destino $j$;

$$
E_{i j}=\frac{E_{i}}{E_{j}}
$$

$M_{i j}=$ proporção de matrículas nas escolas da zona origem $i$ em relação às da zona destino $j$;

$$
M_{i j}=\frac{M_{i}}{M_{j}}
$$

$n=$ número de zonas de tráfego.

\subsubsection{Definição das Variáveis de Saída}

A variável de saída do modelo é o modo de viagem a pé, e os atributos desta variável a ser expressos são a duração dos tempos das viagens e os motivos das viagens. Deste modo o vetor de saída das viagens encadeadas a pé estará representado pelos padrões de encadeamento do tempo de duração de cada viagem e pelos padrões das atividades de destino de cada viagem. Geralmente os tempos são obtidos dos dados coletados na pesquisa domiciliar através da hora de saída na origem e da hora de chegada no destino, ambas declaradas pelo entrevistado, referindo-se a viagens realizadas no dia anterior. O mesmo acontece com os motivos das viagens. Dessa forma, os padrões de viagens encadeadas a pé levam em conta o número de viagens realizadas (duas, três, ou quatro), o tempo de duração de cada viagem (em minutos), a atividade que motiva a viagem e o modo de transporte utilizado, no caso, a pé como pode ser observado na Figura 5.2. 


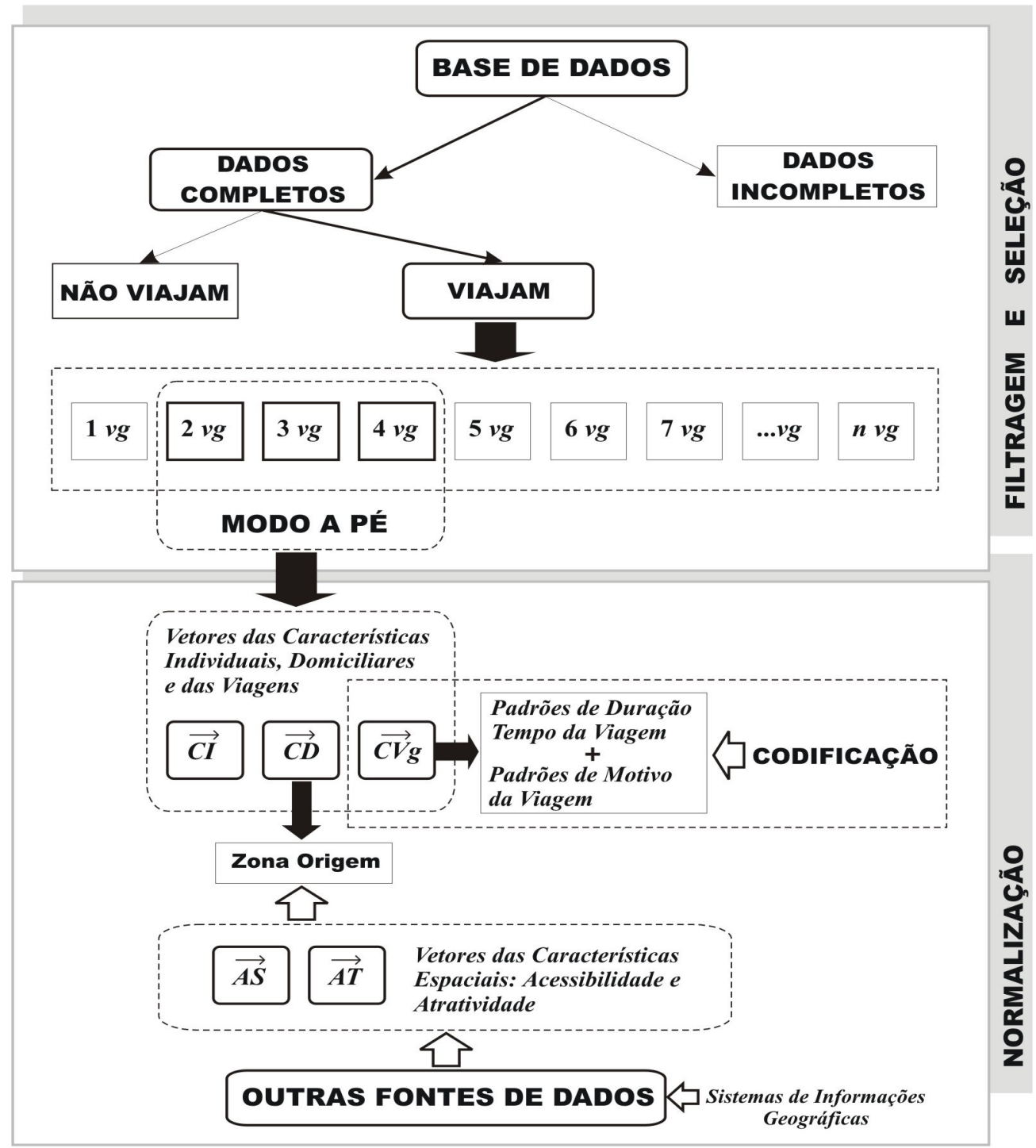

Figura 5.2: Estrutura da seleção e pré-processamento de dados

\subsubsection{Definição da Amostra}

Uma vez definidos os atributos das variáveis de entrada e de saída, prossegue-se com o procedimento de amostragem, no qual serão obtidos subconjuntos da base de dados filtrada e selecionada, para representar a composição do conjunto original de dados. Dependendo dos padrões de cadeias de viagens a serem modelados, esta amostra poderá ser modificada, aumentada, reduzida, ou até mantida do mesmo tamanho que o conjunto de dados original. Isto porque, geralmente, como observado nos dados da 
pesquisa origem-destino da Região Metropolitana de São Paulo 1987 (ICHIKAWA, PITOMBO e KAWAMOTO, 2002), do total de viagens, indivíduos que realizam uma ou mais de quatro viagens totalizam aproximadamente 5\%, enquanto $47 \%$ das pessoas fazem duas viagens, 5\% fazem três viagens, $9 \%$ fazem quatro viagens e $34 \%$ não viajam. Posto que, se o padrão de cadeias a ser modelado corresponde a duas viagens, será necessária a extração de uma amostra através de um processo de amostragem aleatória. Já para o caso de padrões de cadeia de três e quatro viagens isto não será necessário, entre outras razões, pelo número limitado de indivíduos que realizam três e quatro viagens a pé, quando comparadas com a freqüência de indivíduos que fazem duas viagens. Outro razão é que perante um número insuficiente de casos similares a rede ficaria impossibilitada de aprender e conseqüentemente diferenciar os padrões no espaço de características dos indivíduos.

\subsection{FASE 3: PRÉ-PROCESSAMENTO DOS DADOS PARA MODELAGEM}

Previamente ao treinamento, e, para atingir melhores resultados no treinamento da rede, é necessário realizar o pré-processamento dos dados (MASTERS, 1994; STEIN, 1993a). Este pré-processamento envolve, por um lado, a codificação e a normalização dos dados referentes às variáveis representativas, para posterior apresentação à rede, e por outro lado, prepara os dados no formato de leitura compatível com o simulador da RNA.

\subsubsection{Codificação}

A codificação objetiva, por um lado, o agrupamento dos atributos numéricos das variáveis de saída, isto é, a duração de cada viagem, em intervalos, e as atividades que motivaram a viagem; e, por outro lado define uma melhor representação dos dados de entrada para a rede.

Para isso, será feita uma adaptação do método proposto por Ichikawa, Pitombo e Kawamoto (2002). Na Figura 5.3 estão apresentados exemplos de padrões de viagens encadeadas a pé, para duas, três e quatro viagens, em que os algarismos romanos 
indicam a sequiência de realização da viagem e os algarismos arábicos representam os códigos correspondentes aos tempos de duração de cada viagem. Os padrões das viagens encadeados a pé são representados pela junção dos códigos dos padrões de duração de cada viagem aos códigos dos padrões de atividades que motivaram a viagem.

Na Figura 5.3, pode ser observado, a representação final dos padrões das cadeias de viagens a pé para cada vetor de viagens. Cada vetor de viagens está constituído por padrões com seis dígitos. Para o vetor de duas viagens (Figura 5.3a), os dois primeiros dígitos correspondem aos códigos da duração das viagens e o quinto dígito à atividade. No vetor de três viagens (Figura 5.3b), os três primeiros códigos correspondem as durações das viagens, e, o quinto e sexto dígitos às atividades. Para quatro viagens (Figura 5.3c), os quatro primeiros dígitos são referentes aos códigos das durações das viagem, e, os dois últimos as de atividades. Para o dígito sem duração de viagem, ou sem atividade, corresponderá o código zero.

\begin{tabular}{|l|c|c|}
\hline (a) Duas viagens & (b) Três viagens & (c) Quatro viagens \\
\hline & \multicolumn{1}{|c|}{$\mathbf{W}, \mathbf{S}, \mathbf{A}$} & \\
\hline
\end{tabular}

Figura 5.3: Codificação dos padrões das cadeias de viagens a pé

Com esses critérios definidos acima, segue-se a codificação dos tempos de duração de cada viagem e das atividades que motivaram a viagem.

- Tempos de duração de cada viagem, conforme mostrado na Tabela 5.1, são definidos três intervalos para a duração de cada viagem. Intervalos para a duração $\boldsymbol{t}<\boldsymbol{a}$ correspondem ao código 1; durações maiores do que $\boldsymbol{a}$ minutos e menores ou iguais do que $\boldsymbol{b}$ minutos recebem o código 2, e duração $\boldsymbol{t}$ superior a $\boldsymbol{b}$ minutos tem o código 3 . 
Tabela 5.1: Codificação dos tempos de duração de cada viagem

\begin{tabular}{c|c|c}
\hline $\begin{array}{c}\text { Tempos de Duração de Cada } \\
\text { Viagem (t) em minutos }\end{array}$ & Codificação & $\begin{array}{c}\text { Valor da } \\
\text { Normalização }\end{array}$ \\
\hline $\boldsymbol{t}<=\boldsymbol{a}$ & 1 & 0,3 \\
$\boldsymbol{a}<\boldsymbol{t}<=\boldsymbol{b}$ & 2 & 0,65 \\
$\boldsymbol{t}>\boldsymbol{b}$ & 3 & 0,9 \\
\hline
\end{tabular}

$a, b=$ limites dos intervalos de tempo.

- Atividades que motivam a viagem, agregadas em três motivos gerais de viagens ao Trabalho $(\mathbf{W})$ com código 1, Estudo $(\mathbf{S})$ recebe o código 2, e Outras Atividades $(\mathbf{A})$ com código 3, como pode ser observado na Tabela 5.2.

Tabela 5.2: Codificação da Atividade Motivo da Viagem $\boldsymbol{A}_{(W, S, A, H)}$

\begin{tabular}{l|c|c|c}
\hline $\begin{array}{l}\text { Atividade Motivo } \\
\text { da Viagem Agregada }\end{array}$ & $\begin{array}{c}\text { Abreviação } \\
\text { do Motivo }\end{array}$ & $\begin{array}{c}\text { Código do } \\
\text { Motivo }\end{array}$ & $\begin{array}{c}\text { Valor da } \\
\text { Normalização }\end{array}$ \\
\hline Trabalho & W & 1 & 0,3 \\
Estudos & S & 2 & 0,65 \\
Outras Atividades & $\mathbf{A}$ & 3 & 0,9 \\
Domicílio & $\mathbf{H}$ & $(*)$ & - \\
\hline
\end{tabular}

(*) O domicílio não recebe código por que as viagens são com base domiciliar

\subsubsection{Normalização}

A normalização de dados é executada antes de iniciar o processo de treinamento, na etapa de pré-processamento dos dados. Nas RNAs, quando funções de transferência não linear são utilizadas, os valores da saída devem ser transformados em intervalos típicos, como por exemplo, entre $[0,1]$ ou $[-1,1]$. Este processo conhecido como normalização, evita problemas computacionais e facilita a aprendizagem da rede. A escolha do método depende da composição do vetor de entrada, sendo quatro os métodos recomendados por Azoff ${ }^{2}$ (1994) apud Zhang, Patuwo e Hu (1998):

a) Ao longo de um canal de normalização: Um canal é definido como um conjunto de elementos na mesma posição dos vetores de entrada dentro do conjunto de treinamento ou de teste. Cada canal pode ser considerado como uma variável de entrada independente. Se os vetores de entrada são colocados dentro de uma matriz, a

${ }^{2}$ Azoff, E. M. (1994). Neural network time series forecasting og financial markets. John Wiley and Sons, Chichester. apud ZHANG, e Patuwo e Hu (1998). 
normalização é executada coluna por coluna ao longo do canal, isto é, a normalização se produz para cada variável de entrada individualmente.

b) Através de um canal de normalização: Este tipo de normalização é executado por cada vetor de entrada independentemente, isto é, a normalização é através de todos os elementos dentro de um padrão de dados.

c) Canal de normalização misto: Como o nome sugere, este método utiliza combinações do método $(a)$ e $(b)$, anteriores.

d) Normalização exterior: Todos os dados de treinamento são normalizados dentro de um intervalo específico, que independe dos valores dos elementos dentro de um padrão de dados.

$\mathrm{Na}$ presente tese será realizada a normalização ao longo de um canal de normalização e, como mostra a Tabela 5.3, utilizar-se-á a equação de transformação linear, para intervalos de normalização entre [0,1 e 0,9], com tais valores limites são normalizados os códigos dos atributos de saída da RNA $\left[x_{\operatorname{mín}}=0\right.$ e $\left.x_{\text {máx }}=3\right]$, conforme observado na Tabela 5.1. e Tabela 5.2.

Tabela 5.3: Equações típicas de normalização (ZHANG, PATUWO e HU, 1998).

\begin{tabular}{l|l}
\hline \multicolumn{1}{c|}{ Tipo de Normalização } & \multicolumn{1}{c}{ Equação } \\
\hline Transformação Linear para [0,1] & $x_{n}=\left(x_{0}-x_{\min }\right) /\left(x_{\max }-x_{\min }\right)$ \\
\hline Transformação Linear para [a,b] & $x_{n}=(b-a)\left(x_{0}-x_{\min }\right) /\left(x_{\max }-x_{\min }\right)$ \\
\hline Normalização Estatística & $x_{n}=\left(x_{0}-\bar{x}\right) / \bar{s}$ \\
\hline Normalização Simples & $x_{n}=x_{0} / x_{\max }$ \\
\hline
\end{tabular}

Onde:

$x_{n}$ e $x_{0}$ representam o dado normalizado e o dado original;

$x_{\text {mín }}, x_{\text {máx }}, \bar{x}$ e $\bar{s}$ são o mínimo, máximo, média e desvio padrão ao longo das colunas ou linhas, respectivamente. 


\subsubsection{Partições}

Para simular uma RNA é preciso gerar partições da amostra para treinamento e teste. A partição de treinamento é utilizada para desenvolvimento do modelo de RNA e a partição de teste é adotada para avaliar a habilidade de previsão do modelo. Muitas vezes uma terceira partição - chamada de validação - é também utilizada para evitar o problema de overfitting ou para determinar o ponto de interrupção no processo de treinamento. Embora não exista uma regra geral de divisão, vários fatores tais como as características do problema, o tipo e a quantidade disponível de dados devem ser considerados ao tomar a decisão.

Não existem regras definitivas para a adoção do tamanho da partição da amostra. A quantidade de dados necessários para o treinamento da rede depende da estrutura da rede, do método de treinamento, e da complexidade do problema particular ou da quantidade de ruído nos dados disponíveis. Como em qualquer abordagem estatística, o tamanho das partições está fortemente relacionado com a precisão requerida, isto é, uma partição de maior tamanho geralmente fornece resultados mais precisos. Dantas (2002) utiliza por exemplo duas partições, uma de $75 \%$ e a outra de $25 \%$. Outros autores como Furtado (1998), Raia Jr. (2000), Wermersch (2002), utilizam o critério definido por Pretchelt $^{3}$ (1994), em que as partições devem conter 50\%, 25\% e $25 \%$ de todos os dados da amostra, respectivamente.

A rigor, estes critérios não são regras estritas, porém na presente modelagem as partições deverão conter valores em torno dos recomendados por Pretchelt ${ }^{3}$ (1994). Ao gerar as partições é necessário que os dados que formarão os conjuntos de treinamento, validação e teste, sejam aleatoriamente organizados e sem reposição. Para cada apresentação das partições às RNAs, os dados serão aleatoriamente reordenados, e destes serão selecionados as partições correspondentes a treinamento, validação e teste. A cada simulação este procedimento será seguido como se apresenta a seguir no programa de simulação.

\footnotetext{
${ }^{3}$ Pretchelt, L. (1994). Proben 1: a set of neural network benchmark problems and benchmark rules. Germany, Facultät für Informatik / Universität Karlsruhe. / Technical Report, 21 / apud Furtado (1998).
} 


\subsection{FASE 4: SIMULAÇÃO DAS RNAs MLP e ELMAN}

Quanto a simulação das RNAs, existem vários aplicativos disponíveis no mercado, para simular diversos tipos de redes. Entretanto, nem todos dispõem da rede Elman, o algoritmo da rede a ser utilizada neste trabalho. Além disso, por questão de facilidade na apresentação dos dados à rede, e, pela conveniência do formato das saídas, após da modelagem, é desejável que o aplicativo seja um dos dois softwares: $S N N S^{4}$ Stuttgard Neural Network Simulator versão 4.2 (ZELL et al. 1998) ou MATLAB ${ }^{5}$ versão 6.1 (The MathWorks, Inc.), com o toolbox de redes neurais. Por executar o treinamento, validação e teste em um processo continuo e paralelo, será empregado o MATLAB, que no entanto requer a elaboração de um programa de simulação na linguagem do software utilizando-se das funções definidas no toolbox de redes neurais (DEMUTH e BEALE, 1996; MATSUMOTO, 2001).

\subsubsection{Programa de Simulação}

O código fonte do programa de simulação foi desenvolvido para dois tipos de redes: a MLP e a Elman. As características do programa são as seguintes:

\section{GERACÃO DE DADOS}

- Apresentação do arquivo com a amostra;

\% Embaralhamento dos dados

- Embaralhamento dos dados a cada treinamento;

\% Definição dos tamanhos dos conjuntos

- Definição do tamanho do conjunto de treinamento;

- Definição do tamanho do conjunto de validação;

- Definição do tamanho do conjunto de teste;

\% Definição dos vetores para treinamento e dos alvos associados

- Definição do vetor para treinamento;

- Definição do vetor alvo associado ao treinamento;

\% Definição dos vetores para validação e dos alvos associados

- Definição do vetor para validação;

- Definição do vetor alvo associado à validação;

${ }^{4}$ SNNS. Stuttgart Neural Network Simulator. v4.2 - http://www-ra.informatik.uni-tuebingen.de/SNNS/

${ }^{5}$ MATLAB. The Language of Technical Computing. v6.1 - http://www.mathworks.com/ 
\% Definição dos vetores para teste e dos alvos associados

- Definição do vetor para teste;

- Definição do vetor alvo associado ao teste;

INICIALIZAČ̃̃O DA ARQUITETURA DA REDE

- Definição do número de neurônios na 1a. camada (Nh1);

- Definição do número de neurônios na 2a. camada $(\mathrm{Nh} 2)<(\mathrm{Nh} 1)$;

- Definição do número de neurônios na camada de saída;

\% Definição do algoritmo de treinamento e das funções de ativação

- Definição do tipo de rede a simular (MLP = newff); (Elman = newelm);

- Definição da topologia da rede e das funções de ativação;

- Definição do algoritmo de treinamento;

\% Modificação dos parâmetros de treinamento da rede

- Definição do ciclo de treinamento em que é mostrada a curva de treinamento;

- Definição do taxa de aprendizagem (lr);

- Definição do fator de momento (mc);

- Definição do número de épocas de treinamento (epochs);

- Definição do erro desejado de treinamento (goal);

$\%$ Treinamento da rede

- Definição da função de treinamento da rede;

- Definição da função que simula a rede com o conjunto de treinamento;

- Cálculo do erro para o conjunto de treinamento;

\% Validação da rede

- Definição da função de validação da rede;

- Cálculo do erro para o conjunto de validação;

$\%$ Teste da rede

- Definição da função de teste da rede;

- Cálculo do erro para o conjunto de teste;

\% Mostra valores dos erros

- Apresentação dos erros de treinamento, validação e teste;

CÁLCULO DA PORCENTAGEM DE ACERTOS

\% Desnormalização do conjunto de Treinamento

- Desnormalização dos alvos do conjunto de treinamento;

\% Calculo da taxa de acertos do Treinamento

- Apresentação da Taxa de acerto do treinamento;

\% Desnormalização do conjunto de Validação

- Desnormalização dos alvos do conjunto de validação; 
\% Desnormalização do conjunto de Teste

- Desnormalização dos alvos do conjunto de teste;

\% Cálculo da taxa de acertos da Validação

- Apresentação da Taxa de acerto da validação;

\% Cálculo da taxa de acertos do Teste

- Apresentação da Taxa de acerto do teste;

\% Mostra as taxas de acertos

- Apresentação das Taxas de acerto do treinamento, validação, e teste;

\% Salva os arquivos de Teste

- Gravação dos arquivos de teste desejado (alvo) e calculado;

\subsubsection{Seleção da Topologia das RNAs}

Na topologia de uma RNA, o número de neurônios de entrada corresponde ao número de variáveis no vetor de entrada utilizado, e o número de neurônios de saída está diretamente relacionado com o problema em questão. A função de ativação tanto para os neurônios da camada intermediária como para os de saída, introduz um grau de não linearidade na RNA, podendo usar funções de ativação logísticas, como serão utilizadas no programa de simulação, mostrado na seção anterior.

Quanto ao número de camadas intermediárias, resultados encontrados por Lippman $^{6}$ (1987); Cybenko ${ }^{7}$ (1988); Lapedes e Farber $^{8}$ (1988) apud Zhang, Patuwo e Hu (1998) mostram que na maior parte de problemas não é necessário mais do que duas camadas intermediárias, e que são preferíveis redes com menor número de neurônios intermediários, pela melhor capacidade de generalização e redução nos problemas de overfitting. Entretanto, o caminho mais comum para determinar o número de nós intermediários é via experimentação, processo conhecido como tentativa e erro.

\footnotetext{
${ }^{6}$ Lippman, R.P. (1987). An introduction to computing with neural nets, IEEE ASSP Magazine, april, 422. apud Zhang, Patuwo e Hu (1998).

${ }^{7}$ Cybenko, G. (1988). Continues valued neural network with two hidden layers are sufficient. Technical Report, Tuft university. apud Zhang, Patuwo e Hu (1998).

${ }^{8}$ Lapedes, A. e Farber, R. (1988). How neural nets work. In: Anderson, D.Z., (Ed.), Neural Information Processing Systems, American Institute of Physics, New York, pp. 442-456. apud Zhang, Patuwo e Hu (1998).
} 
Quanto ao número de neurônios intermediários, em redes com uma camada intermediária, as experiências indicam, para evitar problemas de overfitting, ser conveniente utilizar " $2 n+1$ ” (LIPMANN 6 , 1987; HECHT-NIELSEN $\left.{ }^{9}, 1990\right)$, “ $2 n$ " (WONG $\left.{ }^{10}, 1991\right)$, “ $n$ " (TANG ${ }^{11}$ e FISHWICK, 1993), “n/2” (KANG $\left.{ }^{12}, 1991\right)$ neurônios na camada intermediária, onde $n$ é o número de neurônios de entrada, embora nem todas essas heurísticas funcionem bem para todos os problemas (ZHANG, PATUWO e HU, 1998).

\subsubsection{Processo de Treinamento Validação e Teste}

O treinamento é o processo no qual determinam-se os pesos numéricos das conexões, os quais constituem-se no principal recurso da RNA e que na forma de conhecimento apreendido é armazenado pela rede (HAYKIN, 1999). Um Algoritmo de Aprendizado, é utilizado no treinamento para adaptar os parâmetros da RNA, da forma que a rede possa aprender uma determinada função. Existem dois tipos de algoritmo de aprendizado: aprendizado supervisionado, em que a entrada e saída desejada na rede são fornecidas por um supervisor externo, com o objetivo de ajustar os parâmetros da rede e encontrar uma ligação entre os pares de entrada e saída fornecidos; e, o aprendizado não supervisionado, em que não existe supervisor ou professor para acompanhar o processo de aprendizado (BRAGA, CARVALHO e LUDERMIR, 1999).

Será utilizado o aprendizado supervisionado, onde se provê a rede com um conjunto de treinamento de vetores de entrada, cada um com um vetor de saída desejado associado, $\left\{\left(x_{i}, d_{i}\right),\left(x_{1}, d_{1}\right), \ldots,\left(x_{n}, d_{n}\right)\right\}$. Para uma dada entrada $x_{i}(t)$ no instante de tempo $t$, a diferença entre a saída desejada $d(t)$ e a saída observada $y(t)$ da rede é o erro: $e(t)=d(t)$ $-y(t)$. O erro quadrático médio total sobre o conjunto de treinamento é então dado por:

\footnotetext{
${ }^{9}$ Hecht-Nielsen, R. (1990). Neurocomputing. Addison-Wesley, Menlo Park, CA. apud Zhang, Patuwo e $\mathrm{Hu}$ (1998).

${ }^{10}$ Wong, F. S. (1991). Time series forecasting using backpropagation neural networks. Neurocomputing 2, 147-159. apud Zhang, Patuwo e Hu (1998).

${ }^{11}$ Tang, Z. e Fishwick, P.A. (1993). Feedforward neural nets as models for time series forecasting. ORSA Journal on Computing 5 (4), 374-385. apud Zhang, Patuwo e Hu (1998).

${ }^{12}$ Kang, S. (1991). An investigation of the use of feedforward neural networks for forecasting. Ph.D. Thesis, Kent State University. apud Zhang, Patuwo e Hu (1998).
} 


$$
\mathrm{E}(w)=\frac{1}{N} \sum_{i=0}^{j}\left(d_{i}-y_{i}(w)\right)^{2}
$$

O objetivo do treinamento é determinar o conjunto de pesos $\boldsymbol{w}$ que minimiza a diferença $\mathrm{E}(w)$ entre a soma ponderada das entradas pelos pesos (saída calculada pela rede) e a saída desejada (alvo), ou seja, o erro da resposta da rede. O treinamento da rede neural resulta em um problema de otimização, minimização dos erros quadráticos das saídas, conforme apresentado na eq. 5.3. Considerando uma estrutura de rede não linear, o algoritmo de gradiente descendente é o mais utilizado entre os métodos de otimização.

Um método de gradiente descendente é o algoritmo de retropropagação conhecido como backpropagation. Neste algoritmo, a taxa de aprendizagem, deve ser especificada, determinando a magnitude da mudança de pesos. Pequenas taxas motivam um lento processo de aprendizagem. Entretanto, grandes taxas de aprendizagem podem causar oscilações da rede no espaço de pesos. Para melhorar o método inclui-se um parâmetro chamado momentum, permitindo rápidas convergências enquanto minimiza a tendência de oscilação (BRAGA, CARVALHO e LUDERMIR, 1999). No programa desenvolvido no MATLAB, foi utilizado o algoritmo backpropagation com momentum, variando as taxas de aprendizagem entre 0,05 e 0,1 , e as taxas de momentum entre 0,1 e 0,9 .

\subsection{FASE 5: PÓS-PROCESSAMENTO DOS ATRIBUTOS DE SAÍDA DAS RNAs}

Nesta fase apresentam-se os procedimentos de desnormalização e codificação, que ao serem aplicados determinarão os padrões de encadeamento de viagens a pé calculados pela rede neural e que poderão ser comparados com os padrões alvo (esperados), tanto em cada segmento da viagem como em toda a cadeia.

\subsubsection{Desnormalização dos Atributos de Saída}

O objetivo da desnormalização é trazer de volta os valores originais dos atributos de saída, fazendo com que a análise dos resultados se torne mais precisa. No item 5.4.2 
foi estabelecido que os intervalos de normalização são [0,1 e 0,9], e em função disso, a equação de desnormalização a ser aplicada será:

$$
x_{\mathrm{o}}=\left(x_{n} /(b-a)\right)\left(x_{\text {máx }}-x_{\text {mín }}\right)+x_{\text {mín }}
$$

Onde:

“ $a$ " e " $b$ " representam o intervalo de normalização mínimo e máximo;

$x_{n}$ e $x_{\mathrm{o}}$ representam o dado normalizado e o dado original;

$x_{\text {mín }}, x_{\text {máx }}$, são os valores mínimo e máximo de $x$, respectivamente.

O programa implementado no MATLAB executa a desnormalização para os valores alvos de cada partição: treinamento, validação e teste.

\subsubsection{Codificação}

Procedida a desnormalização com a aplicação da eq. 5.4, a nova codificação objetiva determinar os intervalos aos quais pertence o dado original $x_{\mathrm{o}}$ obtido do valor $x_{n}$ calculado pela rede. Na Tabela 5.4 é apresentado o critério utilizado na codificação.

Tabela 5.4: Codificação do dado calculado $x_{\mathrm{o}}$

\begin{tabular}{c|c}
\hline Valor Desnormalizado $x_{\mathbf{o}}$ & Codificação \\
\hline$x_{\mathrm{o}}<=0,125$ & 0 \\
$0,125<x_{\mathrm{o}}<=0,475$ & 1 \\
$0,475<x_{\mathrm{o}}<=0,775$ & 2 \\
$x_{\mathrm{o}}>0,775$ & 3 \\
\hline
\end{tabular}

\subsection{FASE 6: ANÁLISE DE RESULTADOS}

Nesta fase analisam-se os resultados obtidos pelo modelo, para os diversos experimentos realizados, tanto na simulação da rede MLP como da rede Elman. Por se tratar de uma primeira experiência na modelagem de padrões de viagens encadeadas, não existem critérios específicos sobre os quais possa se basear uma avaliação. Entretanto, tomando em consideração principalmente os trabalhos de Ichikawa (2002) e 
Pitombo (2003) em que se analisam as relações existentes entre padrões de viagens encadeadas e as características socioeconômicas associadas aos indivíduos, foram definidos os seguintes critérios nos quais a análise será baseada:

a) O nível de agregação utilizado: em nível individual, a taxa de acerto é geralmente baixa por causa das diferenças na preferência e gostos pessoais. Como indicado por Ortúzar e Willumsem (1994), os valores das taxas de acerto na modelagem desagregada são menores que os obtidos na modelagem agregada.

b) As variáveis incluídas no modelo: a existência de indivíduos com os mesmos atributos nas variáveis socioeconômicas individuais e domiciliares, não garantem comportamentos individuais iguais em relação aos padrões reproduzidos de viagens encadeadas, podendo-se apresentar distintas respostas das esperadas.

c) A representação do modelo: por se tratar de padrões de viagens encadeadas, não necessariamente um melhor desempenho da rede, por exemplo, em termos de Erro Quadrático Médio (EQM), garante uma adequada representação em termos dos padrões reproduzidos. Pode ocorrer a compensação entre padrões com erro muito pequeno e os padrões com erros muito grandes.

\subsubsection{Tabulação, Análise e Interpretação}

A cada simulação, os resultados dos padrões modelados serão tabulados de maneira que existindo os padrões desejados e os calculados pela rede, possam ser realizadas uma comparação do acerto global e uma outra comparação pontual para cada segmento de viagem. Paralelamente, os tipos de padrões representados também serão comparados. Todavia para cada experimento a análise e interpretação vai mostrar quais das topologias das redes apresentam melhores resultados em termos de representação dos padrões. 


\subsubsection{Desempenho da Rede Neural}

Embora existam muitas medidas de desempenho para avaliar o nível de acerto de uma RNA, as medidas de precisão são definidas em termos do erro da previsão que é a diferença entre o valor real ou observado e o valor previsto. Existem várias medidas de precisão na literatura e cada uma delas tem suas vantagens e desvantagens. As mais freqüentemente usadas são apresentadas na Tabela 5.5, que podem ser chamadas também de medida quantitativas:

Tabela 5.5: Medidas de desempenho da rede

\begin{tabular}{l|l}
\hline \multicolumn{1}{c|}{ Medidas de Desempenho } & \multicolumn{1}{c}{ Equação } \\
\hline Desvio médio absoluto (Mean Absolute Deviation - MAD) & $\operatorname{MAD}=\frac{\Sigma\left|e_{t}\right|}{N}$ \\
\hline Somatória do Erro Quadrático (Sum of Squared Error - SSE) & $\mathrm{SSE}=\Sigma\left(e_{t}\right)^{2}$ \\
\hline $\begin{array}{l}\text { Erro Quadrático Médio (Mean Squared Error - MSE) } \\
\text { Raiz do Erro Quadrático Médio (Root Mean Squared Error - RMSE) }\end{array}$ & $\mathrm{MSE}=\frac{\Sigma\left(e_{t}\right)^{2}}{N}$ \\
\hline $\begin{array}{l}\text { A média absoluta do erro em percentagem (Mean Absolute Percentage }=\sqrt{M S E} \\
\text { Error - MAPE) }\end{array}$ & $\mathrm{MAPE}=\frac{1}{N}\left|\frac{e_{t}}{y_{t}}\right|(100)$ \\
\hline
\end{tabular}

Onde: $e_{t}=$ previsão do erro individual; $y_{t}=$ valor observado; $N=$ número de casos.

Bocanegra (2002) recomenda utilizar outras três medidas de avaliação para identificar o(s) modelo(s) de melhor desempenho: a Comparação Gráfica, o Scattergram (medidas qualitativas) e o Coeficiente de Determinação $\left(\mathrm{R}^{2}\right)$ (medida quantitativa). Na Comparação Gráfica são plotados, lado a lado, em um mesmo gráfico, tanto os resultados observados como os previstos pelas RNAs. Através de uma análise visual são confrontados os resultados. No Scattergram, os dados também são plotados como pontos em um gráfico, com o propósito de tornar explícito o quão próximo estão as previsões dos valores alvo. No eixo $x$ pode-se plotar o valor previsto pelas RNAs e no eixo y o valor alvo (valor observado) correspondente. De maneira ideal, os pontos devem formar uma linha de $45^{\circ}$ que passa pela origem dos eixos. 
No Coeficiente de Determinação $\left(\mathrm{R}^{2}\right)$, cujo valor varia entre 0 e 1 , são comparados os valores reais $y_{t}$ e estimados $y_{i}$, de forma semelhante ao processo empregado em análises de regressão. Se $\mathrm{R}^{2}$ for igual a 1 , existirá uma correlação perfeita na amostra, isto é, não haverá diferença entre os valores estimados e os valores reais. De outra forma, se o coeficiente de determinação for igual a 0 , a equação de regressão (ou o modelo de RNA) não terá utilidade para prever valor de $y_{t}$.

Em função das limitações associadas com cada medida individual, pode-se utilizar múltiplas medidas de desempenho em um problema particular. Julgar um método como sendo o melhor em uma aplicação, não será necessariamente o melhor em termos de outras aplicações, como no caso da avaliação da eficiência das RNAs em reproduzir padrões de encadeamento de viagens a pé. Porém, para a análise e definição da rede de melhor desempenho, serão utilizadas medidas quantitativas e qualitativas. Dentre as quantitativas está o melhor valor de classificação $(M V C)$ e o menor valor do EQM. O $M V C$ fornece um valor expresso em porcentagem, o quanto a rede consegue representar os valores alvo. As medidas de análises qualitativas serão obtidas através da Comparação Gráfica entre os valores dos padrões observados e os melhores resultados dos valores previstos em termos de $M V C$ e o $E Q M$. 


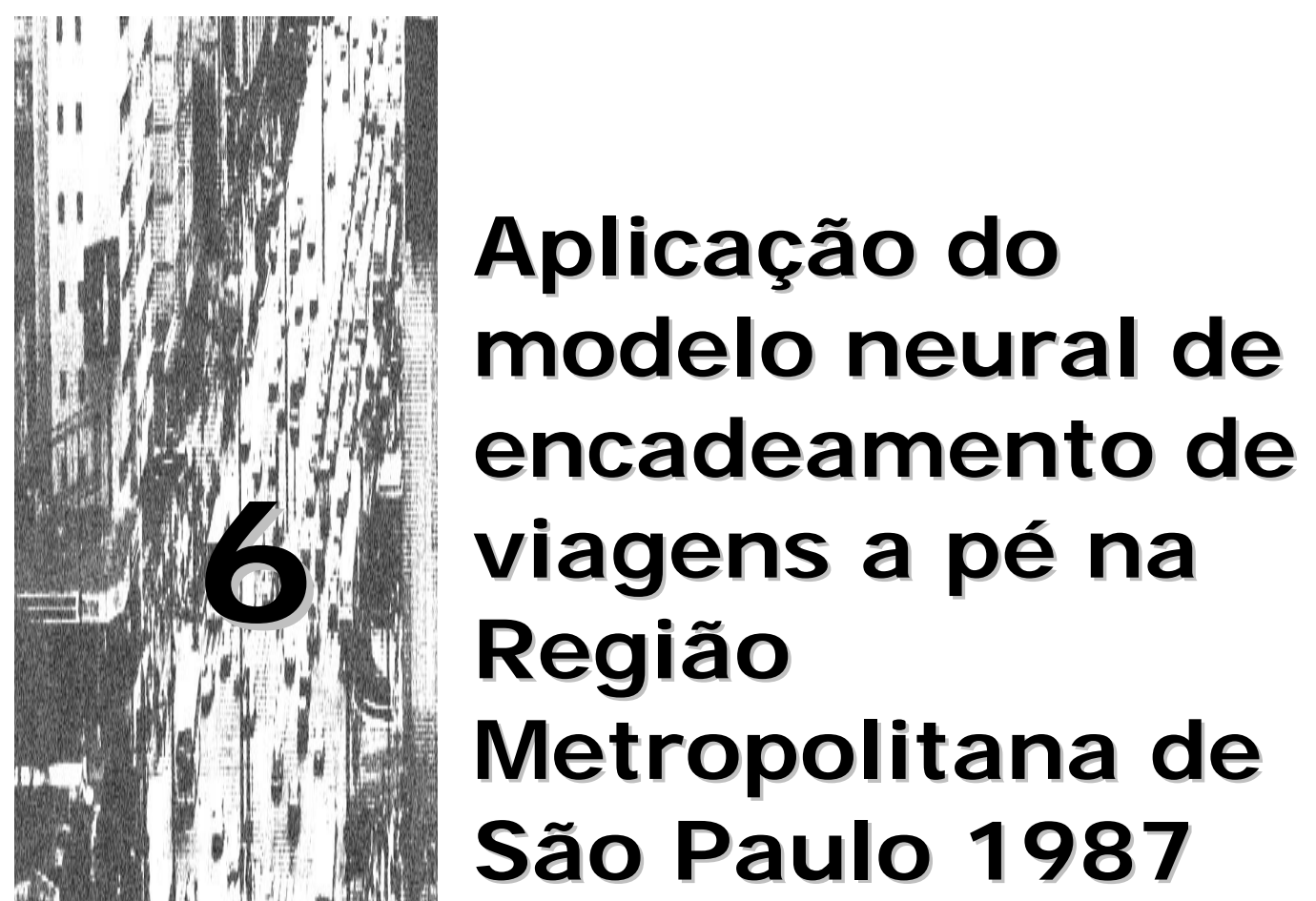

É sempre lindo andar, na cidade de São Paulo O clima engana, a vida é grana, em São Paulo A japonesa loura, a nordestina moura em São Paulo Gatinhas punk, um jeito ianque, em São Paulo Na grande cidade me realizar

Morando num BNH

Na periferia, a fábrica escurece o dia...

- Premeditando o Breque, São Paulo, São Paulo -

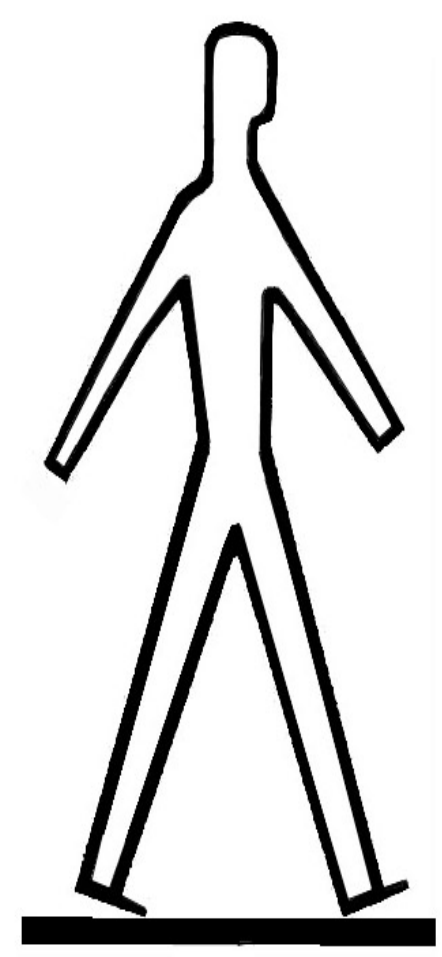

Na Metrópole: Textos de antropologia urbana. Jose Guilherme C. Magnani e Lílian de Luca Torres 


\section{APLICAÇÃO DO MODELO NEURAL DE ENCADEAMENTO DE VIAGENS A PÉ NA REGIÃO METROPOLITANA DE SÃO PAULO 1987}

\subsection{INTRODUÇÃO}

Neste capítulo estão desenvolvidas as fases da aplicação do modelo MONEVPE para reproduzir padrões de encadeamento das viagens a pé na Região Metropolitana de São Paulo 1987 (RMSP87). O objetivo é analisar a viabilidade da aplicação do modelo fazendo uso das RNAs. Para isso serão utilizados os dados da RMSP87 que correspondem a Pesquisa Origem-Destino 1987, apresentados na seção 6.2, e os dados das características do Espaço Urbano. Ainda nessa seção, é realizada uma análise das características das variáveis de entrada, como dos atributos de saída do modelo. Na seção 6.3 é aplicado o modelo MONEVPE, considerando o uso de uma topologia de Rede Neural Estática MLP e de uma topologia de Rede Neural Recorrente Elman.

\subsection{COLETA, SELEÇÃO E ANÁLISE DOS DADOS DA REGIÃO METROPOLITANA DE SÃO PAULO 1987}

A RMSP é a maior região metropolitana do Brasil e uma das maiores no mundo. As pesquisas O/D da RMSP, realizadas a cada dez anos pela Cia do Metropolitano de São Paulo, constitui-se segundo Vasconcelos (2002) no único registro sistemático e de 
qualidade sobre mobilidade em grandes cidades, no Brasil e também no exterior, em função da inexistência de séries semelhantes em outros países.

A análise dos dados da pesquisa O/D da RMSP já foi feita em vários outros estudos de transportes, como por exemplo Ichikawa, Pitombo e Kawamoto (2002), Ichikawa (2002), Pitombo (2003), Strambi e Bilt (1998), Strambi e Bilt (2001), Vasconcelos (2002), Vasconcelos e Scatena (1996). Esses estudos têm trazido enormes benefícios para a compreensão da dinâmica dos deslocamentos cotidianos da população e seus condicionantes sociais e econômicos, bem como da relação entre o processo de desenvolvimento urbano e o uso do solo e dos sistemas de transporte.

Assim, conforme considerações feitas anteriormente, os dados da pesquisa O/D da RMSP87 e informações das características do espaço urbano da RMSP87, obtidas por intermédio de um Sistema de Informações Geográficas, são utilizados no presente estudo de caso. A seguir descrevem-se estas bases de dados.

\subsubsection{Dados da Pesquisa Domiciliar Origem-Destino da RMSP 1987}

A Região Metropolitana de São Paulo (RMSP) em 1987, segundo o Instituto Brasileiro de Geografia e Estatística (IBGE), contava à época com uma população de 16 milhões de habitantes, distribuídos em 38 municípios, agrupados em 254 zonas, sendo que a Pesquisa Origem-Destino foi realizada em 204 zonas de tráfego, pela Companhia do Metropolitano de São Paulo (METRÔ, 1990).

Os dados considerados da RMSP87 (ver Apêndice A) estão distribuídos em cinco grupos, constituídos por: Dados Gerais, Dados do Domicílio, Dados da Família, Dados da Pessoa e Dados da Viagem. Dessa primeira base são obtidos os padrões individuais de atividades/viagem, e viagens encadeadas a pé (VEP). Porém, antes é necessário realizar uma filtragem e seleção dos dados como indicado no método de verificação da modelagem do cap. 5 . 


\section{a) Filtragem e seleção dos dados.}

Segundo o que foi especificado anteriormente, o processo de filtragem e seleção dos dados tem por objetivo a formação dos vetores das viagens encadeadas a pé. Com tal propósito, do conjunto total dos dados da pesquisa O/D correspondentes a 110.629 indivíduos pesquisados, foram excluídos os dados incompletos, dados que apresentam incongruências e dados de indivíduos com idade menor o igual a três anos, resultando em um conjunto de 101.411 indivíduos. Estes foram classificados, em função das viagens realizadas, em indivíduos que realizam viagens $(65,9 \%)$ e indivíduos que não realizam viagens $(43,1 \%)$.

A base de dados contendo os indivíduos que realizam viagens foi subdividida em três conjuntos, em função do número total de viagens realizadas durante o dia. $\mathrm{O}$ primeiro conjunto está constituído pelos indivíduos que realizam duas viagens (45.104), o segundo por três viagens (4.037), e o terceiro por quatro viagens (8.234). A partir desses conjuntos foram gerados três vetores, contendo as informações das variáveis socioeconômicas individuais e domiciliares, assim como dos atributos das viagens por indivíduo. Nesses vetores, em função dos atributos das viagens, foram selecionados os indivíduos que realizam especificamente cadeias de viagens a pé, que iniciam e finalizam no domicílio.

Desta maneira, o primeiro vetor contém dados de 17.642 indivíduos que fazem duas viagens, o segundo vetor com 281 indivíduos que fazem três viagens, e o terceiro vetor, com 2.229 indivíduos que fazem quatro viagens. Em cada vetor os dados estão distribuídos em cinco grupos: Dados Gerais (contendo identificadores da zona de tráfego onde foi realizada a pesquisa); Dados do Domicílio (contendo identificadores do domicílio); Dados da Família (contendo identificadores da família, condição de ocupação, número de veículos, características socioeconômicas tais como renda familiar mensal); Dados da Pessoa (identificadores do indivíduo, características socioeconômicas como salário médio mensal, localização do emprego, localização da escola); e, Dados de Viagem (origem, destino, motivo, modo, e duração da viagem). A seguir, descrevem-se as características desses dados. 


\section{b) Características das variáveis individuais e domiciliares.}

Para cada um dos vetores antes mencionados, analisaremos as características comportamentais das variáveis individuais e domiciliares e sua relação com as viagens realizadas. Essas variáveis, apresentadas na Tabela 6.1, com freqüência e porcentagem, são as utilizadas neste trabalho:

- Número de automóveis por domicílio (AUT): nenhum automóvel, dois ou mais automóveis;

- Gênero do indivíduo (SEXO): masculino ou feminino;

- Situação Familiar do Indivíduo (SF): dividido em quatro categorias: chefe, cônjuge, filho, e outros;

- Idade (IDADE): expressa em anos e maior de 3 anos;

- Grau de Instrução do indivíduo (GI): dividido em cinco categorias: Analfabeto $/ 4^{\circ}$ Série Incompleta, $1^{\circ}$ Grau Incompleto $/ 4^{\circ}$ Serie Completa, $1^{\circ} \mathrm{Grau}$ Completo, Colegial Concluído, e Superior Concluído;

- Salário Médio Mensal (SMED) do indivíduo em salários mínimos (SM): com valores referentes à época, 1987.

- Trabalha (TRAB): sim ou não;

- Estuda (EST): sim ou não.

Na Tabela 6.1 observa-se que dos indivíduos que realizam duas, três e quatro viagens VEP, em média 67\% não possuem nenhum automóvel, 54,6\% são mulheres, e, 50,6\% estão na categoria de filhos (SF). Quanto ao GI, em média 44,2\% estão na categoria de Analfabeto/4 $4^{\mathrm{a}}$ Série Incompleta e 33,3\% na categoria de $1^{\circ}$ Grau Incompleto/4 ${ }^{\mathrm{a}}$ Serie Completa. Quanto à IDADE, existe uma clara diferença para cada vetor de viagens, como pode ser observado também na Figura 6.1. Quem faz duas viagens estão mais concentrados na faixa de 4 até 16 anos, enquanto que os que fazem três viagens estão uniformemente distribuídos em todas as faixas de idade. Os que fazem quatro viagens, estão mais concentrados na faixa de 15 a 19 anos e de 22 até 40 
anos. Quanto ao SMED, 76\% dos indivíduos que fazem duas viagens não têm renda individual, entretanto os que fazem três viagens estão distribuídos nas faixas de zero a dez SM, sendo menor que para quatro viagens, como pode ser observado na Figura 6.2. Ainda na Tabela 6.1, é observado que a atividade principal de quem faz duas viagens é estudo, com 68,7\%, e no caso de três viagens, 64,1\% não trabalham, e 60,1\% não estudam. Para quatro viagens, a atividade principal é trabalho para 64,2\%.

Tabela 6.1: Freqüência das Variáveis Individuais e Domiciliares - RMSP87

\begin{tabular}{|c|c|c|c|c|c|c|c|c|}
\hline \multicolumn{2}{|c|}{ Variáveis Individuais e Domiciliares } & \multicolumn{7}{|c|}{ Vetores das Viagens } \\
\hline \multirow{2}{*}{\multicolumn{2}{|c|}{ Características }} & \multicolumn{2}{|c|}{ Duas } & \multicolumn{2}{|c|}{ Três } & \multicolumn{2}{|c|}{ Quatro } & \multirow{2}{*}{\begin{tabular}{|r|} 
Média \\
$\begin{array}{r}\text { Freq. } \\
\text { (\%) }\end{array}$
\end{tabular}} \\
\hline & & Freq. & $\begin{array}{r}\text { Freq. } \\
(\%)\end{array}$ & Freq. & $\begin{array}{r}\text { Freq. } \\
(\%)\end{array}$ & Freq. & $\begin{array}{r}\text { Freq. } \\
(\%)\end{array}$ & \\
\hline \multirow{2}{*}{ AUT } & Nenhum automóvel & 11.887 & 67,4 & 190 & 67,6 & 1.469 & 65,9 & 67,0 \\
\hline & Mais de um automóvel & 5.755 & 32,6 & 91 & 32,4 & 760 & 34,1 & 33,0 \\
\hline \multirow{2}{*}{ SEXO } & Masculino & 8.560 & 48,5 & 113 & 40,2 & 1.059 & 47,5 & 45,4 \\
\hline & Feminino & 9.082 & 51,5 & 168 & 59,8 & 1.170 & 52,5 & 54,6 \\
\hline \multirow{4}{*}{ SF } & Chefe & 2.205 & 12,5 & 73 & 26,0 & 587 & 26,3 & 21,6 \\
\hline & Cônjuge & 1.612 & 9,1 & 72 & 25,6 & 512 & 23,0 & 19,2 \\
\hline & Filho & 12.159 & 68,9 & 118 & 42,0 & 910 & 40,8 & 50,6 \\
\hline & Outros & 1.666 & 9,4 & 18 & 6,4 & 220 & 9,9 & 8,6 \\
\hline \multirow{5}{*}{ GI } & Analfabeto $/ 4^{\circ}$ Série Incompleta & 10.426 & 59,1 & 122 & 43,4 & 669 & 30,0 & $\overline{44,2}$ \\
\hline & $\begin{array}{l}1^{\circ} \text { Grau Incompleto } / 4^{\circ} \text { Serie } \\
\text { Comp. }\end{array}$ & 5.289 & 30,0 & 77 & 27,4 & 948 & 42,5 & 33,3 \\
\hline & $1^{\circ}$ Grau Completo & 1.156 & 6,6 & 42 & 14,9 & 360 & 16,2 & 12,5 \\
\hline & Colegial Concluído & 558 & 3,2 & 25 & 8,9 & 188 & 8,4 & 6,8 \\
\hline & Superior Concluído & 213 & 1,2 & 15 & 5,3 & 64 & 2,9 & 3,1 \\
\hline \multirow{6}{*}{ IDADE } & $4<=$ IDADE $<=10$ & 6.662 & 37,8 & 56 & 19,9 & 128 & 5,7 & 21,1 \\
\hline & $10<$ IDADE $<=15$ & 4.777 & 27,1 & 35 & 12,5 & 339 & 15,2 & 18,2 \\
\hline & $15<$ IDADE $<=25$ & 2.151 & 12,2 & 42 & 14,9 & 602 & 27,0 & 18,0 \\
\hline & $25<$ IDADE $<=40$ & 2.104 & 11,9 & 71 & 25,3 & 721 & 32,3 & 23,2 \\
\hline & $40<\mathrm{IDADE}<=60$ & 1.462 & 8,3 & 57 & 20,3 & 357 & 16,0 & 14,9 \\
\hline & IDADE $>60$ & 486 & 2,8 & 20 & 7,1 & 82 & 3,7 & 4,5 \\
\hline \multirow{7}{*}{ SMED } & $0=\mathrm{SM}$ & 13.403 & 75,9 & 149 & 53,0 & 855 & 38,4 & 55,8 \\
\hline & $0<\mathrm{SM}<=3$ & 2.258 & 12,8 & 68 & 24,2 & 758 & 34,0 & 23,7 \\
\hline & $3<\mathrm{SM}<=10$ & 1.722 & 9,8 & 53 & 18,9 & 518 & 23,2 & 17,3 \\
\hline & $10<\mathrm{SM}<=20$ & 185 & 1,1 & 8 & 2,9 & 77 & 3,5 & 2,5 \\
\hline & $20<\mathrm{SM}<=30$ & 41 & 0,2 & 3 & 1,0 & 16 & 0,7 & 0,7 \\
\hline & $30<\mathrm{SM}<=40$ & 12 & 0,1 & 0 & 0 & 0 & 0 & 0,0 \\
\hline & $\mathrm{SM}>40$ & 21 & 0,1 & 0 & 0 & 5 & 0,2 & 0,1 \\
\hline \multirow{2}{*}{ EST } & Sim & 12.126 & 68,7 & 101 & 35,9 & 693 & 31,1 & 45,3 \\
\hline & Não & 5.516 & 31,3 & 180 & 64,1 & 1.536 & 68,9 & 54,7 \\
\hline \multirow{2}{*}{ TRAB } & Sim & 4.166 & 23,6 & 112 & 39,9 & 1.431 & 64,2 & 42,6 \\
\hline & Não & 13.476 & 76,4 & 169 & 60,1 & 798 & 35,8 & 57,4 \\
\hline
\end{tabular}




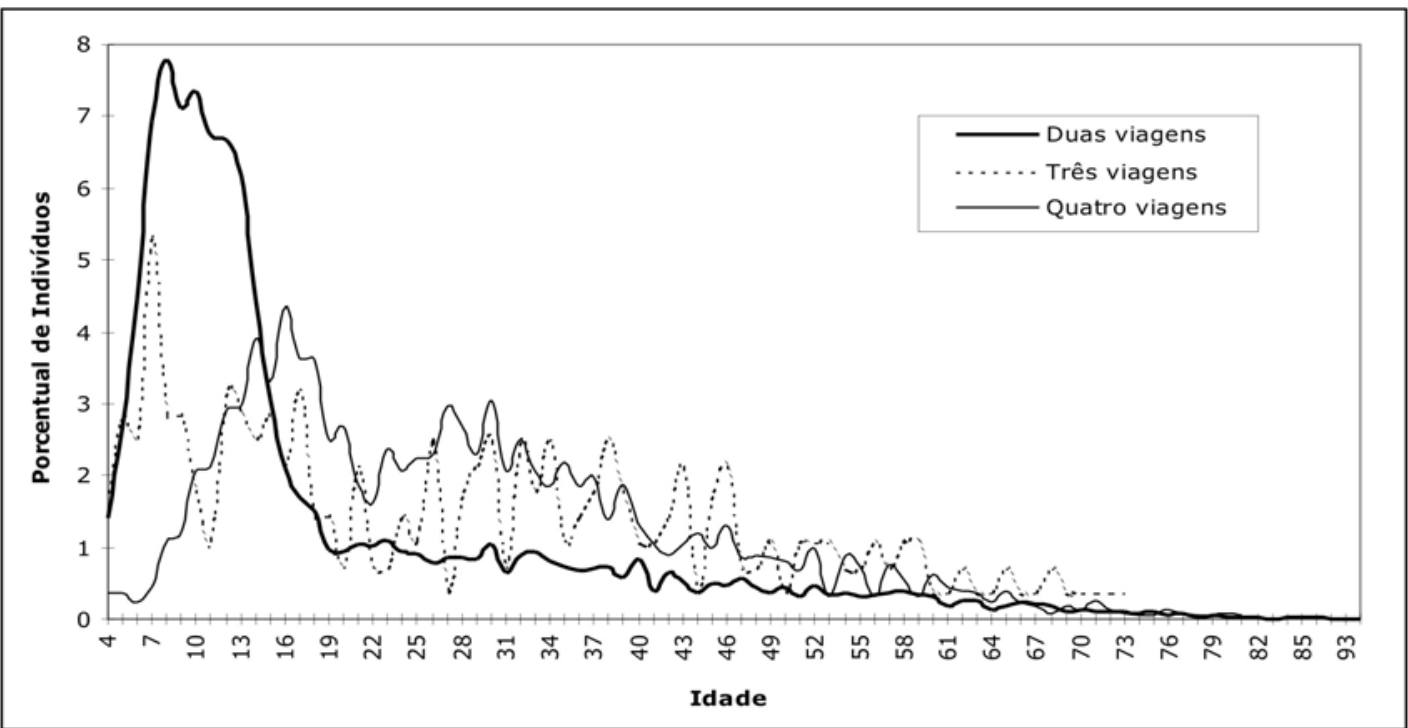

Figura 6.1: Porcentual de indivíduos que fazem viagens a pé por IDADE - RMSP87.

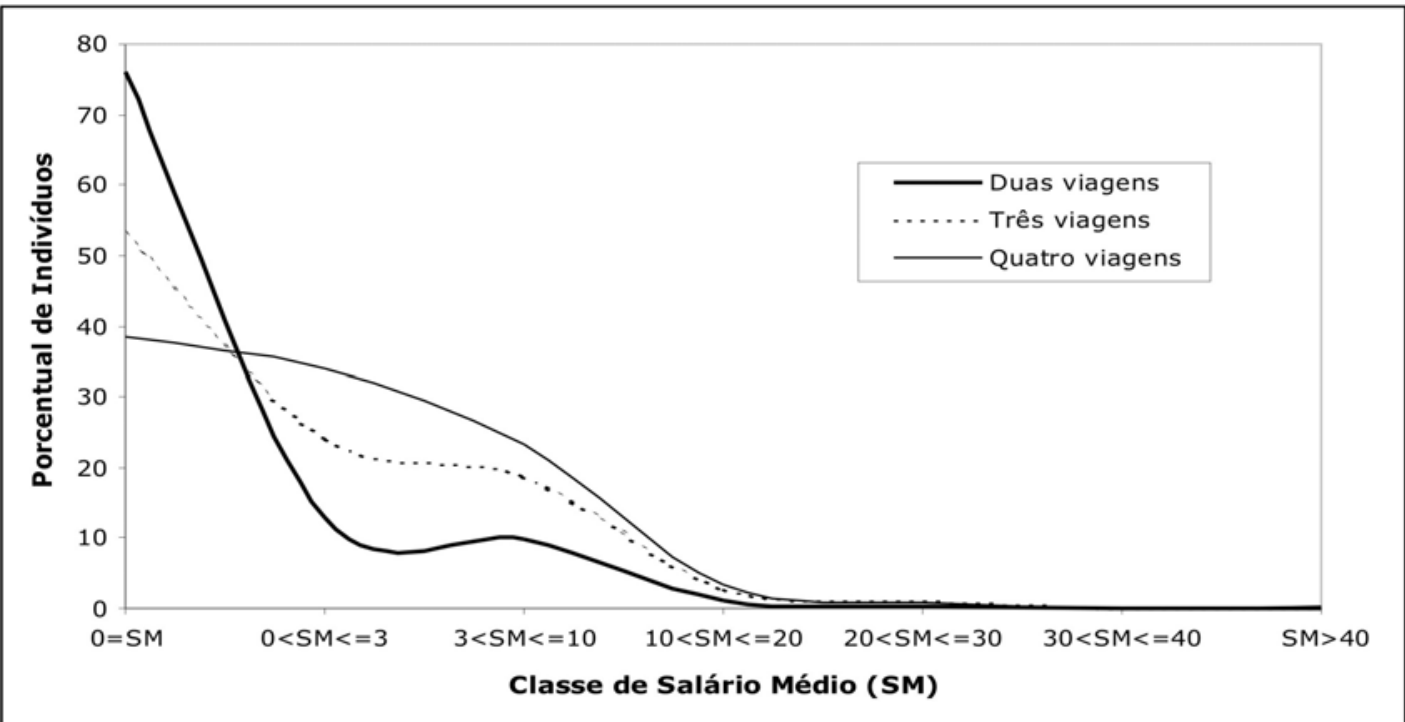

Figura 6.2: Porcentual de indivíduos que fazem viagens a pé por classe de SMED RMSP87.

\section{c) Características de viagem.}

Quanto às características de viagem, os atributos a serem analisados são: as atividades que motivaram a viagem, e o tempo de duração de cada viagem (Dur). 
- Atividades que motivaram a viagem, foram agregadas em três motivos gerais de viagens: Trabalho (W), Escola (S), e Outras Atividades (A), como podem ser observados na Tabela 6.2.

Tabela 6.2: Agregação da Atividade (Motivo da Viagem)

\begin{tabular}{l|l|c}
\hline $\begin{array}{l}\text { Explicação da Atividade } \\
\text { Motivo } \\
\text { da Viagem }\end{array}$ & \multicolumn{2}{|l}{ Características da modelagem / Motivo } \\
\cline { 2 - 3 } & $\begin{array}{l}\text { Atividade Motivo } \\
\text { da Viagem Agregada }\end{array}$ & $\begin{array}{l}\text { Código do } \\
\text { Motivo }\end{array}$ \\
\hline $\begin{array}{l}\text { Trabalho na indústria (1) } \\
\text { Trabalho no comércio (2) } \\
\text { Trabalho em serviços (3) }\end{array}$ & Trabalho & W \\
\hline Escola ou educação (4) & Estudos & S \\
\hline $\begin{array}{l}\text { Compras (5) } \\
\text { Negócios (6) } \\
\text { Médico/dentista/saúde (7) } \\
\text { Recreação ou visitas (8) }\end{array}$ & Outras Atividades & A \\
\hline Residência (9) & Domicílio & H \\
\hline
\end{tabular}

1 a 9 - codificação adotada pelo METRO-SP/87

A agregação da tipologia dos padrões das atividades (Motivo da Viagem) mostrada na Tabela 6.2 permite distinguir duas categorias de cadeias de viagens. A primeira é a categoria chamada de “cadeias simples” que abrange uma viagem individual desde o domicílio para um determinado destino e o retorno para o domicílio, com três tipos de alternativas HWH, HSH, HAH. A segunda categoria é chamada de “cadeias complexas”, e abrange a seqüência de mais de duas viagens individuais que iniciam e finalizam no domicílio. Nesta categoria, a grande quantidade de detalhes envolvidos permite distinguir entre vários tipos de alternativas de cadeias complexas. Considerando o motivo trabalho como atividade principal, existem quatro alternativas baseados nos pontos onde a troca de viagens não-trabalho pode ocorrer em decorrência da existência de paradas para realizar outras atividades antes e/ou depois da atividade principal: (a) indo ao trabalho $\mathbf{H}+\mathbf{W H}$; (b) retornando do trabalho $\mathbf{H W}+\mathbf{H}$; e, (c) ambos, indo ao trabalho e retornando do trabalho $\mathbf{H}+\mathbf{W}+\mathbf{H}$.

Os critérios mencionados anteriormente permitiram realizar a análise estatística das características dos padrões de atividades/viagens para o modo a pé, nos vetores de dois, três e quatro viagens, os quais são apresentados na Tabela 6.3. Nessa tabela 
observam-se informações sobre número de indivíduos que viajam a pé, sobre zonas de destino para a primeira viagem, e o motivo do primeiro destino da viagem. Observa-se que do total de indivíduos que realizam duas, três e quatro viagens, os indivíduos que fazem especificamente VEP representam, respectivamente, 39,1\%, 6,9\%, e 27,2\%. Observa-se também que a maior ocorrência de VEP está concentrada no vetor de duas viagens, com $87,5 \%$.

Tabela 6.3: Características das viagens encadeadas a pé

\begin{tabular}{|c|c|c|c|c|c|c|c|c|c|}
\hline \multirow{3}{*}{$\begin{array}{l}\text { Número } \\
\text { de } \\
\text { Viagens }\end{array}$} & \multirow{2}{*}{\multicolumn{2}{|c|}{$\begin{array}{l}\text { Indivíduos / } \\
\text { Viagens }\end{array}$}} & \multicolumn{7}{|c|}{ Padrões / Viagens } \\
\hline & & & \multicolumn{2}{|c|}{ Modo a Pé } & \multicolumn{2}{|c|}{$\begin{array}{c}\text { Zonas O/D } \\
\text { Primeiro Destino }\end{array}$} & \multicolumn{3}{|c|}{$\begin{array}{c}\text { Motivo da Viagem } \\
\text { Primeiro Destino }\end{array}$} \\
\hline & Qtd. & $\begin{array}{c}\text { Freq. } \\
\text { Rel. } \\
(\%)\end{array}$ & Qtd. & $\begin{array}{c}\text { Freq. } \\
\text { Rel. } \\
(\%)\end{array}$ & $\begin{array}{c}\mathbf{Z O}=\mathbf{Z D} \\
\text { Qtd. }\end{array}$ & $\begin{array}{c}\mathbf{Z O} \neq \mathbf{Z D} \\
\text { Qtd. }\end{array}$ & $\begin{array}{l}\text { HW+ } \\
\text { Qtd. }\end{array}$ & $\begin{array}{l}\text { HS+ } \\
\text { Qtd. }\end{array}$ & $\begin{array}{l}\text { HA+ } \\
\text { Qtd. }\end{array}$ \\
\hline Duas & 45.104 & 78,6 & 17.642 & 87,5 & 17.520 & 122 & 3.751 & 12.148 & 1.743 \\
\hline Três & 4.077 & 7,1 & 281 & 1,4 & 225 & 56 & 75 & 83 & 123 \\
\hline Quatro & 8.198 & 14,3 & 2.229 & 11,1 & 1.832 & 397 & 1.297 & 745 & 187 \\
\hline Total & 57.379 & 100 & 20.152 & 100 & \begin{tabular}{|l|}
19.577 \\
\end{tabular} & 575 & 5.123 & 12.976 & 2.053 \\
\hline
\end{tabular}

Na mesma Tabela pode-se observar que dos 17.642 indivíduos que realizam duas VEP, 99,3\% das viagens são realizadas dentro da mesma zona de residência $(\mathbf{Z O}=\mathbf{Z D})$, isto é viagens internas. Destes, 68,9\% (12.148 indivíduos) têm como motivo da viagem o estudo (HS+), para 21,2\% o motivo é trabalho (HW+) e 9,9\% não realizam outras atividades (HA+). Dos 281 indivíduos que realizam três VEP, na primeira viagem, 80,1\% se destinam à própria zona de residência, e tem como motivo outras atividades (43,8\%), estudo (29,5\%), e trabalho (26,7\%). Dos 2.229 indivíduos que realizam quatro VEP, 82,2\% escolhem como primeiro destino a zona de residência, sendo trabalho o motivo do primeiro destino para 58,2\%, escola para 33,4\% e 8,4\% para outras atividades. Para quatro viagens, 99\% das VEP tem no meio da cadeia o domicílio $(\mathbf{H}+\mathbf{H}+\mathbf{H})$.

Das informações obtidas anteriormente pode-se concluir para indivíduos que fazem VEP, existe uma grande probabilidade de ocorrência de três eventos: (i) a zona de destino da primeira viagem coincide com a zona de residência $(\mathbf{Z O}=\mathbf{Z D})$; (ii) a 
atividade no destino da primeira viagem é trabalho (W) ou estudo (S); e, (iii) no meio da cadeia de quatro viagens o indivíduo retorna para o domicílio (+H+).

- Tempo de duração de cada viagem (DUR). Para vetores de duas, três e quatro VEP, o tempo médio de viagem é de 15,4 min., 18,9 min., e 12,2 min., respectivamente. O tempo máximo de viagem é de 195 min. para duas viagens, de 120 min. para três viagens e de 210 min. para quatro viagens. Além disso, como observado na Figura 6.3, a distribuição porcentual de indivíduos por tempo médio de viagem está concentrada no intervalo de cinco a trinta minutos. Embora exista uma concentração de indivíduos em cinco, dez, quinze e trinta minutos, isto pode ser resultado da forma como foi conduzida a entrevista.

Da análise anterior e considerando que na RMSP87 o tempo médio de viagens a pé está em torno da média de 15 min. (METRÔ, 1990), pode-se estabelecer três intervalos de tempo para definição dos padrões de tempo de VEP: (i) menores ou iguais a 10 min., (ii) maiores a 10 min., e menores ou iguais a 20 min., e, (iii) acima de 20 minutos.

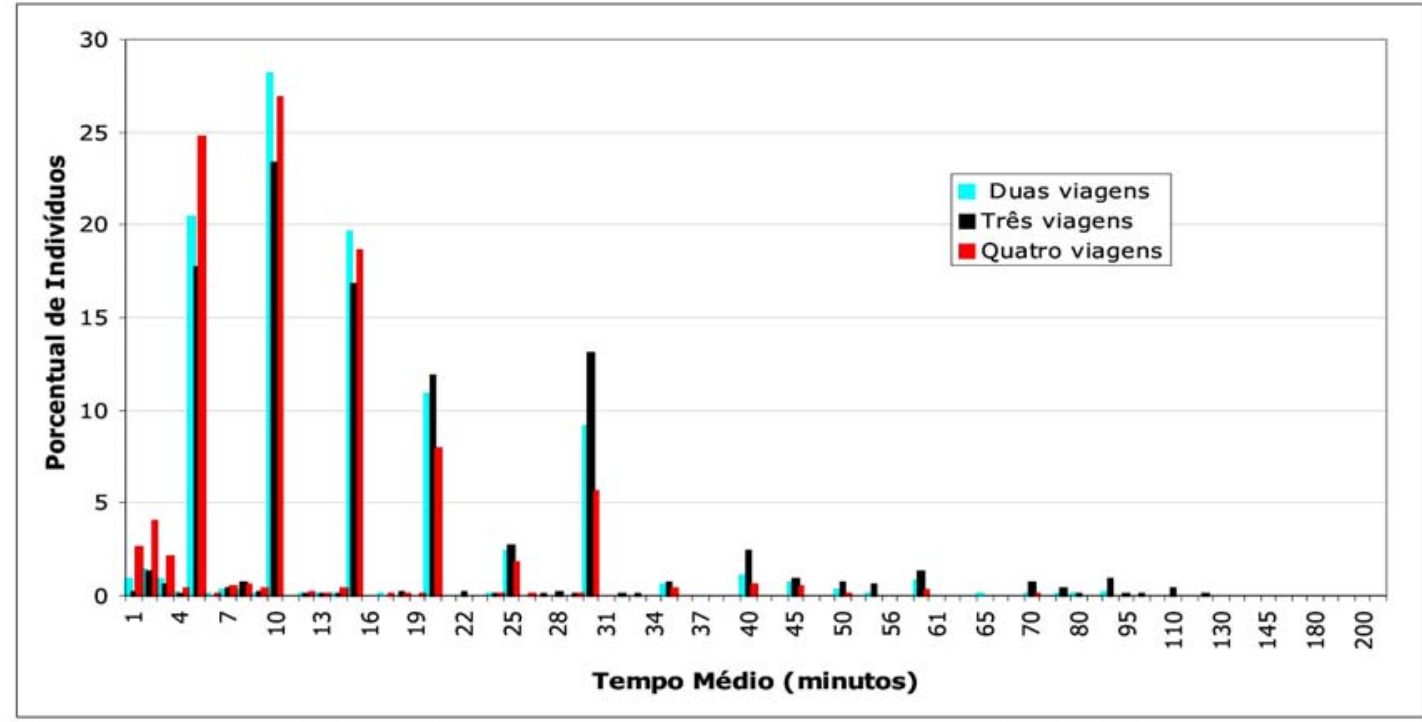

Figura 6.3: Porcentual de indivíduos por tempo médio de viagem - RMSP87. 


\subsubsection{Características do Espaço Urbano da RMSP/87}

A segunda base de dados está constituída pelas Características do Espaço Urbano da Região Metropolitana de São Paulo 1987 das Zonas de Tráfego (ZT). Esses dados foram obtidos do Metrô (1990) e do mapa digitalizado da RMSP87 através de um software de Sistema de Informações Geográficas (TransCA $D^{1}$ ). Desta base de dados será obtido o Vetor de Dados Espaciais por Zona de Tráfego que constitui as variáveis de entrada do modelo.

A base de dados contém: Dados Gerais das ZT (identificadores e nomenclatura), Coordenadas Geográficas por ZT, Distâncias medidas pelo sistema viário entre os centróides das ZT (em km). É necessário indicar que nestas distâncias não foi considerado nenhum outro tipo de características do sistema viário, tais como obstáculos, condições da via etc. Na Figura 6.4 podem ser observadas as zonas de tráfego da RMSP87, incluindo as ZT que não foram pesquisadas por corresponderem a grandes equipamentos urbanos sem residentes e outros com ocupação rarefeita.

\section{a) Cálculo da acessibilidade por distância média entre ZT}

A acessibilidade por distância média entre zonas de tráfego foi calculada através de um indicador do tipo separação média entre os centróides das zonas de tráfego, como foi definido no método de verificação da modelagem do cap. 5, item 5.3.2. Com esses valores foi construída uma matriz de distâncias entre centróides, previamente normalizadas para intervalos de [0,1 e 0,9], cujos valores podem ser encontrados na Tabela A.1 do Apêndice. Na Figura 6.5 pode ser observado o mapa temático de acessibilidade por distância média entre zonas da RMSP87, dividida em cinco classes, sendo que os valores normalizados maiores representam distâncias médias maiores e, conseqüentemente, menor acessibilidade. Distâncias médias normalizadas menores, definem uma maior acessibilidade, como observado na Figura 6.5, a região central da RMSP87 apresenta melhor acessibilidade do que a região da periferia.

\footnotetext{
${ }^{1}$ Caliper Corporation. 1172 Beacon Street, Newton, Massachusetts, USA.
} 


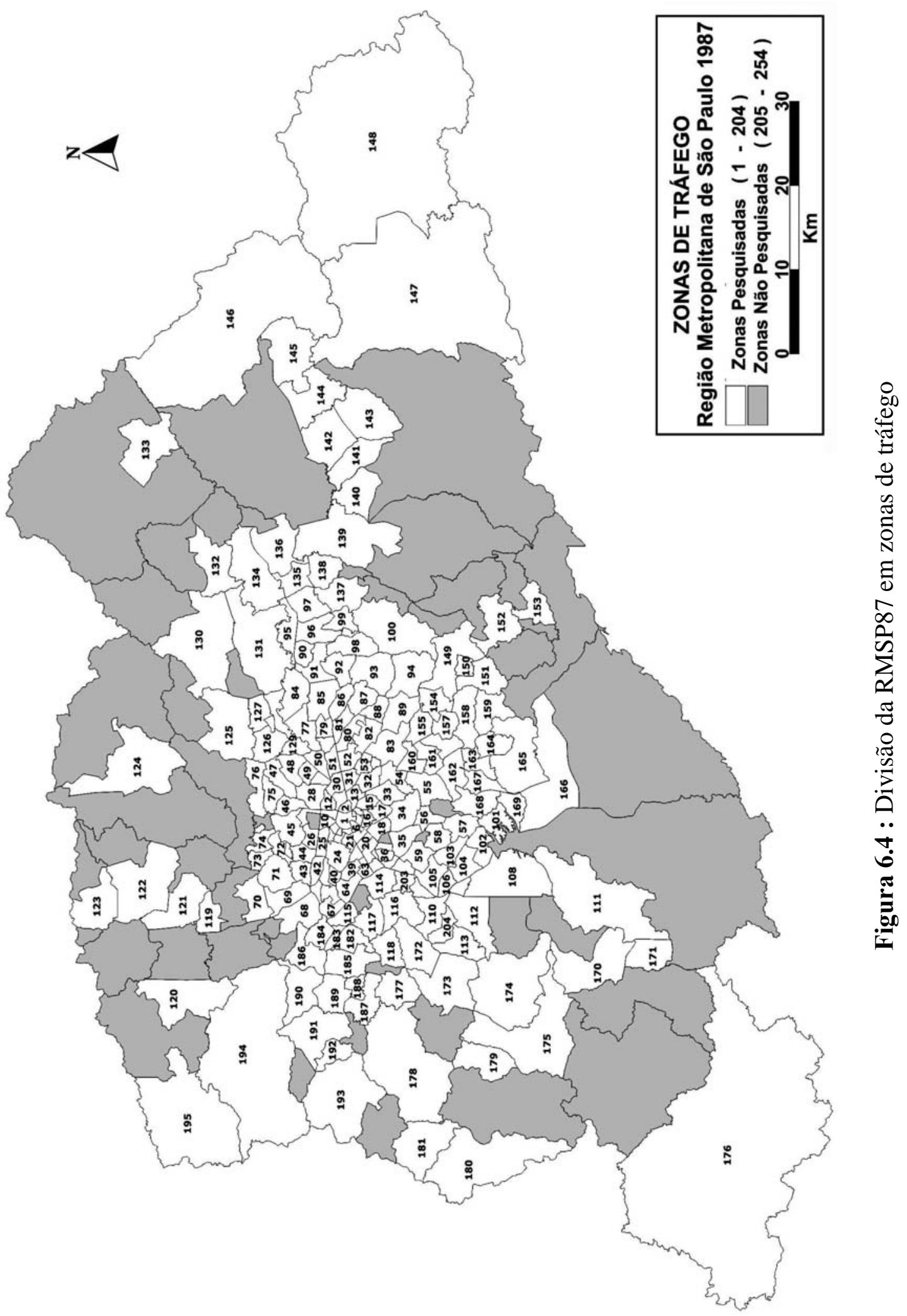




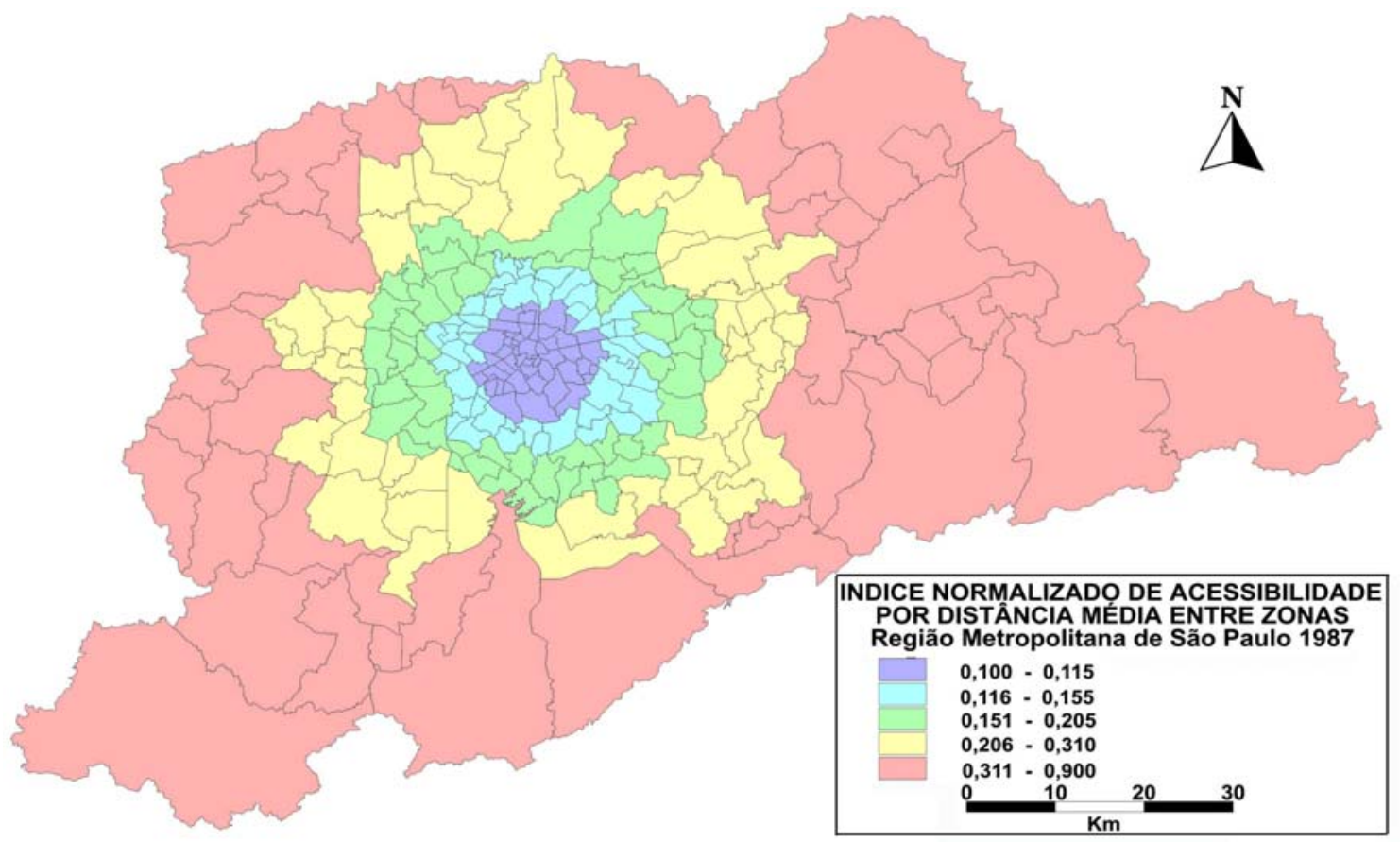

Figura 6. 5: Mapa temático de acessibilidade por distância média entre zonas da RMSP87

\section{b) Cálculo da atratividade por empregos e matrículas.}

No cálculo da atratividade por empregos e estudos, foram considerados dados correspondentes a Número de Empregos $^{2}$ (Industria, Comercio, Serviços e outros) e Número de Matrículas na Escola ${ }^{2}$ por ZT da RMSP87. Com esses dados foram calculados Índices Normalizados de Atratividade por Empregos (INAE) e Índices Normalizados de Atratividade por Matrículas (INAM), entre cada ZT. O método para cálculo desses índices foi definido no item 5.3.2 do cap. 5. Através do método obtêm-se os vetores contendo os valores dos INAM e INAE da RMSP87, apresentados na Tabela A2 e Tabela A3, respectivamente, do Apêndice. Com esses vetores e fazendo uso do TransCAD, foram criados os mapas temáticos dos INAM e INAE da RMSP87, como pode ser observado na Figura 6.6 e Figura 6.7, respectivamente. Em ambos os mapas, os valores dos índices por zona de tráfego foram divididos em cinco classes, sendo que os valores normalizados maiores representam maiores atratividades.

\footnotetext{
${ }^{2}$ Dados proporcionados pela Companhia do Metropolitano de São Paulo - METRO-SP, 2001.
} 


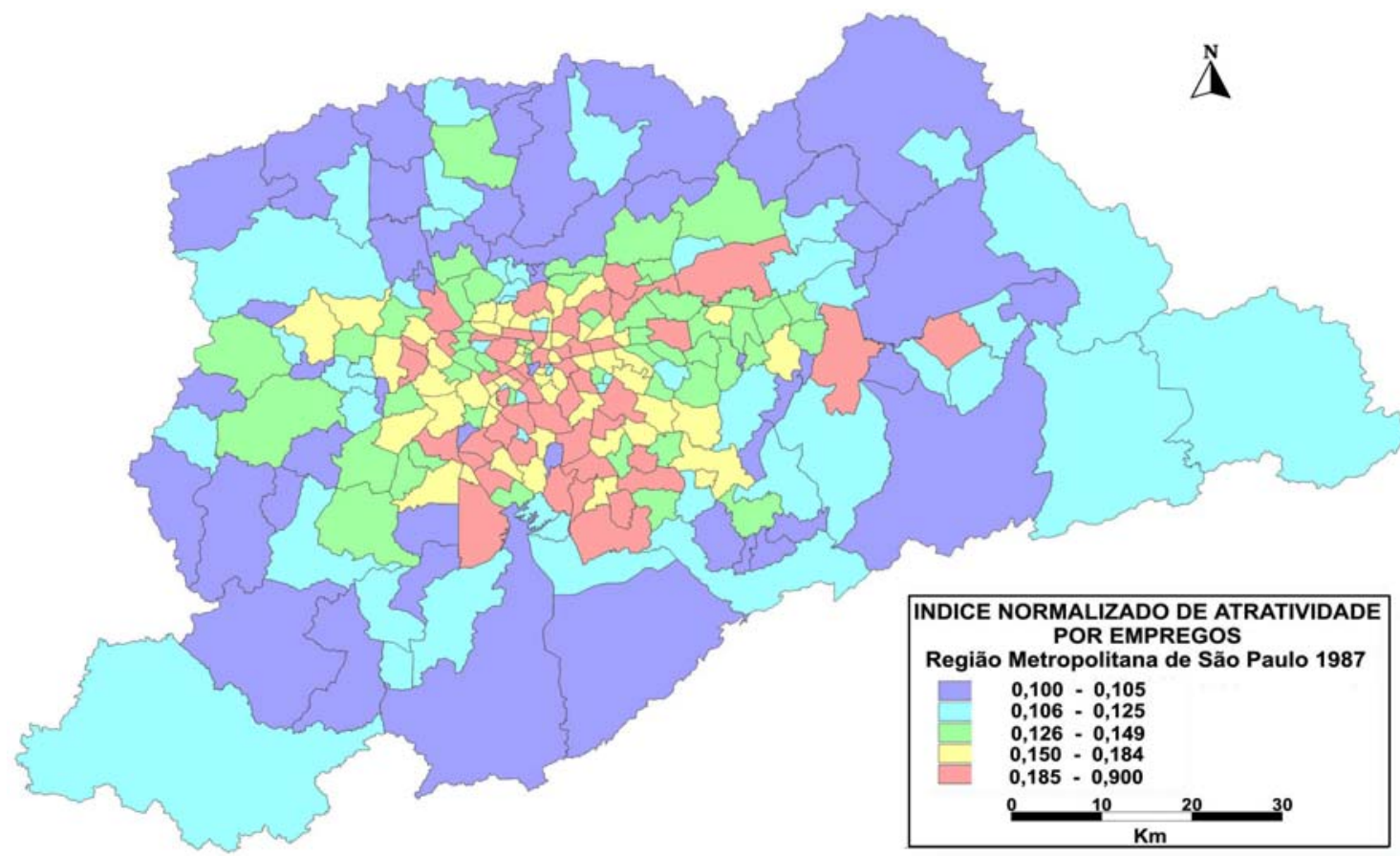

Figura 6.6: Mapa temático do índice normalizado de atratividade por empregos da

\section{RMSP87}

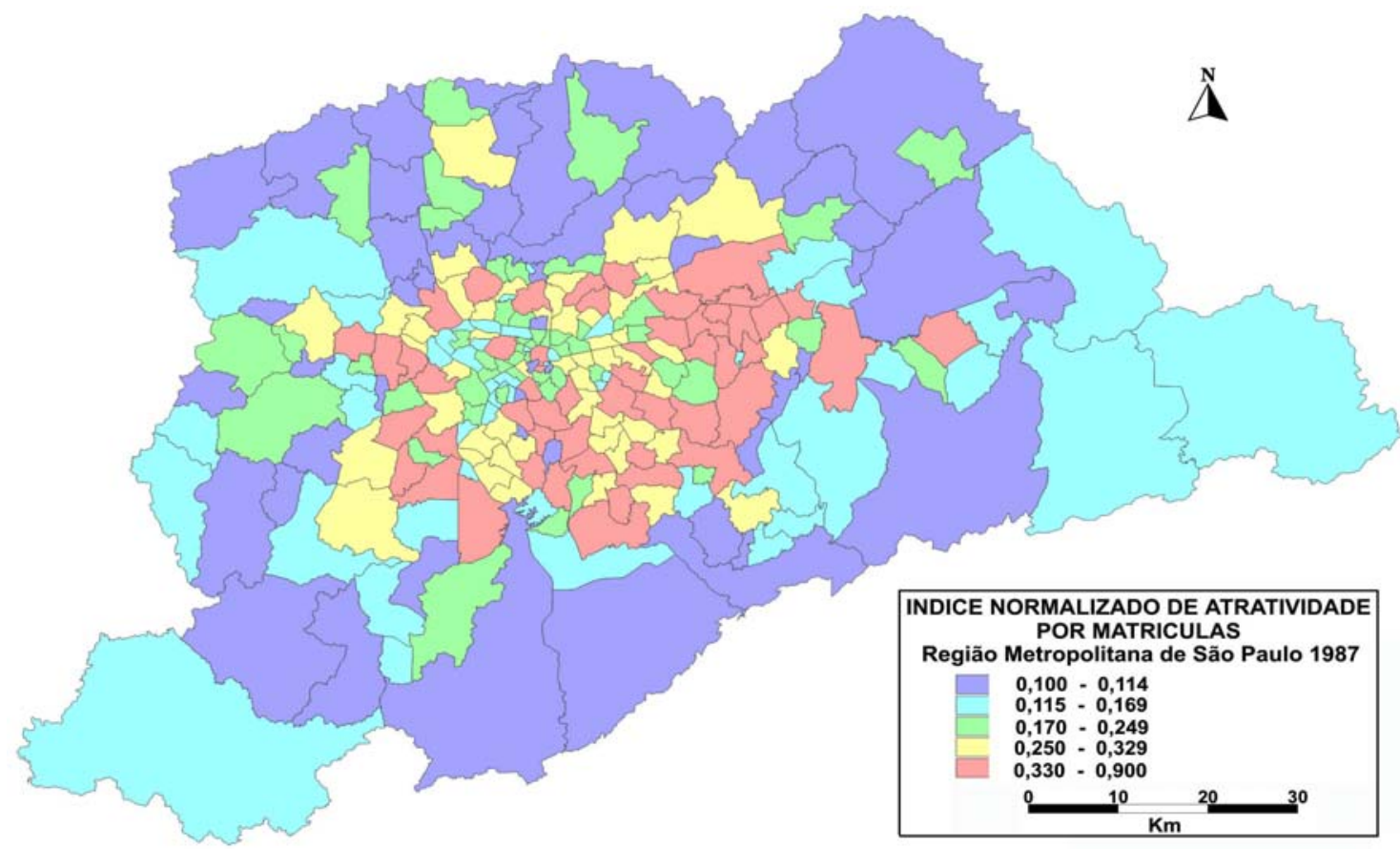

Figura 6.7: Mapa temático do índice normalizado de atratividade por matrículas da

\section{RMSP87}




\subsection{DEFINIÇÃO DAS VARIÁVEIS DE ENTRADA E DE SAÍDA}

O número de variáveis de entrada e de saída definem o número de neurônios de entrada e de saída da RNA, respectivamente. Para fins de simulação, são agrupadas as variáveis em vetores, o qual possibilita seu melhor tratamento, codificação e normalização. Assim, os vetores dos dados sócio-econômicos Individuais e Domiciliares $(\overrightarrow{C I}, \overrightarrow{C D})$ e os dados Espaciais $(\overrightarrow{A S}, \overrightarrow{A T})$ da RMSP por ZT, constituem as variáveis de entrada. Os vetores das variáveis de saída são formados pelos padrões de duração de viagem para duas, três e quatro viagens, como é definido a seguir.

\subsubsection{Caracterização das Variáveis de Entrada}

As variáveis de entrada estão agrupadas em dois vetores, totalizando onze variáveis. No primeiro Vetor dos Dados Socioeconômicos Individuais e Domiciliares, reúnem-se oito variáveis: (1) Número de automóveis; (2) Gênero; (3) Situação Familiar; (4) Idade; (5) Grau de Instrução; (6) Renda Média Mensal; (7) Trabalha; e, (8) Estuda, como observado na Tabela 6.4. O segundo vetor está formado pelo Vetor dos Dados Espaciais por Zona de Tráfego, com três variáveis: (1) Índice Normalizado de Distância Média entre ZT; (2) Índice Normalizado de Atratividade por Matrículas entre ZT; e, (3) Índice Normalizado de Atratividade por Empregos entre ZT.

\section{a) Normalização das variáveis de entrada.}

Em geral o processo de normalização depende exclusivamente das funções de ativação dos neurônios. A função de ativação utilizada é a sigmóide, variando entre valores maiores do que 0 e menores do que 1 . Na Tabela 6.4 é apresentado o valor de cada variável normalizada, em função da eq.(6.1).

$$
x_{n}=(b-a)\left(x_{0}-x_{\min }\right) /\left(x_{\max }-x_{\min }\right)
$$

Onde:

$x_{n}$ e $x_{0}$ representam o dado normalizado e o dado original;

$x_{\text {mín }}, x_{\text {máx }}$, são os valores mínimo e máximo do intervalo origem da normalização, isto é, das colunas dos vetores das variáveis individuais e domiciliares; e, 
$b, a$, são os valores dos intervalos destino da normalização com mínimo de 0,1 e máximo de 0,9 , respectivamente.

Para o Vetor dos Dados Espaciais por Zona de Tráfego, as Tabelas A1, A2, e A3 do Apêndice, apresentam os valores Normalizados da Distância Média, de Atratividade por Matrículas, Atratividade por Empregos entre ZT.

Tabela 6.4: Normalização do Vetor dos Dados Socioeconômicos Individuais e Domiciliares.

\begin{tabular}{|c|c|c|c|c|}
\hline $\begin{array}{c}\text { Neurônios de } \\
\text { Entrada / Variável }\end{array}$ & \multicolumn{2}{|c|}{ Variáveis de Entrada / Características } & $\begin{array}{r}\text { Val } \\
\text { Norn }\end{array}$ & $\begin{array}{l}\text { da } \\
\text { ação }\end{array}$ \\
\hline 1 & \multicolumn{2}{|l|}{ AUT $(0-6)$} & \multicolumn{2}{|c|}{$(*)$} \\
\hline 1 & \multicolumn{2}{|l|}{ SEXO $(1-2)$} & 0,1 & 0,9 \\
\hline 1 & $\begin{array}{l}\text { Situação Familiar } \\
\text { SF }(1-7)\end{array}$ & $\begin{array}{ll}\text { (1) Chefe } & \text { (2) Cônjuge } \\
\text { (3) Filho } & (4-7) \text { Outros }\end{array}$ & \multicolumn{2}{|c|}{$(*)$} \\
\hline 1 & \multicolumn{2}{|l|}{ IDADE $(4-90)$} & \multicolumn{2}{|c|}{$(*)$} \\
\hline 1 & $\begin{array}{l}\text { Grau de Instrução } \\
\text { do indivíduo } \\
\text { GI }(1-5)\end{array}$ & $\begin{array}{l}\text { (1) Analfabeto/4 } 4^{\mathrm{a}} \text { Serie Incompleta } \\
\text { (2) } 1^{\circ} \text { Grau Incompleto/4 } 4^{\mathrm{a}} \text { Serie Comp. } \\
\text { (3) } 1^{\mathrm{o}} \text { Grau Completo } \\
\text { (4) Colegial Concluído } \\
\text { (5) Superior Concluído }\end{array}$ & & \\
\hline 1 & \multicolumn{2}{|c|}{ Salário Médio Mensal - SMED (0 SM- 102,6 SM) } & \multicolumn{2}{|c|}{$(*)$} \\
\hline 1 & \multicolumn{2}{|l|}{$\mathbf{E S T}(0-1)$} & 0,1 & 0,9 \\
\hline 1 & \multicolumn{2}{|l|}{ TRAB $(0-1)$} & 0,1 & 0,9 \\
\hline
\end{tabular}

(*) Equação de normalização (6.1).

\section{b) Caracterização do padrão de duração de cada VEP}

Para a caracterização dos padrões de VEP foi realizada a codificação dos tempos de duração de cada viagem conforme definido no cap. 5, no item 5.4.1. Foram escolhidos como limites dos intervalos de duração: $\boldsymbol{a}=10 \mathrm{~min}$. e $\boldsymbol{b}=20 \mathrm{~min}$. As agregações das durações de cada viagem ficaram divididas em três intervalos: tempos de duração $(\boldsymbol{t})$ menores ou iguais a 10 min., código 1; maiores do que $10 \mathrm{~min}$. e menores que 20 min., código 2, e de duração superior a 20 min. código 3, como observado na Tabela 6.5.

Tabela 6.5: Codificação dos tempos de duração de cada viagem 


\begin{tabular}{c|c|cc|ccc|crcr}
\hline \multirow{2}{*}{$\begin{array}{c}\text { Tempos de } \\
\text { Duração de } \\
\text { Cada Viagem } \\
\text { (t) minutos }\end{array}$} & \multirow{2}{*}{ Código } & \multicolumn{2}{c|}{$\begin{array}{c}\text { Duas } \\
\text { Viagens }\end{array}$} & \multicolumn{3}{c|}{$\begin{array}{c}\text { Três } \\
\text { Viagens }\end{array}$} & \multicolumn{4}{c}{ Quatro Viagens } \\
\cline { 3 - 11 } & & $\mathbf{1}^{\text {a. }}$ & $\mathbf{2}^{\text {a. }}$ & $\mathbf{1}^{\text {a. }}$ & $\mathbf{2}^{\text {a. }}$ & $\mathbf{3}^{\text {a. }}$ & $\mathbf{1}^{\text {a. }}$ & $\mathbf{2}^{\text {a. }}$ & $\mathbf{3}^{\text {a. }}$ & $\mathbf{4}^{\text {a. }}$ \\
\hline $\boldsymbol{t}<=10$ & 1 & 9.642 & 8.990 & 123 & 147 & 105 & 1.401 & 1.375 & 1.419 & 1.353 \\
$10<\boldsymbol{t}<=20$ & 2 & 5.362 & 5.580 & 84 & 70 & 92 & 601 & 621 & 617 & 624 \\
$\boldsymbol{t}>20$ & 3 & 2.638 & 3.072 & 74 & 64 & 84 & 227 & 233 & 193 & 252 \\
\hline
\end{tabular}

Com esta codificação, são formados os padrões de duração dos tempos das VEP os quais representam o número de viagens realizadas -, a duração de cada viagem (em minutos), e, o modo de transporte utilizado, no caso a pé. Aplicando essa codificação para o conjunto de 20.152 indivíduos que fazem duas, três e quatro viagens encadeadas a pé, obtém-se a Tabela 6.6, dos padrões de duração das VEP. Na Tabela 6.6, pode-se observar que para duas viagens tem-se 9 padrões, com os quatro primeiros padrões (11, 22, 33, 12) representado 90,1\% da cadeia de duas VEP. Para três viagens obtém-se 27 padrões, observando-se uma dispersão na freqüência de indivíduos por padrão, e, se selecionados acima de 11 indivíduos por padrão, 65,1\% do grupo de três viagens pode ser representados por 9 padrões. Para quatro viagens obtêm-se 67 padrões, dos quais 16 padrões representam $86,7 \%$ do total das quatro VEP.

\section{c) Caracterização dos padrões das atividades por cada VEP}

Além da obtenção dos padrões por duração de cada VEP, como observado no item anterior, é necessário, para caracterização dos padrões de VEP, a codificação dos padrões de atividades por vetor de viagens. Como observado na Tabela 6.7, o código 1 corresponde à atividade Trabalho, a Estudo corresponde o código 2, e Outras Atividades, o código 3. Nesta Tabela pode ser observada a freqüência de cada atividade por vetor de viagens, o que permite definir os padrões de atividades respectivos por vetor. No caso de duas viagens o padrão estará representado por um código, para três viagens por dois códigos, e para quatro viagens também por dois códigos, pois a maioria da $2^{\text {a. }}$ atividade está motivada pelo retorno ao domicílio (99\%), e quantidade mínima para outras atividades. Com esses critérios são formados os padrões de atividades de VEP, representando a quantidade de viagens realizadas, o padrão de atividade de cada viagem e o modo de transporte utilizado, no caso a pé.

Tabela 6.6: Freqüência dos padrões de duração da viagem. 


\begin{tabular}{|c|c|c|c|c|c|c|c|c|}
\hline \multicolumn{2}{|c|}{$\begin{array}{c}\text { Padrões / } \\
\text { Duração } \\
\text { da Viagem }\end{array}$} & $\begin{array}{c}\text { Freq. } \\
\text { Ind. }\end{array}$ & $\begin{array}{c}\text { Freq. } \\
\text { Rel. } \\
(\%)\end{array}$ & $\begin{array}{c}\text { Freq. } \\
\text { Acum. } \\
(\%) \\
\end{array}$ & $\begin{array}{c}\text { Padrões / } \\
\text { Duração } \\
\text { da Viagem }\end{array}$ & $\begin{array}{c}\text { Freq. } \\
\text { Ind. }\end{array}$ & $\begin{array}{c}\text { Freq. } \\
\text { Rel. } \\
(\%)\end{array}$ & $\begin{array}{c}\text { Freq. } \\
\text { Acum. } \\
(\%)\end{array}$ \\
\hline \multirow{9}{*}{$\begin{array}{c}\text { Duas } \\
\text { Viagens }\end{array}$} & 11 & 8.433 & 47,8 & 47,8 & 2223 & 32 & 1,4 & 78,1 \\
\hline & 22 & 4.207 & 23,8 & 71,6 & \multirow{42}{*}{$\begin{array}{c}\text { Quatro } \\
\text { Viagens }\end{array}$} & 30 & 1,3 & 79,4 \\
\hline & 33 & 2.218 & 12,6 & 84,2 & & 29 & 1,3 & 80,7 \\
\hline & 12 & 1.032 & 5,8 & 90,1 & & 25 & 1,1 & 81,8 \\
\hline & 23 & 677 & 3,8 & 93,9 & & 24 & 1,1 & 82,9 \\
\hline & 21 & 478 & 2,7 & 96,6 & & 21 & 0,9 & 83,8 \\
\hline & 32 & 341 & 1,9 & 98,5 & & 21 & 0,9 & 84,8 \\
\hline & 13 & 177 & 1,0 & 99,6 & & 21 & 0,9 & 85,7 \\
\hline & 31 & 79 & 0,4 & 100,0 & & 21 & 0,9 & 86,7 \\
\hline \multirow{27}{*}{$\begin{array}{c}\text { Três } \\
\text { Viagens }\end{array}$} & 111 & 57 & 20,3 & 20,3 & & 19 & 0,85 & 87,5 \\
\hline & 333 & 24 & 8,5 & 28,8 & & 19 & 0,85 & 88,4 \\
\hline & 212 & 20 & 7,1 & 35,9 & & 17 & 0,76 & 89,1 \\
\hline & 112 & 19 & 6,8 & 42,7 & & 17 & 0,76 & 89,9 \\
\hline & 211 & 15 & 5,3 & 48,0 & & 16 & 0,72 & 90,6 \\
\hline & 122 & 13 & 4,6 & 52,7 & & 13 & 0,58 & 91,2 \\
\hline & 222 & 13 & 4,6 & 57,3 & & 12 & 0,54 & 91,8 \\
\hline & 113 & 11 & 3,9 & 61,2 & & 12 & 0,54 & 92,3 \\
\hline & 313 & 11 & 3,9 & 65,1 & & 11 & 0,49 & 92,8 \\
\hline & 221 & 9 & 3,2 & 68,3 & & 10 & 0,45 & 93,2 \\
\hline & 233 & 9 & 3,2 & 71,5 & & 10 & 0,45 & 93,7 \\
\hline & 322 & 8 & 2,8 & 74,4 & & 10 & 0,45 & 94,1 \\
\hline & 323 & 8 & 2,8 & 77,2 & & 9 & 0,40 & 94,5 \\
\hline & 121 & 7 & 2,5 & 79,7 & & 9 & 0,40 & 94,9 \\
\hline & 133 & 7 & 2,5 & 82,2 & & 8 & 0,36 & 95,3 \\
\hline & 213 & 7 & 2,5 & 84,7 & & 7 & 0,31 & 95,6 \\
\hline & 332 & 6 & 2,1 & 86,8 & & 7 & 0,31 & 95,2 \\
\hline & 232 & 5 & 1,8 & 88,6 & & 7 & 0,31 & 96,2 \\
\hline & 321 & 5 & 1,8 & 90,4 & & 7 & 0,31 & 96,6 \\
\hline & 331 & 5 & 1,8 & 92,2 & & 6 & 0,27 & 96,8 \\
\hline & 123 & 4 & 1,4 & 93,6 & & 6 & 0,27 & 97,1 \\
\hline & 132 & 4 & 1,4 & 95,0 & & 5 & 0,22 & 97,3 \\
\hline & 312 & 4 & 1,4 & 96,4 & & 4 & 0,18 & 97,5 \\
\hline & 223 & 3 & 1,1 & 97,5 & & 4 & 0,18 & 97,7 \\
\hline & 231 & 3 & 1,1 & 98,6 & & 4 & 0,18 & 97,8 \\
\hline & 311 & 3 & 1,1 & 99,6 & & 3 & 0,13 & 97,9 \\
\hline & 131 & 1 & 0,4 & 100,0 & & 3 & 0,13 & 98,1 \\
\hline \multirow{7}{*}{$\begin{array}{l}\text { Quatro } \\
\text { Viagens }\end{array}$} & 1111 & 1.090 & 48,9 & 48,9 & & 3 & 0,13 & 98,3 \\
\hline & 2222 & 295 & 13,2 & 62,1 & & 3 & 0,13 & 98,4 \\
\hline & 1122 & 89 & 4,0 & 66,1 & & 3 & 0,13 & 98,5 \\
\hline & 3333 & 82 & 3,7 & 69,8 & & 3 & 0,13 & 98,6 \\
\hline & 2211 & 75 & 3,4 & 73,2 & & 2 & 0,09 & 98,7 \\
\hline & 1112 & 44 & 2,0 & 75,1 & & 2 & 0,09 & 98,8 \\
\hline & 1211 & 33 & 1,5 & 76,6 & & 26 & 1,20 & 100,0 \\
\hline
\end{tabular}

$\left(^{1}\right)$ Dezoito padrões com freqüência igual ou menor de dois indivíduos por padrão.

Tabela 6.7: Codificação das atividades por cada viagem 


\begin{tabular}{|c|c|c|c|c|c|c|c|c|c|c|c|c|}
\hline \multirow{3}{*}{ 胥 } & \multirow{3}{*}{ ○َ } & \multirow{2}{*}{\multicolumn{2}{|c|}{$\frac{\text { Duas Viagens }}{1^{\mathrm{a} \cdot}}$}} & \multicolumn{4}{|c|}{ Três Viagens } & \multicolumn{5}{|c|}{ Quatro Viagens } \\
\hline & & & & \multicolumn{2}{|c|}{$1^{\mathrm{a} \cdot}$} & \multicolumn{2}{|c|}{$2^{a \cdot}$} & \multicolumn{2}{|c|}{$1^{\mathrm{a} .}$} & \multirow{2}{*}{$\begin{array}{c}2^{\text {a. }} \\
\text { Freq } \\
\text { Absoluta }\end{array}$} & \multicolumn{2}{|c|}{$3^{a \cdot}$} \\
\hline & & $\begin{array}{c}\text { Freq } \\
\text { Absoluta }\end{array}$ & $\begin{array}{c}\text { Freq } \\
\%\end{array}$ & $\begin{array}{c}\text { Freq } \\
\text { Absolut }\end{array}$ & $\begin{array}{c}\text { Freq } \\
\%\end{array}$ & $\begin{array}{c}\text { Freq } \\
\text { Absoluta }\end{array}$ & $\begin{array}{c}\text { Freq } \\
\%\end{array}$ & $\begin{array}{c}\text { Freq } \\
\text { Absoluta }\end{array}$ & $\begin{array}{c}\text { Freq } \\
\%\end{array}$ & & $\begin{array}{c}\text { Freq } \\
\text { Absoluta }\end{array}$ & $\begin{array}{c}\text { Freq } \\
\%\end{array}$ \\
\hline $\mathbf{W}$ & 1 & 3.751 & 21,3 & 75 & 26,7 & 19 & 6,7 & 1.285 & 57,7 & $(*)$ & 1.050 & 47,1 \\
\hline $\mathbf{S}$ & 2 & 12.148 & 68,8 & 83 & 29,5 & 71 & 25,3 & 745 & 33,4 & $(*)$ & 867 & 38,9 \\
\hline $\mathbf{A}$ & 3 & 1.743 & 9,9 & 123 & 43,8 & 191 & 68,0 & 199 & 8,9 & 25 & 312 & 14,4 \\
\hline
\end{tabular}

$\left(^{*}\right)$ O motivo da $2^{\text {a. }}$ atividade destino é o domicílio.

Aplicando essa codificação para o conjunto de 20.152 indivíduos que fazem, duas, três e quatro viagens encadeadas a pé, obtém-se a Tabela 6.8, dos padrões de atividades das VEP. Na Tabela 6.8, pode-se observar que para duas viagens tem-se 3 padrões, com os padrões 2 (S) e 1 (W) representado 90,1\% da cadeia de duas VEP. Para três viagens obtém-se 9 padrões, observando-se que os padrões 33 (AA), 23 (SA) e 13 (WA) representam 68,0\% dos padrões de atividades da cadeia de três VEP. Para quatro viagens obtêm-se 9 padrões, dos quais os padrões 11 (WW), 22 (SS), 12 (WS), 23 (SA) e 33 (AA) representam 90,7\% do total das VEP.

Tabela 6.8: Padrões das atividades por viagem.

\begin{tabular}{|c|c|c|c|c|c|c|c|c|c|}
\hline \multicolumn{2}{|c|}{$\begin{array}{c}\text { Padrões / } \\
\text { Atividade/ } \\
\text { Viagem }\end{array}$} & $\begin{array}{c}\text { Freq. } \\
\text { Absoluta }\end{array}$ & $\begin{array}{c}\text { Freq. } \\
\text { Rel. } \\
(\%)\end{array}$ & $\begin{array}{c}\text { Freq. } \\
\text { Acum. } \\
(\%)\end{array}$ & \multicolumn{2}{|c|}{$\begin{array}{c}\text { Padrões / } \\
\text { Atividade/ } \\
\text { Viagem }\end{array}$} & $\begin{array}{c}\text { Freq. } \\
\text { Absoluta }\end{array}$ & $\begin{array}{c}\text { Freq. } \\
\text { Rel. } \\
(\%)\end{array}$ & $\begin{array}{c}\text { Freq. } \\
\text { Acum. } \\
(\%) \\
\end{array}$ \\
\hline \multirow{3}{*}{$\begin{array}{c}\text { Duas } \\
\text { Viagens }\end{array}$} & 2 & 12.148 & 68,9 & 68,9 & \multirow{12}{*}{$\begin{array}{c}\text { Quatro } \\
\text { Viagens }\end{array}$} & 11 & 974 & 43,7 & 43,7 \\
\hline & 1 & 3.751 & 21,3 & 90,1 & & 22 & 561 & 25,2 & 68,9 \\
\hline & 3 & 1.743 & 9,9 & 100,0 & & 12 & 243 & 10,9 & 79,8 \\
\hline \multirow{9}{*}{$\begin{array}{c}\text { Três } \\
\text { Viagens }\end{array}$} & 33 & 107 & 38,1 & 38,1 & & 23 & 129 & 5,8 & 85,6 \\
\hline & 23 & 46 & 16,4 & 54,4 & & 33 & 115 & 5,2 & 90,7 \\
\hline & 13 & 38 & 13,5 & 68,0 & & 13 & 68 & 3,1 & 93,8 \\
\hline & 22 & 29 & 10,3 & 78,3 & & 32 & 63 & 2,8 & 96,6 \\
\hline & 12 & 28 & 10,0 & 88,3 & & 21 & 55 & 2,5 & 99,1 \\
\hline & 32 & 14 & 5,0 & 93,2 & & 31 & 21 & 0,9 & 100,0 \\
\hline & 11 & 9 & 3,2 & 96,4 & & - & - & - & - \\
\hline & 21 & 8 & 2,8 & 99,3 & & - & - & - & - \\
\hline & 31 & 2 & 0,7 & 100,0 & & - & - & - & - \\
\hline
\end{tabular}


Aplicando as codificações de duração de cada viagem e das atividades ao conjunto de 20.152 indivíduos que fazem, duas, três e quatro VEP, gera-se a Tabela 6.9, com os padrões de VEP baseado em atividades. Nesta Tabela 6.9 e nos exemplos da Figura 6.8, nota-se, para todos os vetores, que os padrões estão constituídos por seis dígitos, correspondendo os quatro primeiros à duração de viagem (duração da primeira viagem - Dur_1 ${ }^{\mathbf{a}}$, duração da segunda viagem - Dur_ $\mathbf{2}^{\mathbf{a}}$, duração da terceira viagem Dur_3 $3^{\mathrm{a}}$, duração da quarta viagem - Dur_4 $4^{\mathrm{a}}$ ), e os dois últimos à atividade (primeira atividade - At._1, segunda atividade - At._2). Assim, para o vetor de duas viagens, os dois primeiros são os códigos das durações das viagens e o quinto dígito o da atividade; para o vetor de três viagens, os três primeiros são os códigos das durações das viagens e os dois últimos das atividades; e, para quatro viagens os quatro primeiros códigos são os das durações de viagem e os dois últimos das atividades.

\begin{tabular}{|c|c|c|c|c|c|}
\hline (a) Duas viagens & \multicolumn{2}{|c|}{ (b) Três viagens } & \multicolumn{3}{|c|}{ (c) Quatro viagens } \\
\hline $2\left(\begin{array}{c}\mathbf{W} \\
i i\end{array}\right)_{\mathbf{H}}^{3}$ & 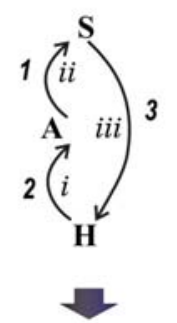 & 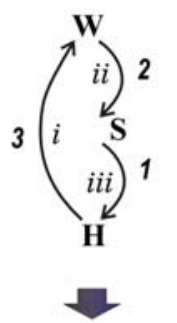 & r & 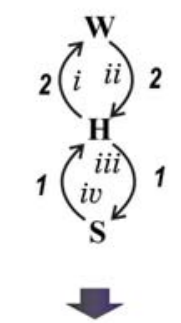 & \\
\hline $23 \mathrm{~W}$ & $213 \mathrm{AS}$ & $321 \mathrm{WS}$ & $1212 \mathrm{WW}$ & $2211 \mathrm{WS}$ & 约 \\
\hline$\theta$ & $v$ & E & e & v & \\
\hline 230010 & 213032 & 321012 & 121211 & 221112 & שू \\
\hline
\end{tabular}

Figura 6.8: Exemplos de padrões de VEP baseadas em atividades

Tabela 6.9: Padrões de VEP da duração de viagem e do tipo de atividade. 


\begin{tabular}{|c|c|c|c|c|c|c|c|c|c|}
\hline $\begin{array}{r}\mathrm{Pa} \\
\mathrm{Du} \\
\text { Viagem }\end{array}$ & $\begin{array}{l}\text { rões } \\
\text { ação } \\
\text { Atividade }\end{array}$ & $\begin{array}{c}\text { Freq. } \\
\text { Absoluta }\end{array}$ & $\begin{array}{c}\text { Freq. } \\
\text { Rel. } \\
(\%)\end{array}$ & $\begin{array}{c}\text { Freq. } \\
\text { Acum. } \\
(\%)\end{array}$ & $\begin{array}{r}\mathrm{Pa} \\
\mathrm{Du} \\
\text { Viagem }\end{array}$ & $\begin{array}{l}\text { Irões } \\
\text { ação } \\
\text { Atividade }\end{array}$ & $\begin{array}{c}\text { Freq. } \\
\text { Absoluta }\end{array}$ & $\begin{array}{c}\text { Freq. } \\
\text { Rel. } \\
(\%)\end{array}$ & $\begin{array}{c}\text { Freq. } \\
\text { Acum. } \\
(\%)\end{array}$ \\
\hline & 110020 & 6.460 & 36,6 & 36,6 & & 111111 & 666 & 29,9 & 29,9 \\
\hline & 220020 & 2.875 & 16,3 & 52,9 & & 111122 & 269 & 12,1 & 41,9 \\
\hline & 110010 & 1.449 & 8,2 & 61,1 & & 222211 & 131 & 5,9 & 47,8 \\
\hline & 330010 & 952 & 5,4 & 66,5 & & 222222 & 89 & 4,0 & 51,8 \\
\hline & 120020 & 838 & 4,8 & 71,3 & & 111112 & 55 & 2,5 & 54,3 \\
\hline & 220010 & 836 & 4,7 & 76,0 & & 222212 & 32 & 1,4 & 55,7 \\
\hline & 330020 & 799 & 4,5 & 80,5 & & 112212 & 30 & 1,3 & 57,1 \\
\hline & 110030 & 524 & 3,0 & 83,5 & & 111123 & 28 & 1,3 & 58,3 \\
\hline & 220030 & 496 & 2,8 & 86,3 & & 333311 & 27 & 1,2 & 59,5 \\
\hline & 330030 & 467 & 2,6 & 89,0 & & 221112 & 26 & 1,2 & 60,7 \\
\hline & 230020 & 393 & 2,2 & 91,2 & & 111133 & 24 & 1,1 & 61,8 \\
\hline & 210020 & 370 & 2,1 & 93,3 & & 112223 & 21 & 0,9 & 62,7 \\
\hline & 320020 & 239 & 1,4 & 94,6 & & 333322 & 19 & 0,9 & 63,6 \\
\hline $\begin{array}{c}\text { Duas } \\
\text { Viagens }\end{array}$ & 230010 & 196 & 1,1 & 95,8 & & 333333 & 18 & 0,8 & 64,4 \\
\hline & 120010 & 131 & 0,7 & 96,5 & & 222233 & 17 & 0,8 & 65,1 \\
\hline & 130020 & 120 & 0,7 & 97,2 & & 111121 & 16 & 0,7 & 65,9 \\
\hline & 230030 & 88 & 0,5 & 97,7 & & 111222 & 15 & 0,7 & 66,5 \\
\hline & 320010 & 65 & 0,4 & 98,1 & & 111132 & 14 & 0,6 & 67,2 \\
\hline & 210010 & 64 & 0,4 & 98,4 & & 331112 & 13 & 0,6 & 67,7 \\
\hline & 120030 & 63 & 0,4 & 98,8 & & 222322 & 12 & 0,5 & 68,3 \\
\hline & 310020 & 54 & 0,3 & 99,1 & & 221122 & 11 & 0,5 & 68,8 \\
\hline & 210030 & 44 & 0,2 & 99,3 & & 211111 & 11 & 0,5 & 69,3 \\
\hline & 130010 & 41 & 0,2 & 99,6 & & 112222 & 11 & 0,5 & 69,8 \\
\hline & 320030 & 37 & 0,2 & 99,8 & Ouatro & 111211 & 11 & 0,5 & 70,3 \\
\hline & 310010 & 17 & 0,1 & 99,9 & Viagens & 111113 & 11 & 0,5 & 70,7 \\
\hline & 130030 & 16 & 0,1 & 100,0 & & 322211 & 10 & 0,4 & 71,2 \\
\hline & 310030 & 8 & 0,0 & 100,0 & & 121122 & 10 & 0,4 & 71,6 \\
\hline & 333033 & 14 & 5,0 & 5,0 & & 333312 & 9 & 0,4 & 72,1 \\
\hline & 111033 & 14 & 5,0 & 10,0 & & 222223 & 9 & 0,4 & 72,5 \\
\hline & 111022 & 12 & 4,3 & 14,2 & & 221132 & 9 & 0,4 & 72,9 \\
\hline & 111023 & 9 & 3,2 & 17,4 & & 122211 & 9 & 0,4 & 73,3 \\
\hline & 111013 & 9 & 3,2 & 20,6 & & 121222 & 9 & 0,4 & 73,7 \\
\hline & 212033 & 8 & 2,8 & 23,5 & & 121123 & 9 & 0,4 & 74,1 \\
\hline & 111012 & 8 & 2,8 & 26,3 & & 332322 & 8 & 0,4 & 74,4 \\
\hline & 222033 & 7 & 2,5 & 28,8 & & 222311 & 8 & 0,4 & 74,8 \\
\hline Três & 211033 & 7 & 2,5 & 31,3 & & 221222 & 8 & 0,4 & 75,1 \\
\hline Viagens & 322033 & 5 & 1,8 & 33,1 & & 221211 & 8 & 0,4 & 75,5 \\
\hline & 313033 & 5 & 1,8 & 34,9 & & 221121 & 8 & 0,4 & 75,9 \\
\hline & 221033 & 5 & 1,8 & 36,7 & & 212222 & 8 & 0,4 & 76,2 \\
\hline & 212013 & 5 & 1,8 & 38,4 & & 111311 & 8 & 0,4 & 76,6 \\
\hline & 211023 & 5 & 1,8 & 40,2 & & 223313 & 7 & 0,3 & 76,9 \\
\hline & 113033 & 5 & 1,8 & 42,0 & & 222213 & 7 & 0,3 & 77,2 \\
\hline & 112033 & 5 & 1,8 & 43,8 & & 121211 & 7 & 0,3 & 77,5 \\
\hline & 112023 & 4 & 1,4 & 45,2 & & 113323 & 7 & 0,3 & 77,8 \\
\hline & 333013 & 3 & 1,1 & 46,3 & & 112213 & 7 & 0,3 & 78,2 \\
\hline & Outros $^{2}$ & 151 & 53,7 & 100,0 & & Outros $^{3}$ & 487 & 21,8 & 100,0 \\
\hline
\end{tabular}

( $\left.{ }^{2}\right)$ Dezoito padrões com freqüệncia de no máximo três indivíduos por padrão.

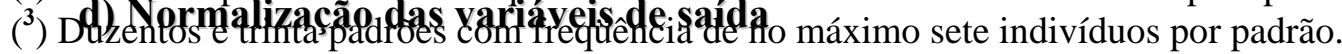


O método de normalização utilizada foi aplicado ao longo de um canal de normalização, utilizando-se a equação de transformação linear 6.1, para intervalos de normalização entre [0,1 e 0,9]. Com tais valores limites são normalizados os códigos das durações de viagens, e os códigos das atividades, conforme observado na Tabela 6.10, onde: o código $\mathbf{0}$ da variável de saída corresponde ao valor $\mathbf{0 , 1}$; o código $\mathbf{1}$ corresponde ao valor $\mathbf{0 , 3 5}$; o código 2 corresponde a $\mathbf{0 , 6 5}$; e, o código 3 corresponde ao valor 0,9. O vetor de viagens está constituído por seis neurônios.

Tabela 6.10: Normalização do vetor dos dados de saída

\begin{tabular}{c|c|c|c}
\hline $\begin{array}{c}\text { VETOR DE } \\
\text { VIAGENS }\end{array}$ & $\begin{array}{c}\text { Número de } \\
\text { Neurônios de Saída }\end{array}$ & $\begin{array}{c}\text { Código das } \\
\text { Variáveis de Saída }\end{array}$ & $\begin{array}{c}\text { Valores da } \\
\text { Normalização }\end{array}$ \\
\hline \multirow{2}{*}{$\begin{array}{c}\text { Duas, Três, Quatro } \\
\text { Viagens }\end{array}$} & \multirow{6}{*}{$\mathbf{0}$} & 0,1 \\
& & $\mathbf{1}$ & 0,35 \\
& & $\mathbf{3}$ & 0,65 \\
\hline
\end{tabular}

O vetor normalizado dos padrões de viagens encadeadas a pé, será obtido em função da codificação do padrão de saída por vetor de viagem. Por exemplo, em se tratando de três viagens, se o vetor codificado for 121012 (Dur_1 ${ }^{\mathbf{a}}$, menor ou igual a dez minutos; Dur_2 $\mathbf{2}^{\mathbf{a}}$, entre dez e vinte minutos; Dur_3 $\mathbf{3}^{\mathrm{a}}$, menor ou igual a dez minutos; At._1 igual a Trabalho; At._2 igual a Estudo), o padrão normalizado será:

\section{$\begin{array}{llllll}0,35 & 0,65 & 0,35 & 0,1 & 0,35 & 0,65\end{array}$}

\subsection{APLICAÇÃO DO MODELO NEURAL DE ENCADEAMENTO DE VIAGENS A PÉ}

Com base no item anterior, e do item 4.4.1 do cap. 4, formulação da arquitetura de Rede Neural do modelo, pode-se estabelecer a Estrutura do Modelo Neural de Encadeamento de Viagens para as condições dos dados da RMSP87, conforme apresentado na Figura 6.8. A estrutura do modelo mostra tanto os dados de entrada como os dados de saída a serem modelados pela Rede Neural Artificial, seja esta uma rede Estática como a MLP ou uma rede recorrente como a Elman. Tanto os vetores dos dados Socioeconômicos Individuais e Domiciliares $(\overrightarrow{C I}, \overrightarrow{C D})$, como os dados Espaciais 
$(\overrightarrow{A S}, \overrightarrow{A T})$ e dados dos padrões de VEP com as durações das viagens e os tipos de atividades, foram normalizados de forma a garantir que os potenciais de ativação da camada oculta se encontrem dentro da faixa de trabalho das funções de ativações dos seus neurônios, como foi explicado no item anterior.

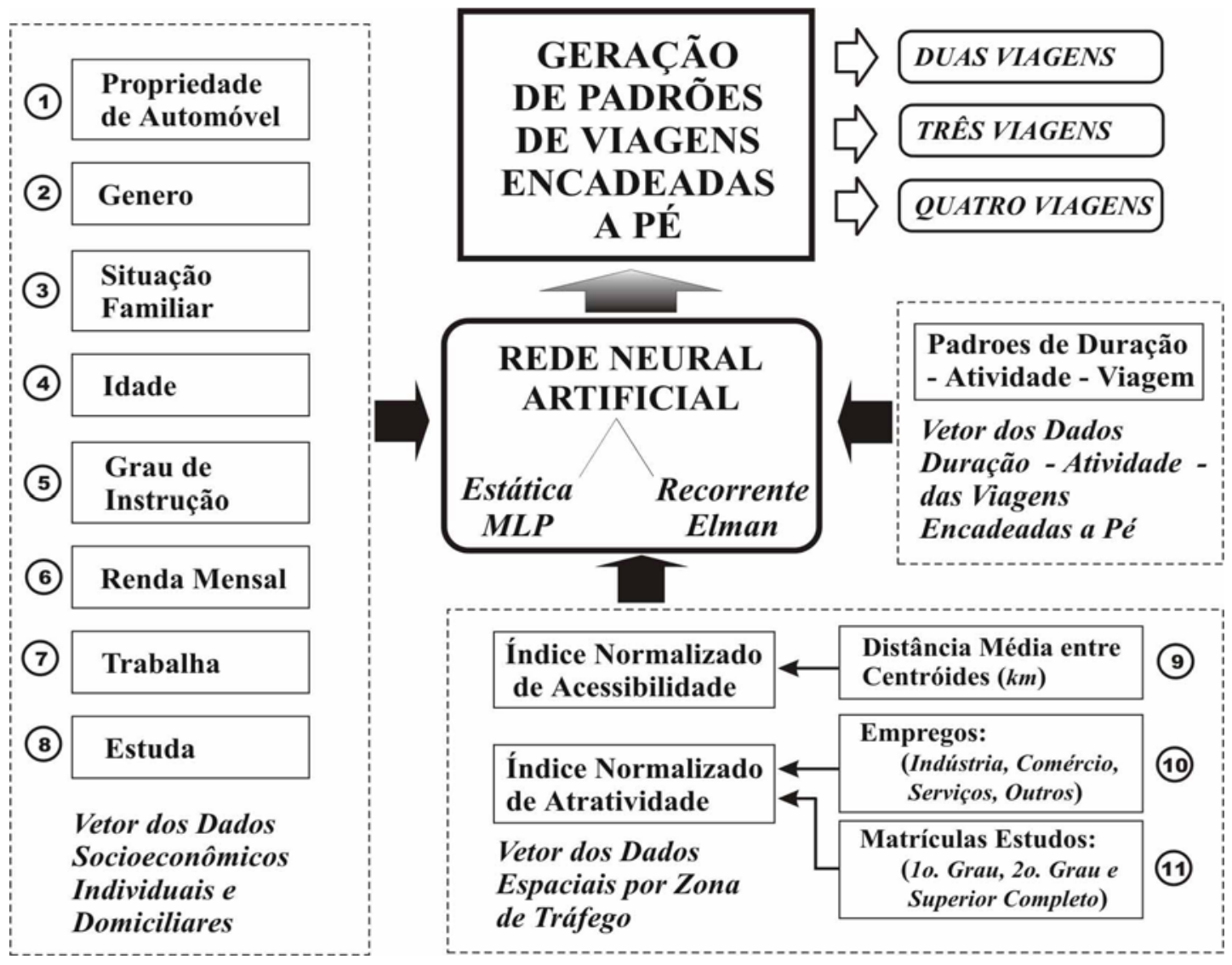

Figura 6.9: Estrutura do Modelo de Viagens Encadeadas a Pé - RMSP87

\subsubsection{Modelagem do Vetor dos Padrões de Duração e Tipo de Atividade das Viagens Encadeadas a Pé}

O modelo MONEVPE foi aplicado em forma individual para cada vetor de viagens, para duas, três e quatro viagens da RMSP87. Para avaliar o desempenho do Modelo em aplicações de previsão de viagens encadeadas, foram modeladas diversas configurações de Redes MLP e Redes Elman, para reproduzir os padrões de encadeamento de viagens. A seguir temos uma descrição. 
De acordo com o método de aplicação do modelo definido no cap. 5, foi elaborado um programa no MatLab, para modelagem das redes MLP e Elman. No programa, após a entrada do vetor de dados, de forma aleatória esses são divididos em três conjuntos. O primeiro é destinado para treinamento, o segundo para validação e o terceiro para teste, conforme pode ser observado no Apêndice. Para cada treinamento é realizada a seleção aleatória desses três conjuntos. Conseqüentemente, uma determinada arquitetura passa por cinco treinamentos independentes. Para cada treinamento é definida uma taxa de aprendizagem, que vai de 0,001 até 0,05. O simulador permite a observação direta das curvas de erro, o que possibilita interromper a modelagem nos casos em que as taxas não estejam sendo atingidas, e alterar a taxa. Das cinco arquiteturas, escolheu-se aquela que apresentou o melhor resultado.

No caso específico da presente modelagem, não foi necessário utilizar mais do que uma camada intermediária. Com isso são obtidas 10 arquiteturas de redes de tipologias diferentes, para cada vetor de viagens, e para diferentes valores do conjunto de treinamento, validação e teste. A denominação de cada rede é feita de acordo com o tipo de rede utilizada, e número de unidades na camada intermediária. Adicionalmente é agregada uma letra para diferenciar redes com o mesmo número de neurônios na camada intermediária, mas com parâmetros de simulação diferentes, isto é taxas de aprendizagem, número de iterações, etc. Por exemplo a denominação M6b significa que a rede utilizada é uma MLP com 6 unidades intermediárias. A denominação E3a representa a uma rede Elman com 3 neurônios na camada intermediária.

Após a modelagem, realizou-se a desnormalização dos conjuntos de teste dos valores observados e dos estimados pelo modelo. Esta desnormalização visa a obtenção das taxas de acerto em forma agregada e desagregada do conjunto de teste. Com isso, para cada rede, são obtidas a taxa de acerto geral dos PVE, a taxa de acerto da duração de viagem para cada segmento de viagem, a taxa de acerto para cada atividade em cada segmento de viagem, e a taxa de acerto por padrão de viagens encadeadas. Este processo foi aplicado tanto para a modelagem com redes MLP como com as redes Elman. Esses valores são apresentados no cap. 7 de Análise de Resultados. 
A forma como foram gerados os conjuntos de dados para cada vetor de viagens é apresentado a seguir.

\section{a) Aplicação do modelo para o Vetor de Duas Viagens.}

O vetor de duas viagens está constituído por 17.642 indivíduos, e conforme observado na Tabela 6.9, apresenta 26 padrões de VEP, sendo que os quatro primeiros padrões representam $70 \%$ do total. Para fins de aplicação do modelo, como indicado e definido no cap. do Método, uma amostra de 10\% foi retirada aleatoriamente do vetor de três viagens (1.800 indivíduos) com os seus respectivos atributos. Este novo vetor foi disposto no formato do MatLab, para entrada dos dados no programa, como indicado anteriormente. Na Figura 6.10, é apresentada a freqüência relativa de padrões de VEP para a amostra do vetor de duas viagens, na qual os padrões $11 \mathrm{~S}, \mathbf{2 2 S}, 11 \mathrm{~W}$ e $33 \mathrm{~W}$ representam 37,6\%, 16,2\%, 9,4\% e 5,0\% da amostra, respectivamente.

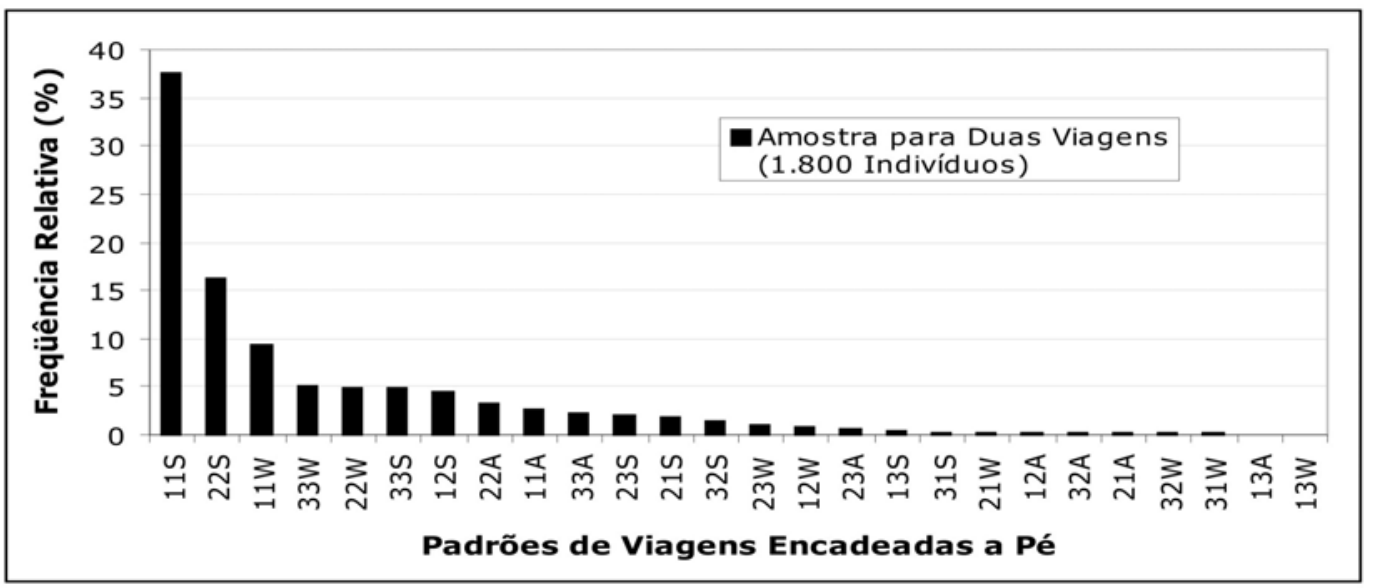

Figura 6.10: Freqüência relativa de padrões de VEP para a amostra de DUAS viagens

\section{b) Aplicação do modelo para o Vetor de Três Viagens.}

Este vetor está constituído por um conjunto de 281 indivíduos e 118 padrões de VEP, e não foi necessária a obtenção de uma amostra, pelo fato de o vetor ser de pouca quantidade. Como foi observado na Tabela 6.9, não existe uma preponderância de algum tipo de padrão. Na Figura 6.11 pode ser observada a distribuição da freqüência relativa de padrões de VEP. 


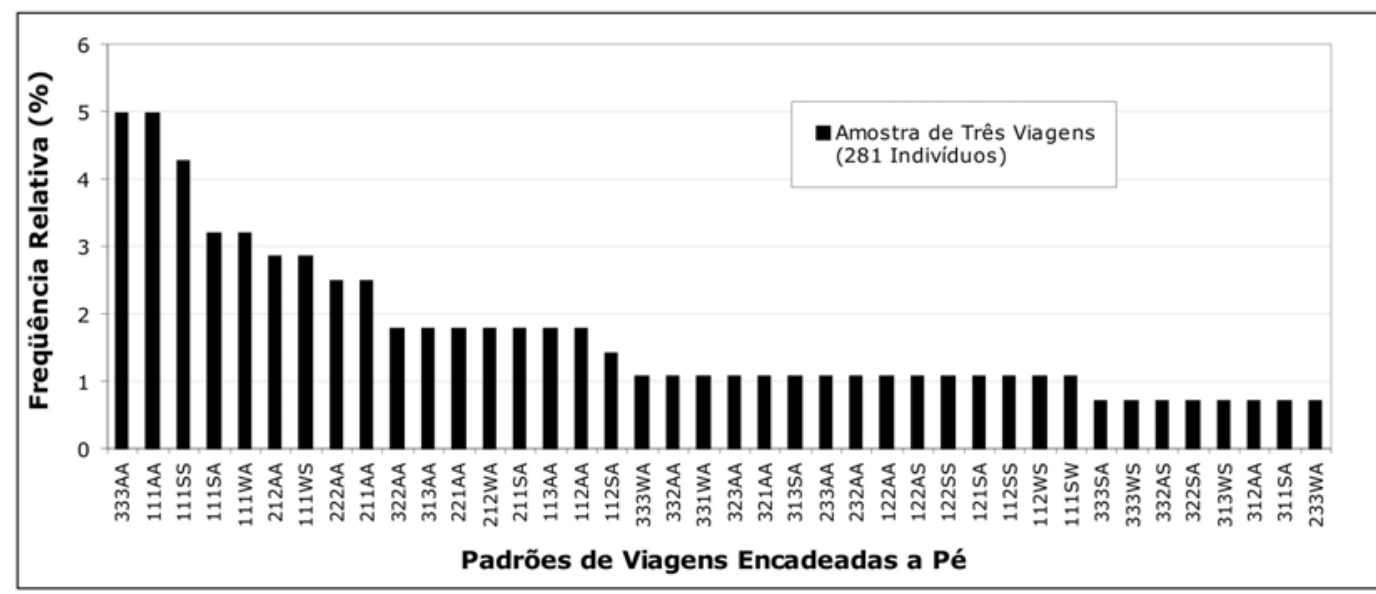

Figura 6.11: Freqüência relativa de padrões de VEP para a amostra de TRÊS viagens

\section{c) Aplicação do modelo para o Vetor de Quatro Viagens.}

O vetor de quatro viagens está constituído por 2.229 indivíduos, agrupados em 275 padrões de VEP. Como observado na Tabela 6.9, os 36 primeiros desses padrões, por ordem de freqüência de maior a menor, representam o $75 \%$ do comportamento dos dados do vetor de quatro viagens. Por esse motivo, para modelagem retirou-se uma amostra desses 36 padrões, obtendo-se um subconjunto para modelagem de 1.675 indivíduos, cuja freqüência por padrão pode ser observada na Figura 6.12. Esse novo vetor foi disposto no formato do simulador para modelagem das redes.

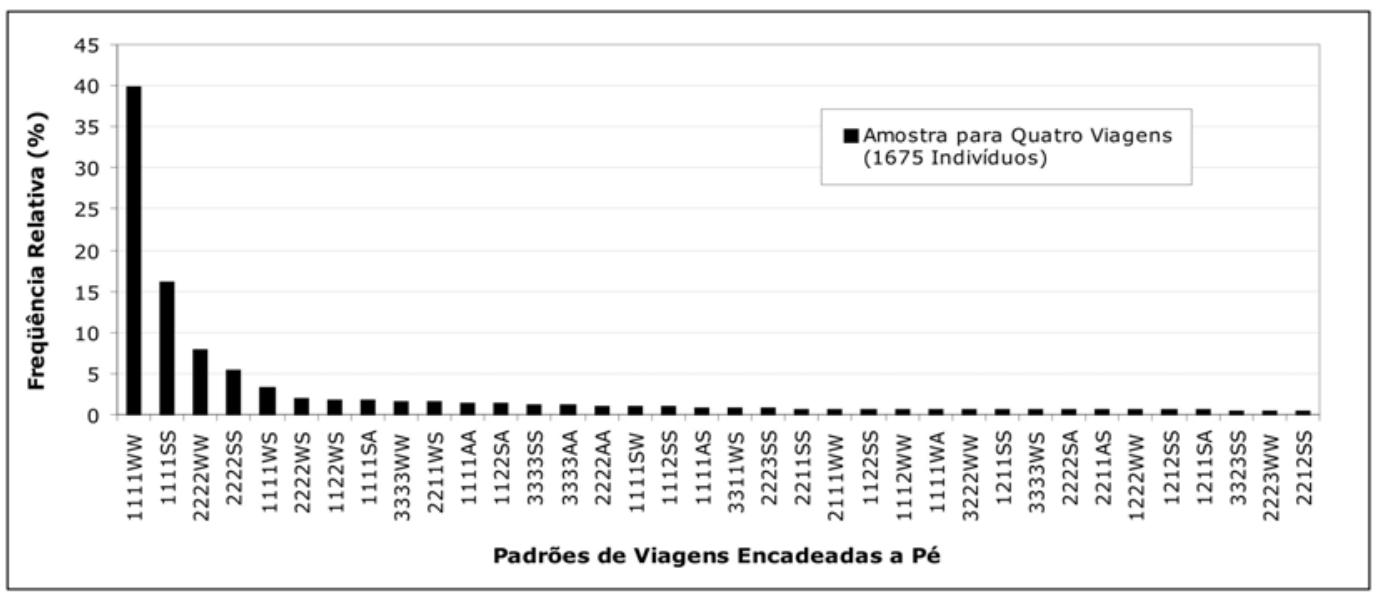

Figura 6.12: Freqüência relativa de padrões de VEP para a amostra de QUATRO viagens 


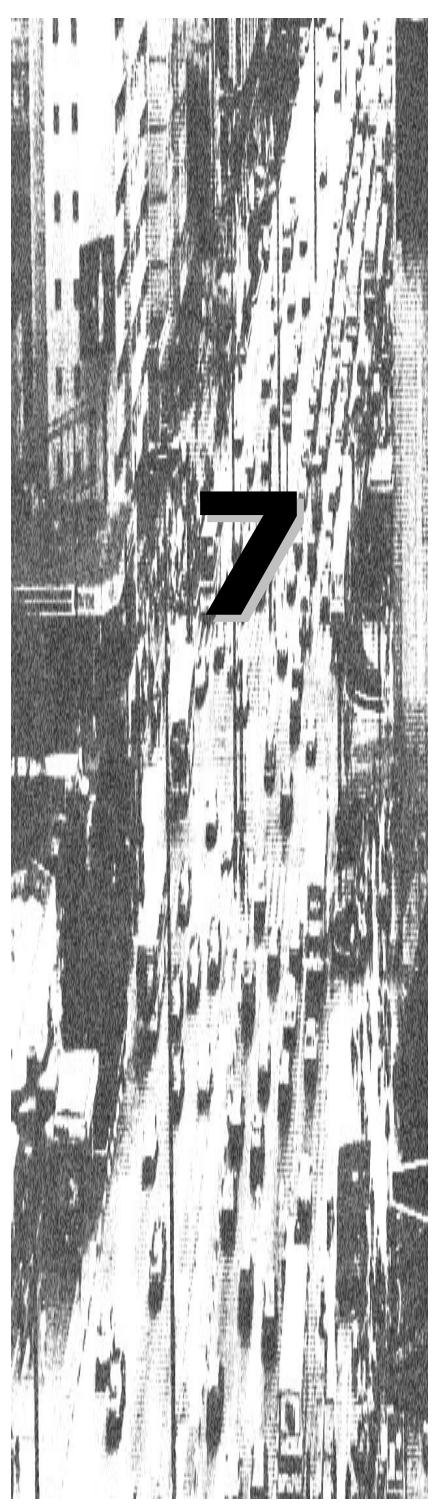

\section{Análise de resultados}

"Genius is 1 percent inspiration and 99 percent perspiration"

- Thomas Alva Edison -

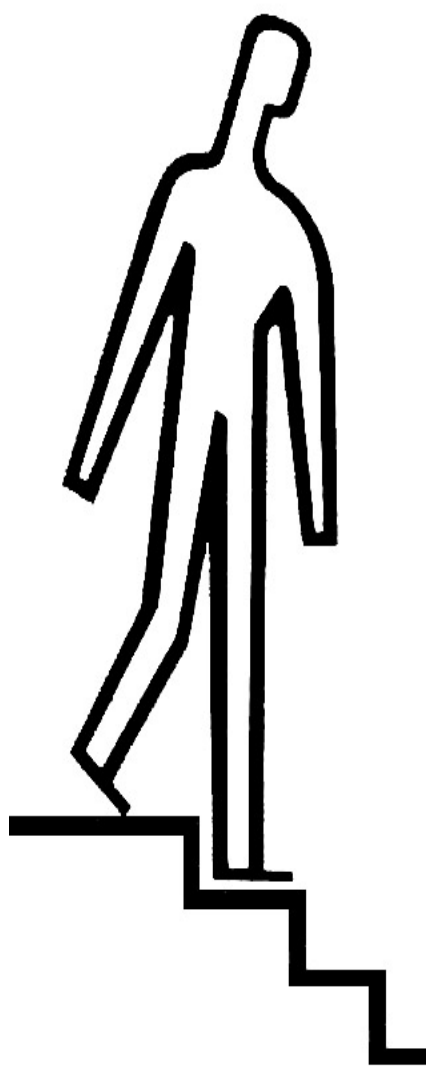




\section{ANÁLISE DE RESULTADOS}

\subsection{INTRODUÇÃO}

Neste capítulo é apresentada a análise dos resultados da modelagem de padrões de viagens encadeadas a pé (VEP) para as diversas simulações realizadas fazendo uso das redes neurais artificiais estáticas MLP e dinâmicas Elman. Nesta análise, os resultados são avaliados procurando verificar a viabilidade da aplicação das RNAs para representação dos aspectos temporais e espaciais do comportamento das VEP. Essa avaliação procura compreender o quanto e o que a rede está conseguindo reproduzir dos padrões de VEP, no que se refere aos padrões de maior representatividade na amostra, pois, de certa forma, esse conhecimento poderá servir as Políticas de Planejamento e Gerenciamento da Demanda por Transportes, considerando ainda que na RMSP, cerca de $53,7 \%$ das pessoas que possuem menores rendas realizam viagens a pé (PITOMBO, 2003).

Inicialmente, na seção 7.2 são definidos os critérios utilizados para esta análise de resultados da modelagem. Por meio desses critérios específicos e gerais, os "acertos" de classificação e erro quadrático médio dos padrões de VEP - do vetor de duas, três e quatro viagens - são analisados de forma geral na seção 7.3, e, posteriormente, de forma específica por cada vetor de viagens, nas seções 7.4, 7.5 e 7.6, respectivamente. As aspas na palavra acerto serão comentadas adiante. 


\subsection{CRITÉRIOS PARA ANÁLISE DE RESULTADOS}

Segundo a bibliografia pesquisada esta é a primeira experiência de modelagem de padrões de viagens encadeadas na área de análise da demanda de transportes baseada em atividades usando RNAs. Na literatura consultada não foi encontrada nenhuma abordagem que levasse em consideração as respostas na forma de padrões seqüenciados tal como adotada na presente modelagem. Tampouco foram encontrados critérios específicos de avaliação da eficiência das RNAs em reproduzir padrões de encadeamento de viagens a pé, embora existam medidas estatísticas de avaliação do desempenho de uma RNA em outras aplicações diversas. Por esta razão, para comparar os valores de classificação por tipo de rede e por tipo de padrão de encadeamento, foram usadas medidas de análise quantitativas e qualitativas.

Dentre as medidas de análise quantitativas está o cálculo do acerto da classificação $(A C)$ para cada predição, o acerto de classificação médio $(A C M)$ para o conjunto de predições, e o erro quadrático médio $(E Q M)$ para as mesmas condições de predição. Para determinar o $A C$ da rede foi utilizado o conjunto de teste da amostra após a simulação, calculando-se os acertos de classificação para cada simulação em função do número de padrões classificados corretamente no conjunto de teste. $\mathrm{O} A C M$ forneceu um valor expresso em porcentagem, o quanto às redes conseguem representar os valores alvo, enquanto o EQM indicou um valor absoluto do "erro" da previsão, penalizando erros maiores ao elevar ao quadrado a diferença entre o valor alvo e o valor previsto. A comparação qualitativa foi feita através de Gráficos contendo a freqüência dos padrões observados e a frequiência dos melhores resultados previstos em termos do ACM e EQM.

Para a análise dos padrões reproduzidos, foi selecionada a rede com melhor desempenho. O objetivo dessa seleção foi o de obter uma topologia de rede viável que fornecesse suporte para a análise dos resultados por ela gerados em termos de PVE reproduzidos. Para tal foram calculados o desvio padrão e os limites de acerto de classificação (mínimo e máximo) das topologias de redes, para nível de confiança de 95\%. A rede com melhor acerto de classificação foi selecionada dentro dos limites de acerto de classificação, com base em duas condições: $i$ ) que a rede possua um $A C$ o mais 
próximo possível do acerto de classificação médio $(A C M)$; e, $i i)$ que apresente o menor valor de $E Q M$.

Reforçando os critérios de análise, foram utilizadas informações das relações existentes entre padrões de viagens encadeadas e as características socioeconômicas associadas aos indivíduos que fazem VEP, segundo estudos realizados por Ichikawa (2002) e Pitombo (2003).

Além desses critérios específicos, existem critérios gerais estabelecidos na formulação do modelo MONEVPE no cap 4, e sua sistematização descritos no item 5.2 do cap. 5 que foram importantes para a avaliação do modelo, os quais são expostos a seguir:

a) As taxas de "acerto" na modelagem desagregada são menores que as obtidas na modelagem agregada (ORTÚZAR e WILLUMSEM, 1994). Esse fato pode ser explicado pelas diferenças no comportamento individual. Com isso o "acerto" a rigor não necessariamente expressa a performance da modelagem, mas pode ser considerada como uma medida que permita conhecer o que a rede está classificando adequadamente, e como o está classificando.

b) Indivíduos com características similares, nem sempre se comportam de formas similares com relação aos padrões reproduzidos de viagens encadeadas.

c) Por se tratar da representação de padrões de viagens encadeadas, compostos de diferentes aspectos, um melhor desempenho da RNA não garante necessariamente que a representação, em termos dos padrões reproduzidos, seja a mais adequada.

d) A natureza funcional da rede Elman permite representar associações entre estados consecutivos, é de se esperar que este tipo de rede reproduza melhor a seqüência das cadeias de padrões de VEP do que a rede MLP. 
e) Para avaliar a representação espacial das cadeias reproduzidas quanto à distância percorrida, adotou-se uma velocidade da caminhada de 4,5 km/h (WERMERSCH, 2002). Com isso, durações de viagens menores ou iguais a dez minutos (código 1) equivaleriam a deslocamentos iguais ou menores a $0,75 \mathrm{~km}$, durações entre dez e vinte minutos (código 2) equivaleriam a deslocamentos entre $0,75 \mathrm{~km}$ e $1,75 \mathrm{~km}$; e, durações acima de 20 min. (código 3) equivaleriam a deslocamentos superiores a 1,75 km.

\subsection{ANÁLISE DA MODELAGEM GERAL DAS VIAGENS ENCADEADAS}

Antes de começar a análise desta modelagem, é necessário lembrar que as variáveis de entrada no modelo foram agrupadas em dois vetores, totalizando onze variáveis. No primeiro, o Vetor dos Dados Socioeconômicos Individuais e Domiciliares, foram reunidos oito variáveis: (1) Número de automóveis; (2) Gênero; (3) Situação Familiar; (4) Idade; (5) Grau de Instrução; (6) Renda Média Mensal; (7) Trabalha; e, (8) Estuda. O segundo vetor foi formado pelo Vetor dos Dados Espaciais por Zona de Tráfego, com três variáveis: (1) Índice Normalizado de Distância Média entre ZT; (2) Índice Normalizado de Atratividade por Matrículas entre ZT; e, (3) Índice Normalizado de Atratividade por Empregos entre ZT. As variáveis de saída foram agrupadas no vetor de padrões de VEP da duração de viagem e do tipo de atividade para duas, três e quatro viagens, totalizando seis saídas.

A amostra utilizada para modelagem foi constituída de 3.756 indivíduos (a qual foi dividida em conjuntos de treinamento, validação e teste), e os dados foram agrupados em 180 padrões de VEP, correspondendo 26 padrões ao vetor de duas viagens, 118 ao vetor de três, e 36 ao vetor de quatro viagens, padrões esses que em relação ao total de padrões da amostra representaram 14,4\%, 65,6\% e 20,0\%, e em relação ao total de indivíduos na amostra equivalem a 47,9\%, 7,5\% e 44,6\%, respectivamente.

Em geral, as redes Elman "acertaram" na classificação de 20 padrões de VEP, dos quais 6 correspondem a duas viagens, 2 a três, e, 12 a quatro viagens - correspondentes a $30,0 \%, 10,0 \%$ e $60,0 \%$ dos padrões corretamente classificados. As redes MLP 
acertaram na classificação de 26 padrões de VEP, dos quais 8 são de duas viagens, 4 de três, e 14 de quatro viagens, os que correspondem proporcionalmente a 30,8\%, 15,4\% e 53,8\% do total de padrões classificados pela rede MLP (Tabela 7.1).

Em se tratando de Planejamento dos Transportes, é observado que a definição de políticas gerais visam atingir o comportamento majoritário da população em relação aos sistemas de transportes, em contrapartida políticas específicas visam comportamentos específicos dos usuários do sistema. Com isso, a representação de padrões de viagens encadeadas que correspondam a comportamentos majoritários, subvencionará instrumentos que poderiam ser utilizados na definição dessas linhas de políticas. Perante isso, a avaliação da representatividade dos padrões que as redes reproduziram, determinou que os cinco padrões com maior freqüência $(11 S, 22 S, 22 \mathrm{~W}, 1111 \mathrm{WW}$, 1111SS) representam em média o 58,9\% dos indivíduos da amostra de teste (tais valores estão remarcados em negrita na Tabela 7.1). Como observado, embora o acerto de classificação geral dos padrões não seja favorável em relação à frequiência de padrões modelados, apesar disso, a representatividade inerente de cada padrão resulta sendo de maior importância. Adicionalmente, esses padrões correspondem a cadeias simples com duração menor ou igual a dez minutos, ou entre dez e vinte minutos (com deslocamento máximo de 1,75 km.) e com atividade principal Estudo e Trabalho. Todavia, padrões com duração superior a 20 minutos (distâncias maiores a 1,75km) foram pouco reproduzidos, como por exemplo o padrão 3333AA (Tabela 7.1).

Ao comparar a proporção dos padrões classificados da rede MLP e Elman, observa-se que os padrões de quatro VEP são aproximadamente o dobro dos padrões de duas VEP, proporção observada também na amostra utilizada, como exposto no parágrafo anterior. Entretanto, a proporção para padrões de três VEP corretamente classificados (da rede MLP e Elman) mostra-se muito distante da proporção de padrões observada na amostra. Por outro lado, como pode ser observado na Tabela 7.1, a somatória da frequiência média de classificação dos padrões de VEP, para as redes MLP e Elman, correspondem a 72,6\% e 66,6\%, respectivamente. Esses valores mostram a existência de aproximadamente um $30 \%$ de padrões que a rede não estaria conseguindo reproduzir adequadamente. Assim, as comparações anteriores motivaram os seguintes 
questionamentos: i) quais padrões de VEP as redes não estariam conseguindo reproduzir?; e, ii) quais outros padrões a rede está reproduzindo? Esses questionamentos serão respondidos mais adiante na sub-seção de análise de resultados dos conjuntos de teste, das redes selecionadas como as de melhor desempenho.

Tabela 7.1: Acerto de classificação médio de padrões de VEP para as redes MLP e Elman

\begin{tabular}{|c|c|c|c|c|c|c|}
\hline \multirow{3}{*}{ Viagens } & \multicolumn{3}{|c|}{ Redes MLP } & \multicolumn{3}{|c|}{ Redes ELMAN } \\
\hline & \multicolumn{3}{|c|}{$\begin{array}{l}\text { Acerto de Classificação } \\
\text { Médio / padrão }\end{array}$} & \multicolumn{3}{|c|}{$\begin{array}{l}\text { Acerto de Classificação } \\
\text { Médio / padrão }\end{array}$} \\
\hline & Padrões & $\begin{array}{l}\text { Freq. } \\
\text { Rel. }\end{array}$ & $\begin{array}{c}\text { Freq. Rel. } \\
(\%)\end{array}$ & Padrões & $\begin{array}{l}\text { Freq. } \\
\text { Rel. }\end{array}$ & $\begin{array}{l}\text { Freq. Rel. } \\
\text { (\%) }\end{array}$ \\
\hline \multirow{8}{*}{ Duas } & $11 \mathrm{~S}$ & 85 & 20,2 & $11 \mathrm{~S}$ & 88 & 20,6 \\
\hline & $22 S$ & 13 & 3,1 & $22 S$ & 17 & 3,9 \\
\hline & $22 \mathrm{~W}$ & 10 & 2,4 & $22 \mathrm{~W}$ & 7 & 1,6 \\
\hline & $11 \mathrm{~W}$ & 4 & 1,0 & $11 W$ & 3 & 0,7 \\
\hline & $12 S$ & 4 & 0,9 & $12 S$ & 3 & 0,7 \\
\hline & $22 \mathrm{~A}$ & 1 & 0,3 & $22 \mathrm{~A}$ & 1 & 0,2 \\
\hline & $12 W$ & 1 & 0,2 & -- & -- & -- \\
\hline & $21 S$ & 1 & 0,2 & -- & -- & -- \\
\hline \multirow{4}{*}{ Três } & 212AA & 2 & 1,4 & 111SS & 1 & 2,0 \\
\hline & 222AA & 1 & 1,3 & 211AA & 1 & 1,5 \\
\hline & 212SA & 1 & 1,4 & -- & -- & -- \\
\hline & $111 W W$ & 1 & 2,3 & -- & -- & -- \\
\hline \multirow{14}{*}{ Quatro } & 1111WW & 116 & 29,5 & 1111WW & 119 & 29,3 \\
\hline & 1111SS & 15 & 3,7 & 1111Ss & 10 & 2,5 \\
\hline & 1111WS & 3 & 0,8 & 1111WS & 3 & 0,8 \\
\hline & 2222SS & 3 & 0,8 & $1112 S S$ & 2 & 0,5 \\
\hline & 2211WS & 2 & 0,5 & 2222SS & 2 & 0,4 \\
\hline & 1122WS & 2 & 0,5 & 1111SA & 2 & 0,4 \\
\hline & 1111SA & 2 & 0,5 & 2222WS & 1 & 0,3 \\
\hline & $1112 S S$ & 1 & 0,2 & $1122 S S$ & 1 & 0,3 \\
\hline & 2222AA & 1 & 0,2 & 1122WS & 1 & 0,3 \\
\hline & 1211SS & 1 & 0,3 & 2211WS & 1 & 0,2 \\
\hline & 2222WS & 1 & 0,2 & 2222AA & 1 & 0,2 \\
\hline & 3333AA & 1 & 0,2 & 1112WW & 1 & 0,2 \\
\hline & 2212SS & 1 & 0,2 & -- & -- & -- \\
\hline & 2222SA & 1 & 0,2 & -- & -- & -- \\
\hline \multicolumn{3}{|c|}{ Total (\%) } & 72,6 & Total (\%) & & 66,6 \\
\hline
\end{tabular}

Nas Tabelas 7.2 e 7.3 são apresentados: o acerto da classificação geral; o acerto da classificação por viagem; e, o EQM geral dos padrões de VEP para as dez topologias diferentes das redes simuladas MLP e Elman. Os resultados permitem afirmar que a 
rede MLP apresentou um melhor desempenho na classificação geral dos padrões de VEP quando comparada com a rede Elman, embora o acerto de classificação médio $(A C M)$ geral e por viagem sejam próximos para ambas as topologias de redes. $\mathrm{O} A C M$ da rede MLP foi de $28,9 \%$ com desvio padrão de $1,14 \%$, e para a rede Elman foi de $28,1 \%$ com desvio padrão de $1,05 \%$. Observa-se também que a rede M12f apresentou a maior freqüência de acerto de classificação $(31,2 \%)$ e o menor valor de $E Q M$ de 2,59. Entretanto, as freqüências de acerto de classificação para duas e quatro viagens não foram as melhores, pois, quando comparadas as de outras redes, constatou-se que eram menores. Quanto ao $A C M$ para as cadeias de viagens, é observado que tanto para a rede MLP quanto para a Elman, o $A C M$ para quatro viagens é maior do que para duas viagens, enquanto que para três viagens é pouco significativo. Uma provável explicação para essa ocorrência é que os indivíduos que fazem três VEP estão sujeitos a uma maior diversidade de padrões, pois, cada padrão é representado por poucos indivíduos. Isto será apreciado na análise do conjunto de teste que será desenvolvido a seguir.

Tabela 7.2: Acerto da classificação por topologia da rede MLP para padrões de VEP.

\begin{tabular}{|c|c|c|c|c|c|c|c|c|c|c|c|c|}
\hline \multirow{3}{*}{$\begin{array}{c}\text { Topologia } \\
\text { da } \\
\text { Rede } \\
\text { MLP }\end{array}$} & \multicolumn{3}{|c|}{$\begin{array}{c}\text { Partições da } \\
\text { Amostra }\end{array}$} & \multicolumn{8}{|c|}{ Acerto da Classificação Geral } & \multirow{3}{*}{ 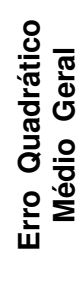 } \\
\hline & \multirow{2}{*}{ 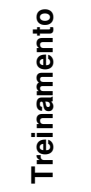 } & \multirow{2}{*}{ 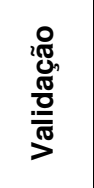 } & \multirow{2}{*}{ 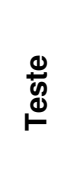 } & \multicolumn{2}{|c|}{$\begin{array}{c}\text { Acerto } \\
\text { Geral }\end{array}$} & \multicolumn{2}{|c|}{$\begin{array}{c}\text { Duas } \\
\text { Viagens }\end{array}$} & \multicolumn{2}{|c|}{$\begin{array}{c}\text { Três } \\
\text { Viagens }\end{array}$} & \multicolumn{2}{|c|}{$\begin{array}{l}\text { Quatro } \\
\text { Viagens }\end{array}$} & \\
\hline & & & & Freq & $\%$ & Freq & $\%$ & Freq & $\%$ & Freq & $\%$ & \\
\hline M6a & 1.878 & 939 & 939 & 268 & 28,5 & 103 & 11,0 & -- & -- & 165 & 17,6 & 2,739 \\
\hline M3b & 1.878 & 939 & 939 & 283 & 30,1 & 130 & 13,8 & -- & -- & 153 & 16,3 & 2,854 \\
\hline M6c & 1.878 & 939 & 939 & 264 & 28,1 & 126 & 13,4 & -- & -- & 138 & 14,7 & 2,961 \\
\hline M8d & 1.878 & 939 & 939 & 267 & 28,4 & 141 & 15,0 & 1 & 0,1 & 125 & 13,3 & 2,885 \\
\hline M6e & 1.978 & 1.039 & 739 & 206 & 27,9 & 99 & 13,4 & -- & -- & 107 & 14,5 & 2,884 \\
\hline M12f & 1.878 & 939 & 939 & 293 & 31,2 & 130 & 13,8 & 1 & 0,1 & 162 & 17,3 & 2,590 \\
\hline M12g & 1.878 & 939 & 939 & 274 & 29,2 & 132 & 14,1 & 1 & 0,1 & 141 & 15,0 & 2,735 \\
\hline M12h & 1.878 & 939 & 939 & 256 & 27,3 & 112 & 11,9 & 1 & 0,1 & 143 & 15,2 & 2,709 \\
\hline M12i & 1.978 & 1.039 & 739 & 215 & 29,1 & 99 & 13,4 & -- & -- & 116 & 15,7 & 2,824 \\
\hline M6k & 1.978 & 1.039 & 739 & 213 & 28,8 & 94 & 12,7 & 1 & 0,1 & 118 & 16,0 & 2,899 \\
\hline \multicolumn{4}{|c|}{ Acerto de Classificação Médio } & & 28,9 & & 13,3 & & 0,1 & & 15,5 & 2,808 \\
\hline
\end{tabular}


Tabela 7.3: Acerto da classificação por topologia da rede Elman para padrões de VEP.

\begin{tabular}{|c|c|c|c|c|c|c|c|c|c|c|c|c|}
\hline \multirow{3}{*}{$\begin{array}{c}\text { Topologia } \\
\text { da } \\
\text { Rede } \\
\text { ELMAN }\end{array}$} & \multicolumn{3}{|c|}{$\begin{array}{c}\text { Partições da } \\
\text { Amostra }\end{array}$} & \multicolumn{8}{|c|}{ Acerto da Classificação Geral } & \multirow{3}{*}{ 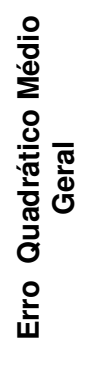 } \\
\hline & \multirow{2}{*}{ 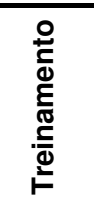 } & \multirow{2}{*}{ 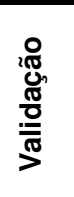 } & \multirow{2}{*}{$\underset{\stackrel{\Phi}{\Phi}}{\stackrel{\Phi}{-}}$} & \multicolumn{2}{|c|}{$\begin{array}{c}\text { Acerto } \\
\text { Geral }\end{array}$} & \multicolumn{2}{|c|}{$\begin{array}{c}\text { Duas } \\
\text { Viagens }\end{array}$} & \multicolumn{2}{|c|}{$\begin{array}{c}\text { Três } \\
\text { Viagens }\end{array}$} & \multicolumn{2}{|c|}{$\begin{array}{l}\text { Quatro } \\
\text { Viagens }\end{array}$} & \\
\hline & & & & Freq & $\%$ & Freq & $\%$ & Freq & $\%$ & Freq & $\%$ & \\
\hline E3a & 1.878 & 939 & 939 & 275 & 29,3 & 126 & 13,4 & -- & -- & 149 & 15,9 & 3,011 \\
\hline E3b & 1.878 & 939 & 939 & 269 & 28,6 & 121 & 12,9 & -- & -- & 148 & 15,8 & 3,030 \\
\hline E3c & 1.878 & 939 & 939 & 255 & 27,2 & 101 & 10,8 & -- & -- & 154 & 16,4 & 3,065 \\
\hline E3d & 1.878 & 939 & 939 & 277 & 29,5 & 128 & 13,6 & -- & -- & 149 & 15,9 & 3,004 \\
\hline E3e & 2.078 & 939 & 739 & 205 & 27,7 & 93 & 12,6 & -- & -- & 112 & 15,2 & 3,030 \\
\hline E6f & 2.078 & 939 & 739 & 201 & 27,2 & 104 & 14,1 & 1 & 0,1 & 96 & 13,0 & 2,792 \\
\hline E3g & 1.878 & 939 & 939 & 275 & 29,3 & 145 & 15,4 & -- & -- & 130 & 13,8 & 2,958 \\
\hline E6h & 1.878 & 939 & 939 & 265 & 28,2 & 135 & 14,4 & -- & -- & 130 & 13,8 & 3,155 \\
\hline E9i & 1.878 & 939 & 939 & 251 & 26,7 & 108 & 11,5 & -- & -- & 143 & 15,2 & 2,953 \\
\hline E6k & 2.178 & 939 & 639 & 254 & 27,1 & 114 & 12,1 & 1 & 0,1 & 139 & 14,8 & 3,028 \\
\hline Acerto de & assifi & ção & édio & & 28,1 & & 13,0 & & 0,1 & & 15,0 & 3,003 \\
\hline
\end{tabular}

Para escolher a rede de melhor desempenho, foi aplicado o critério estabelecido no item 7.2, determinando-se que o intervalo de confiança para a rede MLP está entre $28,2 \%$ e $29,6 \%$, e, para a rede Elman, entre $27,4 \%$ e $28,8 \%$. Nesses intervalos foram escolhidas duas redes: a rede $\mathbf{M 1 2 g}$ com $A C=29,2 \%$ e $E Q M=2,735$, e a rede $\mathbf{E 3 b}$ com $A C=28,6 \%$ e $E Q M=3,03$, cujos valores são remarcados em negrito nas Tabelas $7.2 \mathrm{e}$ 7.3, respectivamente. Para essas redes selecionadas, foi realizada a análise dos resultados dos conjuntos de teste após a simulação, como é apresentado a seguir.

\subsubsection{Análise dos Resultados dos Conjuntos de Teste das Redes M12g e E3b}

Nesta seção serão respondidos os questionamentos levantados parágrafos acima. Para isso, a análise para cada rede - M12g e E3b - foi realizada em função da freqüência relativa de classificação de padrões observados e padrões previstos pela rede, utilizando-se para isso o conjunto da amostra de teste de 939 indivíduos, obtido após a simulação. 


\section{a) Rede M12g}

$\mathrm{Na}$ Figura 7.1, mostra-se a distribuição dos padrões de viagens encadeadas reproduzidos da rede $\mathbf{M 1 2 g}$ em termos de freqüência relativa de classificação. No conjunto de teste foram observados 105 padrões de VEP, sendo que a rede acerta na classificação de 14 padrões de VEP (29,2\% dos padrões da amostra) equivalente a 274 indivíduos, e 89 padrões são previstos incorretamente sendo equivalentes a 665 indivíduos. Desses padrões classificados incorretamente, 33 são iguais a padrões observados na amostra, equivalentes a 472 indivíduos (50,3\%); e, 48 padrões (20,5\%) são diferentes aos observados no conjunto de teste (equivalentes a 193 indivíduos).

Ao observar a freqüência dos padrões na Figura 7.1, por exemplo do padrão 1111WW a freqüência observada foi de 18,3\% (172 indivíduos), e do padrão previsto foi 12,6\% (118 indivíduos). Já no caso do padrão $\mathbf{1 1 S}$ a frequiência observada foi de 17,9\% (168 indivíduos), enquanto que a prevista foi de 10,4\% (98 indivíduos). Constata-se também que os padrões observados 1111WW, 11S, 22S, 1111SS e 11W são os padrões mais representativos da amostra de teste $(55,6 \%$ da amostra de teste), enquanto que os correspondentes padrões previstos representam 26,5\%. Isso mostra claramente que esses padrões estão perdendo classificação para outros padrões, como corroborado no observado na Figura 7.1.

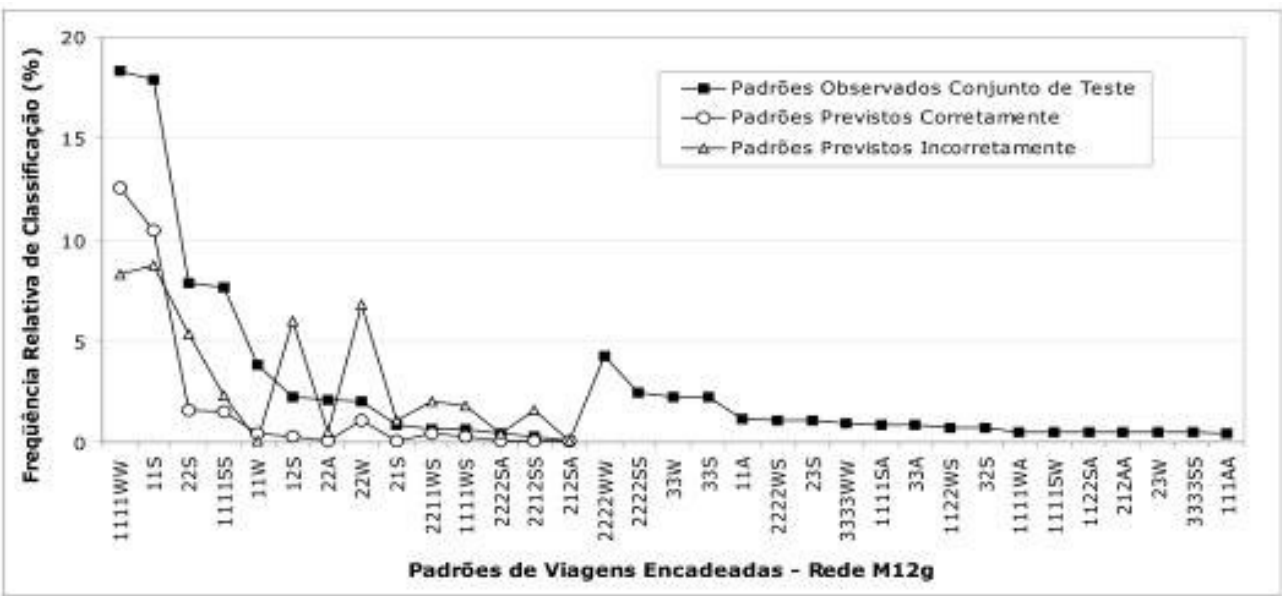

Figura 7.1: Classificação dos padrões observados e previstos de viagens encadeadas do conjunto de teste da rede M12g. 
Como foi analisado anteriormente, embora a rede $\mathbf{M 1 2 g}$ tenha reproduzido vários dos padrões observados, existem outros padrões que não foram adequadamente classificados, os que somados representam um $70,8 \%$ de erro na classificação dos padrões reproduzidos pela rede. Por outro lado, na Figura 7.1 pode ser observado que padrões tais como 2222WW, 1111WW, 1111SS, 22S, 11S e 11W, apresentam freqüências de classificação abaixo do valor observado, e em outros como o 12S e 22W, as frequiências estão acima do observado. Assim, foi realizada uma segmentação da amostra de teste para determinar quais padrões a rede reproduziu em lugar daqueles que perderam classificação, e quais outros não foram reproduzidos pela rede M12g (não obstante tenham sido observados). Para isso dividimos a análise por tipo de viagens:

i) Primeiramente foram selecionados do conjunto de teste os padrões com freqüência de classificação acima de 1,0\% que perderam classificação para outros padrões. Para a rede M12g, constatou-se que:

- Padrões de duas viagens: padrões com segmento da duração de viagem menores ou iguais a $20 \mathrm{~min}$. (deslocamentos inferiores a 1,75 km.) e com atividade Estudo, foram reproduzidos pela rede como padrões com igual atividade, e com algum dos segmentos da duração de viagem diferentes do padrão observado. Por exemplo, para o padrão $22 \mathrm{~S}$ a rede reproduziu o padrão $\mathbf{1 1 S}$ com freqüência de 4,3\% (40 indivíduos); o padrão $11 \mathrm{~S}$ foi reproduzido como $12 \mathrm{~S}$ com freqüência de 3,4\%; o padrão $11 \mathrm{~S}$ foi reproduzido como $22 \mathrm{~S}$ com $2,6 \%$ de freqüência; para o padrão $22 \mathrm{~S}$ a rede reproduziu o padrão $\mathbf{1 2 S}$ com $1,3 \%$ de freqüência. Ainda que a atividade seja a mesma para todos esses padrões, a rede reproduz o mesmo tipo de padrão até com duas alternativas de classificação. Isso está estreitamente relacionado com as características dos indivíduos que fazem estes tipos de padrões. Em se tratando de viagens para escola e com durações menores a 20 min., é de supor que tais pessoas tenham um nível de instrução entre $1^{\circ}$ ou $2^{\circ}$ graus, na sua maioria morando nas proximidades da escola. As poucas diferenças entre esses indivíduos podem estar relacionas com o sexo, a idade, e o período em que se deslocam à escola. Essas diferenças poderiam explicar o comportamento na representação da rede. Como indicado por Pitombo (2003), crianças mais novas, em idade escolar, 
realizam viagens à escola durante o dia, já as mais velhas com o mesmo grau de instrução das mais novas preferem estudar no período da noite. Tais características dos indivíduos estariam determinando que a rede os classifique com até dois padrões parecidos. Outros padrões que a rede classificou de forma errada foram o $11 W$ e o $33 W$. Para ambos, a rede reproduz o padrão $22 \mathrm{~W}$ com freqüências de $2,1 \%$ e $1,6 \%$, respectivamente. Nesses padrões a rede estabeleceu algo parecido com um valor médio na duração de viagem, pois entre durações menores ou iguais a $10 \mathrm{~min}$. e superiores a $20 \mathrm{~min}$., a rede replicou durações entre 10 e $20 \mathrm{~min}$. Esse comportamento pode se dever a que os indivíduos que representam tais padrões exerçam profissões alternativas em que a localização do lugar de trabalho muda de um indivíduo para outro, gerando segmentos de duração de viagem diferentes.

- Padrões de três viagens: foi observado somente o padrão 111SS, para o qual a rede reproduz o padrão $\mathbf{1 1 S}$ com freqüência de $0,2 \%$. Neste caso particular, a rede não conseguiu reproduzir o padrão na sua totalidade, aproximando-o a um padrão de duas viagens.

- Padrões de quatro viagens: foi observado o padrão 2222WW para o qual a rede reproduz o padrão $1111 W W$ com freqüência de 2,9\%. Indivíduos que fazem viagens a pé na sua maioria possuem rendas baixas e geralmente desenvolvem suas atividades em diferentes lugares. Em vista disso, a representação da rede do padrão 1111WW não seria um erro de classificação, pelo fato do indivíduo ter mais flexibilidade quanto à escolha do lugar de trabalho, e como tal, da duração de viagem. Um outro padrão foi o $1111 \mathrm{WW}$ que a rede o replicou como $22 \mathrm{~W}$ com frequiência de $1,1 \%$, e o padrão $\mathbf{1 1 1 1 S S}$ reproduzido como $\mathbf{1 1 1 2 S S}$ com 1,0\% de freqüência. Nesse ultimo padrão o fato da rede não ter representado a duração da quarta viagem impossibilitou que fosse classificado corretamente.

O erro, em alguns dos padrões analisados anteriormente, a rigor não se trataria de um erro de classificação. $\mathrm{O}$ que a rede poderia estar representando é a probabilidade de indivíduos com as mesmas características fazerem escolhas de padrões com um mesmo tipo de atividade, mas com durações de viagens diversas, dado que as localizações do 
lugar de trabalho são diferentes. Para confirmar esta afirmação, foi realizada uma análise segmentada nos vetores dos Dados Socioeconômicos Individuais e Domiciliares e nos Dados Espaciais por Zona de Tráfego (Acessibilidade e Atratividade por Empregos e Matrículas), para os padrões 11S e 22S, por estarem apresentando um maior desbalanceamento entre a freqüência observada e a prevista.

Assim, foi realizada a segmentação do conjunto de dados da amostra do vetor de duas viagens (1800 indivíduos), caracterizando os indivíduos em dois conjuntos pela sua homogeneidade em relação ao padrão de viagens encadeadas $11 S$ e 22S. Nesses conjuntos foi codificada cada uma das variáveis socioeconômicas individuais e domiciliares e espaciais, obtendo-se um padrão socioeconômico espacial (PSE) representativo do indivíduo. Dois conjuntos foram gerados: o primeiro, do padrão 11S, constituído por 676 indivíduos e 371 padrões PSE; e o segundo, do padrão 22S, constituído por 291 indivíduos e 204 padrões PSE. Das curvas de frequiências relativas obtidas para os conjuntos $11 \mathrm{~S}$ e $\mathbf{2 2 S}$ em relação aos PSE, apresentados na Figura 7.2, foi observada a inexistência da diferença significativa nas características de ambos os conjuntos. Aliás, foram obtidos 100 PSE comuns a ambos os conjuntos, de onde resultou 200 indivíduos com as mesmas características socioeconômicas e espaciais que fizeram tanto o padrão $11 S$ como o $22 \mathrm{~S}$.

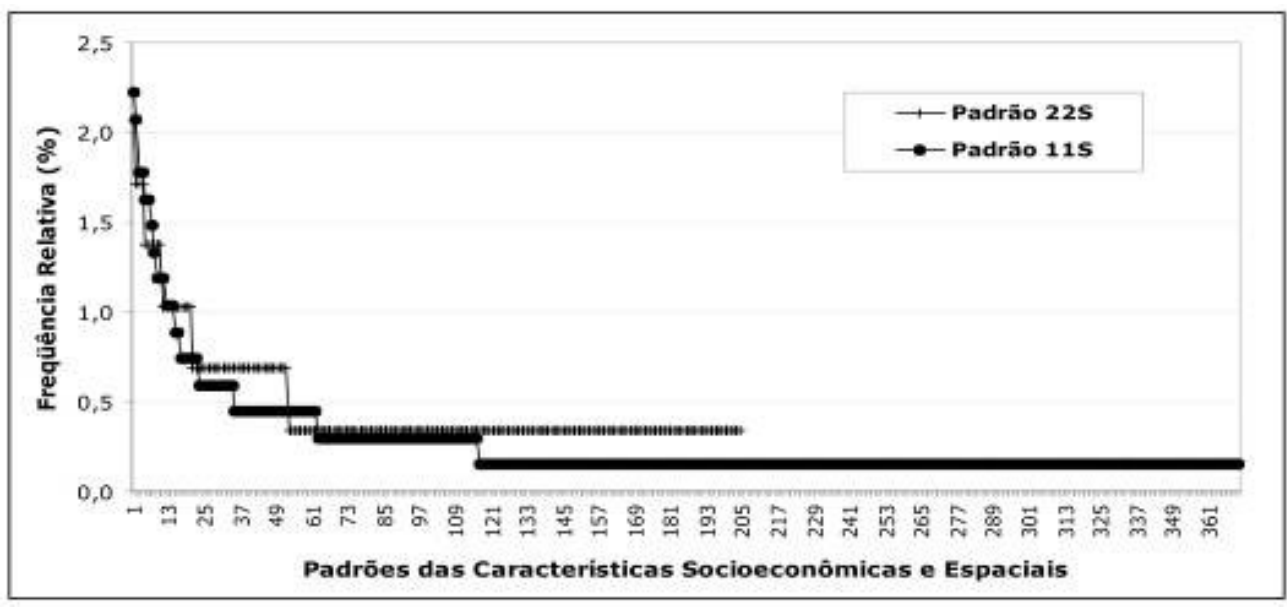

Figura 7.2: Frequiência relativa das características socioeconômicas e espaciais para o conjunto de indivíduos que fazem padrões de VEP 11S e 22S. 
Conseqüientemente, o acontecido na classificação dos padrões 11S e 22S tornou-se mais clara, mostrando que o desbalanceamento na classificação foi resultado da diversidade da escolha por parte dos indivíduos, não obstante estes pertençam a grupos homogêneos. Este fato também foi observado por Pitombo (2003), quem sugeriu que a existência da variação no comportamento do indivíduo, expressa em termos de diferenças na escolha de padrões de viagens é devido ao caráter probabilístico do comportamento e da observação feita em apenas um dia. Com tais resultados, é plenamente demonstrado que na realidade a rede não está errando, e sim representando a probabilidade de indivíduos de similares características fazerem padrões de encadeamento diferentes.

\section{b) Rede E3b}

Para a rede E3b, foram observados 105 padrões de VEP, a rede reproduz corretamente 9 padrões e replica incorretamente 68 padrões. Desses, somente 25 padrões são iguais aos padrões observados (476 indivíduos, ou 51,7\% do conjunto de teste). Na Figura 7.3, mostra-se a distribuição dos padrões de VEP observados, previstos corretamente e incorretamente pela rede $\mathbf{E 3 b}$, em termos de freqüência relativa de classificação.

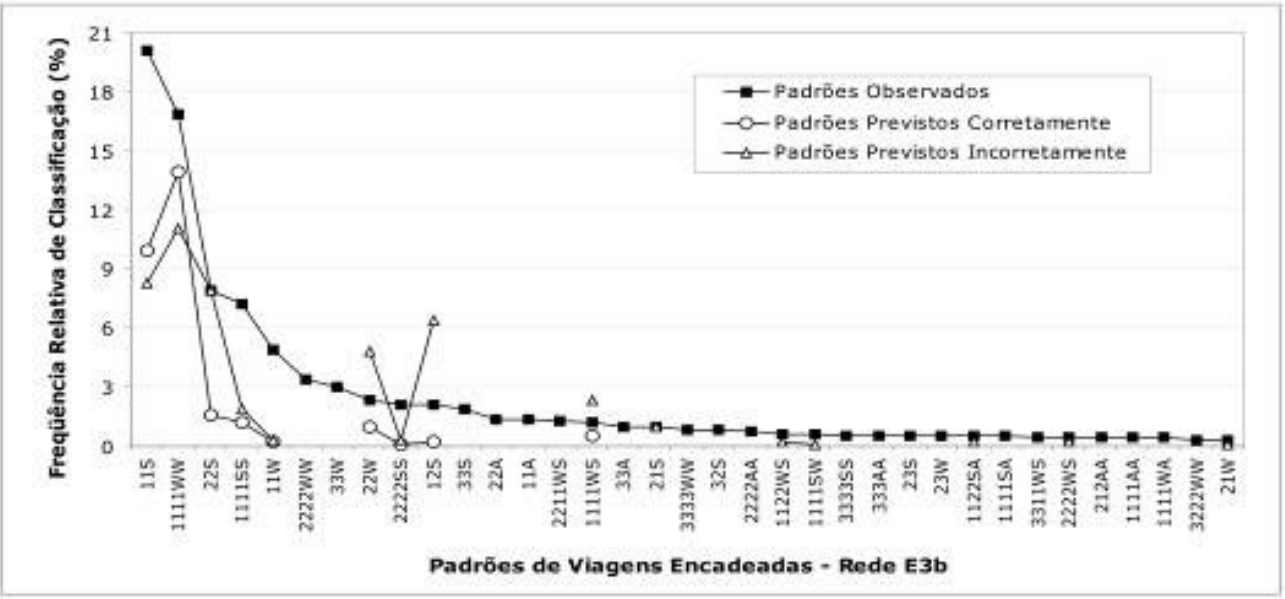

Figura 7.3: Classificação dos padrões observados e previstos de viagens encadeadas do conjunto de teste da rede $\mathbf{E} \mathbf{3 b}$. 
Da Figura 7.3, observa-se que a rede E3b reproduz 5 e 4 padrões do vetor de duas e quatro VEP, respectivamente. Em geral, os padrões 1111WW e 1111WS são reproduzidos adequadamente. Não obstante, existem padrões em que as freqüências de classificação são diferentes dos observados como por exemplo, os padrões observados $22 \mathrm{~S}$ e $\mathbf{1 1 W}$, cujas freqüências foram menores a 3\%. Observase padrões em que a freqüência de classificação prevista foi $10 \%$ da freqüência de classificação do padrão observado (padrões 11 e 2222SS). Ou, padrões previstos incorretamente em que a freqüência de classificação prevista é quase o dobro da freqüência do valor observado, como acontece com os padrões $\mathbf{2 2 W}$, 12S e 1111WS. Embora as redes tenham previsto alguns dos padrões observados, existem outros padrões que não foram adequadamente classificados. Assim como realizado no caso da rede $\mathbf{M 1 2 g}$, também foi realizada a segmentação da amostra de teste da rede $\mathbf{E 3 b}$. A discussão desses pontos segue abaixo:

i) Primeiramente foram selecionados do conjunto de teste os padrões apresentados a rede e que não foram reproduzidos, e constatou-se que:

- Padrões de duas viagens: 18 padrões não foram representados corretamente pela rede, somando $13,4 \%$ da frequiência do conjunto de teste. Padrões com duração acima de 20 minutos (deslocamentos superiores a 1,75 min.), são os mais encontrados neste grupo, assim como padrões cuja componente da atividade é "Outras Atividades". Por exemplo, os padrões $33 \mathbf{W}(3,0 \%)$, $33 \mathbf{S}(1,9), 22 \mathrm{~A}$ $(1,4 \%), \mathbf{1 1} \mathbf{A}(1,4 \%), 33 \mathbf{A}(1,0 \%), 32 \mathrm{~S}(0,9)$. É muito provável que o erro seja devido a baixa performance da rede em reproduzir durações superiores a 20 min., com isso a classificação do padrão ficou afetada. Outro motivo possível da classificação incorreta de padrões com o segmento de Outras Atividades, estaria na diversidade de alternativas envolvidas nesta classe, os quais correspondem desde atividades de lazer próximas do domicílio (padrão 11A) até atividades como visitas ou compras (padrão 22A).

- Padrões de três viagens: 42 padrões não foram representados, somando 7,1\% da frequiência do conjunto de teste. São encontrados padrões cuja componente de 
atividade é "Outras Atividades". No relacionado com a duração não foi observado preponderância de algum tipo. Por exemplo, os padrões 333AA $(0,5 \%)$, 212AA $(0,4)$, 112AA $(0,3 \%)$, 111AA $(0,3 \%)$, 111WA $(0,3 \%)$, 333WA $(1,4 \%)$. Adicionalmente, é observada uma baixa frequiência dos padrões, pois dos 46, 35 apresentaram frequiência relativa igual a um. Além disso, quando observada a amostra total de 3.756 dados, muitos desses padrões só se apresentaram uma vez, como é o caso do padrão 333WW. Para este caso específico, é de se supor que o padrão foi aleatoriamente incluído no conjunto de teste, sem que a rede pudesse aprender suas características.

- Padrões de quatro viagens: 31 padrões não foram representados corretamente, somando $14,7 \%$ da freqüência do conjunto de teste. De forma semelhante ao acontecido anteriormente para duas viagens, neste caso, não há preponderância de alguma característica específica. Por exemplo, os padrões 2222WW (3,4\%), 2211WS (1,3), 3333WW (0,9\%), 2222AA $(0,7 \%)$, 3333SS $(0,5 \%)$, 1111SA $(0,5 \%)$.

Em decorrência do observado nos casos anteriores, foi confirmado que: o maior número de padrões não reproduzidos corresponde a três viagens, e padrões com durações superiores a 20 min. foram encontrados nos grupos não replicados pela rede. A baixa frequiência por padrão explicaria o por que a rede não consegue reproduzir padrões de três viagens. No relacionado com a duração, acredita-se que seja a pouca performance da rede em representar os atributos espaciais dos indivíduos que fazem estes tipos de padrões.

ii) Em segundo lugar, foram selecionados do conjunto de teste os padrões reproduzidos incorretamente pela rede. Constatou-se que além de padrões de duas, três e quatro viagens, existiram "outros códigos", que poderiam aproximar-se de algum tipo de padrão, pois os erros apresentaram-se no segmento da duração ou no segmento da atividade. 
- Padrões de duas viagens: foram encontrados 9 padrões de este tipo, erroneamente representados pela rede. As características observadas correspondem as mesmas apresentadas pela rede $\mathbf{M 1 2 g}$, isto é em relação aos padrões 11S, 22S, 11W, 22W, 12S, 21S.

- Padrões de três viagens: 9 foram representados erroneamente pela rede, somando 5,2\% da freqüência do conjunto de teste. São encontrados padrões cuja duração preponderante é do tipo 221. Por exemplo, os padrões 221AS (1,5\%), 212AW $(1,4), 221 S W(1,2 \%), 221 W W(0,3 \%)$.

- Padrões de quatro viagens: 18 foram representados erroneamente, somando 9,3\% da frequiência do conjunto de teste. A diferença do caso anterior de três viagens, neste caso não existe preponderância de algum tipo de característica. Por exemplo os padrões 2211SW (4,0\%), 2211WW (1,2), 1211WW (0,9\%), 2121WS $(0,7 \%), \mathbf{1 1 1 2 W S}(0,4 \%)$, 2211AW $(0,3 \%)$. Além dos padrões 1111WW, 1111SS e 2222SS, cujo comportamento é similar ao observado no caso da rede M12g.

- Outros códigos: em total são 13 códigos, somando 6,2\% de freqüência. Alguns deles poderiam aproximar-se à codificação de três viagens, pois o erro está na duração da terceira viagem, ou na segunda atividade. Por exemplo os códigos “220031”, “120021”, “220021”, ou “221010”, “111010”, “121010”. Em outros casos, poderiam aproximar-se da codificação para quatro viagens, dado que o erro se produziu na segunda atividade ou na duração da terceira viagem. Por exemplo os códigos “121110”, “221110”, “111110”, ou “220111”, “120111”.

Como observado, os maiores erros de classificação estão relacionados com a representação de segmentos de duração e atividades que envolvem mais de duas viagens. Nisso, os padrões de quatro viagens são mais afetados, sendo provável que indivíduos que fazem esse tipo de padrão, na sua maioria, deslocam-se em dois períodos de tempo durante o dia, um pela manhã e outro pela tarde (dados da RMSP87), e, desenvolvem atividades diversas que nem sempre coincidem na localização espacial. No relacionado com os códigos, os erros correspondem a erros específicos no segmento da duração ou da atividade, o que estaria mais relacionado com um erro de aprendizado de 
padrões pouco representativos no conjunto de treinamento (padrões de três viagens). Outra explicação desses padrões estarem sendo classificados incorretamente, pode ser obtido das características dos indivíduos, confirmando-se que indivíduos com atributos socioeconômicos e de viagens similares não se comportam de maneira similar, realizando diferentes padrões de viagens encadeadas (ICHIKAWA, 2002).

Embora as topologias das redes simuladas sejam diferentes, no geral, a distribuição dos padrões previstos para ambas as redes foram similares. Isso permite inferir que independentemente do tipo de rede, as características dos dados de entrada do modelo definem a freqüência de classificação dos padrões previstos pela rede. Outro achado importante está relacionado com a complexidade das cadeias de viagens, pois, as redes conseguem representar a seqüência de viagens dos padrões de cadeias simples e cadeias complexas, além de representar a escolha das atividades compulsórias como Estudo (S) e Trabalho (W). No tocante a duração da viagem, cadeias com durações menores ou iguais a dez minutos (código 1), e entre dez e vinte minutos (código 2) são reproduzidas com maior freqüência.

Quanto à representação espacial, a maioria dos indivíduos que fazem cadeias do tipo 1111WW e 1111SS, com duração de cada viagem de no máximo 10 min., são indivíduos que realizam as viagens na mesma zona do domicílio. No caso do padrão 1111WW, por se tratar de indivíduos de baixa renda as viagens são eminentemente por motivo trabalho. No caso específico do padrão 1111SS, trata-se de indivíduos em idade escolar que provavelmente no período da manhã assistem a escola, e no período da tarde fazendo cursos como computação, inglês etc. Quanto às cadeias simples com atividade preponderante Estudo, como por exemplo 11S e 22S, as pessoas que fazem esses padrões, na maioria, têm grau de instrução entre $1^{\circ}$ e $2^{\circ}$ graus, e suas escolas estão localizadas na proximidade de suas residências. Este tipo de comportamento pode ser explicado pela política da Secretaria de Educação do Estado de São Paulo que recomenda que os estudantes de escola pública sejam matriculados em escolas próximas às suas residências. 


\subsection{ANÁLISE DA MODELAGEM PARA DUAS VIAGENS ENCADEADAS}

Os resultados da modelagem estão apresentados na Tabela 7.4 e Tabela 7.5, onde se observam os valores de classificação por topologia de rede MLP e Elman, respectivamente. Encontram-se também, informações sobre a topologia da rede simulada, o número de neurônios na camada intermediária, a codificação da rede, as partições da amostra com o número de elementos por conjunto de treinamento, validação e teste, juntamente com a frequiência com que indivíduos do conjunto de teste fazem duas VEP. Facilitando uma melhor visualização e análise dos resultados da simulação, os valores correspondentes à classificação dos padrões de encadeamento estão apresentados de três formas: i) Freqüência dos Padrões Corretamente Classificados por Topologia de Rede, ii) Freqüência dos Padrões Corretamente Classificados por Cadeia de Viagem, desagregada em Classificação da Duração de Viagem (duração da primeira viagem - Dur_1 $\mathbf{1}^{\mathbf{a} \cdot}$, duração da segunda viagem - Dur_2 $\mathbf{2}^{\mathbf{a} \cdot}$ ) e Classificação de Atividades; e, iii) Freqüência dos Padrões de Encadeamento Classificados Corretamente. O acerto médio de classificação em porcentagem (\%) também estão apresentados nas mesmas tabelas. 


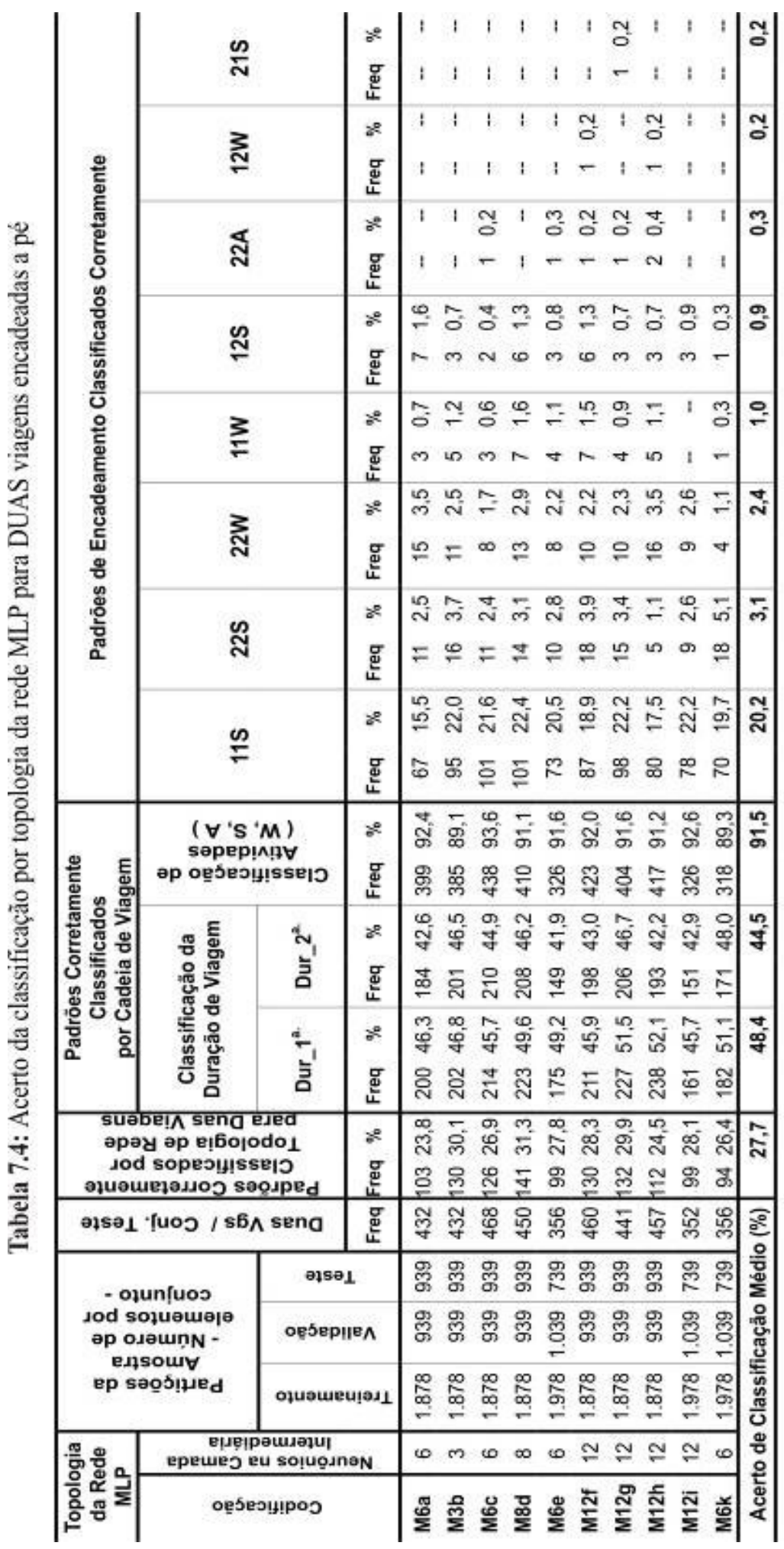




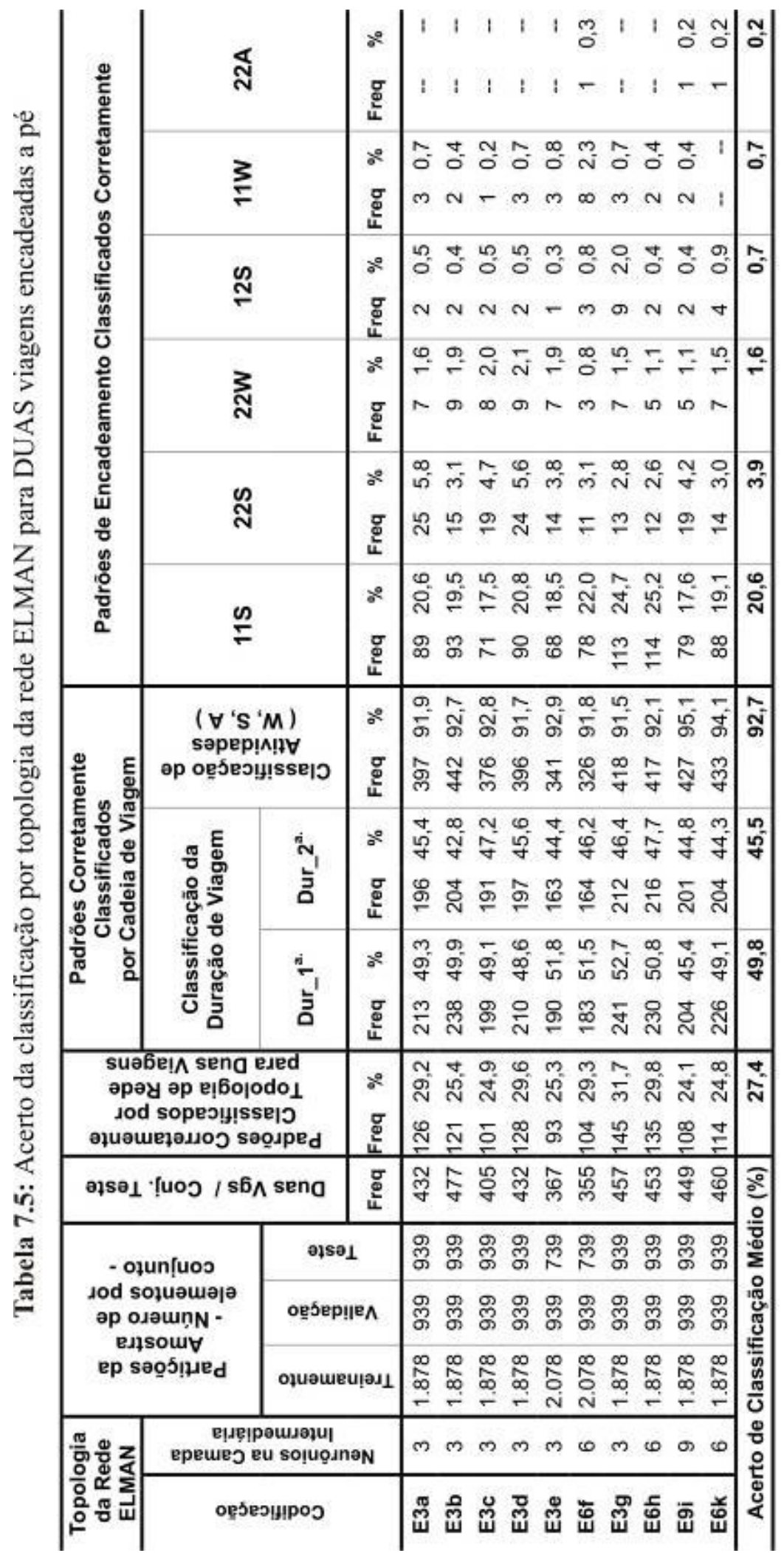


Conforme foi indicado nos critérios de análise descritos na seção 7.2, além dos níveis de acerto da classificação das RNAs mostrados na Tabela 7.4 e Tabela 7.5, também foram calculados os valores de Erro Quadrático Médio (EQM) de classificação dos PVE por topologia das redes MLP e Elman. Esses valores estão apresentados nas Tabelas 7.6 e 7.7, e nelas podem ser observados cinco valores de EQM para cada topologia de rede. O primeiro valor do $E Q M_{G}$ está relacionado com a classificação geral correta dos padrões de viagens encadeadas a pé por topologia de rede, o qual foi calculado em função do padrão de saída observado (alvo) e do padrão de saída previsto pela rede. O segundo valor de $E Q M$ foi relacionado com a classificação geral do padrão de duração da primeira e segunda viagens $\left(E Q M_{D}\right.$ - Dur_Geral). Finalmente, os três valores restantes de EQM mostram separadamente os erros correspondentes a cada segmento do padrão de viagens encadeadas a pé, isto é, para cada segmento de duração da viagem $\left(E Q M_{D 1}-\right.$ Dur_1 ${ }^{\text {a. }}, E Q M_{D 2}-$ Dur_2 $\left.2^{\text {a. }}\right)$ e atividade $\left(E Q M_{A}\right)$. Os menores valores dos EQM estão remarcados em negrito em cada coluna. Com todas essas informações, a análise da classificação geral dos padrões de VEP para duas viagens foi realizada na seguinte seção.

Tabela 7.6: Erro quadrático médio $(\boldsymbol{E Q M})$ de classificação por topologia da rede MLP para DUAS viagens encadeadas a pé.

\begin{tabular}{|c|c|c|c|c|c|}
\hline \multirow{2}{*}{$\begin{array}{c}\text { Topologia } \\
\text { da Rede } \\
\text { MLP }\end{array}$} & \multirow{2}{*}{$\begin{array}{c}E Q M_{G} \\
\text { dos Padrões por } \\
\text { Topologia de } \\
\text { Rede para Duas } \\
\text { Viagens }\end{array}$} & \multicolumn{3}{|c|}{$\begin{array}{c}\text { EQM por Cadeia da Duração } \\
\text { de Viagem }\end{array}$} & \multirow{2}{*}{$\begin{array}{c}E Q M_{\mathrm{A}} \\
\text { por Cadeia de } \\
\text { Atividades }\end{array}$} \\
\hline & & $\begin{array}{c}E Q M_{D} \\
\text { Dur_Gral }\end{array}$ & $\begin{array}{l}E Q M_{D 1} \\
\text { Dur_1 }\end{array}$ & $\begin{array}{l}E Q M_{D 2} \\
\text { Dur_2 }\end{array}$ & \\
\hline M6a & 1,625 & 1,514 & 0,766 & 0,748 & 0,111 \\
\hline M3b & 1,627 & 1,484 & 0,734 & 0,750 & 0,144 \\
\hline M6c & 1,568 & 1,472 & 0,735 & 0,737 & 0,096 \\
\hline M8d & 1,504 & 1,396 & 0,671 & 0,724 & 0,109 \\
\hline M6e & 1,596 & 1,469 & 0,685 & 0,784 & 0,126 \\
\hline M12f & 1,530 & 1,424 & 0,717 & 0,707 & 0,107 \\
\hline M12g & 1,429 & 1,277 & 0,621 & 0,655 & 0,152 \\
\hline M12h & 1,460 & 1,346 & 0,696 & 0,650 & 0,114 \\
\hline M12i & 1,509 & 1,409 & 0,744 & 0,665 & 0,099 \\
\hline M6k & 1,385 & 1,244 & 0,607 & 0,638 & 0,140 \\
\hline
\end{tabular}


Tabela 7.7: Erro quadrático médio $(\boldsymbol{E} \boldsymbol{Q M})$ de classificação por topologia da rede Elman para DUAS viagens encadeadas a pé

\begin{tabular}{|c|c|c|c|c|c|}
\hline \multirow{2}{*}{$\begin{array}{l}\text { Topologia } \\
\text { da Rede } \\
\text { ELMAN }\end{array}$} & \multirow{2}{*}{$\begin{array}{c}E Q M_{G} \\
\text { dos Padrões por } \\
\text { Topologia de } \\
\text { Rede para Duas } \\
\text { Viagens }\end{array}$} & \multicolumn{3}{|c|}{$\begin{array}{c}\text { EQM por Cadeia da Duração } \\
\text { de Viagem }\end{array}$} & \multirow{2}{*}{$\begin{array}{c}E Q M_{\mathrm{A}} \\
\text { por Cadeia de } \\
\text { Atividades }\end{array}$} \\
\hline & & $\begin{array}{c}E Q M_{D} \\
\text { Dur_Gral }\end{array}$ & $\begin{array}{l}E Q M_{D 1} \\
\text { Dur_1 }\end{array}$ & $\begin{array}{l}E Q M_{D 2} \\
\text { Dur_2. }\end{array}$ & \\
\hline E3a & 1,558 & 1,442 & 0,701 & 0,741 & 0,116 \\
\hline E3b & 1,468 & 1,356 & 0,658 & 0,698 & 0,111 \\
\hline E3c & 1,420 & 1,274 & 0,657 & 0,617 & 0,146 \\
\hline E3d & 1,572 & 1,454 & 0,715 & 0,738 & 0,118 \\
\hline E3e & 1,387 & 1,275 & 0,613 & 0,662 & 0,112 \\
\hline E6f & 1,408 & 1,276 & 0,628 & 0,648 & 0,132 \\
\hline E3g & 1,678 & 1,547 & 0,768 & 0,779 & 0,131 \\
\hline E6h & 1,585 & 1,439 & 0,684 & 0,755 & 0,146 \\
\hline E9i & 1,434 & 1,352 & 0,653 & 0,699 & 0,082 \\
\hline E6k & 1,417 & 1,326 & 0,652 & 0,674 & 0,091 \\
\hline
\end{tabular}

\subsubsection{Análise da Classificação dos Padrões de VEP por Topologia de Rede para Duas Viagens}

Os resultados para as dez topologias das redes modeladas Elman e MLP, mostrados nas Tabelas 7.4 e 7.5 e Figura 7.4, permitem afirmar que a rede MLP e a rede Elman apresentaram desempenhos semelhantes na classificação dos padrões e na representação dos segmentos com a duração das viagens e tipo de atividades para duas VEP.

Os oito padrões de VEP reproduzidos pelas redes MLP e os seis pelas redes Elman, representam 78,3\% dos indivíduos do vetor de duas viagens constituído por 1800 indivíduos e 26 padrões de VEP. Todavia, a freqüência relativa por padrão do vetor de duas viagens é maior que o $A C M$ por padrão das redes modeladas (Tabelas 7.4 e 7.5). Por exemplo, para a rede Elman, o $A C M$ previsto do padrão $11 S$ foi de $20,6 \%$, enquanto que a freqüência observada do vetor de duas viagens foi igual a 36,6\%. Para outros padrões tais como 22S, 22W, 12S e 11W, o melhor $A C M$ foi de 3,9\%, 2,4\%, $0,9 \%$ e $1,0 \%$, respectivamente, ao passo que as freqüências observadas foram iguais a iguais a 16,2\%, 4,8\%, 4,6\% e 9,4\% (Figura7.4(b)). Essa diferença do observado para o previsto mostra claramente que a rede não está classificando adequadamente esses 
padrões, como foi analisado na seção 7.3. Quanto a padrões em que a duração da primeira viagem é diferente da segunda viagem, como no caso do padrão $12 S$, é muito provável que a pessoa tenha realizado uma pequena parada em algum lugar para realizar uma outra atividade relacionada com Estudo, a qual não foi informada no momento da entrevista. Está informação adicional poderia brindar uma característica a mais às informações apresentadas a rede que possibilitariam sua melhor classificação.

Quanto ao segmento de duração da viagem a rede Elman proporcionou resultados ligeiramente melhores do que a rede MLP. A freqüência geral de classificação para duas viagens foi próxima de 30\%, enquanto cada segmento de duração da viagem (Dur_1 ${ }^{\mathbf{a}}$, Dur_2 $2^{\mathbf{a}}$ ) foi replicado em torno de 50\%. Mostrando a existência de um $20 \%$ de casos em que as redes reproduziram ou a primeira duração, ou a segunda. Observou-se também que o segmento do padrão correspondente à atividade teve freqüência média de classificação de 91,5\% para a rede MLP e 92,7\% para a Elman (Figura 7.3). Essa diferença de $50 \%$ da classificação da atividade em relação à duração de viagem mostra que o erro da classificação estaria relacionado com a representação do segmento duração de viagem.

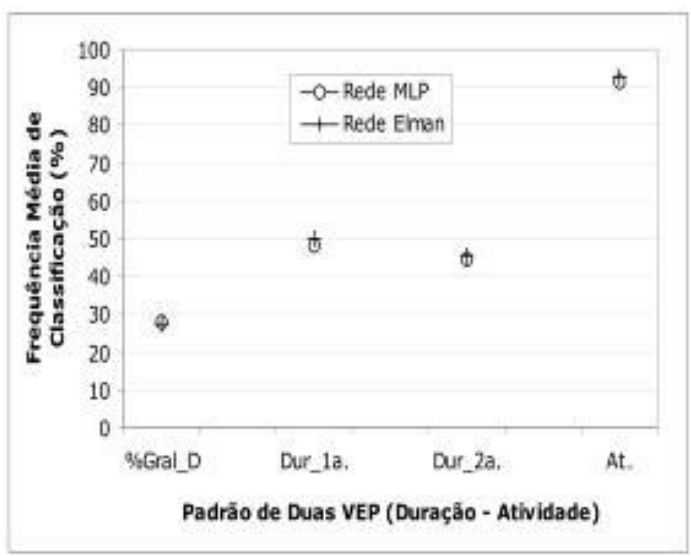

(a)

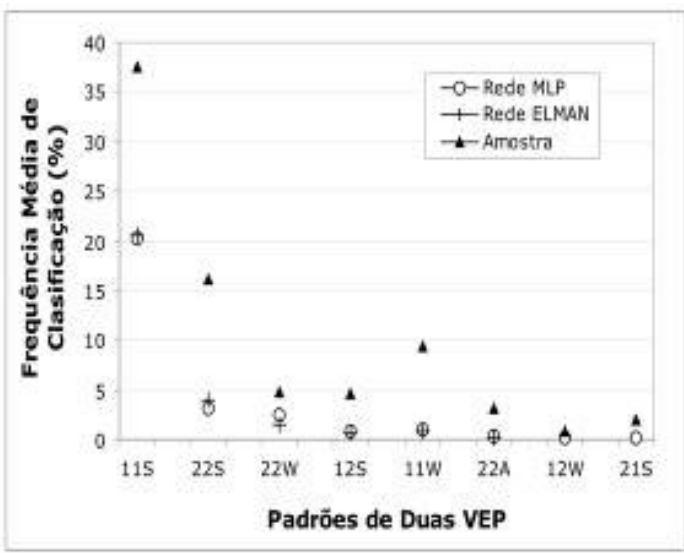

(b)

Figura 7.4: Freqüência média de classificação das redes MLP e Elman para DUAS viagens encadeadas.

Em relação aos valores do $E Q M_{G}$, nas Tabelas 7.6 e 7.7, observou-se que os menores valores obtidos correspondem a uma topologia de rede M6k com valor de 
1,385 e de uma rede E3e com valor de 1,38. A essas redes correspondem os menores valores de $E Q M_{D}$ de 1,275 para a rede Elman e 1,244 para a MLP. Entretanto para essas redes o acerto da classificação é menor que o $A C M$ da classe. Isso mostra que nem sempre os melhores valores de acerto de classificação por rede correspondem a menores valores do $E Q M$ de classificação da duração de viagem por rede.

\subsubsection{Análise da Classificação por Cadeia de Viagem para Duas Viagens: Duração - Atividade}

Foi constatado que o nível de acerto na classificação de atividades está acima de $90 \%$ (Tabelas 7.4 e 7.5 e Figura 7.5), enquanto o menor $E Q M_{A}=0,082$ correspondeu à rede Elman E9i. Em forma agregada, o $A M C$ geral das atividades reproduzidas pela rede MLP foi de $91,5 \%$ e a distribuição do acerto na classificação por tipo de atividade foi de 21,0\% para Trabalho (W), 66,6\% para Estudo (S) e, 3,9\% para Outras Atividades (A). Na rede Elman o $A M C$ agregado foi de $92,7 \%, 20,2 \%$ para $\mathbf{W}, 67,70 \%$ para $\mathbf{S}$ e $4,8 \%$ para A. Entretanto, observou-se que o maior acerto de classificação de $95,1 \%$ foi atingido pela rede E9i e pela rede M6c com 93,6\%.

Considerando os $A C M$ das atividades, nota-se que a rede Elman conseguiu valores ligeiramente maiores para $A C M$ e menores para $E Q M$, quando comparada com a rede MLP. Portanto, pode-se afirmar que independentemente do tipo de rede, as redes modeladas conseguem reproduzir de forma satisfatória (ACM superior a 90\%) a influência das atividades compulsórias como estudo $(\mathbf{S})$ e trabalho $(\mathbf{W})$ na seqüência de viagens dos padrões de VEP. Este fato também foi observado por Ichikawa (2002) que concluiu que indivíduos que trabalham realizam predominantemente viagens apenas ao trabalho (padrão HWH). Da mesma forma, aqueles que somente estudam realizam, na maioria das vezes, viagens apenas à escola (padrão HSH).

Adicionalmente, corroborando os acertos de classificação das atividades obtidas pelas redes, do Vetor das variáveis Individuais e Domiciliares dos indivíduos que fazem duas viagens encadeadas a pé na RMSP87 (Tabela 6.1 do cap. 6), constata-se que: a maior parte dos indivíduos estudam $(\mathbf{S}, 68,7 \%)$, trabalham em menor proporção (W, $23,6 \%)$, estão em idade escolar (64,9\% são menores de 15 anos de idade), e; a sua 
situação familiar 68,9\% é de filhos. Em função dessas características e da distribuição do acerto na classificação por tipo de atividade, apresentado nas Figuras 7.5(a) e (b), pode-se inferir que as redes conseguiram reproduzir a probabilidade de os indivíduos fazerem viagens à escola, ou ao trabalho, em função de suas características Individuais e Domiciliares. Isto é confirmado por Pitombo (2003), que constatou que um dos padrões mais freqüentes, nos dados da RMSP87, corresponde a viagens realizadas a pé com atividade Estudo (padrão HSH) e com duração de cada viagem menor a 20 min. Tais padrões são realizados pelos indivíduos em períodos compreendidos entre as 0:00h 8:00 (casa-escola), 8:00 - 11:30h (escola-casa); 11:30h - 14:30 (casa-escola), 14:30 17:30h (escola-casa); e, 14:30h - 17:30 (casa-escola), 17:30 - 24:00h (escola-casa).

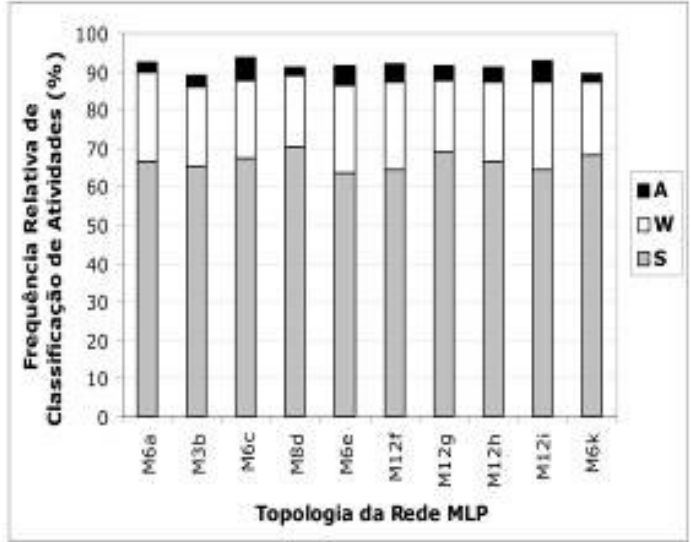

(a)

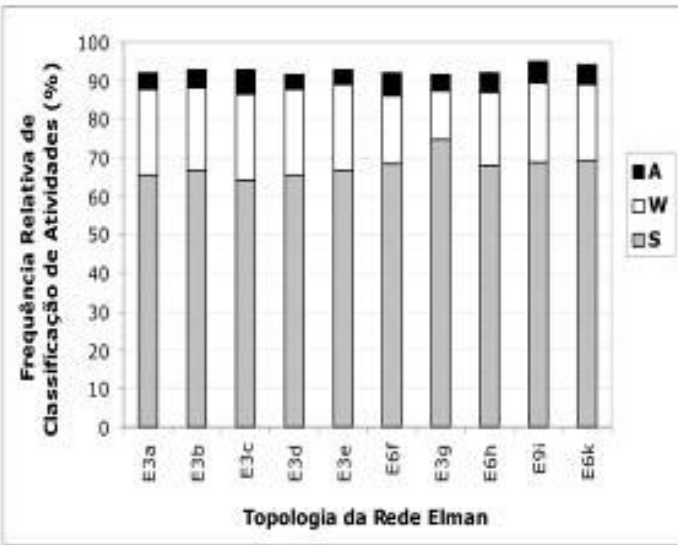

(b)

Figura 7.5: Classificação de atividades por topologia de redes MLP e Elman para DUAS viagens encadeadas.

Quanto à representação da duração da viagem - para todas as redes simuladas -, observou-se que o acerto de classificação da duração por cadeia de viagem é de $50 \%$ do acerto da classificação de atividades. Isso mostra que a duração da viagem depende de outros fatores além da ocupação individual e da necessidade que as pessoas têm de exercer atividades compulsórias. Considerando que a viagem é realizada a pé, a duração da viagem é afetada por restrições do espaço físico que independem das características individuais e domiciliares. Portanto, acredita-se que a inclusão dos índices de acessibilidade e atratividade na modelagem não tenham contribuído como foi desejado para a representação do segmento correspondente à duração da viagem no padrão de 
VEP, como foi observado através dos padrões de VEP reproduzidos pelas diferentes topologias de redes.

\subsubsection{Análise da Classificação por Padrão de Encadeamento para Duas Viagens}

A rede MLP reproduziu 8 dos 26 padrões de viagens encadeadas correspondentes ao vetor de duas VEP. Sendo o padrão 11S o melhor representado com uma média de classificação de 20,2\%, seguido do padrão $\mathbf{2 2 S}$ com $A C M$ de 3,1\% e dos padrões $\mathbf{2 2} \mathbf{W}$ e $11 \mathrm{~W}$ com $A C M$ de $2,4 \%$ e $1,0 \%$, respectivamente. A rede Elman replicou seis PVE com $A C M$ de $20,6 \%$ para o padrão $\mathbf{1 1 S}$, de 3,9\% para o padrão $22 \mathrm{~S}$ e de $1,6 \%$ e $0,7 \%$ para os padrões $\mathbf{2 2 W}$ e 12S, respectivamente. Comparando os $A M C$ de ambas as redes, observase que não existe diferença significativa entre a rede Elman e a rede MLP. Independentemente do tipo de rede modelada, a atividade Estudo (S) foi reproduzida com maior acerto, seguida da atividade Trabalho $(\mathbf{W})$.

Enquanto ao padrão de VEP previsto por cada topologia de redes Elman e MLP, foi constatado que, independentemente da rede, existe um tipo de padrão predominante: 11S com valores de classificação no intervalo de $15 \%$ até $26 \%$. Outros padrões de VEP apresentaram valores inferiores a 6\%, tais como o padrão 22S (Figura 7.6).

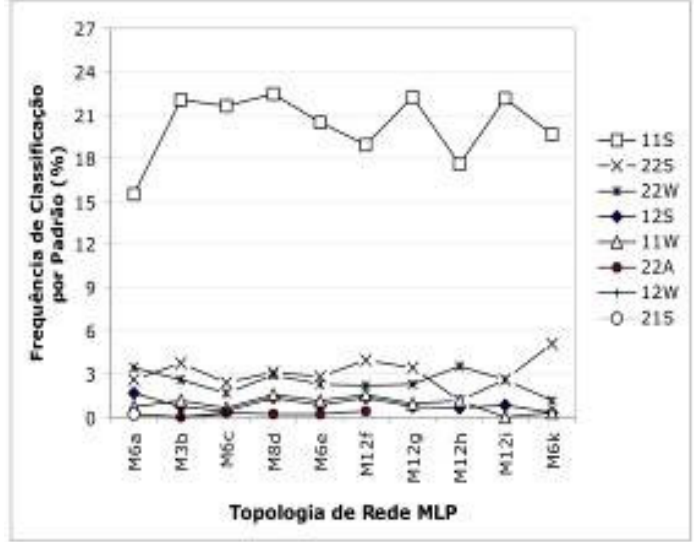

(a)

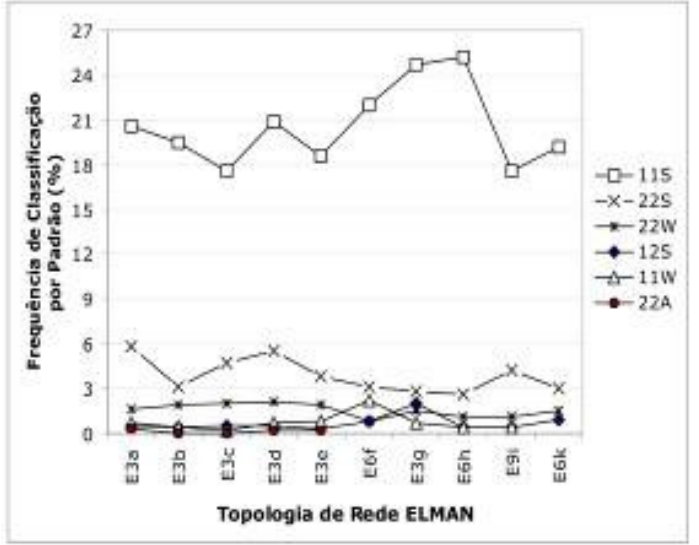

(b)

Figura 7.6: Classificação de padrões de VEP por topologia de redes MLP e Elman para DUAS viagens encadeadas. 
Quanto o padrão 11S, não apresentou um comportamento de classificação uniforme em todas as tipologias de redes MLP, com acerto de classificação variando entre um mínimo de 15,5\% e um máximo de 22,4\% (Figura 7.6(a)). Nas redes Elman, esse padrão apresentou uma maior variabilidade no acerto da classificação, com máximo de $25,2 \%$ e mínimo de $17,5 \%$ (Figura 7.6(b)). Com relação ao padrão $\mathbf{2 2 S}$, o acerto de classificação foi quase uniforme nas topologias de redes MLP simuladas, com valor mínimo de 1,1\% e máximo de 5,1\%. Nas redes Elman a frequiência deste padrão foi mais uniforme, variando entre $2,6 \%$ e $5,8 \%$. Os padrões $11 \mathrm{~S}$ e $22 \mathrm{~S}$ correspondem a indivíduos em idade escolar, morando nas proximidades da escola, e que no máximo se deslocam $1,75 \mathrm{~km}$ da residência. A programação das atividades desses indivíduos estão governadas por compromissos e prioridades assumidos, no caso os estudos, e desenvolvem essas atividades em limites de tempo estabelecidos, podendo-se afirmar que são padrões bem definidos.

Considerando a duração da viagem, tanto a rede MLP quanto a rede Elman conseguiram reproduzir padrões de VEP em que a duração da primeira e da segunda viagem foi maior do que $10 \mathrm{~min}$. e menor ou igual a $20 \mathrm{~min}$. (padrão $\mathbf{2 2 S}$ ou $\mathbf{2 2 W}$ ), e os padrões cuja duração da primeira e da segunda viagem foi menor ou igual a $10 \mathrm{~min}$. (padrão 11S ou 11W). Os padrões com duração superior a $30 \mathrm{~min}$. (deslocamentos acima de $1,75 \mathrm{~km}$.), como por exemplo o $33 \mathbf{A}, 33 \mathbf{W}, \mathbf{2 3 W}$ não foram reproduzidos pelas redes. No caso do padrão $\mathbf{2 3 W}$, a duração da segunda viagem é maior que a duração da primeira viagem. O conhecimento das causas que deram lugar a esta diferença de duração da viagem poderia servir como informações adicionais de classificação para a rede, e assim diferencia-lo dos outros indivíduos.

Finalmente, foi observado que apesar de as redes MLP e Elman possuírem diferentes arquiteturas e terem sido treinadas com diferentes atributos, elas conseguiram discriminar de forma semelhante as diferentes características dos padrões de duas VEP. A quantidade de similaridades observadas pode conduzir ao delineamento de características gerais de representação dos padrões de VEP usando RNAs. 


\subsection{ANÁLISE DA MODELAGEM PARA TRÊS VIAGENS ENCADEADAS}

Este é o vetor de viagens em que poderia ser avaliada a capacidade da rede em representar o sequênciamento das viagens, dado que estes tipos de cadeias são diferentes das de duas e quatro viagens. Entretanto a pouca frequiência de indivíduos por padrão impossibilitou melhores alcances do estudo.

O vetor de três viagens ficou constituído por 281 dados, conseqüência do número limitado de indivíduos que realizam três viagens a pé, e dos quais foram obtidos 118 padrões. Destes, 17 padrões apresentaram freqüência acima de 1,4\% (maior o igual a 4 indivíduos por padrão), enquanto os 101 padrões restantes contaram com freqüência por padrão menor do que 1,1\% (igual ou menores a 3 indivíduos por padrão).

Os resultados da modelagem com os valores de classificação por topologia de rede MLP e Elman, para três viagens, estão apresentados nas Tabelas 7.8 e 7.9, seguindo o mesmo modelo de apresentação adotado na análise para duas viagens. A diferença está no fato de que os valores de Classificação da Duração de Viagem e da Classificação de Atividades foram desagregados em duração da primeira, segunda e terceira viagem $\left(\right.$ Dur_1 ${ }^{\text {a. }}$, Dur_2 $2^{\text {a. }}$, Dur_3 ${ }^{\text {a. }}$ ), e primeira e segunda atividade (At._1 ${ }^{\text {a. }}$, At._2 $\mathbf{2}^{\text {a. }}$ ). Os valores correspondentes ao Erro Quadrático Médio estão dispostos nas Tabelas 7.10 e 7.11, em função do "erro" de classificação dos padrões de VEP para três viagens $\left(E Q M_{G}\right)$, o "erro" por cadeia da duração de viagem $\left(E Q M_{D 1}, E Q M_{D 2}\right.$ e $\left.E Q M_{D 3}\right)$ e por cadeia de atividades $\left(E Q M_{A 1}\right.$ e $\left.E Q M_{A 2}\right)$. 


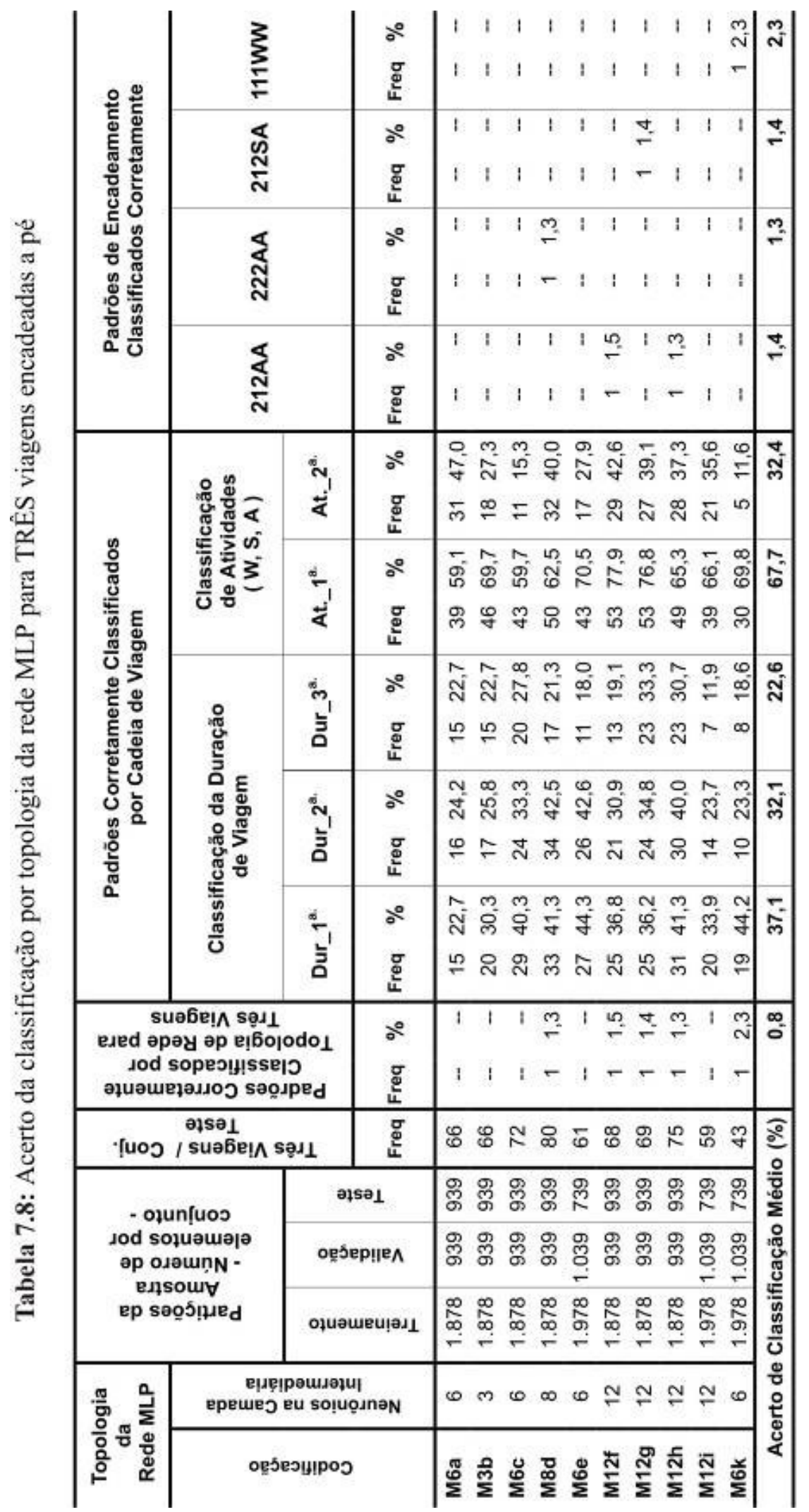




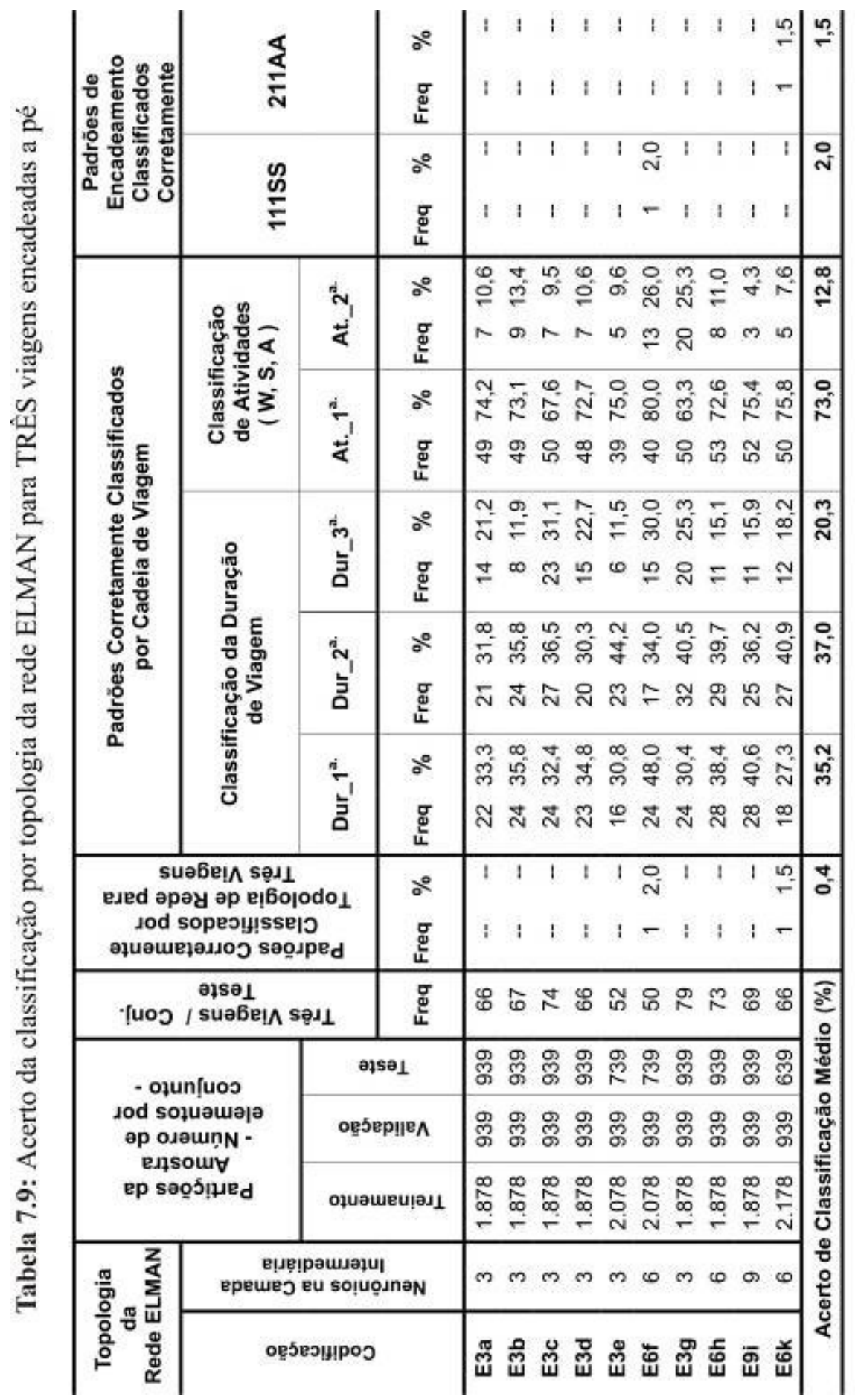


Tabela 7.10: Erro quadrático médio $(\boldsymbol{E} Q M)$ de classificação por topologia da rede MLP para TRÊS viagens encadeadas a pé

\begin{tabular}{|c|c|c|c|c|c|c|c|c|}
\hline \multirow{2}{*}{ 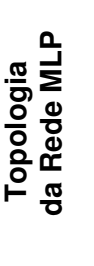 } & \multirow{2}{*}{ 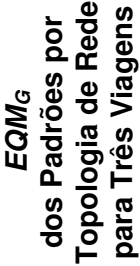 } & \multicolumn{4}{|c|}{$\begin{array}{c}\text { EQM por Cadeia da Duração } \\
\text { de Viagem }\end{array}$} & \multicolumn{3}{|c|}{$\begin{array}{c}E Q M_{A} \text { por Cadeia de } \\
\text { Atividades }\end{array}$} \\
\hline & & $\begin{array}{c}E Q M_{D} \\
\text { Dur_Gral. }\end{array}$ & $\begin{array}{l}E Q M_{D 1} \\
\text { Dur_1 }\end{array}$ & $\begin{array}{l}E Q M_{D 2} \\
\text { Dur_2 } 2^{\text {a. }}\end{array}$ & $\begin{array}{l}E Q M_{D 3} \\
\text { Dur_3 }\end{array}$ & $\begin{array}{l}E Q M_{A} \\
\text { At._Gral. }\end{array}$ & $\begin{array}{l}E Q M_{A 1} \\
\text { At._1 }{ }^{\text {. }}\end{array}$ & $\begin{array}{l}E Q M_{A 2} \\
\text { At._2 }\end{array}$ \\
\hline M6a & 5,879 & 3,652 & 1,136 & 1,076 & 1,439 & 2,227 & 0,500 & 1,727 \\
\hline M3b & 6,742 & 3,788 & 0,924 & 0,879 & 1,985 & 2,955 & 439 & 2,515 \\
\hline M6c & 6,125 & 3,236 & 0,931 & 0,917 & 1,389 & 2,889 & 0,861 & 2,028 \\
\hline M8d & 5,863 & 3,325 & 0,888 & 0,988 & 1,450 & 2,538 & 0,525 & 2,013 \\
\hline M6e & 6,607 & 3,377 & 0,951 & 0,803 & 1,623 & 3,230 & 0,541 & 2,689 \\
\hline M12f & 4,750 & 3,029 & 0,721 & 0,779 & 1,529 & 1,721 & ,397 & 1,324 \\
\hline M12g & 4,870 & 2,812 & 0,812 & 0,870 & 1,130 & 2,058 & 406 & 1,652 \\
\hline M12h & 5,360 & 2,867 & 0,707 & 0,800 & 0 & 2,493 & ,467 & 2,027 \\
\hline M12i & 6,000 & 3,441 & 1,0 & 0,9 & 1,475 & 2,559 & 0,492 & 2,068 \\
\hline M6k & 8,395 & 5,023 & 0,767 & 1,116 & 3,140 & 3,372 & 0,512 & 2,860 \\
\hline
\end{tabular}

Tabela 7.11: Erro quadrático médio (EQM) de classificação por topologia da rede Elman para TRÊS viagens encadeadas a pé

\begin{tabular}{|c|c|c|c|c|c|c|c|c|}
\hline \multirow{2}{*}{ 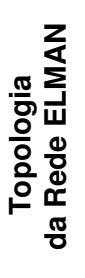 } & \multirow{2}{*}{ 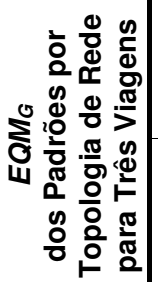 } & \multicolumn{4}{|c|}{$\begin{array}{c}\text { EQM por Cadeia da Duração } \\
\text { de Viagem }\end{array}$} & \multicolumn{3}{|c|}{$\begin{array}{c}E Q M_{A} \text { por Cadeia de } \\
\text { Atividades }\end{array}$} \\
\hline & & $\begin{array}{c}E Q M_{D} \\
\text { Dur_Gral. }\end{array}$ & $\begin{array}{l}E Q M_{D 1} \\
\text { Dur_1 }^{\text {a. }}\end{array}$ & $\begin{array}{l}E Q M_{D 2} \\
\text { Dur_2 }\end{array}$ & $\begin{array}{l}E Q M_{D 3} \\
\text { Dur_3 }\end{array}$ & $\begin{array}{c}E Q M_{A} \\
\text { At._Gral. }\end{array}$ & $\begin{array}{l}E Q M_{A 1} \\
\text { At._1 }{ }^{\text {a. }}\end{array}$ & $\begin{array}{l}E Q M_{A 2} \\
\text { At._2 }\end{array}$ \\
\hline E3a & 8,364 & 4,424 & 1,076 & 0,955 & 2,394 & 3,939 & 0,394 & 3,545 \\
\hline E3b & 10,030 & 4,851 & 1,045 & 0,866 & 2,940 & 5,179 & 0,627 & 4,552 \\
\hline E3c & 8,459 & 3,838 & 0,919 & 0,878 & 2,041 & 4,622 & 0,730 & 3,892 \\
\hline E3d & 8,318 & 4,364 & 1,106 & 0,924 & 2,333 & 3,955 & 0,409 & 3,545 \\
\hline E3e & 10,173 & 4,654 & 0,981 & 0,673 & 3,000 & 5,519 & 0,654 & 4,865 \\
\hline E6f & 5,480 & 3,400 & 0,700 & 0,960 & 1,740 & 2,080 & 0,380 & 1,700 \\
\hline E3g & 6,911 & 3,570 & 0,848 & 0,823 & 1,899 & 3,342 & 0,823 & 2,519 \\
\hline E6h & 9,137 & 4,630 & 1,068 & 1,014 & 2,548 & 4,507 & 0,603 & 3,904 \\
\hline E9i & 9,275 & 4,362 & 0,986 & 0,725 & 2,652 & 4,913 & 0,594 & 4,319 \\
\hline E6k & 9,909 & 4,379 & 0,955 & 0,682 & 2,742 & 5,530 & 0,652 & 4,879 \\
\hline
\end{tabular}

Os valores das Tabelas 7.10 e 7.11, mostram que o menor valor do $E Q M_{G}=4,750$ e $E Q M_{A}=1,721$ correspondem a uma topologia de rede MLP com doze neurônios na camada intermediária (M12f). Para a cadeia da duração de viagem, o menor valor de $E Q M_{D}$ foi 2,812, correspondente à rede $\mathbf{M 1 2 g}$. 


\subsubsection{Análise da Classificação dos Padrões de VEP por Topologia de Rede para Três Viagens}

Como foi observado nos dados dos vetores para três viagens, os padrões de VEP apresentaram freqüência relativa por padrão abaixo do necessário para simulação, o que possivelmente influiu no número de padrões reproduzidos pelas redes. Conforme está apresentado nas Tabelas 7.8 e 7.9, a rede MLP conseguiu reproduzir no máximo 4 padrões, enquanto a rede Elman reproduziu 2 padrões (Figura 7.7(b)). Os $A C M$ das topologias de redes modeladas são de $0,8 \%$ para a rede MLP, e de $0,4 \%$ para a rede Elman. O ACM da duração da primeira viagem para a rede MLP foi de $37,1 \%$ e de $35,2 \%$ para a rede Elman. Quanto ao valor do $A C M$ na duração da segunda viagem, foi maior para a rede Elman com $37,0 \%$ do que para a rede MLP com 32,1\%. No que se refere ao $A C M$ das atividades, o maior valor coube à rede Elman, para primeira atividade com 73,0\% e a rede MLP na segunda atividade com 32,4\% (Figura 7.7(a)).

Com relação aos padrões reproduzidos, foi observado que os valores de $A C M$ para as topologias das redes MLP e Elman, em alguns padrões (212AA, 222AA, 111SS e 211AA), foram a metade da frequiência por padrão de VEP da amostra do vetor de três viagens, e outros (212SA e 111WW) excederam essas freqüências (Figura 7.7(b)). Porém, a avaliação do melhor desempenho de uma rede com respeito da outra em função desses resultados, ficou distante do desejado.

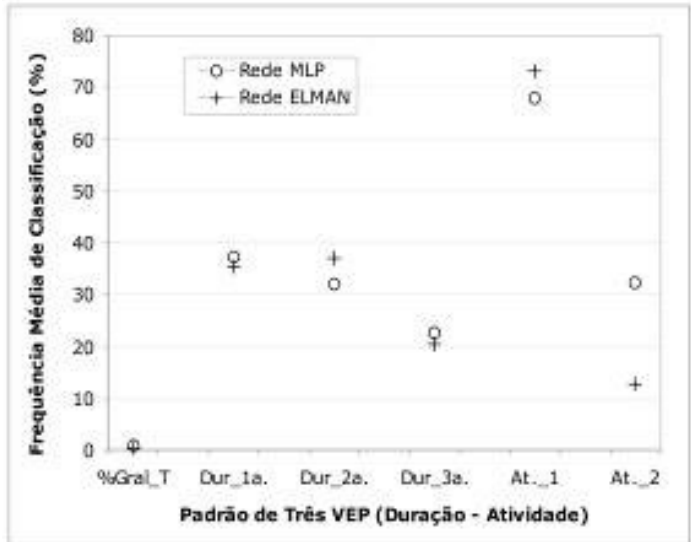

(a)

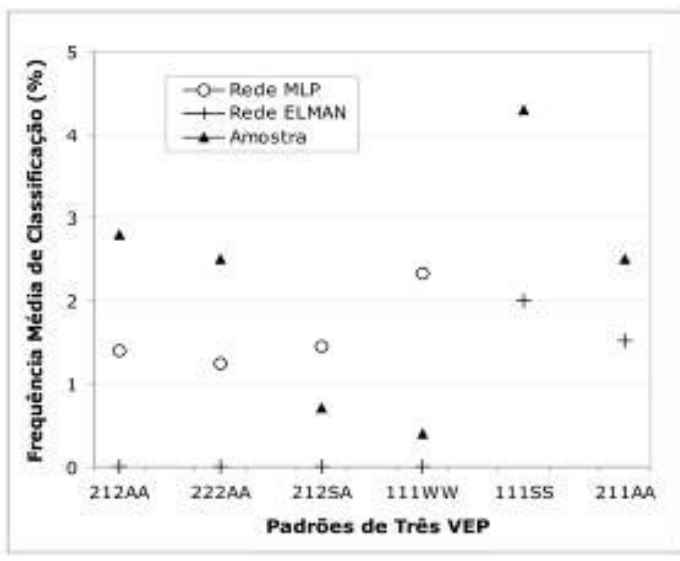

(b)

Figura 7.7: Frequiência média de classificação das redes MLP e Elman para TRÊS viagens encadeadas. 
Na Figura 7.7(a) mostra que conforme aumenta o segmento da duração de viagem, as redes vão perdendo capacidade de classificação, isto é, as redes não estão conseguindo relacionar as informações do estado anterior com as informações do estado seguinte. O mesmo comportamento é observado com os segmentos das atividades, em que o segmento da segunda atividade é classificada em menos do $50 \%$ da primeira atividade. Isso pode ser devido, ente outros fatores à agregação realizada para a representação das Outras Atividades. Atividades como compras, negócios, médico/dentista, saúde, recreação ou visitas, nem sempre estão localizadas no mesmo lugar, nem são realizadas no mesmo período de tempo - a diferença de atividades como $\mathbf{W}$ e $\mathbf{S}$ que geralmente apresentam uma localização e períodos bem definidos -. Essa seria uma das explicações de por que a rede não está conseguindo representar a duração de viagem dos padrões de três viagens e errando no segmento da segunda atividade.

\subsubsection{Análise de Classificação por Cadeia de Viagem para Três Viagens: Duração - Atividade}

A freqüência de classificação da duração da viagem e das atividades observado para as topologias das redes Elman e MLP, apresentados nas Tabelas 7.10 e 7.11, permitiu inferir duas coisas: i) o segmento final de duração da viagem não é adequadamente representado $\left(\mathbf{D u r} \mathbf{3}^{\mathbf{a}}\right.$ ), obtendo uma freqüência de classificação de 20\%, 10\% a menos que a duração anterior (Dur_2 $\mathbf{2}^{\mathbf{a}}$ ); e, ii) independentemente da classificação para o segmento duração da viagem, as redes conseguiram classificar melhor o segmento correspondente à classificação da primeira atividade (At._1 $\mathbf{1}^{\mathrm{a}}$ ).

A melhor previsão da rede MLP, no segmento da primeira viagem, foi para Outras Atividades (27,0\%), seguida de Trabalho (20,4\%) e Estudo (20,3\%), e para a rede Elman de 26,6\% (W), 23,4\% (A) e 22,9\% (S). No segmento da segunda viagem observou-se a predominância da classe $\mathbf{A}$ seguida em menor proporção por $\mathbf{S}$, e, com porcentagem mínima, a classe W. Os valores obtidos para a rede MLP foram de 23,2\%, $6,7 \%$ e 2,4\%, enquanto para a rede Elman foi de 5,4\%, 4,0\% e 3,4\%, respectivamente. Para as redes MLP a freqüência de previsão da classe Outras Atividades foi 
aproximadamente quatro vezes a freqüência da classe Estudo no segmento da segunda viagem (Figuras 7.8 e 7.9 ).

Esses valores da frequiência de classificação das atividades reproduzidas pelas redes estão próximos das freqüências observadas para os dados de cada viagem do vetor de três viagens da RMSP87, como pode ser observado na Tabela 6.7, do cap. 6. Assim, os indivíduos que fazem três VEP, na primeira viagem realizam principalmente Outras Atividades (43,8\%), Estudo (29,5\%) e Trabalho (26,7\%). Enquanto que na segunda viagem a frequiência de $\mathbf{A}$ é muito maior que na primeira viagem $(68,0 \%)$, seguida de $\mathbf{S}$ $\operatorname{com} 25,3 \%$ e em menor proporção $\mathbf{W}$ com $6,7 \%$.

Quando comparadas estas frequiências com aquelas reproduzidas pelas redes, pode-se observar que na primeira viagem ambas as redes conseguem se aproximar do comportamento observado nos dados da RMSP87. Entretanto, para a segunda atividade, a rede MLP consegue representar melhor a probabilidade da realização de Outras Atividades na segunda viagem. Por outro lado, contrariando o que se esperava, a rede Elman apresentou uma baixa performance na representação da segunda atividade (Figura7.8(b)). Constatou-se também que as redes MLP com maior número de neurônios na camada intermediária conseguiram melhor classificação de atividades (Figuras 7.8(a) e 7.9(a)).

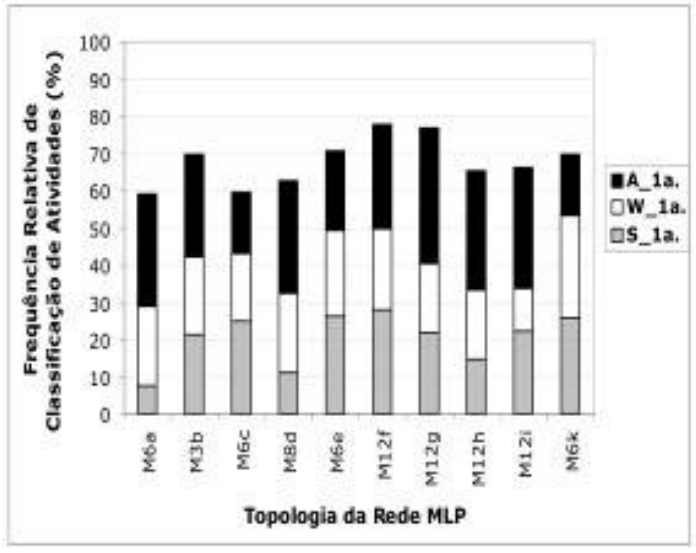

(a)

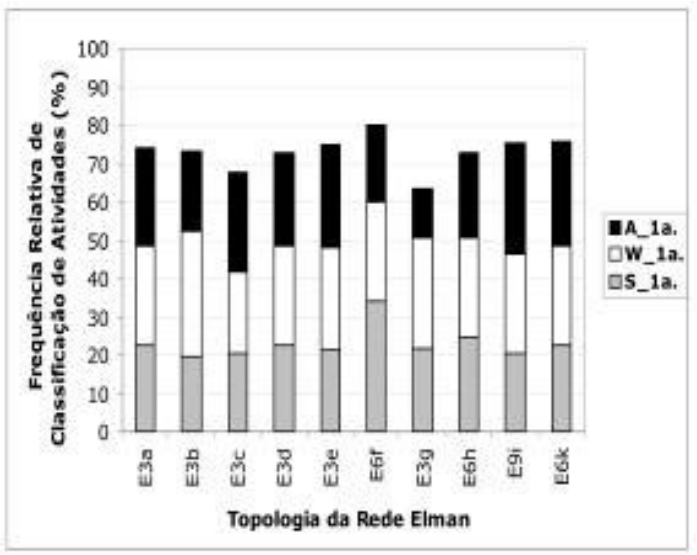

(b)

Figura 7.8: Classificação de atividades por topologia de redes MLP e Elman para TRÊS viagens encadeadas. 


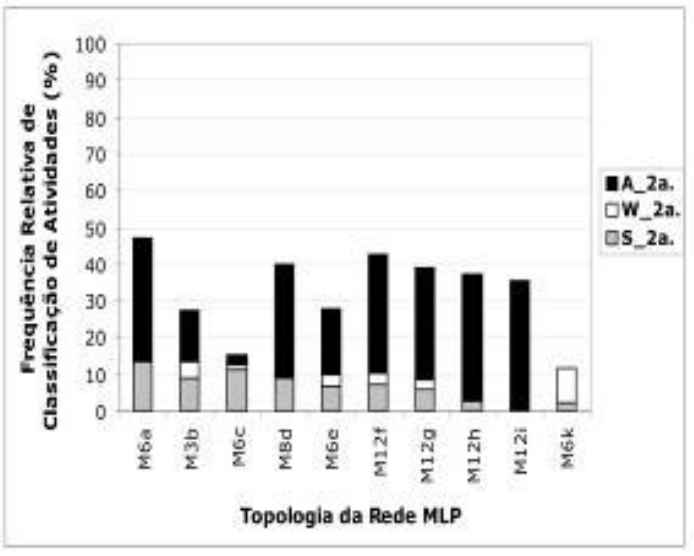

(a)

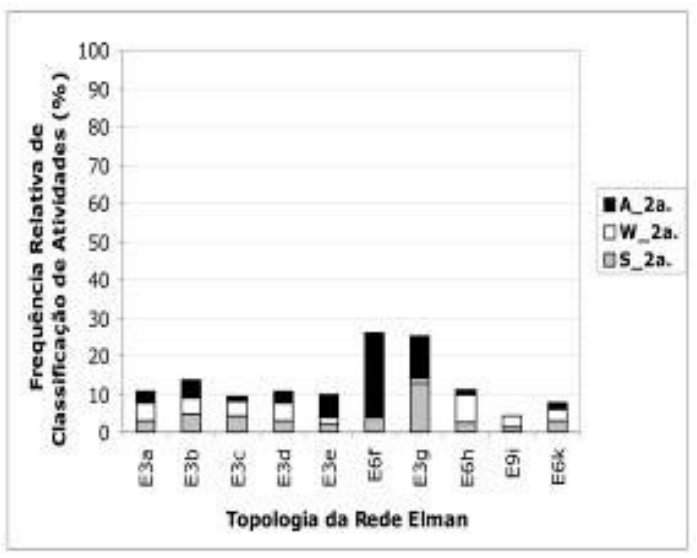

(b)

Figura 7.9: Classificação de atividades por topologia de redes MLP e Elman para TRÊS viagens encadeadas.

\subsubsection{Análise da Classificação por Padrão de Encadeamento para Três Viagens}

As topologias das redes Elman conseguiram reproduzir 2 padrões de VEP, enquanto as topologias das redes MLP reproduziram 4 dos 117 padrões contidos no conjunto da amostra de 281 indivíduos que fazem três VEP. Das Tabelas 7.8 e 7.9 constatou-se que a freqüência de padrões reproduzidos por topologia de rede não foi maior do que três e nem menor do que um, tanto para redes Elman como para MLP (Figura 7.10).

O padrão melhor representado pela rede Elman foi o 111SS com ACM de 2,0\%, seguido do padrão 211AA com 1,5\%. A rede MLP reproduziu os padrões 111WW, 222AA com $A C M$ de $2,3 \%, 1,3 \%$,respectivamente, e com 1,4\% para os padrões 212AA e 212SA. Além disso, segundo os dados do vetor de três VEP da RMSP87 (Tabela 6.9 do cap. 6), esses mesmos padrões apresentaram freqüências não tão próximas às representadas pelas redes. Assim, por exemplo, a frequiência do padrão 111SS foi de 4,3\%, e para os padrões 211AA, 111WW, 222AA, 212AA, e 212SA foi de 2,5\%, 0,4\%, $2,5 \%, 2,8 \%$ e $0,7 \%$, respectivamente. 


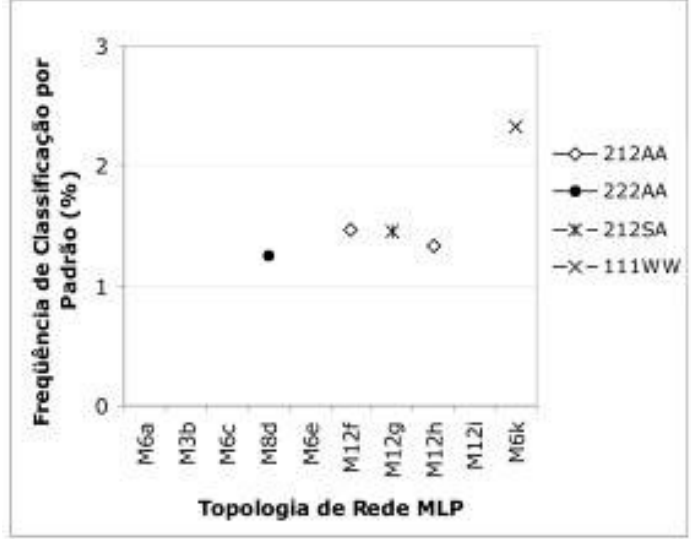

(a)

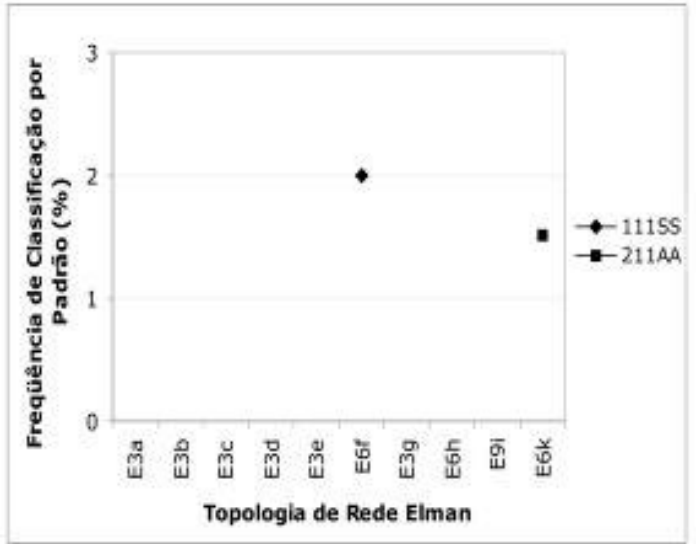

(b)

Figura 7.10: Classificação de padrões de VEP por topologia de redes MLP e Elman para TRÊS viagens encadeadas.

Conforme observado, a diferença da freqüência relativa por padrão, entre os padrões reproduzidos pelas redes e os do vetor de dados, foi inferior a $2 \%$. Essa observação permitiu inferir que o fato de as redes não conseguirem reproduzir maior número de padrões é devido à baixa freqüência de indivíduos por padrão: por causa do número insuficiente de casos similares, a rede não consegue aprender e, conseqüentemente, não consegue diferenciar os padrões no espaço das características dos indivíduos. Além disso, como foi indicado anteriormente, o vetor de três viagens contém 17 padrões com frequiência acima de 1,4\% (4 ou mais indivíduos por padrão), e 101 padrões com frequiência menor do que 1,1\% (3 ou menos indivíduos por padrão). Perante essa distribuição de indivíduos por padrão, é provável, que na formação aleatória dos conjuntos de treinamento, validação e teste, alguns dos padrões com maior freqüência passaram a formar parte majoritária de algum de tais conjuntos.

Além dessa variabilidade na representação de padrões por topologia de rede e da frequiência de classificação por padrão apresentadas na Figura 7.11, constatou-se que as redes reproduziram com maior freqüência padrões com durações de viagens menores ou iguais a 10 minutos e entre 10 e 20 min., sendo que tempos maiores a vinte minutos não foram representados pelas redes (padrões com código 3), e que as classes de atividades predominantes foram Outras Atividades (A) e Estudo (S). 


\subsection{ANÁLISE DA MODELAGEM PARA QUATRO VIAGENS ENCADEADAS}

Nas Tabelas 7.12 e 7.13 estão apresentados os resultados das simulações das redes MLP e Elman para o vetor de quatro viagens, seguindo o modelo de apresentação adotado na análise para duas e três viagens. A diferença está no fato de que os valores de Classificação da Duração de Viagem e da Classificação de Atividades foram desagregados em duração da primeira, segunda, terceira e quarta viagem (Dur_1 ${ }^{\text {a. }}$, Dur_2 $2^{\text {a. }}$, Dur_3 $3^{\text {a. }}$, Dur_4 $4^{\text {a. }}$, e primeira e segunda atividade (At._1 ${ }^{\text {a. }}$, At._2 ${ }^{\text {a. }}$ ).

Os valores correspondentes ao Erro Quadrático Médio foram organizados nas Tabelas 7.14 e 7.15, como procedido nas análises de duas e três viagens, de forma a facilitar a análise global e pontual dos resultados. Os menores valores de EQM foram grifados em negrito. 


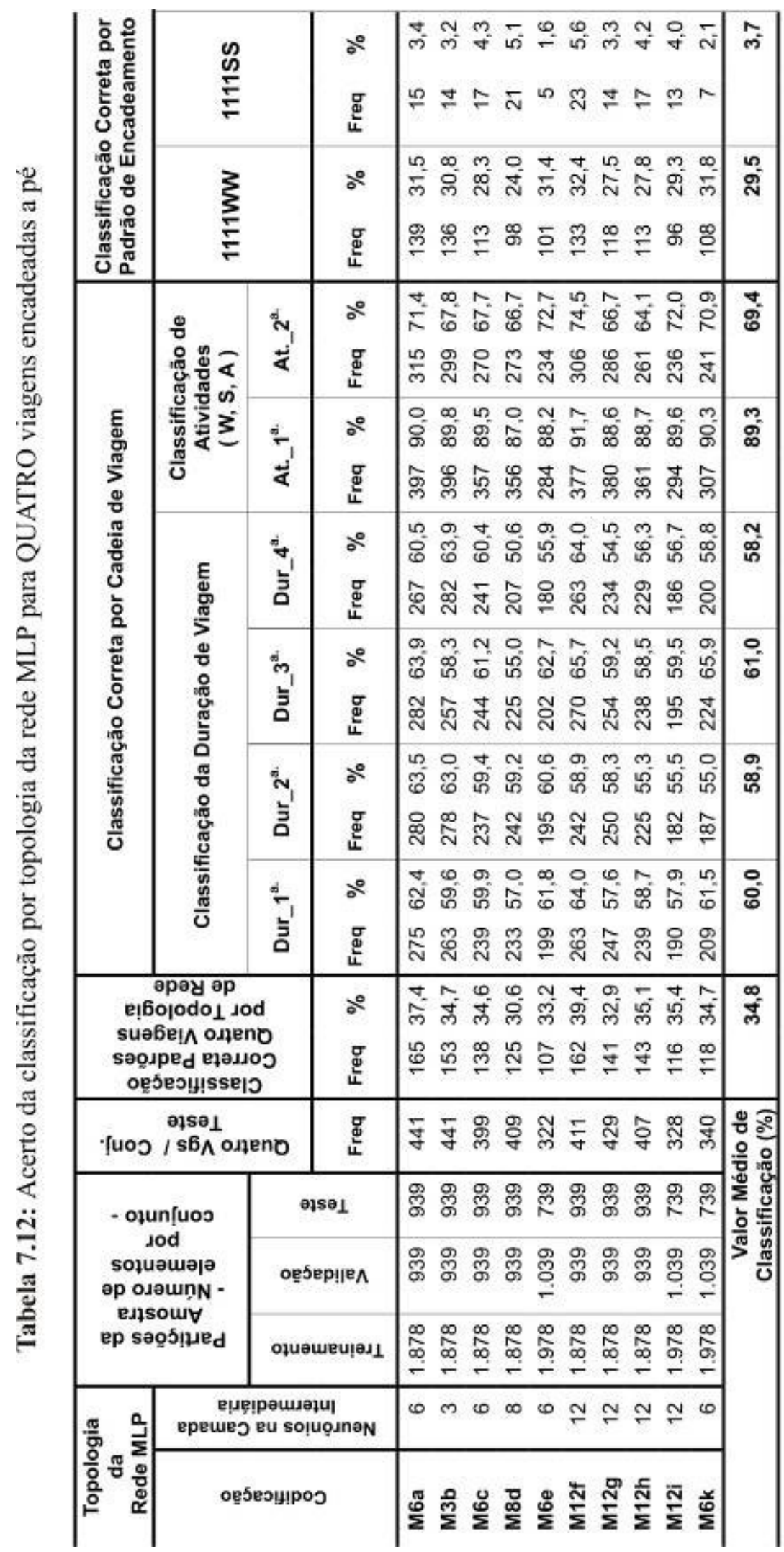




\begin{tabular}{|c|c|c|c|c|c|c|c|c|c|c|c|c|c|}
\hline \multirow{12}{*}{ 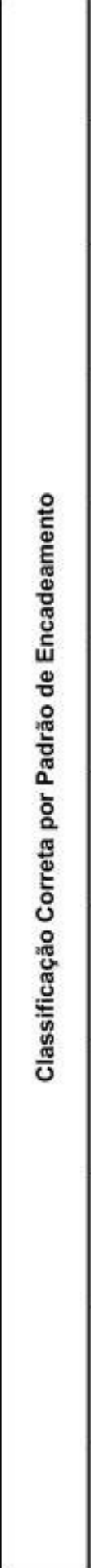 } & స్తి & $\begin{array}{l}\text { ஃ̊ } \\
\text { 。ํ }\end{array}$ & $\begin{array}{l}1 \\
1\end{array}$ & & $\begin{array}{l}1 \\
1\end{array}$ & : & I & $\begin{array}{l}1 \\
1\end{array}$ & & & & & $\stackrel{n}{0}$ \\
\hline & స్త్ & 。゚ & $\begin{array}{l}1 \\
1\end{array}$ & $\begin{array}{l}1 \\
1\end{array}$ & $\begin{array}{l}1 \\
1\end{array}$ & 1 & $\begin{array}{l}1 \\
1\end{array}$ & $\begin{array}{l}1 \\
1\end{array}$ & & I & & & ̌ㅡㅇ \\
\hline & 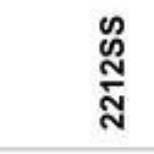 & $\begin{array}{l}\text { ஃ̊ } \\
\text { ర్ర }\end{array}$ & $\begin{array}{l}\text { I } \\
\text { : }\end{array}$ & $\begin{array}{l}1 \\
1\end{array}$ & $\begin{array}{l}1 \\
1\end{array}$ & 4 & 1 & ! & & ! & & : & Nू \\
\hline & 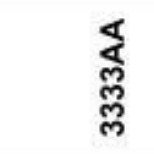 & $\begin{array}{l}\text { ஃ̊ } \\
\text { ర్జ }\end{array}$ & i & 1 & ! & 1 & 1 & $\begin{array}{l}\tilde{\sigma} \\
\sigma \\
-\end{array}$ & : & : & : & ; & Ň \\
\hline & 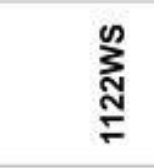 & $\begin{array}{l}\text { ஃ̊ } \\
\text { ్ㅜㄴ }\end{array}$ & i & 1 & ! & $0^{0}$ & 1 & ' & ; & i & 1 & & $\because 0$ \\
\hline & స్ & 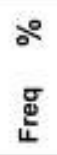 & I & 1 & 1 & yू- & 1 & 1 & $i$ & ve & 1 & & ỹ \\
\hline & 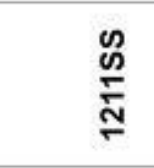 & ஃ゚ & $\begin{array}{l}1 \\
1\end{array}$ & $\begin{array}{l}1 \\
1\end{array}$ & $\begin{array}{l}1 \\
1\end{array}$ & 1 & 1 & $\begin{array}{l}\text { Na } \\
0 \\
-\end{array}$ & 4 & I & 1 & & $\stackrel{m}{0}$ \\
\hline & ホ্র & 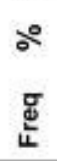 & $\begin{array}{l}\text { ב̃ } \\
-\end{array}$ & & 1 & 1 & 1 & 1 & 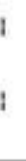 & 1 & 1 & i & Nू \\
\hline & $\stackrel{\text { 心 }}{\stackrel{\text { }}{\rightleftarrows}}$ & 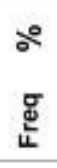 & & 1 & 1 & 1 & $i$ & $\begin{array}{l}\text { N } \\
\text { - } \\
-\end{array}$ & : & - & ! & 1 & జ̃ \\
\hline & $\underset{⿱ 亠 N}{\stackrel{N}{N}}$ & $\begin{array}{l}\text { ஃ } \\
\text { ఫ్ర }\end{array}$ & $\begin{array}{l}\text { ž } \\
\text { - } \\
-\end{array}$ & & $\begin{array}{l}1 \\
1\end{array}$ & & & 1 & & i & $\begin{array}{l}m \\
0 \\
0 \\
-\end{array}$ & & $\stackrel{0}{0}$ \\
\hline & $\underset{⿱}{\rightleftarrows}$ & $\begin{array}{l}\text { ஃ̊ } \\
\text { ్ㅜㄴ }\end{array}$ & $\begin{array}{l}\text { g- } \\
0 \\
+\end{array}$ & \begin{tabular}{l} 
ב \\
\hdashline \\
-
\end{tabular} & & i & i & $\begin{array}{l}0 \\
0 \\
\text { No }\end{array}$ & & & $\begin{array}{l}\stackrel{0}{0} \\
\sim \\
N\end{array}$ & & $\stackrel{\infty}{0}$ \\
\hline & జ્心 & $\begin{array}{l}\text { ஃ̊ } \\
\frac{\sigma}{2} \\
\frac{\pi}{4}\end{array}$ & $\begin{array}{l}\text { g- } \\
0 \\
+\end{array}$ & & $\begin{array}{l}9 \\
\sigma^{\circ} \\
-\end{array}$ & & & & & & 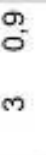 & & $\stackrel{\infty}{\infty}$ \\
\hline \multirow{2}{*}{ 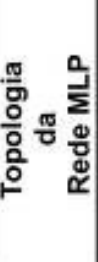 } & \multicolumn{2}{|c|}{ 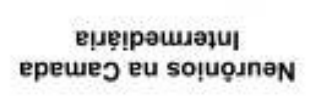 } & $\omega$ & $m$ & $\omega$ & & & $\stackrel{\sim}{\simeq}$ & & & $\stackrel{\sim}{\simeq}$ & & 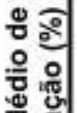 \\
\hline & \multicolumn{2}{|c|}{ ор5еэицроэ } & & . & : & & & 4 & & & $\stackrel{\text { N }}{=}$ & & 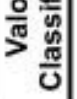 \\
\hline
\end{tabular}




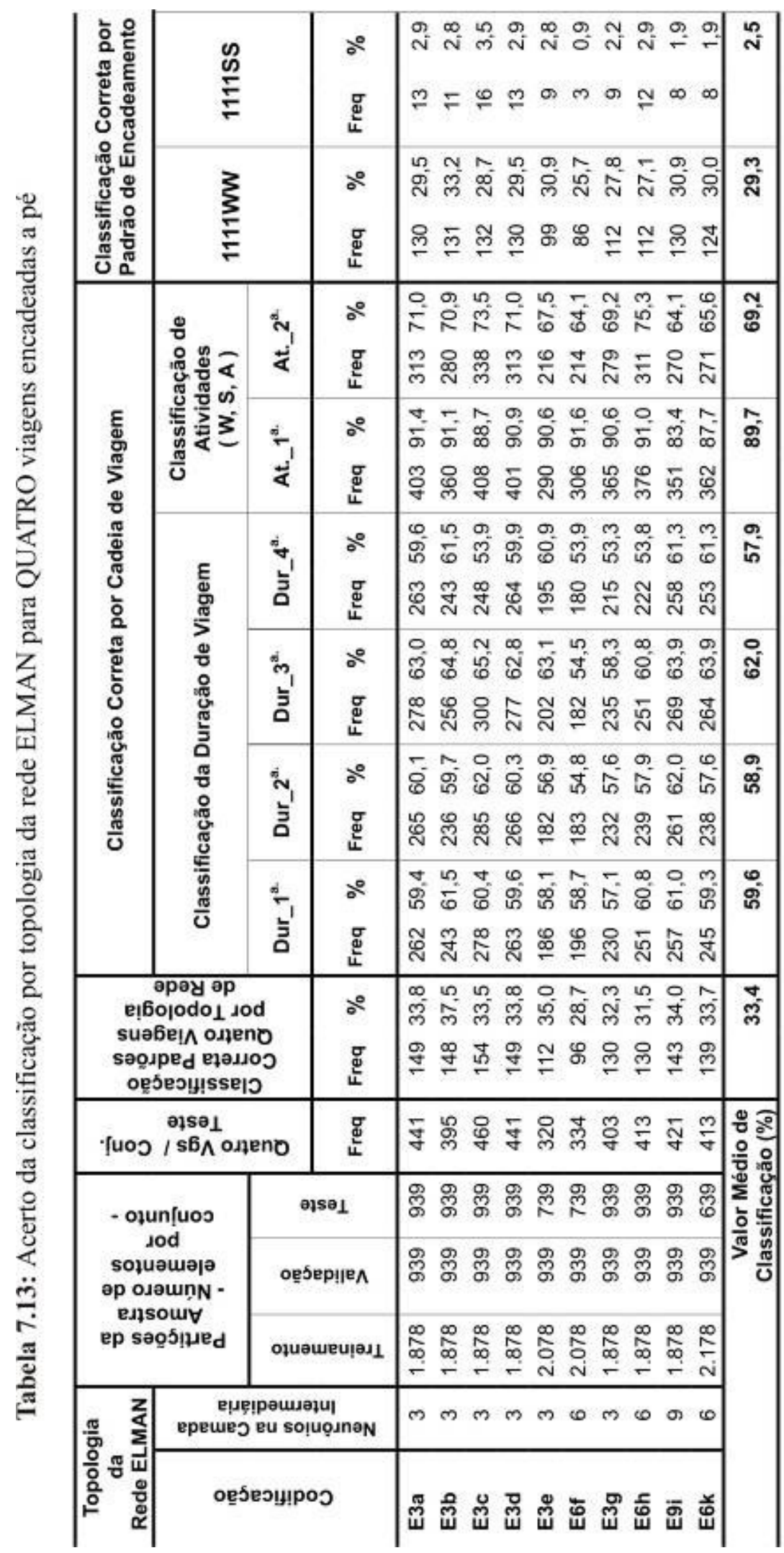




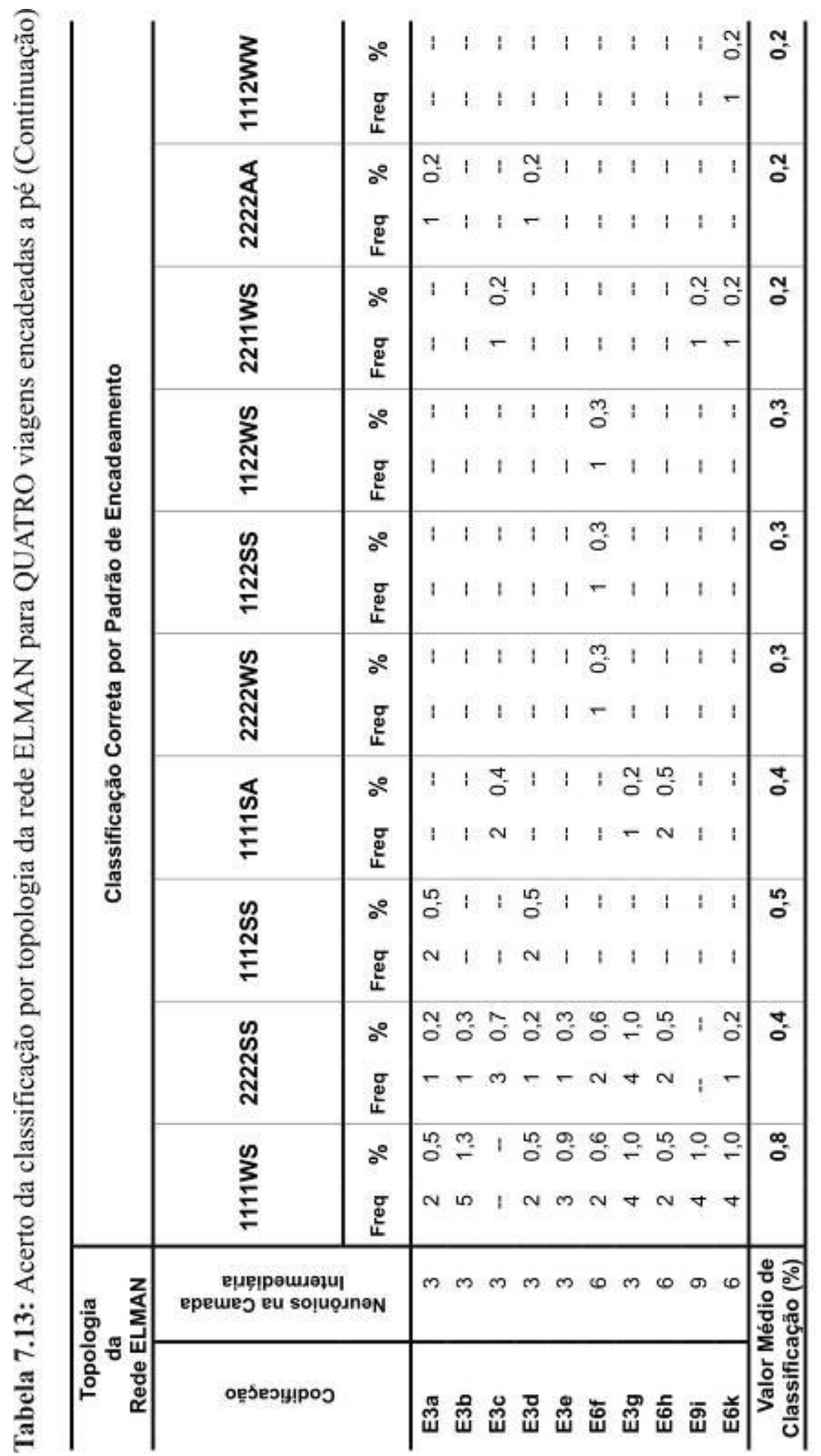


Tabela 7.14: Erro quadrático médio $(\boldsymbol{E} Q M)$ de classificação por topologia da rede MLP para QUATRO viagens encadeadas a pé

\begin{tabular}{|c|c|c|c|c|c|c|c|c|c|}
\hline \multirow{2}{*}{ 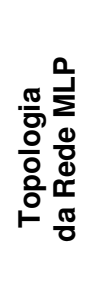 } & \multirow{2}{*}{ 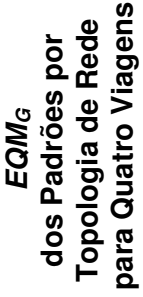 } & \multicolumn{5}{|c|}{$\begin{array}{c}\text { EQM por Cadeia da Duração } \\
\text { de Viagem }\end{array}$} & \multicolumn{3}{|c|}{$\begin{array}{l}E Q M_{A} \text { por Cadeia de } \\
\text { Atividades }\end{array}$} \\
\hline & & $\begin{array}{c}E Q M_{D} \\
\text { Dur_Gral. }\end{array}$ & $\begin{array}{l}E Q M_{D 1} \\
\text { Dur_1 }\end{array}$ & $\begin{array}{l}E Q M_{D 2} \\
\text { Dur_2 }\end{array}$ & $\begin{array}{l}E Q M_{D 3} \\
\text { Dur_3 }^{\text {a. }}\end{array}$ & $\begin{array}{l}E Q M_{D 4} \\
\text { Dur_4 }\end{array}$ & $\begin{array}{c}E Q M_{A} \\
\text { At._Gral. }\end{array}$ & $\begin{array}{l}E Q M_{A 1} \\
\text { At._1 }{ }^{\text {a. }}\end{array}$ & $\begin{array}{l}E Q M_{A 2} \\
\text { At._2 }\end{array}$ \\
\hline M6a & 2,780 & & & 000 & 4 & & 0,621 & ,120 &, 501 \\
\hline M3b & 2,893 & 5,540 & 0,574 & 1,086 & 1,626 & 2,254 & 0,639 & 0,122 & 0,517 \\
\hline M6c & 3,160 & 5,799 & 0,596 & 1,138 & 1,697 & 2,368 & 0,792 & 0,188 & 0,604 \\
\hline M8d & 3,274 & 5,900 & 0,555 & 1,081 & 1,746 & 2,518 & 0,756 & 0,159 & 0,597 \\
\hline M6e & 2,832 & 5,099 & 0,466 & 0,953 & 1,484 & 2,196 & 0,637 & 0,146 & 0,491 \\
\hline M12f & 2,730 & 5,287 & 0,506 & 1,027 & 1,555 & 2,200 & 0,530 & 0,119 & 0,411 \\
\hline M12g & 3,198 & 5,737 & 0,543 & 1,051 & 1,702 & 2,441 & 0,758 & 0,149 & 0,608 \\
\hline M12h & 3,049 & 5,521 & 0,531 & 1,052 & 1,641 & 2,297 & 0,752 & 0,157 & 0,595 \\
\hline M12i & 3,131 & 6,034 & 0,585 & 1,186 & 1,802 & 2,460 & 0,671 & 0,131 & 0,540 \\
\hline M6k & 2,906 & 5,326 & 0,491 & 1,012 & 1,571 & 2,253 & 0,653 & 0,165 & 0,488 \\
\hline
\end{tabular}

Tabela 7.15: Erro quadrático médio $(\boldsymbol{E} Q \boldsymbol{M})$ de classificação por topologia da rede Elman para QUATRO viagens encadeadas a pé.

\begin{tabular}{|c|c|c|c|c|c|c|c|c|c|}
\hline \multirow{2}{*}{ 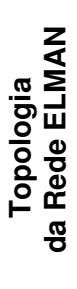 } & \multirow{2}{*}{ 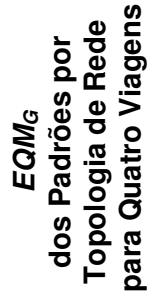 } & \multicolumn{5}{|c|}{$\begin{array}{c}\text { EQM por Cadeia da Duração } \\
\text { de Viagem }\end{array}$} & \multicolumn{3}{|c|}{$\begin{array}{l}E Q M_{A} \text { por Cadeia de } \\
\text { Atividades }\end{array}$} \\
\hline & & $\begin{array}{c}E Q M_{D} \\
\text { Dur_Gral. }\end{array}$ & $\begin{array}{l}E Q M_{D 1} \\
\text { Dur_1 }^{\text {a. }}\end{array}$ & $\begin{array}{l}E Q M_{D 2} \\
\text { Dur_2. }\end{array}$ & $\begin{array}{l}E Q M_{D 3} \\
\text { Dur_3 }^{\text {a. }}\end{array}$ & $\begin{array}{l}E Q M_{D 4} \\
\text { Dur_4 }^{\text {a. }}\end{array}$ & $\begin{array}{c}E Q M_{A} \\
\text { At._Gral. }\end{array}$ & $\begin{array}{l}E Q M_{A 1} \\
\text { At._1 }{ }^{\text {a. }}\end{array}$ & $\begin{array}{l}E Q M_{A 2} \\
\text { At._22. }\end{array}$ \\
\hline E3a & 2,923 & 5,372 & 0,535 & 1,043 & 1,562 & 2,231 & 0,692 & 0,107 & 0,585 \\
\hline E3b & 2,861 & 5,276 & 0,506 & 1,030 & 1,554 & 2,185 & 0,676 & 0,127 & 0,549 \\
\hline E3c & 3,050 & 5,452 & 0,520 & 1,024 & 1,548 & 2,361 & 0,689 & 0,152 & 0,537 \\
\hline E3d & 2,916 & 5,324 & 0,526 & 1,032 & 1,546 & 2,220 & 0,696 & 0,111 & 0,585 \\
\hline E3e & 2,988 & 5,506 & 0,531 & 1,094 & 1,622 & 2,259 & 0,728 & 0,141 & 0,588 \\
\hline E6f & 3,338 & 5,844 & 0,512 & 1,063 & 1,737 & 2,533 & 0,805 & 0,138 & 0,668 \\
\hline E3g & 3,015 & 5,516 & 0,511 & 1,017 & 1,630 & 2,357 & 0,658 & 0,132 & 0,526 \\
\hline E6h & 3,051 & 5,579 & 0,494 & 1,024 & 1,632 & 2,429 & 0,622 & 0,104 & 0,518 \\
\hline E9i & 2,884 & 5,000 & 0,482 & 0,941 & 1,444 & 2,133 & 0,751 & 0,209 & 0,542 \\
\hline E6k & 2,973 & 5,446 & 0,508 & 1,041 & 1,603 & 2,293 & 0,680 & 0,160 & 0,521 \\
\hline
\end{tabular}

O menor valor do $E Q M_{G}$ da rede Elman foi igual a 2,861 (rede E3b) e para a rede MLP correspondeu um valor de 2,73 (rede M12f). A rede E9i apresentou o menor valor 
do $E Q M_{D}=5,000$ de todas as topologias de redes MLP e Elman. No que se refere a classificação das atividades, a rede M12f também apresentou o menor valor de $E Q M_{A}=$ 0,530. Para a rede Elman o $E Q M_{D}=0,622$ correspondeu à rede E6h.

\subsubsection{Análise da Classificação dos Padrões de VEP por Topologia de Rede para Quatro Viagens}

O vetor de quatro viagens é constituído por 1.675 dados obtidos da seleção de 36 padrões de VEP. Os padrões de VEP da amostra mais freqüentes foram o 1111WW, 1111SS, 1111WS, 2222SS, 1112SS, 2211WS e 2222WS com freqüência relativa de $39,8 \%, 16,1 \%, 3,3 \%, 5,3 \%, 0,9 \%, 1,6 \%$, e $1,9 \%$, respectivamente.

Dos resultados das redes MLP e Elman modeladas, apresentados nas Tabelas 7.12 e 7.13, e representados na Figura 7.11, pode-se afirmar que não foi encontrada nenhuma diferença significativa no desempenho de ambas as redes, tanto na freqüência media de classificação por duração de viagem e atividade, quanto nos padrões de viagens encadeadas reproduzidos. Quanto aos padrões de VEP, observou-se que ambas as topologias de redes conseguiram reproduzir o padrão 1111WW com a mesma freqüência de ocorrência da amostra. Dos demais padrões, o melhor representado foi o padrão 1111SS com $A C M$ de 3,7\% pela rede MLP (Figura 7.11(b)).

Era de esperar-se que as redes conseguissem representar melhor as cadeias de duas viagens do que as cadeias de quatro viagens, mas isto não aconteceu. Como pode ser observado nos resultados de quatro viagens da Figura 7.11(a), as redes MLP e Elman conseguiram reproduzir melhor a freqüência da classificação geral dos padrões e a duração das viagens, do que foi reproduzido para duas viagens. Isso mostra a influencia das características das variáveis de entrada na rede. Como constatou-se na Tabela 6.1 do cap. 6, as características das variáveis Individuais e Domiciliares do vetor de duas viagens estão mais concentrados em determinadas classes, embora a probabilidade de indivíduos similares fazerem padrões diferentes é maior. Já para o vetor de quatro viagens, essas características encontram-se distribuídas com certa uniformidade na maior parte das classes, e as restrições de tempo durante o dia limitam os períodos em que as viagens são realizadas, restringindo a duração das viagens. 


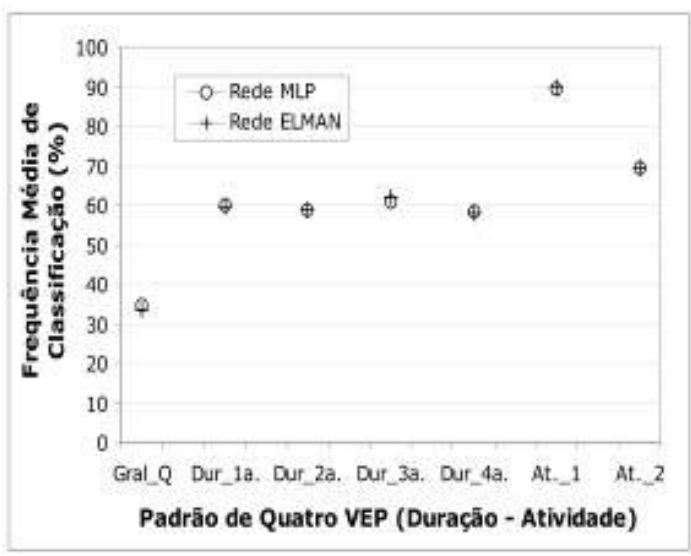

(a)

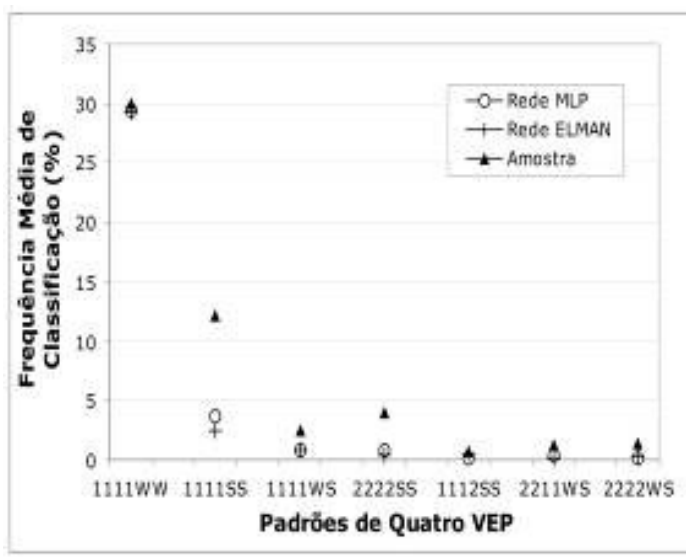

(b)

Figura 7.11: Freqüência média de classificação das redes MLP e Elman para QUATRO viagens encadeadas.

Quanto ao $A C M$, este foi de $34,8 \%$ com desvio padrão de $2,42 \%$, para a rede MLP, e de 33,4\% com desvio padrão de 2,27\% para a rede Elman. Para a duração da viagem, o $A C M$ está em torno de $60 \%$, ou seja $10 \%$ a mais do que o $A C M$ observado na modelagem de duas viagens. Pode ser que, indivíduos que realizam duas viagens têm uma maior variabilidade nas durações de tempo de cada viagem, enquanto que para quem faz quatro viagens as durações ficam mais restritas e com certa padronização. Na classificação das atividades, o $A C M$ se manteve em torno de $90 \%$ para a primeira atividade, similar ao $A C M$ da modelagem de duas viagens, e em torno de $70 \%$ para a segunda atividade

\subsubsection{Análise da Classificação por Cadeia de Viagem para Quatro Viagens: Duração - Atividade}

Nas Tabelas 7.12 e 7.13 foram determinados os $A C M$ da duração de viagem. Quando comparados os $A C M$ das topologias das redes simuladas, Elman e MLP, observou-se que não existe uma diferença significativa entre esses valores. Entretanto, ambas as redes conseguiram melhores $A C M$ para cada segmento de duração da viagem do que os observados para as cadeias de duas e três viagens. Os resultados foram aproximadamente $10 \%$ e $25 \%$ superiores, respectivamente. Conclui-se que as redes conseguiram classificar melhor a duração de viagem dos padrões de quatro VEP. 
Quanto à classificação das atividades, observou-se que quando comparados o $A C M$ do segmento da primeira e segunda viagem, em ambas as redes, o segmento correspondente a primeira viagem foi melhor classificado. Para a rede MLP observou-se um $A C M$ de $89,3 \%$ na primeira viagem e $69,4 \%$ na segunda viagem, e, para a rede Elman esses valores foram de 89,7\% e 69,2\%, respectivamente (Tabelas 7.12 e 7.13).

Para o tipo de atividade classificada por cada rede e em cada segmento da viagem, foi determinado que ambas as redes conseguiram reproduzir a preponderância da classe de atividade Trabalho para o segmento da primeira e segunda viagem, seguido da classe Escola. A distribuição de valores de classificação por tipo de atividade para a rede MLP na primeira atividade (At._1 ${ }^{\text {a }}$.) foi de 61,8\% para Trabalho (W), 26,7\% para Estudo (S) e 0,9\% para Outras Atividades (A). Para a segunda atividade (At._2 ${ }^{\mathbf{a}}$.), 43,7\% foi para $\mathbf{W}, 24,8 \%$ para $\mathbf{S}$ e $0,9 \%$ para $\mathbf{A}$. Na rede Elman, a distribuição de classificação na primeira atividade foi de $61,8 \%$ para $\mathbf{W}, 26,7 \%$ para $\mathbf{S}$ e 1,2\% para $\mathbf{A}$, e na segunda atividade foi de 46,3\% para $\mathbf{W}, 22,1 \%$ para $\mathbf{S}$ e 0,8\% para $\mathbf{A}$ (Figuras 7.12 e 7.13).

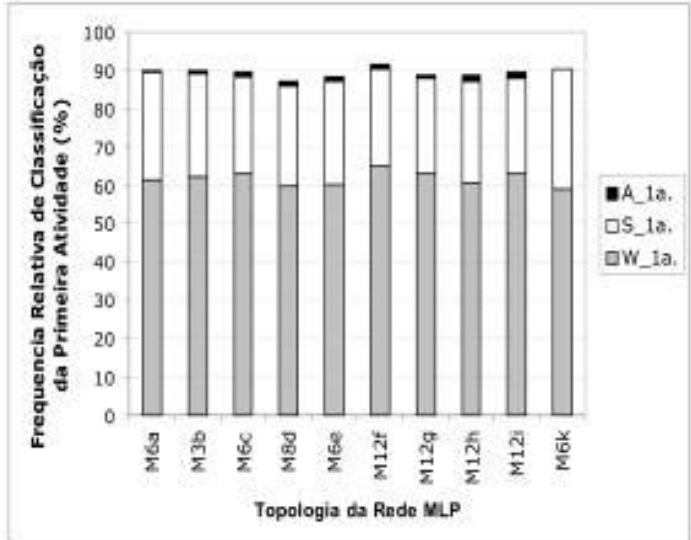

(a)

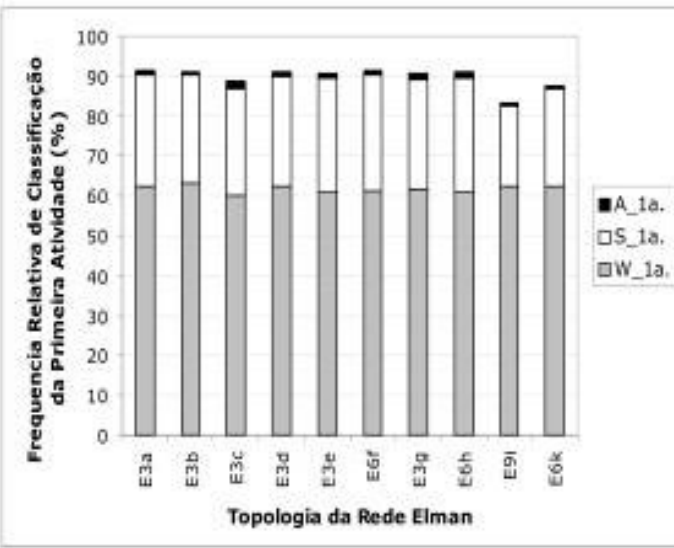

(b)

Figura 7.12: Classificação de atividades por topologia de redes MLP e Elman para QUATRO viagens encadeadas.

Todavia, para os dados observados do vetor de quatro viagens da RMSP87 (Tabela 6.7 do cap. 6), constatou-se que, a primeira atividade realizada foi Trabalho com $57,7 \%$, seguida de Estudo com 33,4\% e Outras Atividades com 8,9\%. A comparar esses valores com os previstos pelas redes, para a At._1 ${ }^{\mathbf{a}}$, observou-se que as redes se 
aproximaram dos valores observados para $\mathbf{W}$ e $\mathbf{S}$, mas ficaram distantes de $\mathbf{A}$. Para a segunda atividade, os dados observados foram $47,1 \%$ para $\mathbf{W}, 38,9 \%$ para $\mathbf{S}$, e $14,4 \%$ para A. Quando comparados os valores observados de $\mathbf{W}$ com os previstos pelas redes para a segunda atividade, nota-se que a frequiência prevista pela rede Elman é próxima do valor observado, para $\mathbf{S}$, a frequiência prevista é inferior em $14 \%$, e para $\mathbf{A}$, o valor observado está acima do previsto em 13\%, aproximadamente.

Dos dados do Vetor das variáveis Individuais e Domiciliares dos indivíduos que fazem quatro viagens encadeadas a pé na RMSP87 (Tabela 6.1 do cap. 6), foi observado, em função das características socioeconômicas, 40,8\% são filhos e 46,3\% são ou Chefes de Família ou Cônjuges, 64,2\% trabalham e 31,1\% estudam. Quanto ao grau de instrução, $30 \%$ são Analfabetos ou com $4^{\circ}$ Série Incompleta, e 42,5 pertencem ao grupo com $4^{\circ}$ Serie Completa mas $1^{\circ}$ Grau Incompleto. No que se refere à Idade, $42 \%$ correspondem a idades entre 10 e 25 anos e 32,3\% entre 25 e 40 anos. Esses dados ajudam a explicar a classificação das atividades apresentada nas Figuras 7.12 e 7.13, pois é de se esperar que indivíduos chefes de família e que trabalham realizem viagens do tipo HWHWH, e se estudam, são filhos, e estão próximos da idade adulta, fazem viagens do tipo HWHSH.

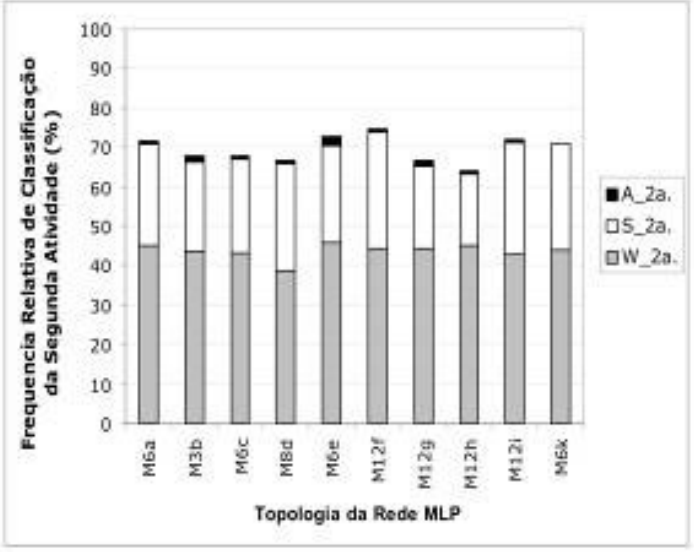

(a)

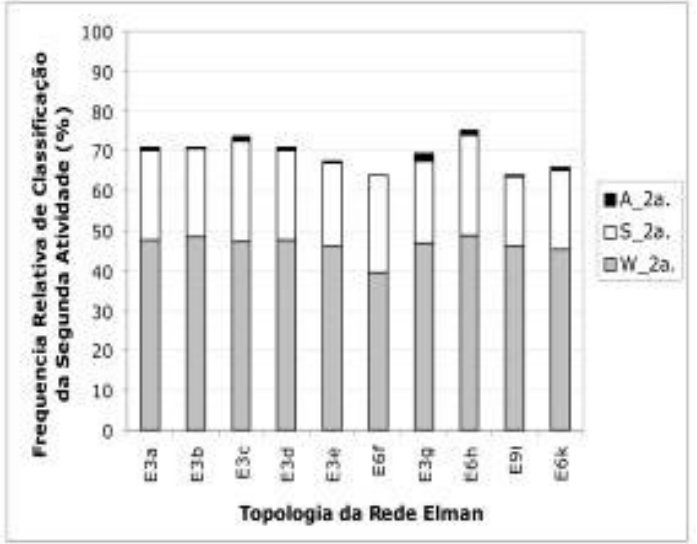

(b)

Figura 7.13: Classificação de atividades por topologia de redes MLP e Elman para QUATRO viagens encadeadas. 


\subsubsection{Análise da Classificação por Padrão de Encadeamento para Quatro Viagens}

A rede MLP e Elman reproduziram respectivamente 14 e 12 dos 36 padrões de viagens encadeadas contidos na amostra do vetor de quatro viagens (Tabelas $7.12 \mathrm{e}$ 7.13), sendo o padrão 1111WW o mais representativo com um valor médio de classificação de 29,5\% (este padrão representou 29,9\% do total da amostra), seguido do padrão 1111SS com $A C M$ de 3,7\%. Observou-se que em forma geral, independentemente do tipo de rede modelada, a atividade Trabalho $(\mathbf{W})$ foi a melhor representada, seguida da atividade Estudo $(\mathbf{S})$. Porém, a variável atividade no padrão de VEP foi adequadamente representada no padrão de viagem, sendo coincidente com o $A C M$ que foi observado para as atividades mostrado no item anterior (Figura 7.14).

No que se refere ao padrão mais predominante, observou-se que, em função da freqüência de classificação por padrão de VEP reproduzidos por cada tipologia de rede, dois tipos de padrões foram os predominantes: 1111WW e 1111SS. A freqüência relativa observada para os dois padrões, em ambas as topologias de redes simuladas, manteve-se estável numa faixa de classificação de $24 \%$ a $33 \%$ (padrão $\mathbf{1 1 1 1 W W}$ ), e de 0.93\% a 6\% (1111SS). Outros padrões como o 2222SS foram classificados próximos de $1 \%$ distante do valor de classificação de $4 \%$ observado na amostra (Figura 7.14).

Como indicado por Pitombo (2003), a realização de padrões do tipo 1111SS e 2222SS, ocorre provavelmente para levar ou buscar crianças na escola, realizadas basicamente pelas empregadas domésticas ou cônjuges. Com isso, os períodos do dia em que são executadas as viagens, assim como os lugares de destino são bem definidos, porém a atratividade por vagas na escola é uma variável de importância na representação desses tipos de padrões. Outra observação, que pode ser derivada do fato que a rede não representou padrões com duração acima de 20 min. (deslocamentos maiores de $1,75 \mathrm{~km}$ ), é resultado da pouca probabilidade de crianças caminharem tais distâncias, sendo o mais provável o uso de outro tipo de modo de transporte. No relacionado com o padrão $\mathbf{1 1 1 1 W W}$, é provável que indivíduos que fazem esses padrões sejam chefes de família trabalhando no período da manhã e à tarde saindo na procura de atividades relacionadas com a manutenção da família. 


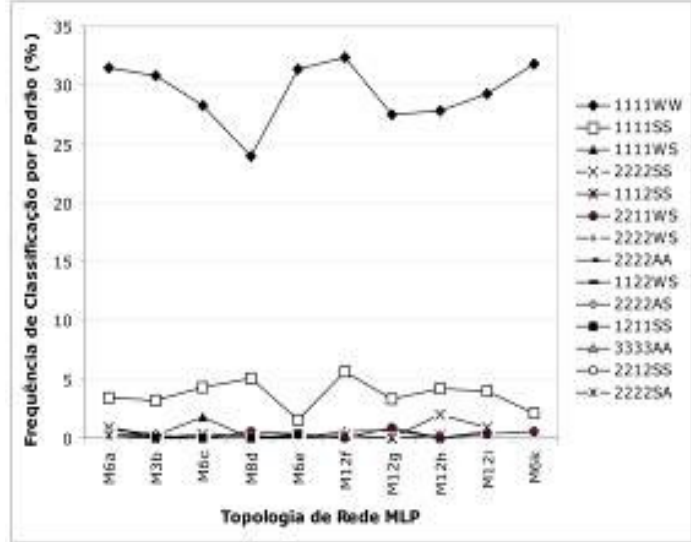

(a)

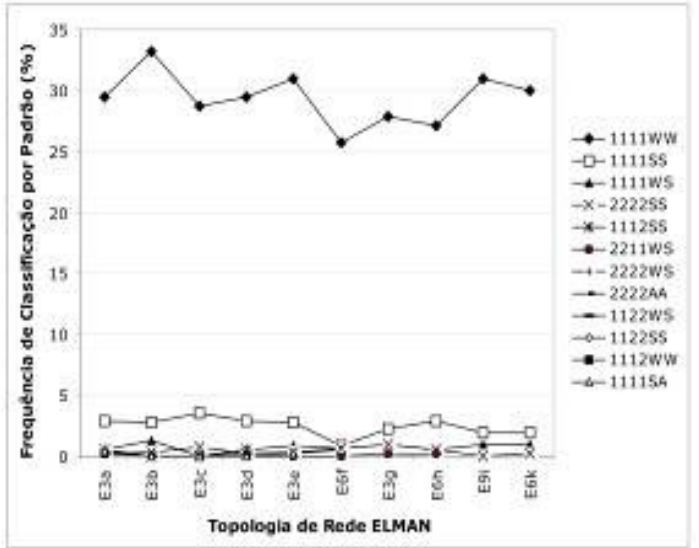

(b)

Figura 7.14: Classificação de PVE por topologia de redes MLP e Elman para QUATRO viagens encadeadas.

A comparação do comportamento dos padrões reproduzidos por ambos os tipos de rede, permite concluir que as duas topologias de rede (Elman e MLP) conseguem representar uniformemente os padrões de VEP, embora as freqüências de classificação não sejam tão próximos dos observados na amostra.

Outro achado importante está relacionado com a representação da duração da atividade. Como foi observado, padrões com duração menor que dez minutos, e entre 10 e vinte minutos, foram majoritários na classificação das redes, embora durações superiores a vinte minutos (código 3) tenham sido pouco reproduzidos como foi o caso do padrão 3333AA com freqüência de 0,2 .

Finalmente, as análises realizadas a partir dos padrões de VEP reproduzidos pelas redes, permitem resumir como conclusão geral deste capítulo em cinco aspectos:

i) em função da representatividade dos padrões, determinou-se que os cinco padrões reproduzidos com maior freqüência pelas redes $(11 S, 22 S, 22 \mathrm{~W}, 1111 \mathrm{WW}$, 1111SS), representaram em média o 58,9\% dos indivíduos da amostra de teste; 
ii) com relação ao acerto de classificação dos padrões, em média, as redes reproduziram $28,5 \%$ dos 180 padrões modelados;

iii) as RNAs conseguiram representar em média com $90 \%$ as influências das atividades Trabalho e Escola na realização de duas e quatro viagens encadeadas;

iv) aspectos da duração de viagem foram representados, para durações menores que dez minutos e entre dez e vinte minutos, com frequiências de classificação em média de $50 \%$, para duas e quatro viagens;

v) Embora a simplificação adotada no processo de modelagem não contribuiu em melhores valores de acerto de classificação, por outro lado o sequenciamento das viagens foi reproduzido, pois puderam ser obtidos padrões tanto de duas, três e quatro viagens encadeadas. 


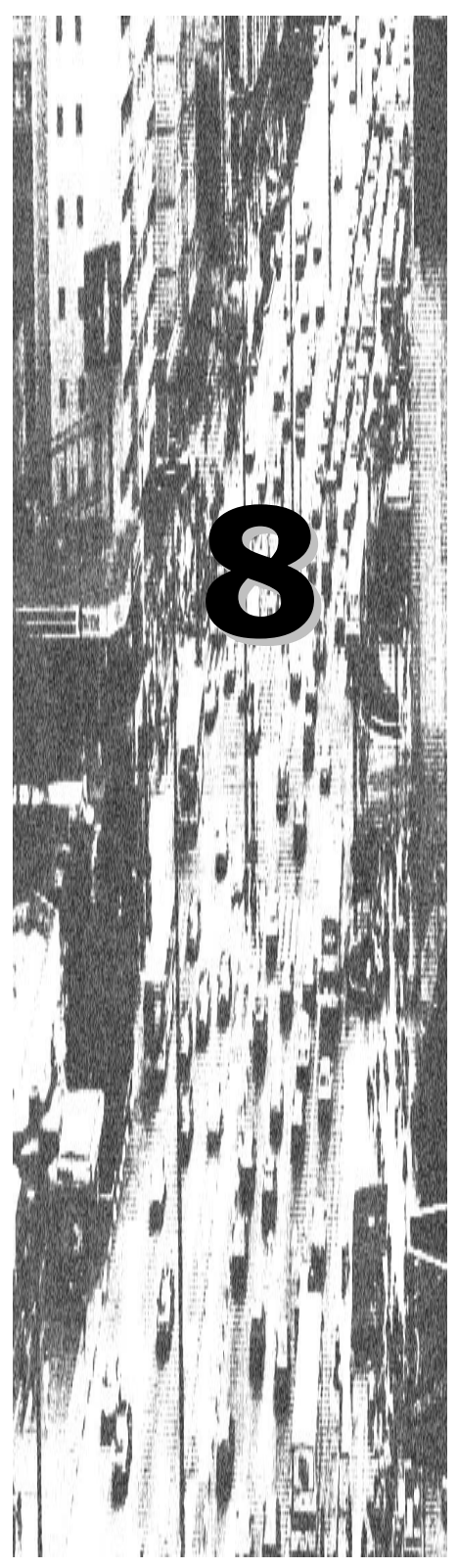

\section{Conclusões e recomendações}

"Lo difícil lo hacemos inmediatamente; lo imposible se demora um poquito"

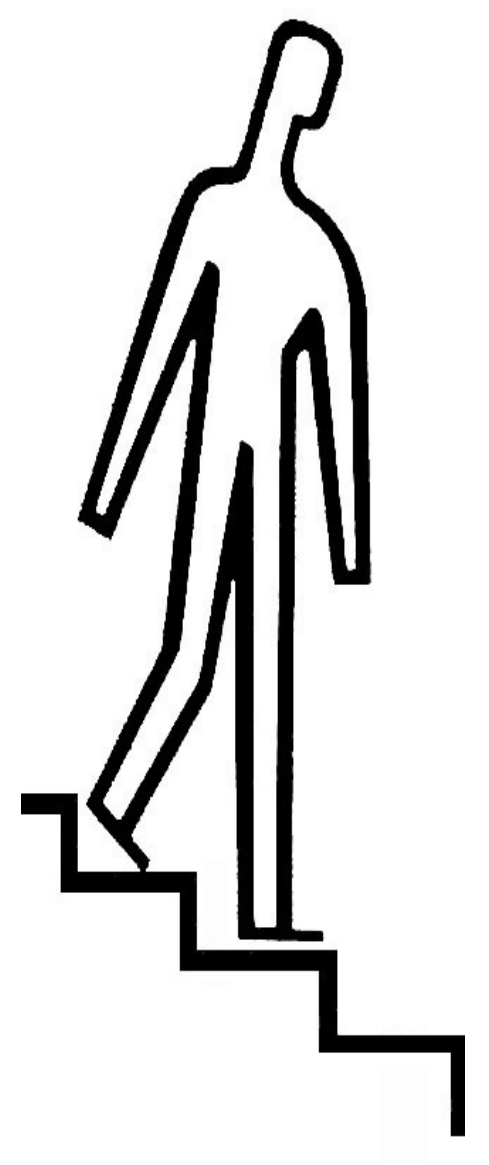




\section{CONCLUSÕES E RECOMENDAÇÕES}

\subsection{INTRODUÇÃO}

Antes de começar a descrição das principais conclusões do presente trabalho, o autor considera necessário realizar uma breve resenha do ponto de partida da pesquisa, e, de como aconteceu a presente abordagem. Acredita-se que isso dará subsídio a reflexão acerca de como aprimorar presente abordagem e de como desenvolver novas abordagens na área de modelagem de viagens encadeadas.

No começo do desenvolvimento do tema desta pesquisa, vários procedimentos foram efetuados para modelagem de encadeamento de viagens diários, fazendo uso de RNAs. Os dados utilizados correspondem aos da Pesquisa Domiciliar Origem/Destino da Região Metropolitana de São Paulo de 1987 (RMSP87). Dessa base foram empregados como vetores de entrada do modelo as características individuais e domiciliares (variáveis comportamentais), e, os atributos das coordenadas das zonas de tráfego (variáveis espaciais). Para os vetores de saída, foram considerados os atributos das viagens, agrupados em quatro modos, quatro motivos de viagem, e, seis períodos de viagem. Posteriormente, nos vetores de saída, em lugar dos atributos das viagens foram considerados os atributos de atratividade por empregos e matrículas das zonas de destino. A quantidade de variáveis envolvidas na modelagem e o tamanho dos arquivos dos dados fizeram perder bastante tempo no seu tratamento, uma etapa prévia à 
simulação. Foram modeladas diversas topologias de redes MLP, assim como diversos arranjos das variáveis comportamentais e espaciais, tanto na divisão por classes, quanto nos limites de normalização das mesmas. Contudo, os acertos de classificação e erros obtidos estiveram aquém do aceitável.

Assim, devido a esta ordem de eventos considerou-se necessário dar um novo direcionamento na pesquisa., sem sair da abordagem de viagens encadeadas. Para isso, vários fatores contribuíram no estabelecimento de novos objetivos. Um primeiro fator foi a descoberta realizada por Ichikawa (2002) que a partir da base de dados da RMSP87 - fazendo uso de um minerador de dados -, determinou que "indivíduos que têm atributos socioeconômicos e de viagem similares não se comportam de maneira similar; pelo contrário, eles fazem diferentes padrões de viagens encadeadas, as quais podem ser descritas em termos de probabilidade ou freqüência associada a cada padrão". Com isso, o acerto por si só não representa de forma total o que a rede está classificando, de tal modo que a procura por resultados com pouco erro ficou fora de cogitação, mudando-se para avaliar a representatividade na classificação dos padrões, isto é, no reconhecimento e reprodução dos padrões. O segundo fator animador foi deparar com redes que possuem características dinâmicas, chamadas de redes temporais. Embora pouco conhecidas e quase não utilizadas na área de transportes, apresentaram-se como potencialmente úteis para resolver o problema de representação espaço-temporal da modelagem de viagens encadeadas. Um outro fator foi a complexidade no arranjo das variáveis utilizadas, e que por se tratar de uma pesquisa pioneira na área, não se contava com experiências que pudessem subsidiar elementos de ponderação, ficando tudo por conta da experimentação.

Com isso, o enfoque da modelagem passou a ser mais específico, considerando apenas o encadeamento de viagens a pé, e os atributos da viagem a serem modelados seriam a duração de viagem e as atividades realizadas. Foi com base nisso que a presente tese foi desenvolvida. 
A seguir, são apresentadas as conclusões referentes aos aspectos ligados à análise de atividades e viagens encadeadas, redes neurais artificiais que permitiram a formulação do modelo, e os resultados da aplicação do mesmo.

\subsection{CONCLUSÕES}

O objetivo principal deste trabalho foi desenvolver a modelagem através do uso das técnicas das Redes Neurais Artificiais (RNA) visando reconhecer e reproduzir padrões de comportamento individual de encadeamento de viagens encadeadas a pé, de modo a acrescentar procedimentos e técnicas de análise e previsão na modelagem da demanda por transportes, que considerem fundamentalmente as dinâmicas do comportamento individual juntamente com as influências domiciliares e as restrições espaço-temporal. Com isso foi desenvolvido um Modelo Neural de Encadeamento de Viagens a Pé (MONEVPE), em cuja formulação foram considerados vários aspectos levantados na revisão bibliográfica.

Como observado na literatura especializada, o desenvolvimento urbano influencia diretamente as decisões individuais e domiciliares. Por outro lado, o desenvolvimento urbano e as decisões individuais afetam o desempenho do sistema de transporte. Como tal, o transporte é um componente vital do sistema socioeconômico. O planejamento seguro, eficiente, e efetivo dos sistemas de transportes é importante para o funcionamento do sistema socioeconômico. Tal planejamento pode ser adequadamente executado sobre a base de um bom entendimento do comportamento da viagem e da habilidade em predizer a resposta dos indivíduos a mudanças no sistema de transporte ou nos sub-sistemas de atividades bem como no ambiente socioeconômico e demográfico.

Em vista disso, primeiramente, desenvolveu-se neste trabalho um levantamento bibliográfico que permitisse o entendimento sobre o comportamento da viagem. A viagem é inerentemente um fenômeno comportamental complexo. Essa complexidade deriva de relações entre a viagem e a participação em atividades e das inter-relações entre viagens individuais. Contudo, os indivíduos tendem a programar e agrupar suas 
atividades diárias e os seus itinerários de viagens de acordo com horários estabelecidos. Este processo de programação de viagens está governado por compromissos e prioridades assumidos, considerando as restrições temporais. A união desses vários segmentos de viagens - com o objetivo de realizar diversas atividades, executadas por um indivíduo num determinado período de tempo -, é conhecida como viagens encadeadas.

Aliás, a análise de viagens baseada em atividades engloba o estudo das viagens encadeadas. Com isso, a formulação do modelo MONEVPE, está sujeito a abordagem baseada em atividades, a qual, para análise da demanda de transportes é fundamentada nos seguintes conceitos: $i$ ) a demanda por viagens é derivada da demanda por atividades que requerem viagens; ii) o comportamento humano está restrito pelo tempo e espaço; iii) o domicílio afeta significativamente as atividades do indivíduo e as decisões referentes às viagens; $i v$ ) as atividades e as decisões referentes às viagens acontecem dinamicamente; e, $v$ ) as seqüências de padrões de comportamento atividade/viagem (não as viagens individuais) são as unidades de análise relevantes.

Foi observado que um significativo avanço na representação do comportamento da viagem está dado pelos padrões de atividade/viagem. O termo padrão de atividade/viagem, ou padrão de viagens, é usado para se referir a um conjunto de viagens realizadas pelo indivíduo dentro de um período fixo de tempo, geralmente 24 horas. Com isso, os atributos das atividades e da viagem - tais como tipo de atividade, modo de transporte, duração de viagem, e, período da viagem - são utilizados para representar esses padrões.

A variedade de padrões de viagens encadeadas, a heterogeneidade dos indivíduos, e a necessidade de representar com mais realismo o fator comportamental, conduziu a uma evolução na estrutura de modelagem da demanda por transportes. A evolução dessas estruturas de modelagem teve início em modelos que representaram a programação diária como viagens isoladas, passando a modelos que combinam viagens explicitamente em tours, e, no estado atual, modelos que combinam tours em um programa diário. Todavia, esses avanços não foram incorporados na modelagem em 
transportes em países emergentes, com a única exceção do Brasil. E coube especificamente a Escola de Engenharia de São Carlos os primeiros trabalhos nesse sentido. Ichikawa, Pitombo e Kawamoto (2002), Ichikawa (2002) e Pitombo (2003), realizaram significativos avanços incorporando aspectos comportamentais, como a representação de padrões de atividades/viagens, na modelagem da demanda por transporte. Todavia, Pitombo (2003) representa através de padrões o modo de transporte, o período do dia em que as viagens foram realizadas e o tempo de viagem. Foi dessa forma, que dando seguimento as pesquisas anteriores, na formulação do modelo MONEVPE, levou-se em consideração a necessidade de representar com mais realismo o fator comportamental das viagens encadeadas a pé. Para isso, mostrando um avanço significativo na estrutura de modelagem, o modelo MONEVPE introduz - na representação dos padrões de VEP - a variável espacial do deslocamento através da duração da viagem, e, a influência da relação entre as viagens através da representação da atividade que motiva a viagem. Quanto as variáveis comportamentais, no MONEVPE foram incluídas variáveis explanatórias em termos de características individuais e domiciliares, e, quanto as variáveis espaço-temporal, atributos de acessibilidade e atratividade, também foram consideradas.

$\mathrm{Na}$ estrutura do modelo MONEVPE foi utilizada a técnica das Redes Neurais Artificiais (RNAs), considerando a quantidade e diversidade de variáveis envolvidas que afetam o encadeamento de viagens, a necessidade de técnicas que representem as dinâmicas do comportamento individual, as influências domiciliares, as restrições espaço-temporal, e, que possibilitem modelar relações complexas (lineares ou nãolineares) - raramente atingidas pela modelagem tradicional.

O processo de modelagem foi conduzido através da aplicação de um modelo individual de geração de padrões de viagens encadeadas a pé, utilizando-se de uma rede estática MLP e da rede dinâmica Elman. Para analisar a viabilidade da aplicação do modelo, tomou-se por base os dados de uma pesquisa de Origem-Destino realizada, em 1987, pelo METRÔ-SP na Região Metropolitana de São Paulo. 
Em se tratando dos dados, como indicado por Vasconcelos (2002), as pesquisas O/D da RMSP constituiem-se - no Brasil e também no exterior - no único registro sistemático e de qualidade sobre mobilidade em grandes cidades. Isso traz enormes benefícios tanto na compreensão da dinâmica dos deslocamentos cotidianos da população e seus condicionantes sociais e econômicos, bem como da relação entre o processo de desenvolvimento urbano e o uso do solo e dos sistemas de transporte, e muito mais no que diz respeito ao desenvolvimento de modelos baseados em atividades. No tocante ao MONEVPE, a existência desses dados facilitaram o processo de modelagem e sua comparação com resultados de outros processos de análise, como os realizados por Ichikawa (2002) e Pitombo (2003). Um tratamento prévio de filtragem e seleção dos dados foi necessário, tendo por objetivo a formação dos vetores das viagens encadeadas a pé, assim como a normalização dos mesmos para facilitar o processo de aprendizado das redes. Algumas informações para representação espacial do deslocamento tais como a distância de caminhada, poderiam ter sido utilizadas no modelo MONEVPE, entretanto, estas não tinham sido coletadas, razão pela qual utilizou-se da duração de viagem - como mencionado acima -, pois desta forma evitarse-ia a introdução de imprecisões na representação do modelo.

Os padrões de viagens encadeadas a pé considerados neste trabalho são referentes a duas, três e quatro viagens. Não foram levados em conta padrões de VEP provenientes de cinco ou mais viagens, uma vez que o número de indivíduos que fazem essas viagens é relativamente pequeno. Em função dessas considerações foram modelados 180 padrões de VEP, correspondentes a uma amostra de 3.756 indivíduos. Desses 180 padrões de viagens encadeados a pé utilizados na modelagem, 26 padrões foram do vetor de duas viagens, 118 do vetor de três, e 36 do vetor de quatro viagens.

Foram realizadas análises do acerto de classificação geral e de classificação específica para cada segmento do padrão de viagens (duração de viagem e atividade), permitindo a comparação dos resultados em termos dos acertos e erros (Erro Quadrático Médio $E Q M$ ) dos padrões de viagens reproduzidos pelas RNAs. Nisso o "acerto" foi considerada como uma medida de referência que permitiu identificar os padrões que a rede está classificando corretamente, e como o estava classificando, pelo que a rigor não 
necessariamente expressou a performance da modelagem. E como foi constatado, nem sempre os melhores valores de acerto de classificação por rede corresponderam a menores valores do $E Q M$ de classificação da duração de viagem.

Por outro lado, no Planejamento dos Transportes, é observado que a definição de políticas gerais visam atingir o comportamento majoritário da população em relação aos sistemas de transportes. Em contrapartida, políticas específicas visam comportamentos específicos dos usuários do sistema. Com isso, a representação de padrões de viagens encadeadas, que correspondam a comportamentos majoritários, subvenciona instrumentos que poderiam ser utilizados na definição dessas linhas de políticas. Com base nessas considerações, a avaliação dos resultados considerará fundamentalmente a representatividade dos padrões por indivíduo. Mesmo que os resultados na classificação geral dos padrões fossem abaixo do nível desejado - com acerto médio de classificação de $28,5 \%$-, foi necessário uma avaliação da representatividade dos padrões que as redes reproduziram. Esta avaliação determinou que os cinco padrões com maior freqüência (11S, 22S, 22W, 1111WW, 1111SS) representam em média o 58,9\% dos indivíduos da amostra de teste, isto é a representatividade individual do modelo MONEVPE está em torno de $60 \%$. Apesar do acerto de classificação geral dos padrões não ser favorável em relação à freqüência de padrões modelados, contudo, a representatividade inerente de cada padrão resulta sendo de maior importância.

Não obstante as topologias das redes simuladas sejam diferentes, os resultados mostram que a distribuição dos padrões previstos para ambas as redes foram similares. Isso permite inferir que as características dos dados de entrada do modelo definem a freqüência de classificação dos padrões previstos pela rede. Além disso, os resultados da modelagem permitem afirmar que a rede MLP apresentou um melhor desempenho na classificação geral dos padrões de VEP quando comparada com a rede Elman, ainda que ambas as topologias de redes tenham apresentado acerto de classificação médio $(A C M)$ geral e por viagem bastante próximos. Quanto ao $A C M$ para as cadeias de viagens, tanto para a rede MLP quanto para a Elman, é observado que: o $A C M$ para quatro viagens $(34,1 \%)$ é maior do que para duas viagens $(27,5 \%)$, enquanto que para três viagens a diferença é pouco significativa. Uma provável explicação para essa ocorrência é que os 
indivíduos que fazem três VEP estão sujeitos a uma maior diversidade de padrões, o que faz com que cada padrão seja representado por poucos indivíduos, diminuindo a capacidade de generalização da rede.

Entre os padrões dos conjuntos de teste que foram corretamente classificados pelas redes, estão os seguintes: 11S, 22S, 22W, 11W, 12S, 22A, 12W, 21S, 212AA, 222A, 212SA, 111WW, 111SS, 211AA, 1111WW, 1111SS, 1111WS, 2222SS, 2211WS, 1122WS, 1111SA, 1112SS, 2222AA, 1211SS, 2222WS, 3333AA, 2212SS, 2222SA, 1122SS, e 1112WW.

Como observado, são padrões que majoritariamente desenvolvem atividades relacionados com Trabalho e Escola. No caso dos padrões $11 \mathrm{~S}$ e 11W, correspondem provavelmente a indivíduos que moram nas proximidades do lugar de estudo e que cursam o $1^{\circ}$ ou $2^{\circ}$ grau. De igual forma, os que trabalham moram próximos ao trabalho. Para esses casos, como para os padrões 22S, 22W, 1111WW, 1111SS, é observado que os padrões representam claramente o comportamento dos indivíduos cujas atividades estão governados por compromissos e prioridades assumidos.

Durações menores ou iguais a dez minutos (código 1) e entre dez e vinte minutos (código 2) foram reproduzidos com maior freqüência. Entretanto, durações acima de 20 minutos (código 3), só foram reproduzidos uma única vez, no caso do padrão 3333AA. Pares de durações iguais foram reproduzidos com maior freqüência, como por exemplo: 11, 22, ou 2211, 1122. É possível que isso se deva ao fato de que para quatro viagens encadeadas os indivíduos geralmente retornam ao domicílio. Em decorrência, as redes reproduzem as cadeias como sendo de duas viagens simples.

No específico, a duração de viagem foi representada com freqüências de classificação em média de $50 \%$, e as influências das atividades compulsórias tais como Trabalho e Escola, foram representadas em média com 90\%. Essa diferença na representação da duração da viagem e classificação de atividades, evidencia que a duração da viagem depende de outros fatores além da ocupação individual e da necessidade que as pessoas têm de exercer atividades compulsórias. Além disso, 
considerando que a viagem é realizada a pé, a duração da viagem é afetada por restrições do espaço físico que independem das características individuais e domiciliares. A atividade com maior freqüência de classificação correta, independentemente do vetor de viagens modelado, foi Estudo (S), seguido de Trabalho (W) e Outras Atividades (A). No que se refere aos padrões de três viagens, a classe $\mathbf{A}$ foi a mais freqüente. Este achado está relacionado com as atividades compulsórias como Estudo (S) e Trabalho (W), podendo-se afirmar que, independentemente do tipo de rede, as redes modeladas conseguem reproduzir de forma satisfatória a influência das atividades compulsórias como estudo $(\mathbf{S})$ e trabalho $(\mathbf{W})$ na seqüência de viagens dos padrões de VEP.

Através de uma segmentação dos padrões do conjunto de teste das redes de melhor desempenho, foi realizada uma análise para determinar quais padrões a rede reproduziu em lugar daqueles que perderam classificação, e quais outros não foram reproduzidos corretamente (embora tenham sido observados). Como resultado, foi observado que padrões com segmento da duração de viagem menores ou iguais a 20 min. (deslocamentos inferiores a $1,75 \mathrm{~km}$.) e com atividade Estudo, foram reproduzidos pela rede como padrões com igual atividade e com algum dos segmentos da duração de viagem diferentes do padrão observado. Para o padrão 22S a rede reproduziu o padrão 11S; o padrão 11S foi reproduzido como 12S; o padrão 11S foi reproduzido como 22S; para o 22S a rede reproduziu o padrão 12S. Em outros casos, padrões do tipo $11 \mathrm{~W}$ e 33W são reproduzidos como 22W. O padrão 111SS foi reproduzido como 11S; 2222WW a rede o reproduz como padrão 1111WW; o 1111SS é reproduzido como 1112SS; o $1111 \mathrm{WW}$ a rede o reproduz como $22 \mathrm{~W}$. Também, foi realizada uma análise segmentada nos vetores dos Dados Socioeconômicos Individuais e Domiciliares e nos Dados Espaciais por Zona de Tráfego (Acessibilidade e Atratividade por Empregos e Matrículas), para os padrões 11S e 22S. Isto possibilitou confirmar o manifestado por Ichikawa (2002) que indivíduos que têm atributos socioeconômicos não se comportam de maneira similar. Conseqüentemente, o acontecido na classificação dos padrões 11S e 22S tornou-se mais clara, mostrando que o desbalanceamento na classificação foi resultado da diversidade da escolha por parte dos indivíduos, não obstante estes 
pertençam a grupos homogêneos. Este fato também foi observado por Pitombo (2003), quem sugeriu que a existência da variação no comportamento do indivíduo, expressa em termos de diferenças na escolha de padrões de viagens, é devido ao caráter probabilístico do comportamento e da observação feita em apenas um dia. Com tais resultados, é plenamente demonstrado que na realidade a rede não está errando, e sim, representando a probabilidade de indivíduos de similares características fazerem padrões de encadeamento diferentes.

Adicionalmente, também constatou-se que além de padrões de duas, três e quatro viagens, existiram "outros códigos" que poderiam aproximar-se algum tipo de padrão, os quais tiveram erro no segmento da duração ou no segmento da atividade. Alguns deles poderiam aproximar-se à codificação de três viagens, a não ser pelo erro na duração da terceira viagem, ou na segunda atividade. Entre tais códigos estão: o “220031”, “120021”, “220021”; ou "221010”, “111010”, “121010”. Em outros casos poderiam aproximar-se da codificação para quatro viagens, dado que o erro se produziu na segunda atividade ou na duração da terceira viagem. Por exemplo os códigos “121110”, “221110”, “111110”, ou “220111”, “120111”. No relacionado com os códigos, os erros correspondem a erros específicos no segmento da duração ou da atividade, podendo-se afirmar que isso está mais relacionado com um erro de aprendizado de padrões pouco representativos no conjunto de treinamento, como acontecido com os padrões de três viagens.

Utilizou-se da rede Elman pela capacidade de recursividade que poderia ter representado melhor a seqüência das cadeias de padrões de VEP, procurando-se associações entre padrões apresentados à rede em instantes de tempo distintos, sendo necessário que os padrões anteriores permaneçam presentes no instante em que o padrão atual é apresentado. Para isso, utilizou-se de mecanismos próprios da rede que considerassem a ordem temporal com que os padrões ocorrem. Pensou-se que tais mecanismos de recursividade da rede, junto da formulação espaço-tempo definidos na concepção do modelo no cap. 4, ajudariam na representação dos aspectos espaçotemporal. Todavia, os resultados obtidos pela rede Elman não superaram os obtidos pela 
rede MLP. Supõe-se que a potencialidade de uso da rede Elman esteja em alguma outra forma de manipulação (apresentação) dos vetores de dados.

Quanto à complexidade da topologia da rede, foi observado que na maioria de trabalhos fazendo uso das RNAs (embora sejam aplicações muito distintas da presente tese), são utilizadas camadas de saída com um único neurônio. Por um lado isto facilita o processo de modelagem, mas pelo observado no presente trabalho, isso deixa pouco representativo o resultado em termos do problema abordado. Considerando as informações inerentes aos padrões, não é recomendável a representação dos padrões numa só saída, pois isso termina tirando representatividade na caracterização de cada elemento do padrão, isto é, das características da viagem e dos atributos das atividades, além de impossibilitar-se a avaliação da segmentação e o sequenciamento das viagens.

Quanto a utilidade da abordagem para se modelar viagens encadeadas a pé, é de amplo conhecimento que $53,7 \%$ das pessoas que possuem menores rendas realizam viagens a pé (PITOMBO, 2003) e que tais viagens representam 30\% dos deslocamentos diários. Porém, a linha de pesquisa aberta com esta forma de modelagem, torna-se promissória como instrumentos para avaliações de políticas relacionadas com setores de poucos recursos, os quais representam uma proporção considerável da população.

A simplificação adotada no desenvolvimento do MONEVPE, em função de existir uma complexidade inerente ao comportamento e representação das viagens encadeadas, pode ter afetado a representatividade do mesmo. É possível que tal simplificação não tenha contribuído no acerto de classificação dos padrões de viagens encadeadas a pé.

Acredita-se que uma melhor compreensão e representação das variáveis espaciais como acessibilidade e atratividade podem contribuir para uma melhor representação dos padrões de viagens encadeadas. Como apresentado no trabalho, no cálculo da acessibilidade foram consideradas as distâncias medidas através da rede viária entre os centróides das zonas de tráfego, fazendo uso de um Sistema de Informações Geográficas. Não foram consideradas as condições das vias e as restrições que o viajante enfrenta nos seus deslocamentos diários, isso poderia ter introduzido uma diminuição 
nos acertos de classificação. Por exemplo, as restrições apresentadas pelo modelo MONEVPE em reproduzir durações acima de vinte minutos, deslocamentos maiores que $1,75 \mathrm{~km}$, confirmam esta afirmação.

A importância e peso das variáveis explanatórias e dos atributos das viagens utilizadas no modelo não foram estudadas previamente à formulação do modelo, pois partiu-se da análise realizada por Ichikawa (2002) e Pitombo (2003) que determinaram as variáveis que definem o comportamento majoritário dos padrões de viagens encadeadas.

Os índices de acessibilidade e atratividade não foram testados para medir o peso correspondente em relação às demais variáveis comportamentais. Embora tenha sido observado uma melhora nos resultados, após a sua inclusão na modelagem especifica de viagens encadeadas a pé.

Características da Rede do Sistema de Transporte bem como das do Uso do Solo da região em estudo são necessárias na inclusão das variáveis que definem as restrições espaço-temporal, necessárias no desenvolvimento de um modelo útil e prático de viagens encadeadas.

Em termos de facilidade de aplicação o uso das RNAs se apresentam como uma técnica mais acessível em termos de interface com o usuário. Entretanto, a principal limitação do modelo está justamente no uso das RNAs, pois fica limitada a avaliação do que se passa nas heurísticas de modelagem próprias das RNAs.

Finalmente, para a modelagem foi de vital importância o conhecimento das características dos dados utilizados. Os resultados da modelagem passam a fazer mais sentido quando são conhecidos os comportamentos das variáveis utilizadas. Todo modelador deve ter um conhecimento profundo e sensibilidade a respeito das variáveis do modelo. 


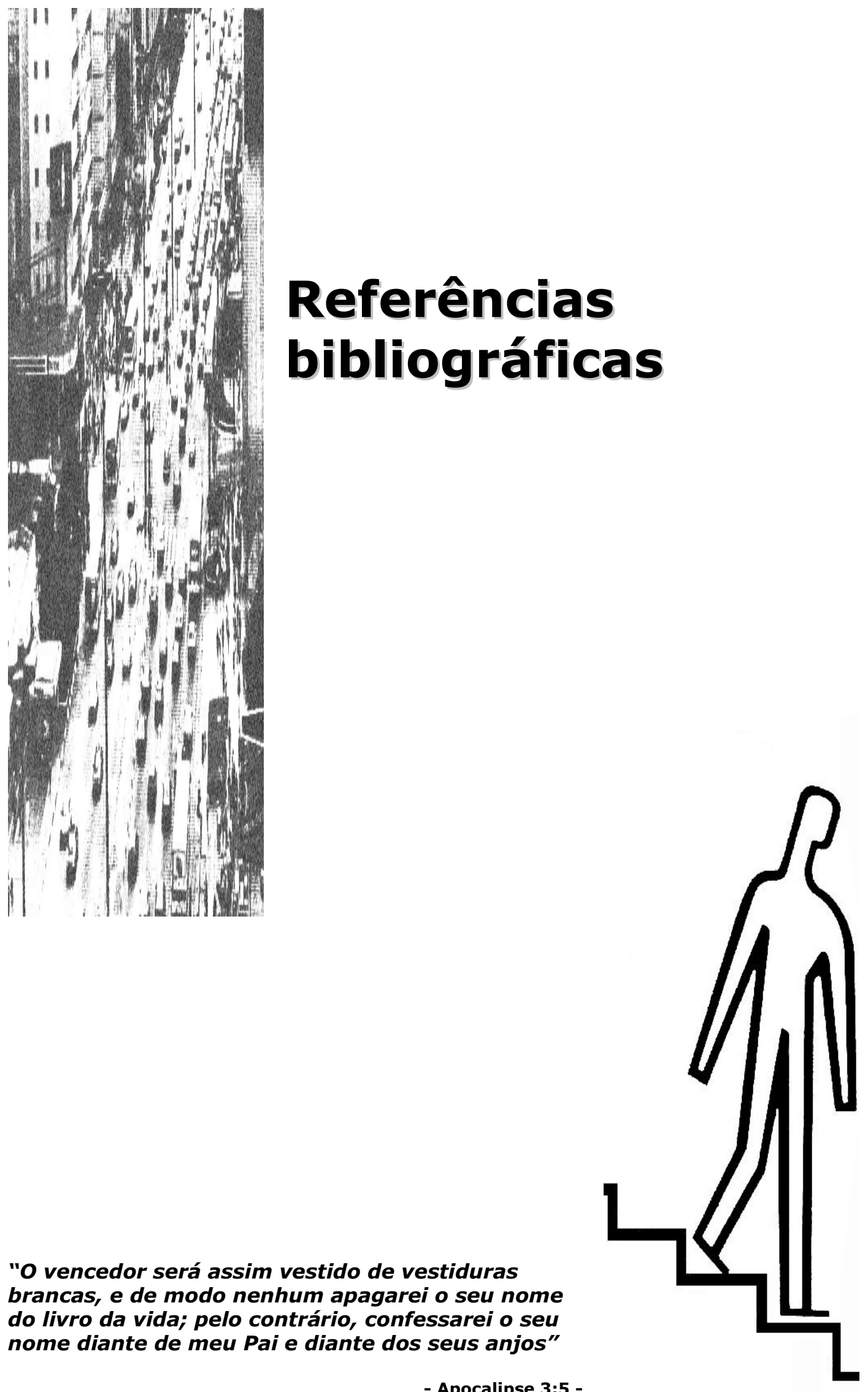

- Apocalipse 3:5 - 


\section{REFERÊNCIAS BIBLIOGRÁFICAS}

ADLER, T.; BEN-AKIVA, M. (1979). A theoretical and empirical model of trip chaining behavior. Transportation Research Part B. (13), p. 243-257.

ARENTZE, T. A. et al. (2001). A qualitative approach to modelling space-time behaviour of individuals in urban environments: the case of trip-chaining.

ARRUDA, F. S. (2000). Integração dos modos não motorizados nos modelos de planejamento de transportes. São Carlos. Dissertação (Mestrado) - Universidade Federal de São Carlos.

BEN-AKIVA, M. E.; SHERMAN, L.; KULLMAN, B. (1978a). Non-home-based models. Transportation Research Record 673, p. 128-133.

BEN-AKIVA, M. E; SHERMAN, L.; KULLMAN, B. (1978b). Aggregate forecasting with a system of disaggregate travel demand models. Proceeding of PTRC Summer Annual Meeting, University of Warwick, England.

BEN-AKIVA, M. E.; BOWMAN, J. L.; GOPINATH, D. (1996). Travel demand model system for the information era. Transportation 23, p. 241-266.

BOCANEGRA, R. CH. W. (2002). Procedimentos para tornar mais efetivo o uso das redes neurais artificiais em planejamento de transportes. São Carlos. Dissertação (Mestrado) - Escola de Engenharia de São Carlos, Universidade de São Paulo.

BOWMAN, J. L. (1995). Activity based travel demand model system with daily activity schedules. Massachusetts Institute of Technology. Thesis (Master) - Departament of Civil and Environmental Engineering. MIT. USA.

BOWMAN, J. L. (1998). The day schedule approach to travel demand analysis. Massachusetts Institute of Technology. Thesis (Doctoral) - Departament of Civil and Environmental Engineering. MIT. USA. 
BOWMAN, J. L.; BEN-AKIVA, M. E. (1997). Activity based travel forecasting. In: Activity-Based Travel Forecasting Conference, June 2-5: Summary, Recommendations and Compendion of Papers, New Orleans, Louisiana. USDOT report \#DOT-T-97-17, 32 pages.

BOWMAN, J. L. et al. (1998). Demostration of an activity based model system for Portland. 8th World Conference on Transport Research, July 12-17, Antwerp, Belgium.

BOWMAN, J. L.; BEN-AKIVA, M. E. (2001). Activity-based disaggregate travel demand model system with activity schedules. Transportation Research Part A. (35), p. 1-28.

BRAGA, A. P.; CARVALHO,A. P. L. F., LUDERMIR, T. B. (1999). Redes neurais artificiais: teoría e aplicações. Notas de aula. ICMC. Escola de Engenharia de São Carlos - USP, São Carlos, SP.

CLARKE, M. I. et al. (1981). Some recent developments in activity-travel analysis and modeling. Transportation Research Record 794, p. 1-8.

D’AGOSTO, M. A. e BALASSIANO, R. (2002). Conservação de energia em sistemas de transportes: uma estrutura de procedimentos. COOPE/UFRJ. In: http://www.ivig.cppe.ufrj.br/arquivos/mdagosto01.pdf , 26 de dezembro de 2002.

DANTAS, A. S. (2002). Neural-Geo-Temporal Model (NGTM) for person travel demand modelling in the strategic planning of urban transportation. Nagoya Institute Technology. Thesis (Doctoral) - Departament of Architecture and Civil Engineering. Nagoya. Japan.

DEMUTH, H.; BEALE, M. (1996). Neural network toolbox for use witn Matlab, user's guide. The MathWorks, Inc.

DOUGHERTY, M. (1995). A review of neural networks applied to transport. Transpn. Res. C, vol. 3, nº 4, p. 247-260.

FAGHRI, A.; HUA, J. (1992). Evaluation of artificial neural networks applications in transportation engineering. Transport Research Record, 1358, p. 71-80.

FAGHRI, A.; SANDEEP, A. (1998). Analysis of performance of backpropagation ANN with different training parameters. In: Neural Networks in Transport Applications. Himanem, V.; Nijkamp, P.; Reggiani, A. \& Raitio, J. Eds. Ashgate Publishing Ltd. England.

FEDERAL HIGHWAY ADMINISTRATION (1992). Reasons why bicycling and walking are and are not being used more extensively as travel modes. FHWA PD-92-041/.

FURTADO, A. N. D. (1998). Uma nova abordagem na avaliação de projetos de transporte: o uso das redes neurais artificiais como técnica para avaliar e ordenar alternativas. São Carlos. Tese (Doutorado) - Escola de Engenharia de São Carlos, Universidade de São Paulo.

GÄRLING, T.; KWAN, M.; GOLLEDGE, R. G. (1994). Computational-process modelling of household activity scheduling. Transpn. Res. B, vol. 28B, $\mathrm{n}^{\circ} 5$, p. 355364. 
GODWIN, P. B. (1981). The usefulness of travel budgets. Transpn. Res. A, vol. 15A, p. 97-106.

GOLOB, J. M.; GOLOB, T. F. (1983). Classification of approaches to travel-behavior analysis. TRB Special Report 201, p. 83-107.

GOLOB, T. F. (1986) A nonlinear canonical correlation analysis of weekly trip chaining behaviour. Transpn. Res. A, vol. 20A, p. 385-399.

GONDIM, M. F. (2001). Transporte não motorizado na legislação urbana no Brasil. Rio de Janeiro. Dissertação (Mestrado) - Universidade Federal de Rio de Janeiro.

GOULIAS, K. G.; PENDYALA, R. M.; KITAMURA, R. (1990). Practical method for the estimation of trip generation and trip chaining. Transportation Research Record 1285 , p. 47-56.

HANSON, S. (1995). The Geography of Urban Transportation. The Guilford Press, New York.

HAYKIN, S. (1999). Neural networks: a comprehensive foundation. Prentice-Hall, Inc. United States of America.

HERTZ, J.; KROGH, A; PALMER, R. G. (1991). Introduction to the theory of neural computation. Santa Fe Institute Studies in the Sciences of Complexity. Addison Wesley. Canada.

HIMANEM, V.; JÄRVI-NYKÄNEN, T.; RAITIO, J. (1998). Daily travelling viewed by self-organizing maps. In Neural Networks in Transport Applications. Himanem, V.; Nijkamp, P.; Reggiani, A. \& Raitio, J. Eds. Ashgate Publishing Ltd. England.

ICHIKAWA, S. M. (2002). Aplicação de Minerador de Dados na Obtenção de Relações entre Padrões de Encadeamento de Viagens Codificados e Características Sócio-Econômicas. São Carlos. Dissertação (Mestrado) - Escola de Engenharia de São Carlos, Universidade de São Paulo.

ICHIKAWA, S. M.; PITOMBO, C. S.; KAWAMOTO, E. (2002). Aplicação de minerador de dados na obtenção de relações entre padrões de viagens encadeadas e características sócio-econômicas. Anais do XVI Congresso de Pesquisa e Ensino em Transportes, ANPET, Natal, vol. 2, pp. 175-186.

INGRAM, D. R. (1971). The concept of acessibility: a search for na operational form. Regional Studies, vol. 5, pp. 101-107.

JOAQUIM, F. M. (1999). Qualidade de vida nas cidades: o aspecto de acessibilidade às atividades urbanas. São Carlos. Dissertação (Mestrado) - Universidade Federal de São Carlos.

KAWAKAMI, S. e ISOBE, T. (1990). Development of a one-day travel-activity scheduling model for workers. In: Developments in Dynamic and Activity-based Approaches to Travel Analysis. P.M. Jones (ed.), Avebury, Aldershot, p. 184-205.

KERMANSHAH (1997)

KITAMURA, R. (1984). Incorporating trip chaining into analysis of destination choice. Transpn. Res. B, vol. 18B, $\mathrm{n}^{\circ} 1$, p. 67-81. 
KITAMURA, R. (1996). Applications of models of activity behavior for activity based demand forecasting. In: Activity-Based Travel Forecasting Conference, June 2-5: Summary, Recommendations and Compendion of Papers, New Orleans, Louisiana. USDOT report \#DOT-T-97-17, 32 pages.

KOSTYNIUK, L. P.; KITAMURA, R. (1986a). Changing effects of automobile ownership on household travel patterns. Transportation Research Record 1085, p. 27-33.

KOSTYNIUK, L. P.; KITAMURA, R. (1986b). Household lifecycle: predictor of travel expenditure. In: Behavioural Research for Transport Policy. VNU Science Press, p. 343-362.

KURANI, K. S.; LEE-GOSSELIN, M. E. H. (1996). Synthesis of past activity analysis applications. In: Activity-Based Travel Forecasting Conference, June 2-5: Summary, Recommendations and Compendion of Papers, New Orleans, Louisiana. USDOT report \#DOT-T-97-17, 26 pages.

LIMA, R. S. (1998). Expansão urbana e acessibilidade: o caso das cidades médias brasileiras. São Carlos. Dissertação (Mestrado) - Escola de Engenharia de São Carlos, Universidade de São Paulo.

MASTERS, T. (1994). Practical neural network recipes in c++ sourcebooks. New York, John Wiley.

MATSUMO, E. Y. (2001). Matlab 6: fundamentos de programação. São Paulo, Ed. Érica.

McGUCKIN, N.; MURAKAMI, E. (1999). Examining Trip-Chaining Behavior: a comparison of travel by men and women. Transportation Research Record 1683, Transportation Research Board, Washington, D. C.

McNALLY, M. (1996). An activity-based microsimulation model for travel demand forecasting. ITS Working Paper UCI-ITS-AS-WP-96-1, Irvine CA.

McNALLY, M. G. (2000). The activity-based approach. Institute of Transportation Studies, University of California, Irvine. USA. UCI-ITS-AS-WP-00-4.

METRÔ (1990). Pesquisa OD/87: síntese das informações. Companhia do Metropolitano de São Paulo, São Paulo.

MMA-IBAMA-IPEA (2002). Meio ambiente e transporte urbano: análise bibliográfica e propostas sob o enfoque das políticas públicas. Ministério do Meio Ambiente MMA, Instituto Brasileiro de Meio Ambiente - IBAMA, Instituto de Pesquisa Econômica Aplicada - IPEA.

NISHII, K.; KONDO, K.; KITAMURA, R. (1988). Empirical analysis of trip chaining behavior. Transportation Research Record 1203, p. 48-5.

ORTÚZAR, J. de D. (2000). Modelos de demanda de transporte. 2a. Edición. Alfaomega. Pontificia Universidad Católica de Chile.

ORTÚZAR, J. de D.; WILLUMSEN, L. G. (1994). Modelling Transport. Second Edition. John Wily \& Sons, Chichester. 
PENDYALA, R. M. et al. (1997). An activity-based microsimulation analysis of transportation control measures. Transport Policy, 4, p. 183-192.

PITOMBO, C. S. (2003). Análise do Comportamento Subjacente ao Encadeamento de Viagens Através do Uso de Minerador de Dados. São Carlos. Dissertação (Mestrado) - Escola de Engenharia de São Carlos, Universidade de São Paulo.

PRASETYO, I. (2001). Travel time saving benefit based on commuter's perception (Jakarta, Indonesia case study). 9th World Conference on Transport Research. July, Seoul, Korea.

RAIA JR., A. A. (2000). Acessibilidade e mobilidade na estimativa de um índice de potencial de viagens utilizando redes neurais artificiais. São Carlos. Tese (Doutorado) - Escola de Engenharia de São Carlos, Universidade de São Paulo.

RAO, P. V. S. et al. (1997). Another insigh into ANN through behavioural analysis of access mode choice. CUPUM '97 Computers in Urban Planning and Urban Management, vol. 1, p. 412-423. Narosa Publishing, Bombay, India.

RDC, Inc. (1995). Activity Based Modeling System for Travel Demand Forecasting Travel Model Improvement Program. Submitted to Metropolitan Washington Council of Governments; U.S. Department of Transportation; U.S. Environmental Protection Agency. San Francisco, CA, USA.

RECKER, W. W. (1995). The household activity pattern problem: general formulation and solution. Transpn. Res. B, vol. 29B, n 1 , p. 61-77.

RECKER, W. W.; McNALLY, M. G.; ROOT, G. S. (1986a). A model of complex travel behavior: Part I-theorical development. Transp. Res. A, vol. 20A, nº 4, p. 307318.

RECKER, W. W.; McNALLY, M. G.; ROOT, G. S. (1986b). A model of complex travel behavior: Part II-an operational model. Transp. Res. A, vol. 20A, no 4, p. 319330.

RODRIGUE, J. P. (1997). Parallel modeling and neural networks: na overview for transportation/land use systems. Transp. Res. C, vol. 5, nº 5, p. 259-271.

RUITER, E. R.; BEN-AKIVA, M. E. (1978). Disaggregate travel demand models for the San Francisco Bay Area: system structure, component models, and application procedures. Transportation Research Record 673, p. 121-128.

RUSSEL e NORVIG, (1996). Inteligencia artificial: un enfoque moderno. Prentice Hall Hispanoamericana S. A. México.

SALES FILHO, L. H. (1996). O uso de indicadores de acessibilidade na avaliação de redes estruturais de transporte urbano. Tribunal de Contas do Estado do Rio de Janeiro, Instituto Serzedello Corrêa. Serie Estudos Econômicos. Rio de Janeiro.

SANCHES, S. P. (1996). Acessibilidade: um indicador de desempenho dos sistemas de transporte nas cidades. Anais do X Congresso de Pesquisa e Ensino em Transportes, ANPET, Brasília, DF. vol. 1, pp. 199-208.

SHIFTAN, Y. (1999). Practical approach to model trip chaining. Transportation Research Record 1645, p. 17-23. 
SHMUELI, D.; SALOMON, I; SHEFER, D. (1996) Neural network analysis of travel behaviour: evaluating tools for prediction. Transpn. Res. C, vol. 4, n 3, p. 151-166.

SHMUELI, D.; SALOMON, I; SHEFER, D. (1998). Neural network analysis of travel behaviour. In: Neural Networks in Transport Applications. Himanem, V.; Nijkamp, P.; Reggiani, A. \& Raitio, J. Eds. Ashgate Publishing Ltd. England.

SOLOMON I.; BEN-AKIVA, M. (1983). The use of the life-style concept in travel demand models. Environment and Planning A, volume 15, page 623-638.

SPEAR, B. D. (1996). New approaches to transportation forecasting models: a synthesis of four research proposals. Transportation 23, p. 215-240.

SRINIVASAN, S. (2000). Linking land use and transportation: measuring the impact of neighborhood-scale spatial patterns on travel behavior. Department of Urban Studies and Planning. Doctor of Philosophy in Urban Studies and Planning.

STEIN, R. (1993a). Preprocessing data for neural networks. AI Expert, march. p. 33-37.

STEIN, R. (1993b). Selecting data for neural networks. AI Expert, february. p. 42-47.

STRAMBI, O.; BILT, K. A v.d. (1998). Análise do diferencial de mobilidade de homens e mulheres e suas implicações face às tendências de evolução da população. Anais do XII Congresso de Pesquisa e Ensino em Transportes, ANPET, Fortaleza, vol. 1, pp. 479-491.

STRAMBI, O.; BILT, K. A v.d. (2001). Mobilidade em São Paulo: uma perspectiva temporal. In Transportes: experiências em rede. FINEP. RECOPE Transportes. Nassi., et al Organizadores. pp. 255-271.

STRATHMAN, J. G.; DUEKER, K. J.; DAVIS, J. S. (1994). Effects of household structure and selected travel characteristics on trip chaining. Transportation 21, p. $23-45$.

STRATHMAN, J. G.; DUEKER, K. J. (1995). Unsderstanding trip chaining. 1990 NPTS Special Reports on Trip and Vehicle Attributes. Report FHWA-PL-95-033. FHWA, U.S. Department of Transportation.

SUPERNAK, J.; TALVITIE, A.; DeJOHN, A. (1983). Person-category trip-generation model. Transportation Research Record 944, p. 74-83.

TANDEL, M. C. F. F (1997). Geração de viagens de passageiros urbanos: modelo individual com a inclusão da influência das características do domicílio. São Carlos. Tese (Doutorado) - Escola de Engenharia de São Carlos, Universidade de São Paulo.

THAMIZ et al. (1996). Trip characteristics of travelers without vehicles. Journal of Transportation Engineering, p.76-81.

TIMMERMANS, H. (2002). Models of activity scheduling behavoiur. In http://www.infra.tlenet/meet5/papers/timmermans1.pdf , Stadf Region Land - Heft 71.

VASCONCELOS, E. A (1996). Transporte urbano nos países em desenvolvimento: reflexões e propostas. São Paulo. Editoras Unidas Ltda. 
VASCONCELOS, E. A (2002). Sociedade, mobilidade e eqüidade na RMSP. Revista dos Transportes Públicos, ANTP, ano 24, $1^{\circ}$ trimestre, pp. 7-33.

VASCONCELOS, E. A.; SCATENA, J. C. (1996). Avaliação social em transportes utilizando pesquisas de origem-destino. Revista dos Transportes Públicos, ANTP, ano $18,3^{\circ}$ trimestre, pp. 57-70.

VERLEYSEN, M. (1998). The explanatory power of artificial neural networks. Methodos: The explanatory power of models in the social sciences. Louvain-laNeuve, Bélgium, november 14-16.

WERMERSCH, F. G. (2002). Uso de redes neurais artificiais para descoberta de conhecimento sobre a escolha do modo de viagem. São Carlos. Dissertação (Mestrado) - Escola de Engenharia de São Carlos, Universidade de São Paulo.

ZELL, A. et al. (1998). SNNS Stuttgart neural network simulator - user manual, version 4.2. Germany, Universität Stuttgart / IPVR / WSI. http://www-ra.informatik.unituebingen.de/SNNS/

ZHANG, G.; PATUWO, E. B.; HU, M. Y. (1998). Forecasting with artificial neural networks: The state of the art. International Journal of Forecasting 14, p. 35-62). 


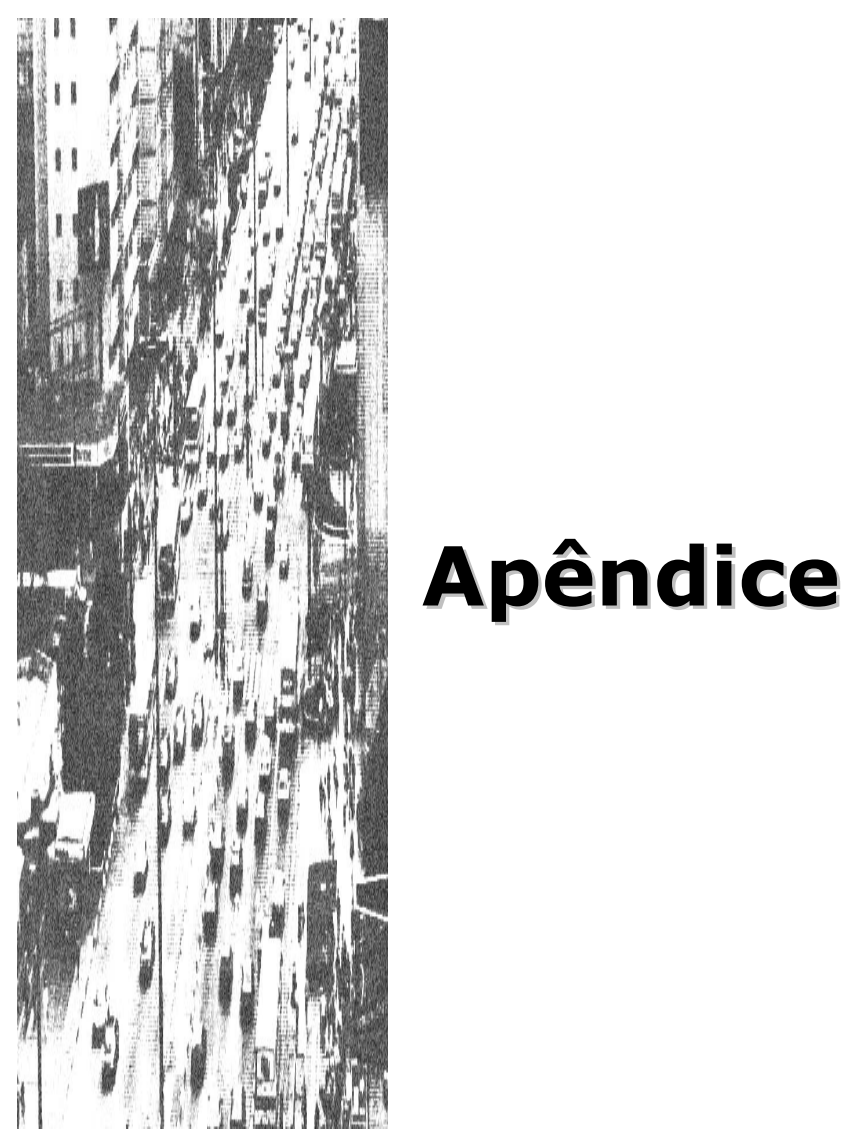

"Tu, porém segue o teu caminho até ao fim; pois descansarás e, ao fim dos dias, te

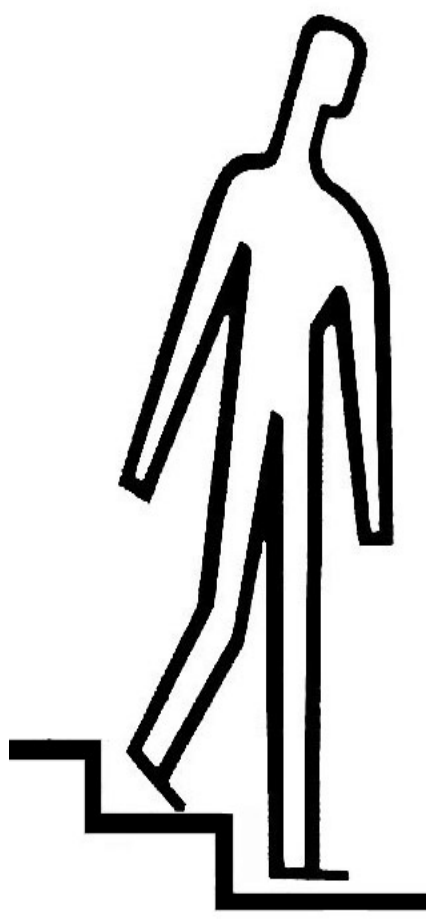
levantarás para receber a tua herança" 


\section{APÉNDICE A}


Tabela A.1: Acessibilidade das Zonas de Tráfego da RMSP/87.

\begin{tabular}{|c|c|c|c|c|c|c|c|c|c|c|c|c|c|c|c|}
\hline ㅇ & 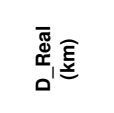 & 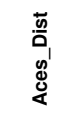 & 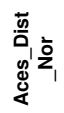 & 오 & 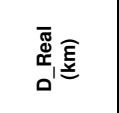 & 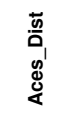 & 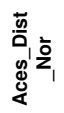 & ㅇ & 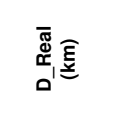 & 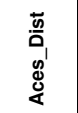 & 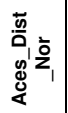 & 요 & 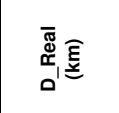 & 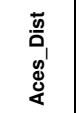 & 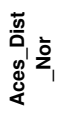 \\
\hline 1 & $4.798,1205$ & 18,965 & 0,101 & 66 & $5.483,356$ & 21,673 & 0,137 & 131 & $7.285,678$ & 28,797 & 0,230 & 196 & $4.979,899$ & 19,683 & 0,110 \\
\hline 2 & $4.795,437$ & 18,954 & 0,101 & 67 & $5.649,889$ & 22,332 & 0,145 & 132 & $9.387,841$ & 37,106 & 0,340 & 197 & $4.987,808$ & 19,715 & 0,111 \\
\hline 3 & $4.781,6845$ & 18,900 & 0,100 & 68 & $5.965,724$ & 23,580 & 0,162 & 133 & $12.966,679$ & 51,252 & 0,526 & 198 & $5.044,8805$ & 19,940 & 0,114 \\
\hline 4 & $4.784,1055$ & 18,910 & 0,100 & 69 & $5.860,563$ & 23,164 & 0,156 & 134 & $8.692,522$ & 34,358 & 0,304 & 199 & $5.030,87$ & 19,885 & 0,113 \\
\hline 5 & $4.787,802$ & 18,924 & 0,100 & 70 & $6.339,978$ & 25,059 & 0,181 & 135 & $8.190,825$ & 32,375 & 0,277 & 200 & $5.373,7965$ & 21,240 & 0,131 \\
\hline 6 & $4.800,2235$ & 18,973 & 0,101 & 71 & $5.733,581$ & 22,662 & 0,150 & 136 & $9.054,426$ & 35,788 & 0,322 & 201 & $5.687,391$ & 22,480 & 0,147 \\
\hline 7 & $4.819,101$ & 19,048 & 0,102 & 72 & $5.476,059$ & 21,645 & 0,136 & 137 & $7.657,734$ & 30,268 & 0,250 & 202 & $6.852,666$ & 27,086 & 0,208 \\
\hline 8 & $4.843,681$ & 19,145 & 0,103 & 73 & $5.854,3425$ & 23,140 & 0,156 & 138 & $8.243,588$ & 32,583 & 0,280 & 203 & $5.438,059$ & 21,494 & 0,134 \\
\hline 9 & $4.850,9345$ & 19,174 & 0,104 & 74 & $5.714,536$ & 22,587 & 0,149 & 139 & $8.952,661$ & 35,386 & 0,317 & 204 & $6.509,902$ & 25,731 & 0,190 \\
\hline 10 & $4.884,6085$ & 19,307 & 0,105 & 75 & $5.498,9665$ & 21,735 & 0,137 & 140 & $10.085,998$ & 39,866 & 0,376 & 205 & $4.977,204$ & 19,673 & 0,110 \\
\hline 11 & $4.851,4255$ & 19,176 & 0,104 & 76 & $5.754,1975$ & 22,744 & 0,151 & 141 & $10.936,581$ & 43,228 & 0,420 & 206 & $4.942,13$ & 19,534 & 0,108 \\
\hline 12 & $4.874,374$ & 19,266 & 0,105 & 77 & $5.559,732$ & 21,975 & 0,141 & 142 & $11.531,952$ & 45,581 & 0,451 & 207 & $5.492,963$ & 21,711 & 0,137 \\
\hline 13 & $4.827,119$ & 19,080 & 0,102 & 78 & $5.239,9905$ & 20,711 & 0,124 & 143 & $12.149,885$ & 48,023 & 0,484 & 208 & $5.276,023$ & 20,854 & 0,126 \\
\hline 14 & $4.812,23$ & 19,021 & 0,102 & 79 & $5.426,0845$ & 21,447 & 0,134 & 144 & $12.712,485$ & 50,247 & 0,513 & 209 & $5.604,857$ & 22,154 & 0,143 \\
\hline 15 & $4.812,5905$ & 19,022 & 0,102 & 80 & $5.277,785$ & 20,861 & 0,126 & 145 & $14.018,24$ & 55,408 & 0,581 & 210 & $5.453,939$ & 21,557 & 0,135 \\
\hline 16 & $4.802,725$ & 18,983 & 0,101 & 81 & $5.403,321$ & 21,357 & 0,132 & 146 & $15.180,887$ & 60,004 & 0,641 & 211 & $6.550,411$ & 25,891 & 0,192 \\
\hline 17 & $4.855,0735$ & 19,190 & 0,104 & 82 & $5.272,026$ & 20,838 & 0,126 & 147 & $15.781,429$ & 62,377 & 0,673 & 212 & $6.967,937$ & 27,541 & 0,214 \\
\hline 18 & $4.873,8175$ & 19,264 & 0,105 & 83 & $5.252,574$ & 20,761 & 0,125 & 148 & $20.149,88$ & 79,644 & 0,900 & 213 & $7.368,206$ & 29,123 & 0,235 \\
\hline 19 & $4.830,162$ & 19,092 & 0,103 & 84 & $6.096,9855$ & 24,099 & 0,168 & 149 & $7.000,2525$ & 27,669 & 0,215 & 214 & $6.662,735$ & 26,335 & 0,198 \\
\hline 20 & $4.872,493$ & 19,259 & 0,105 & 85 & $5.813,724$ & 22,979 & 0,154 & 150 & $7.028,3535$ & 27,780 & 0,217 & 215 & $6.346,195$ & 25,084 & 0,181 \\
\hline 21 & $4.872,0035$ & 19,257 & 0,105 & 86 & $5.703,2115$ & 22,542 & 0,148 & 151 & $7.156,96$ & 28,288 & 0,224 & 216 & $10.734,259$ & 42,428 & 0,410 \\
\hline 22 & $4.872,912$ & 19,261 & 0,105 & 87 & $5.738,2415$ & 22,681 & 0,150 & 152 & $8.241,616$ & 32,576 & 0,280 & 217 & $7.542,139$ & 29,811 & 0,244 \\
\hline 23 & $4.899,779$ & 19,367 & 0,106 & 88 & $5.607,1935$ & 22,163 & 0,143 & 153 & $9.173,354$ & 36,258 & 0,329 & 218 & $8.569,834$ & 33,873 & 0,297 \\
\hline 24 & $4.996,887$ & 19,751 & 0,111 & 89 & $5.702,257$ & 22,539 & 0,148 & 154 & $6.140,773$ & 24,272 & 0,171 & 219 & $10.376,955$ & 41,016 & 0,391 \\
\hline 25 & $4.985,152$ & 19,704 & 0,111 & 90 & $6.655,417$ & 26,306 & 0,198 & 155 & $5.686,163$ & 22,475 & 0,147 & 220 & $8.390,35$ & 33,163 & 0,288 \\
\hline 26 & $5.056,975$ & 19,988 & 0,114 & 91 & $6.364,03$ & 25,154 & 0,182 & 156 & $5.784,8905$ & 22,865 & 0,152 & 221 & $6.921,396$ & 27,357 & 0,211 \\
\hline 27 & $5.042,487$ & 19,931 & 0,114 & 92 & $6.239,977$ & 24,664 & 0,176 & 157 & $6.004,193$ & 23,732 & 0,164 & 222 & $9.672,122$ & 38,230 & 0,355 \\
\hline 28 & $5.015,1545$ & 19,823 & 0,112 & 93 & $6.170,525$ & 24,389 & 0,172 & 158 & $6.393,2295$ & 25,270 & 0,184 & 223 & $8.787,893$ & 34,735 & 0,309 \\
\hline 29 & $5.003,124$ & 19,775 & 0,112 & 94 & $6.349,5165$ & 25,097 & 0,182 & 159 & $6.839,561$ & 27,034 & 0,207 & 224 & $10.213,605$ & 40,370 & 0,383 \\
\hline 30 & $4.895,0365$ & 19,348 & 0,106 & 95 & $7.192,3585$ & 28,428 & 0,225 & 160 & $5.295,2$ & 20,930 & 0,127 & 225 & $9.697,213$ & 38,329 & 0,356 \\
\hline 31 & $4.889,144$ & 19,325 & 0,106 & 96 & $6.988,386$ & 27,622 & 0,215 & 161 & $5.504,662$ & 21,758 & 0,138 & 226 & $7.754,184$ & 30,649 & 0,255 \\
\hline 32 & $4.901,3685$ & 19,373 & 0,106 & 97 & $7.556,5265$ & 29,868 & 0,244 & 162 & $5.739,66$ & 22,686 & 0,150 & 227 & $9.219,849$ & 36,442 & 0,331 \\
\hline 33 & $4.927,0485$ & 19,475 & 0,108 & 98 & $6.605,055$ & 26,107 & 0,195 & 163 & 189,7775 & 24,466 & 0,173 & 228 & $7.646,111$ & 30,222 & 0,249 \\
\hline 34 & $5.038,63$ & 19,916 & 0,113 & 99 & $7.093,007$ & 28,036 & 0,220 & 164 & $6.592,2735$ & 26,056 & 0,194 & 229 & $9.833,674$ & 38,868 & 0,363 \\
\hline 35 & $5.093,2995$ & 20,132 & 0,116 & 100 & $7.038,415$ & 27,820 & 0,217 & 165 & $6.995,1555$ & 27,649 & 0,215 & 230 & $10.194,436$ & 40,294 & 0,382 \\
\hline 36 & $5.038,955$ & 19,917 & 0,113 & 101 & $6.445,094$ & 25,475 & 0,187 & 166 & $7.607,486$ & 30,069 & 0,247 & 231 & $10.338,038$ & 40,862 & 0,389 \\
\hline 37 & $4.940,467$ & 19,528 & 0,108 & 102 & $6.216,0585$ & 24,569 & 0,175 & 167 & $6.165,755$ & 24,371 & 0,172 & 232 & $12.904,818$ & 51,007 & 0,523 \\
\hline 38 & $4.952,513$ & 19,575 & 0,109 & 103 & $5.736,7575$ & 22,675 & 0,150 & 168 & $6.027,574$ & 23,824 & 0,165 & 233 & $9.851,522$ & 38,939 & 0,364 \\
\hline 39 & $5.102,01$ & 20,166 & 0,117 & 104 & $6.049,751$ & 23,912 & 0,166 & 169 & $6.763,8335$ & 26,735 & 0,203 & 234 & $7.721,524$ & 30,520 & 0,253 \\
\hline 40 & $5.210,132$ & 20,593 & 0,122 & 105 & $5.667,0955$ & 22,400 & 0,146 & 170 & $9.711,361$ & 38,385 & 0,357 & 235 & $8.138,775$ & 32,169 & 0,275 \\
\hline 41 & $5.230,665$ & 20,675 & 0,123 & 106 & $5.934,7325$ & 23,457 & 0,160 & 171 & $10.930,691$ & 43,204 & 0,420 & 236 & 9.221 & 36,447 & 0,331 \\
\hline 42 & $5.244,84$ & 20,731 & 0,124 & 107 & $5.697,078$ & 22,518 & 0,148 & 172 & $6.551,5365$ & 25,895 & 0,192 & 237 & $11.611,731$ & 45,896 & 0,456 \\
\hline 43 & $5.402,856$ & 21,355 & 0,132 & 108 & $6.999,11$ & 27,664 & 0,215 & 173 & $7.537,4405$ & 29,792 & 0,243 & 238 & $12.076,075$ & 47,732 & 0,480 \\
\hline 44 & $5.229,3365$ & 20,669 & 0,123 & 109 & $6.189,682$ & 24,465 & 0,173 & 174 & $8.478,994$ & 33,514 & 0,292 & 239 & $7.552,577$ & 29,852 & 0,244 \\
\hline 45 & $5.257,08$ & 20,779 & 0,125 & 110 & $6.136,941$ & 24,257 & 0,171 & 175 & $9.713,468$ & 38,393 & 0,357 & 240 & $8.403,002$ & 33,213 & 0,289 \\
\hline 46 & $5.238,8995$ & 20,707 & 0,124 & 111 & $9.088,815$ & 35,924 & 0,324 & 176 & $15.970,154$ & 63,123 & 0,682 & 241 & $8.163,367$ & 32,266 & 0,276 \\
\hline 47 & $5.436,53$ & 21,488 & 0,134 & 112 & $6.786,5105$ & 26,824 & 0,204 & 177 & $7.250,913$ & 28,660 & 0,229 & 242 & $9.264,726$ & 36,619 & 0,333 \\
\hline 48 & $5.337,7485$ & 21,098 & 0,129 & 113 & $7.013,607$ & 27,722 & 0,216 & 178 & $9.083,206$ & 35,902 & 0,324 & 243 & $8.888,768$ & 35,133 & 0,314 \\
\hline 49 & $5.147,3515$ & 20,345 & 0,119 & 114 & $5.298,164$ & 20,941 & 0,127 & 179 & $9.650,025$ & 38,142 & 0,353 & 244 & $9.405,885$ & 37,177 & 0,341 \\
\hline 50 & $5.131,7965$ & 20,284 & 0,118 & 115 & $5.734,964$ & 22,668 & 0,150 & 180 & $12.197,466$ & 48,211 & 0,486 & 245 & $9.750,143$ & 38,538 & 0,359 \\
\hline 51 & $5.051,543$ & 19,967 & 0,114 & 116 & $5.784,0985$ & 22,862 & 0,152 & 181 & $11.286,732$ & 44,612 & 0,439 & 246 & $11.586,69$ & 45,797 & 0,454 \\
\hline 52 & $5.036,687$ & 19,908 & 0,113 & 117 & $5.800,501$ & 22,927 & 0,153 & 182 & $6.148,365$ & 24,302 & 0,171 & 247 & $8.427,447$ & 33,310 & 0,290 \\
\hline 53 & $4.965,0465$ & 19,625 & 0,110 & 118 & $6.384,9335$ & 25,237 & 0,183 & 183 & $6.130,493$ & 24,231 & 0,170 & 248 & $12.393,775$ & 48,987 & 0,496 \\
\hline 54 & $5.047,869$ & 19,952 & 0,114 & 119 & $7.307,2645$ & 28,882 & 0,231 & 184 & $6.138,724$ & 24,264 & 0,171 & 249 & $11.082,818$ & 43,806 & 0,428 \\
\hline 55 & $5.336,184$ & 21,092 & 0,129 & 120 & $9.032,624$ & 35,702 & 0,321 & 185 & $6.571,524$ & 25,974 & 0,193 & 250 & $6.749,769$ & 26,679 & 0,202 \\
\hline 56 & $5.287,46$ & 20,899 & 0,126 & 121 & $7.772,342$ & 30,721 & 0,256 & 186 & $6.589,907$ & 26,047 & 0,194 & 251 & $6.656,439$ & 26,310 & 0,198 \\
\hline 57 & $5.789,7275$ & 22,884 & 0,152 & 122 & $8.338,491$ & 32,958 & 0,285 & 187 & $7.413,822$ & 29,304 & 0,237 & 252 & $9.418,05$ & 37,225 & 0,341 \\
\hline 58 & $5.468,9895$ & 21,617 & 0,136 & 123 & $9.674,777$ & 38,240 & 0,355 & 188 & $7.089,7645$ & 28,023 & 0,220 & 253 & $8.241,479$ & 32,575 & 0,280 \\
\hline 59 & $5.337,8755$ & 21,098 & 0,129 & 124 & $8.379,291$ & 33,120 & 0,287 & 189 & $7.296,0775$ & 28,838 & 0,231 & 254 & $10.674,263$ & 42,191 & 0,407 \\
\hline 60 & $5.283,9435$ & 20,885 & 0,126 & 125 & $6.617,1905$ & 26,155 & 0,196 & 190 & $7.398,48$ & 29,243 & 0,236 & \multirow{6}{*}{\multicolumn{4}{|c|}{$\begin{array}{r}\text { ZO = Zona de Origem } \\
\text { D_Real = Distância real entre } \\
\text { centróides das zonas de tráfego } \\
\text { Aces_Dist = Acessibilidade por } \\
\text { distância média (eq. } 5.1) \\
\text { Aces_Dist_Nor = Acessibilidade } \\
\text { por distância média normalizada }\end{array}$}} \\
\hline 61 & 5135,983 & 20,300 & 0,118 & 126 & $5.809,8595$ & 22,964 & 0,154 & 191 & $8.248,679$ & 32,603 & 0,280 & & & & \\
\hline 62 & $5.085,5665$ & 20,101 & 0,116 & 127 & $6.262,1925$ & 24,752 & 0,177 & 192 & $8.716,9335$ & 34,454 & 0,305 & & & & \\
\hline 63 & $5.091,391$ & 20,124 & 0,116 & 128 & $5.978,182$ & 23,629 & 0,162 & 193 & $9.845,132$ & 38,914 & 0,364 & & & & \\
\hline 64 & $5.311,359$ & 20,994 & 0,128 & 129 & $5.767,4635$ & 22,796 & 0,151 & 194 & $9.397,694$ & 37,145 & 0,340 & & & & \\
\hline 65 & $5.452,46$ & 21,551 & 0,135 & 130 & $8.135,614$ & 32,157 & 0,275 & 195 & $11.652,015$ & 46,055 & 0,458 & & & & \\
\hline
\end{tabular}


Tabela A.2: Índice Normalizado de Atratividade por Matrículas da RMSP/87.

\begin{tabular}{|c|c|c|c|c|c|c|c|c|c|c|c|c|c|c|c|}
\hline ㅇ & 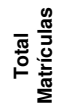 & 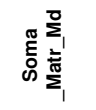 & 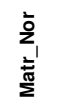 & ㅇ & 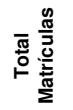 & 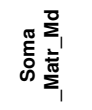 & $\begin{array}{l}\sum_{1} \\
z_{1} \\
\sum^{\pi}\end{array}$ & 요 & 坖 & 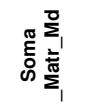 & $\begin{array}{l}\text { के } \\
z_{1} \\
\text { 离 } \\
\sum\end{array}$ & ㅇ & 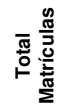 & 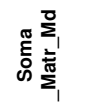 & $\begin{array}{l}z_{1} \\
z_{1} \\
\overline{0} \\
\Sigma\end{array}$ \\
\hline 1 & 26.572 & 944,35 & 356 & 66 & 1.786 & 197,93 & 117 & 131 & 29.484 & 267,01 & 0,384 & 196 & 3.332 & 69,26 & 132 \\
\hline 2 & 3.954 & 438,13 & 0,138 & 67 & 4.820 & 534,07 & 0,146 & 132 & 7.956 & 881,55 & 0,177 & 197 & 3.299 & 365,55 & 0,132 \\
\hline 3 & 2.456 & 272,15 & 0,124 & 68 & 26.368 & $2.921,76$ & 0,354 & 133 & 9.334 & $1.034,27$ & 0,190 & 198 & 2.968 & 328,89 & 0,129 \\
\hline 4 & 793 & 87,92 & 0,108 & 69 & 19.037 & $2.109,38$ & 0,283 & 134 & 2.332 & 258,45 & 0,122 & 199 & 1.382 & 153,17 & 0,113 \\
\hline 5 & 29.520 & $3.270,96$ & 0,385 & 70 & 19.674 & $2.180,04$ & 0,290 & 135 & 24.121 & $2.672,81$ & 0,333 & 200 & 1.241 & 137,55 & 0,112 \\
\hline 6 & 7.240 & 30,70 & 0,103 & 71 & 24.618 & $2.727,85$ & 0,337 & 136 & 3.406 & 377,42 & 0,133 & 201 & 2.019 & 223,67 & 0,119 \\
\hline 7 & 14.920 & $1.653,28$ & 0,244 & 72 & 16.459 & $1.823,79$ & 0,259 & 137 & 19.730 & $2.186,20$ & 0,290 & 202 & 5.364 & 594,35 & 0,152 \\
\hline 8 & 4.375 & 484,78 & 0,142 & 73 & 11.094 & $1.229,28$ & 0,207 & 138 & 12.410 & $1.375,10$ & 0,220 & 203 & 8.402 & 930,97 & 0,181 \\
\hline 9 & 8.379 & 928,39 & 0,181 & 74 & 10.007 & $1.108,89$ & 0,196 & 139 & 32.879 & $3.643,17$ & 0,417 & 204 & 13.220 & $1.464,88$ & 0,227 \\
\hline 10 & 8.250 & 914,13 & 0,180 & 75 & 17.525 & $1.941,87$ & 0,269 & 140 & 2.413 & 267,34 & 0,123 & 205 & 188 & 20,78 & 0,102 \\
\hline 11 & 12.084 & $1.339,00$ & 0,216 & 76 & 12.571 & $1.392,91$ & 0,221 & 141 & 13.102 & $1.451,77$ & 0,226 & 206 & 326 & 36,10 & 0,103 \\
\hline 12 & 11.911 & $1.319,78$ & 0,215 & 77 & 11.927 & $1.321,62$ & 0,215 & 142 & 75.220 & $8.334,89$ & 0,825 & 207 & 132 & 14,67 & 0,101 \\
\hline 13 & 7.381 & 817,91 & 0,171 & 78 & 16.040 & $1.777,28$ & 0,255 & 143 & 2.334 & 258,67 & 0,123 & 208 & 0 & 0,00 & 0,100 \\
\hline 14 & 19.133 & $2.120,01$ & 0,284 & 79 & 11.063 & $1.225,90$ & 0,207 & 144 & 2.211 & 245,01 &, 121 & 209 & 282 & 31,23 & 0,103 \\
\hline 15 & 9.321 & $1.032,81$ & 0,190 & 80 & 22.508 & $2.493,98$ & 0,317 & 145 & 818 & 90,64 & 0,108 & 210 & 19.705 & 183,45 & 0,290 \\
\hline 16 & 10.630 & $1.177,88$ & 0,202 & 81 & 24.403 & $2.704,00$ & 0,335 & 146 & 3.051 & 338,12 & 0,129 & 211 & 119 & 13,18 & 0,101 \\
\hline 17 & 11.922 & $1.321,03$ & 0,215 & 82 & 24.044 & $2.664,22$ & 0,332 & 147 & 3.941 & 436,66 & 0,138 & 212 & 0 & 0,00 & 0,100 \\
\hline 18 & 25.111 & $2.782,40$ & 0,342 & 83 & 45.980 & $5.094,86$ & 0,543 & 148 & 3.135 & 347,43 & 0,130 & 213 & 1.186 & 131,37 & 0,111 \\
\hline 19 & 20.146 & $2.232,31$ & 0,294 & 84 & 26.996 & $2.991,37$ & 0,360 & 149 & 45.239 & $5.012,72$ &, 536 & 214 & 139 & 15,43 & 0,101 \\
\hline 20 & 12.517 & $1.386,95$ & 0,221 & 85 & 33.830 & $3.748,55$ & 0,426 & 150 & 13.357 & $1.480,02$ & ,229 & 215 & 0 & 0,00 & 0,100 \\
\hline 21 & 13.776 & $1.526,44$ & 0,233 & 86 & 21.251 & $2.354,70$ & 0,305 & 151 & 5.895 & 653,15 & 0,157 & 216 & 0 & 0,00 & 0,100 \\
\hline 22 & 8.056 & 892,67 & 0,178 & 87 & 11.409 & $1.264,14$ & 0,210 & 152 & 18.234 & $2.020,46$ & 0,276 & 217 & 439 & 59,48 & 0,114 \\
\hline 23 & 7.901 & 875,50 & 0,176 & 88 & 20.893 & $2.315,03$ & 0,301 & 153 & 4.151 & 459,96 & 0,140 & 218 & 0 & 0,00 & 0,100 \\
\hline 24 & 38.202 & 233,02 & 0,468 & 89 & 41.006 & $4.543,72$ & 0,495 & 154 & 18.896 & $2.093,84$ & 0,282 & 219 & 258 & 28,56 & 0,102 \\
\hline 25 & 253 & 138,82 & 0,112 & 90 & 36.092 & $3.999,23$ & 0,448 & 155 & 21.450 & $2.376,81$ & ,307 & 220 & 0 & ,00 & 0,100 \\
\hline 26 & 14.501 & $1.606,78$ & 0,240 & 91 & 26.405 & $2.925,82$ & 0,355 & 156 & 18.366 & $2.035,12$ & 0,277 & 221 & 0 & 0,00 & 0,100 \\
\hline 27 & 20.040 & $2.220,54$ & 0,293 & 92 & 30.012 & $3.325,57$ & 0,389 & 157 & 36.841 & $4.082,26$ & ,455 & 222 & 0 & 0,00 & 0,100 \\
\hline 28 & 19.910 & $2.206,14$ & 0,292 & 93 & 14.350 & $1.590,10$ & 0,238 & 158 & 37.928 & $4.202,63$ & 0,466 & 223 & 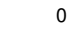 & 0,00 & 0,100 \\
\hline 29 & 11.906 & $1.319,26$ & 0,215 & 94 & 39.113 & $4.334,00$ & 0,477 & 159 & 23.563 & $2.610,88$ & 0,327 & 224 & 0 & 0,00 & 0,100 \\
\hline 30 & 8.134 & 901,35 & 0,178 & 95 & 24.392 & $2.702,75$ & 0,335 & 160 & 21.236 & $2.353,06$ & 305 & 225 & 0 & 00 & 0,100 \\
\hline 31 & 16.178 & $1.792,67$ & 0,256 & 96 & 29.737 & $3.295,00$ & 0,387 & 161 & 23.187 & $2.569,32$ & 324 & 226 & 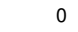 & 00 & 0,100 \\
\hline 32 & 21.489 & $2.381,08$ & 0,307 & 97 & 29.140 & $3.228,90$ & 0,381 & 162 & 41.928 & $4.645,93$ & 0,504 & 227 & 0 & 0,00 & 0,100 \\
\hline 33 & 33.929 & $3.759,57$ & 0,427 & 98 & 33.525 & $3.714,78$ & 0,423 & 163 & 15.933 & $1.765,51$ & 254 & 228 & 0 & 00 & 0,100 \\
\hline 34 & 65.393 & $7.245,95$ & 0,730 & 99 & 25.367 & $2.810,78$ & 0,345 & 164 & 46.563 & $5.159,49$ &, 549 & 229 & 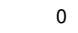 & 00 & 0,100 \\
\hline 35 & 32.483 & $3.599,34$ & 0,413 & 100 & 23.863 & $2.644,22$ & 0,330 & 165 & 39.766 & $4.406,37$ & 0,483 & 230 & 0 &, 00 & 0,100 \\
\hline 36 & 11.968 & $1.326,17$ & 0,215 & 101 & 4.728 & 523,86 & 0,146 & 166 & 3.660 & 405,52 & ,135 & 231 & 06 & 11,71 & 0,101 \\
\hline 37 & 4.358 & 482,89 & 0,142 & 102 & 22.061 & $2.444,50$ & 0,313 & 167 & 11.236 & $1.245,00$ & 0,208 & 232 & . & 0,00 & 0,100 \\
\hline 38 & 11.050 & $1.224,45$ & 0,207 & 103 & 15.406 & $1.707,13$ & 0,249 & 168 & 42.298 & $4.686,85$ & 0,508 & 233 & 0 & 0,00 & 0,100 \\
\hline 39 & 8.619 & 955,01 & 0,183 & 104 & 19.073 & $2.113,45$ & 0,284 & 169 & 9.651 & $1.069,37$ & 193 & 234 & 0 & 00 & 0,100 \\
\hline 40 & 5.437 & 602,45 & 0,152 & 105 & 23.350 & $2.587,30$ & 0,325 & 170 & 4.678 & 518,37 & 0,145 & 235 & 0 & 0,00 & 0,100 \\
\hline 41 & 16.939 & $1.876,98$ & 0,263 & 106 & 16.527 & $1.831,35$ & 0,259 & 171 & 2.797 & 309,87 & 0,127 & 236 & 495 & 276,45 & 0,124 \\
\hline 42 & 3.526 & 390,69 & 0,134 & 107 & 2.202 & 244,01 & 0,121 & 172 & 30.907 & 24,70 & 398 & 237 & 386 & 42,72 & 0,104 \\
\hline 43 & 19.905 & $2.205,61$ & 0,292 & 108 & 82.997 & 196,61 & 0,900 & 173 & 19.848 & $2.199,33$ & 0,291 & 238 & 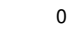 & 0,00 & 0,100 \\
\hline 44 & 9.497 & $1.052,32$ & 0,192 & 109 & 6.410 & 710,27 & 0,162 & 174 & 15.853 & $1.756,59$ & 0,253 & 239 & 0 & 0,00 & 0,100 \\
\hline 45 & 53.445 & $5.922,10$ & 0,615 & 110 & 32.717 & $3.625,25$ & 0,415 & 175 & 1.345 & 149,00 & ,113 & 240 & 279 & 52,58 & 0,122 \\
\hline 46 & 16.991 & $1.882,74$ & 0,264 & 111 & 7.501 & 831,13 & 0,172 & 176 & 4.757 & 527,07 & 0,146 & 241 & 0 & 0,00 & 0,100 \\
\hline 47 & 32.465 & $3.597,32$ & 0,413 & 112 & 48.149 & $5.335,23$ & 0,564 & 177 & 3.995 & 442,70 & 0,139 & 242 & 11 & 11,73 & 0,118 \\
\hline 48 & 36.751 & $4.072,27$ & 0,454 & 113 & 45.095 & $4.996,78$ & 0,535 & 178 & 14.805 & 640,53 & ,243 & 243 & 0 & 0,00 & 0,100 \\
\hline 49 & 15.415 & $1.708,10$ & 0,249 & 114 & 14.792 & $1.639,09$ & 0,243 & 179 & 74 & 8,22 & 0,101 & 244 & 1.096 & 121,43 & 0,111 \\
\hline 50 & 4.114 & 455,91 & 0,140 & 115 & 7.102 & 786,92 & 0,168 & 180 & 378 & 152,74 & 0,113 & 245 & 725 & 80,31 & 0,107 \\
\hline 51 & 21.206 & $2.349,71$ & 0,304 & 116 & 22.196 & $2.459,42$ & 0,314 & 181 & 140 & 458,74 & , 140 & 246 & 90 & 10,03 & 0,101 \\
\hline 52 & 22.604 & $2.504,63$ & 0,318 & 117 & 25.803 & $2.859,13$ & 0,349 & 182 & 45.883 & $.084,18$ & 0,542 & 247 & .137 & 125,96 & 0,111 \\
\hline 53 & 10.007 & $1.108,80$ & 0,196 & 118 & 14.387 & $1.594,20$ & 0,239 & 183 & 20.814 & $2.306,29$ & 0,301 & 248 & 104 & 11,56 & 0,101 \\
\hline 54 & 20.423 & $2.263,00$ & 0,297 & 119 & 14.038 & $1.555,51$ & 0,235 & 184 & 19.146 & 121,53 & 0,285 & 249 & 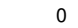 & 0,00 & 0,100 \\
\hline 55 & 36.646 & $4.060,66$ & 0,453 & 120 & 7.816 & 866,01 & 0,175 & 185 & 45.497 & $5.041,40$ & 0,539 & 250 & 05 & 11,59 & 0,101 \\
\hline 56 & 24.539 & $2.719,11$ & 0,337 & 121 & 9.240 & $1.023,81$ & 0,189 & 186 & 16.082 & $1.782,00$ & 0,255 & 251 & 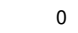 & 0,00 & 0,100 \\
\hline 57 & 37.662 & $4.173,21$ & 0,463 & 122 & 20.597 & $2.282,27$ & 0,299 & 187 & 4.619 & 511,84 & 0,145 & 252 & 0 & 0,00 & 0,100 \\
\hline 58 & 21.776 & $2.412,90$ & 0,310 & 123 & 14.217 & $1.575,29$ & 0,237 & 188 & 8.734 & 967,82 & 0,184 & 253 & 0 & 0,00 & 0,100 \\
\hline 59 & 23.738 & $2.630,27$ & 0,329 & 124 & 7.299 & 808,79 & 0,170 & 189 & 39.671 & $4.395,82$ & 0,482 & 254 & 63 & 6,96 & 0,101 \\
\hline 60 & 4.219 & 467,54 & 0,141 & 125 & 23.001 & $2.548,63$ & 0,322 & 190 & 5.048 & 559,31 & 0,149 & \multirow{6}{*}{\multicolumn{4}{|c|}{$\begin{array}{r}\text { ZO = Zona de Origem } \\
\text { Soma_Matr_Md }=\text { Somatória da } \\
\text { proporção de matrículas da zona de } \\
\text { origem com respeito da zona de } \\
\text { destino (eq. 5.4) } \\
\text { Matr_Nor = Proporção matrículas } \\
\text { normalizadas }\end{array}$}} \\
\hline 61 & 3.922 & 434,62 & 0,138 & 126 & 58.312 & $6.461,33$ & 0,662 & 191 & 20.408 & $2.261,36$ & 0,297 & & & & \\
\hline 62 & 2.277 & 252,28 & 0,122 & 127 & 20.011 & $2.217,40$ & 0,293 & 192 & 13.157 & $1.457,90$ & 0,227 & & & & \\
\hline 63 & 12.333 & $.366,55$ & 0,219 & 128 & 12.646 & $1.401,23$ & 0,222 & 193 & 11.633 & $1.289,03$ & 0,212 & & & & \\
\hline 64 & 5.569 & 617,11 & 0,154 & 129 & 21.884 & $2.424,91$ & 0,311 & 194 & 6.868 & 761,00 & 0,166 & & & & \\
\hline 65 & 7.473 & 828,03 & 0,172 & 130 & 18.728 & $2.075,18$ & 0,281 & 195 & 1.102 & 122,05 & 0,111 & & & & \\
\hline
\end{tabular}


Tabela A.3: Índice Normalizado de Atratividade por Empregos da RMSP/87.

\begin{tabular}{|c|c|c|c|c|c|c|c|c|c|c|c|c|c|c|c|}
\hline 온 & 플 & 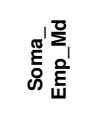 & $\begin{array}{l}\text { 흐 } \\
\text { Z } \\
\text { 을 }\end{array}$ & 온 & 플 & 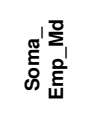 & $\begin{array}{l}\text { 흐 } \\
\text { z } \\
\text { 을 }\end{array}$ & ㅇ & 플 & 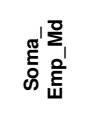 & 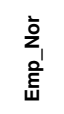 & 욧 & 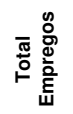 & 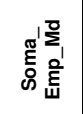 & $\begin{array}{l}\dot{z}_{1} \\
\frac{o}{E} \\
\text { wै }\end{array}$ \\
\hline 1 & 346.758 & $15.177,78$ & 0,900 & 66 & 14.600 & 639,05 & 0,134 & 131 & 74.442 & $3.258,39$ & 0,272 & 196 & 14.593 & 638,72 & 0,134 \\
\hline 2 & 24.012 & $1.051,03$ & 0,155 & 67 & 39.959 & $1.749,03$ & 0,192 & 132 & 7.772 & 340,20 & 0,118 & 197 & 2.778 & 121,60 & 0,106 \\
\hline 3 & 4.410 & 193,04 & 0,110 & 68 & 39.433 & $1.726,00$ & 0,191 & 133 & 10.934 & 478,59 & 0,125 & 198 & 3.018 & 132,11 & 0,107 \\
\hline 4 & 7.349 & 321,67 & 0,117 & 69 & 20.181 & 883,34 & 0,147 & 134 & 9.279 & 406,16 & 0,121 & 199 & 3.272 & 143,21 & 0,108 \\
\hline 5 & 22.848 & $1.000,09$ & 0,153 & 70 & 11.790 & 516,04 & 0,127 & 135 & 18.076 & 791,18 & 0,142 & 200 & 3.243 & 141,94 & 0,107 \\
\hline 6 & 40.149 & 50,09 & 0,103 & 71 & 18.887 & 826,68 & 0,144 & 136 & 6.042 & 264,47 & 0,114 & 201 & 1.309 & 57,29 & 0,103 \\
\hline 7 & 20.084 & 879,08 & 0,146 & 72 & 10.982 & 480,70 & 0,125 & 137 & 25.183 & $1.102,25$ & 0,158 & 202 & 934 & 40,90 & 0,102 \\
\hline 8 & 13.334 & 583,65 & 0,131 & 73 & 4.868 & 213,06 & 0,111 & 138 & 15.227 & 666,49 & 0,135 & 203 & 17.613 & 770,91 & 0,141 \\
\hline 9 & 24.247 & $1.061,31$ & 0,156 & 74 & 8.266 & 361,82 & 0,119 & 139 & 44.077 & $1.929,29$ & 0,202 & 204 & 11.594 & 507,46 & 0,127 \\
\hline 10 & 38.010 & $1.663,71$ & 0,188 & 75 & 16.949 & 741,86 & 0,139 & 140 & 2.116 & 92,61 & 0,105 & 205 & 2.404 & 105,23 & 0,106 \\
\hline 11 & 24.312 & $1.064,14$ & 0,156 & 76 & 15.934 & 697,44 & 0,137 & 141 & 10.577 & 462,97 & 0,124 & 206 & 4.198 & 183,73 & 0,110 \\
\hline 12 & 31.661 & $1.385,83$ & 0,173 & 77 & 17.665 & 773,21 & 0,141 & 142 & 52.696 & $2.306,55$ & 0,222 & 207 & 2.204 & 96,45 & 0,105 \\
\hline 13 & 61.713 & $2.701,21$ & 0,242 & 78 & 21.533 & 942,51 & 0,150 & 143 & 2.902 & 127,01 & 0,107 & 208 & 9.495 & 415,60 & 0,122 \\
\hline 14 & 67.871 & $2.970,76$ & 0,257 & 79 & 14.749 & 645,59 & 0,134 & 144 & 9.770 & 427,64 & 0,123 & 209 & 306 & 13,38 & 0,101 \\
\hline 15 & 33.683 & $1.474,33$ & 0,178 & 80 & 29.661 & $1.298,26$ & 0,168 & 145 & 755 & 33,03 & 0,102 & 210 & 19.979 & 874,49 & 0,146 \\
\hline 16 & 30.098 & $1.317,40$ & 0,169 & 81 & 20.011 & 875,87 & 0,146 & 146 & 3.649 & 159,74 & 0,108 & 211 & 864 & 37,83 & 0,102 \\
\hline 17 & 22.815 & 998,64 & 0,153 & 82 & 25.102 & $1.098,71$ & 0,158 & 147 & 4.044 & 177,03 & 0,109 & 212 & 9.605 & 420,41 & 0,122 \\
\hline 18 & 68.147 & $2.982,85$ & 0,257 & 83 & 39.612 & $1.733,84$ & 0,191 & 148 & 4.250 & 186,03 & 0,110 & 213 & 2.090 & 91,46 & 0,105 \\
\hline 19 & 125.797 & $5.506,23$ & 0,390 & 84 & 20.529 & 898,58 & 0,147 & 149 & 29.520 & $1.292,09$ & 0,168 & 214 & 554 & 24,23 & 0,101 \\
\hline 20 & 46.135 & $2.019,37$ & 0,206 & 85 & 37.425 & $1.638,12$ & 0,186 & 150 & 21.032 & 920,60 & 0,149 & 215 & 1.577 & 69,04 & 0,104 \\
\hline 21 & 32.965 & $1.442,92$ & 0,176 & 86 & 16.637 & 728,22 & 0,138 & 151 & 7.051 & 308,63 & 0,116 & 216 & 185 & 8,10 & 0,100 \\
\hline 22 & 20.607 & 901,97 & 0,148 & 87 & 10.935 & 478,63 & 0,125 & 152 & 19.377 & 848,16 & 0,145 & 217 & .248 & 54,63 & 0,103 \\
\hline 23 & 14.668 & 642,04 & 0,134 & 88 & 20.029 & 876,70 & 0,146 & 153 & 2.342 & 102,49 & 0,105 & 218 & 0 & 0,00 & 0,100 \\
\hline 24 & 72.048 & $3.153,57$ & 0,266 & 89 & 22.626 & 990,34 & 0,152 & 154 & 14.117 & 617,89 & 0,133 & 219 & 0 & 0,00 & 0,100 \\
\hline 25 & 40.210 & $1.760,00$ & 0,193 & 90 & 23.932 & $1.047,52$ & 0,155 & 155 & 22.827 & 999,16 & 0,153 & 220 & 795 & 34,79 & 0,102 \\
\hline 26 & 23.185 & $1.014,83$ & 0,153 & 91 & 18.975 & 830,54 & 0,144 & 156 & 19.843 & 868,54 & 0,146 & 221 & 0 & 0,00 & 0,100 \\
\hline 27 & 27.241 & $1.192,33$ & 0,163 & 92 & 16.593 & 726,28 & 0,138 & 157 & 65.351 & $2.860,46$ & 0,251 & 222 & 562 & 24,62 & 0,101 \\
\hline 28 & 51.698 & $2.262,83$ & 0,219 & 93 & 14.279 & 625,01 & 0,133 & 158 & 44.504 & $1.947,96$ & 0,203 & 223 & 0 & 0,00 & 0,100 \\
\hline 29 & 24.680 & $1.080,26$ & 0,157 & 94 & 27.478 & $1.202,71$ & 0,163 & 159 & 13.169 & 576,42 & 0,130 & 224 & 0 & 0,00 & 0,100 \\
\hline 30 & 47.711 & $2.088,34$ & 0,210 & 95 & 16.779 & 734,44 & 0,139 & 160 & 62.494 & $2.735,38$ & 0,244 & 225 & 0 & 0,00 & 0,100 \\
\hline 31 & 31.679 & $1.386,61$ & 0,173 & 96 & 13.241 & 579,56 & 0,131 & 161 & 21.209 & 928,34 & 0,149 & 226 & 128 & 5,61 & 0,100 \\
\hline 32 & 52.050 & $2.278,25$ & 0,220 & 97 & 20.258 & 886,72 & 0,147 & 162 & 84.070 & $3.679,80$ & 0,294 & 227 & 513 & 22,45 & 0,101 \\
\hline 33 & 71.034 & $3.109,18$ & 0,264 & 98 & 11.525 & 504,44 & 0,127 & 163 & 28.689 & $1.255,74$ & 0,166 & 228 & 0 & 0,00 & 0,100 \\
\hline 34 & 94.399 & $4.131,88$ & 0,318 & 99 & 16.756 & 733,43 & 0,139 & 164 & 60.222 & $2.635,94$ & 0,239 & 229 & 612 & 26,80 & 0,101 \\
\hline 35 & 74.169 & $3.246,42$ & 0,271 & 100 & 11.116 & 486,55 & 0,126 & 165 & 70.264 & $3.075,50$ & 0,262 & 230 & 754 & 33,02 & 0,102 \\
\hline 36 & 47.959 & $2.099,19$ & 0,211 & 101 & 3.096 & 135,51 & 0,107 & 166 & 3.354 & 146,80 & 0,108 & 231 & 1.783 & 78,05 & 0,104 \\
\hline 37 & 25.100 & $1.098,64$ & 0,158 & 102 & 15.268 & 668,30 & 0,135 & 167 & 36.364 & $1.591,68$ & 0,184 & 232 & 1.112 & 48,68 & 0,103 \\
\hline 38 & 38.880 & $1.701,79$ & 0,190 & 103 & 22.513 & 985,42 & 0,152 & 168 & 63.140 & $2.763,67$ & 0,246 & 233 & 0 & 0,00 & 0,100 \\
\hline 39 & 14.147 & 619,20 & 0,133 & 104 & 55.453 & $2.427,22$ & 0,228 & 169 & 3.630 & 158,87 & 0,108 & 234 & 0 & 0,00 & 0,100 \\
\hline 40 & 8.343 & 365,17 & 0,119 & 105 & 64.858 & $2.838,88$ & 0,250 & 170 & 4.788 & 209,59 & 0,111 & 235 & 0 & 0,00 & 0,100 \\
\hline 41 & 40.544 & $1.774,63$ & 0,194 & 106 & 42.476 & $1.859,20$ & 0,198 & 171 & 2.642 & 115,64 & 0,106 & 236 & 220 & 228,48 & 0,112 \\
\hline 42 & 32.895 & $1.439,85$ & 0,176 & 107 & 2.305 & 100,90 & 0,105 & 172 & 35.199 & $1.540,66$ & 0,181 & 237 & 1.305 & 57,10 & 0,103 \\
\hline 43 & 27.795 & $1.216,59$ & 0,164 & 108 & 43.792 & $1.916,82$ & 0,201 & 173 & 18.011 & 788,36 & 0,142 & 238 & 1.325 & 58,02 & 0,103 \\
\hline 44 & 30.890 & $1.352,08$ & 0,171 & 109 & 29.072 & $1.272,48$ & 0,167 & 174 & 20.141 & 881,57 & 0,146 & 239 & 0 & 0,00 & 0,100 \\
\hline 45 & 40.713 & $1.782,02$ & 0,194 & 110 & 37.832 & $1.655,95$ & 0,187 & 175 & 3.001 & 131,35 & 0,107 & 240 & 2.502 & 109,51 & 0,106 \\
\hline 46 & 26.764 & $1.171,50$ & 0,162 & 111 & 3.137 & 137,29 & 0,107 & 176 & 4.660 & 203,98 & 0,111 & 241 & 1.781 & 77,95 & 0,104 \\
\hline 47 & 32.580 & $1.426,03$ & 0,175 & 112 & 30.684 & $1.343,04$ & 0,171 & 177 & 10.171 & 445,20 & 0,123 & 242 & 191 & 8,38 & 0,100 \\
\hline 48 & 41.808 & $1.829,97$ & 0,196 & 113 & 16.981 & 743,27 & 0,139 & 178 & 19.068 & 834,63 & 0,144 & 243 & 331 & 14,49 & 0,101 \\
\hline 49 & 13.801 & 604,08 & 0,132 & 114 & 31.908 & $1.396,63$ & 0,174 & 179 & 47 & 2,07 & 0,100 & 244 & 2.674 & 117,03 & 0,106 \\
\hline 50 & 24.048 & $1.052,57$ & 0,155 & 115 & 31.024 & $1.357,96$ & 0,172 & 180 & 1.930 & 84,46 & 0,104 & 245 & 1.128 & 49,39 & 0,103 \\
\hline 51 & 44.048 & $1.927,98$ & 0,202 & 116 & 34.941 & $1.529,38$ & 0,181 & 181 & 3.194 & 139,78 & 0,107 & 246 & 798 & 34,91 & 0,102 \\
\hline 52 & 35.139 & $1.538,07$ & 0,181 & 117 & 24.288 & $1.063,08$ & 0,156 & 182 & 39.882 & $1.745,66$ & 0,192 & 247 & 1.914 & 83,76 & 0,104 \\
\hline 53 & 12.473 & 545,93 & 0,129 & 118 & 17.981 & 787,05 & 0,141 & 183 & 39.695 & $1.737,48$ & 0,192 & 248 & 323 & 14,15 & 0,101 \\
\hline 54 & 34.862 & $1.525,92$ & 0,180 & 119 & 7.047 & 308,43 & 0,116 & 184 & 21.934 & 960,06 & 0,151 & 249 & 112 & 4,90 & 0,100 \\
\hline 55 & 53.665 & $2.348,93$ & 0,224 & 120 & 8.488 & 371,54 & 0,120 & 185 & 27.668 & $1.211,06$ & 0,164 & 250 & 478 & 20,91 & 0,101 \\
\hline 56 & 30.972 & $1.355,68$ & 0,171 & 121 & 8.988 & 393,41 & 0,121 & 186 & 18.133 & 793,71 & 0,142 & 251 & 3.462 & 151,52 & 0,108 \\
\hline 57 & 26.195 & $1.146,58$ & 0,160 & 122 & 14.196 & 621,38 & 0,133 & 187 & 4.469 & 195,61 & 0,110 & 252 & 208 & 9,09 & 0,100 \\
\hline 58 & 55.017 & $2.408,11$ & 0,227 & 123 & 5.107 & 223,56 & 0,112 & 188 & 6.117 & 267,72 & 0,114 & 253 & 213 & 9,33 & 0,100 \\
\hline 59 & 63.701 & $2.788,21$ & 0,247 & 124 & 10.611 & 464,46 & 0,124 & 189 & 19.802 & 866,73 & 0,146 & 254 & 150 & 6,56 & 0,100 \\
\hline 60 & 22.620 & 990,07 & 0,152 & 125 & 17.322 & 758,21 & 0,140 & 190 & 29.775 & $1.303,25$ & 0,169 & \multirow{6}{*}{\multicolumn{4}{|c|}{$\begin{array}{r}\text { ZO = Zona de Origem } \\
\text { Soma_Emp_Md = Somatoria da } \\
\text { proporção de empregos da zona } \\
\text { de origem com respeito da zona } \\
\text { de destino (eq. 5.3) } \\
\text { Emp_Nor = Proporção empregos } \\
\text { normalizados }\end{array}$}} \\
\hline 61 & 21.722 & 950,76 & 0,150 & 126 & 47.038 & $2.058,90$ & 0,209 & 191 & 27.007 & $1.182,11$ & 0,162 & & & & \\
\hline 62 & 31.235 & $1.367,17$ & 0,172 & 127 & 20.556 & 899,76 & 0,147 & 192 & 10.781 & 471,90 & 0,125 & & & & \\
\hline 63 & 52.384 & $2.292,89$ & 0,221 & 128 & 19.765 & 865,14 & 0,146 & 193 & 15.534 & 679,95 & 0,136 & & & & \\
\hline 64 & 14.631 & 640,39 & 0,134 & 129 & 51.102 & $2.236,77$ & 0,218 & 194 & 7.573 & 331,47 & 0,117 & & & & \\
\hline 65 & 17.854 & 781,48 & 0,141 & 130 & 14.322 & 626,87 & 0,133 & 195 & 2.367 & 103,60 & 0,105 & & & & \\
\hline
\end{tabular}




\section{A.2. CÓDIGO FONTE EM MATLAB (exemplos)}

\section{A.2.1. REDE MLP:}

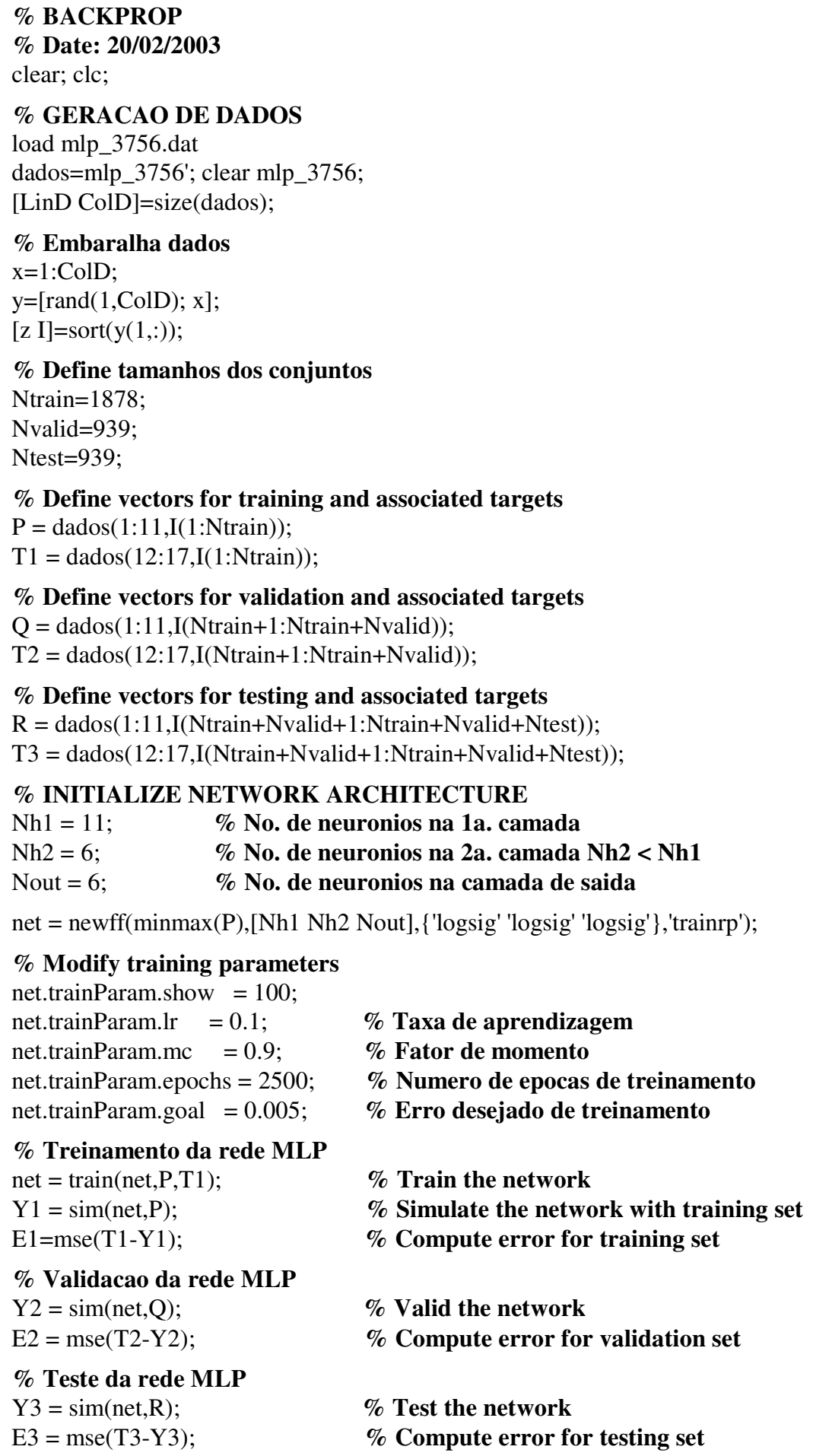

\% Mostra valores dos erros ERROS $=[$ E1 E2 E3]; 
\% Calcula porcentagem de acertos

\section{$\%$ Treinamento}

for $\mathrm{i}=1$ :Nout,

for $\mathrm{j}=1$ :Ntrain,

if $(Y 1(i, j)<0.125)$

$\mathrm{Y} 1(\mathrm{i}, \mathrm{j})=0.1$

$\operatorname{elseif}((\mathrm{Y} 1(\mathrm{i}, \mathrm{j})>=0.125) \&(\mathrm{Y} 1(\mathrm{i}, \mathrm{j})<0.475))$

$\mathrm{Y} 1(\mathrm{i}, \mathrm{j})=0.35$

if $(\mathrm{Y} 1(\mathrm{i}, \mathrm{j})>=0.775)$

$\mathrm{Y} 1(\mathrm{i}, \mathrm{j})=0.9$;

elseif( (Y1(i,j) >= 0.475) \& (Y1(i,j)<0.775) )

$\mathrm{Y} 1(\mathrm{i}, \mathrm{j})=0.65$

end

end

end

end

\% Calcula taxa de acertos treinamento

E_train=abs(T1-Y1);

$\mathrm{W}=\operatorname{sum}($ E_train);

Nerros=length(find $(\mathrm{W}))$;

Tx_acerto $1=100 *($ Ntrain-Nerros $) /$ Ntrain;

\section{\% Validação}

for $\mathrm{i}=1$ :Nout,

for $\mathrm{j}=1$ : Nvalid,

if $(Y 2(i, j)<0.125)$

$\mathrm{Y} 2(\mathrm{i}, \mathrm{j})=0.1$

elseif( $(Y 2(i, j)>=0.125) \&(Y 2(i, j)<0.475))$

$\mathrm{Y} 2(\mathrm{i}, \mathrm{j})=0.35$

if $(Y 2(i, j)>=0.775)$

$\mathrm{Y} 2(\mathrm{i}, \mathrm{j})=0.9$;

elseif( $(\mathrm{Y} 2(\mathrm{i}, \mathrm{j})>=0.475) \&(\mathrm{Y} 2(\mathrm{i}, \mathrm{j})<0.775))$

$\mathrm{Y} 2(\mathrm{i}, \mathrm{j})=0.65$

end

end

end

end

\% Calcula taxa de acertos validação

E_valid =abs(T2-Y2);

$\mathrm{W}=\operatorname{sum}($ E_valid);

Nerros $=$ length $($ find $(\mathrm{W}))$;

Tx_acerto $2=100 *($ Nvalid-Nerros $) /$ Nvalid;

$\%$ Teste

for $\mathrm{i}=1$ :Nout,

for $\mathrm{j}=1$ : Ntest,

if $(Y 3(i, j)<0.125)$

$\mathrm{Y} 3(\mathrm{i}, \mathrm{j})=0.1$;

elseif( $(Y 3(i, j)>=0.125) \&(Y 3(i, j)<0.475))$

$\mathrm{Y} 3(\mathrm{i}, \mathrm{j})=0.35$;

if $(Y 3(i, j)>=0.775)$

$\mathrm{Y} 3(\mathrm{i}, \mathrm{j})=0.9$;

$\operatorname{elseif}((\mathrm{Y} 3(\mathrm{i}, \mathrm{j})>=0.475) \&(\mathrm{Y} 3(\mathrm{i}, \mathrm{j})<0.775))$

$\mathrm{Y} 3(\mathrm{i}, \mathrm{j})=0.65$

end

end

end 
end

\% Calcula taxa de acertos teste

E_test =abs(T3-Y3);

$\mathrm{W}=$ sum(E_test);

Nerros=length(find (W));

Tx_acerto3=100*(Ntest -Nerros)/Ntest;

\% Mostra as taxas de acertos

Taxas=[Tx_acerto1 Tx_acerto2 Tx_acerto3]

\% Salva os arquivos de Teste

size(T3);

R3 = T3';

dlmwrite ('tsaida_m3756a.txt',R3,' ',0,0)

size(Y3);

D3 = Y3';

dlmwrite ('ysaida_m3756a.txt',D3,' ',0,0)

\% FIM

\section{A.2.2. REDE ELMAN:}

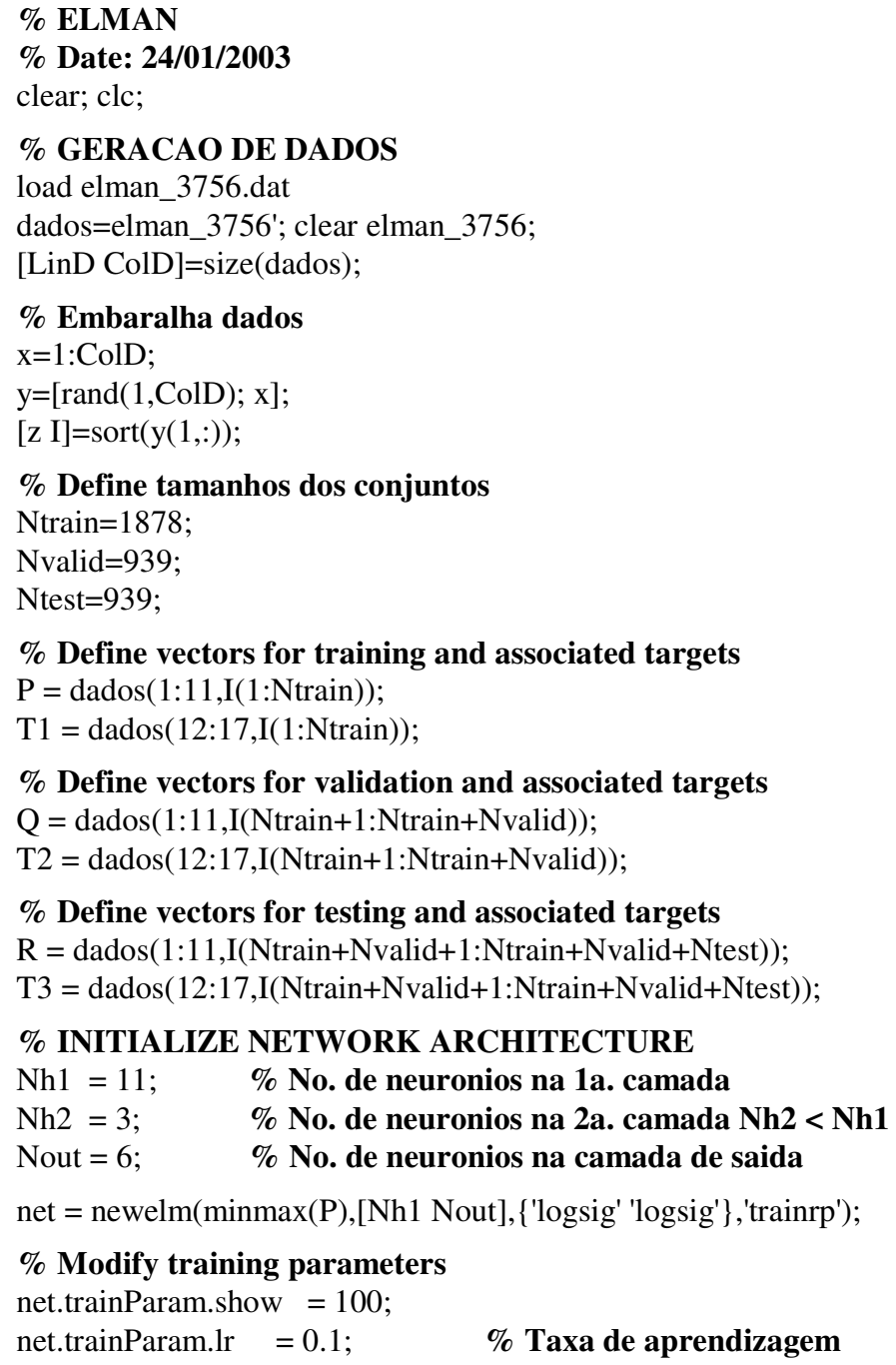

$\%$ Define vectors for validation and associated targets $\mathrm{Q}=\operatorname{dados}(1: 11, \mathrm{I}($ Ntrain+1:Ntrain+Nvalid $))$; 


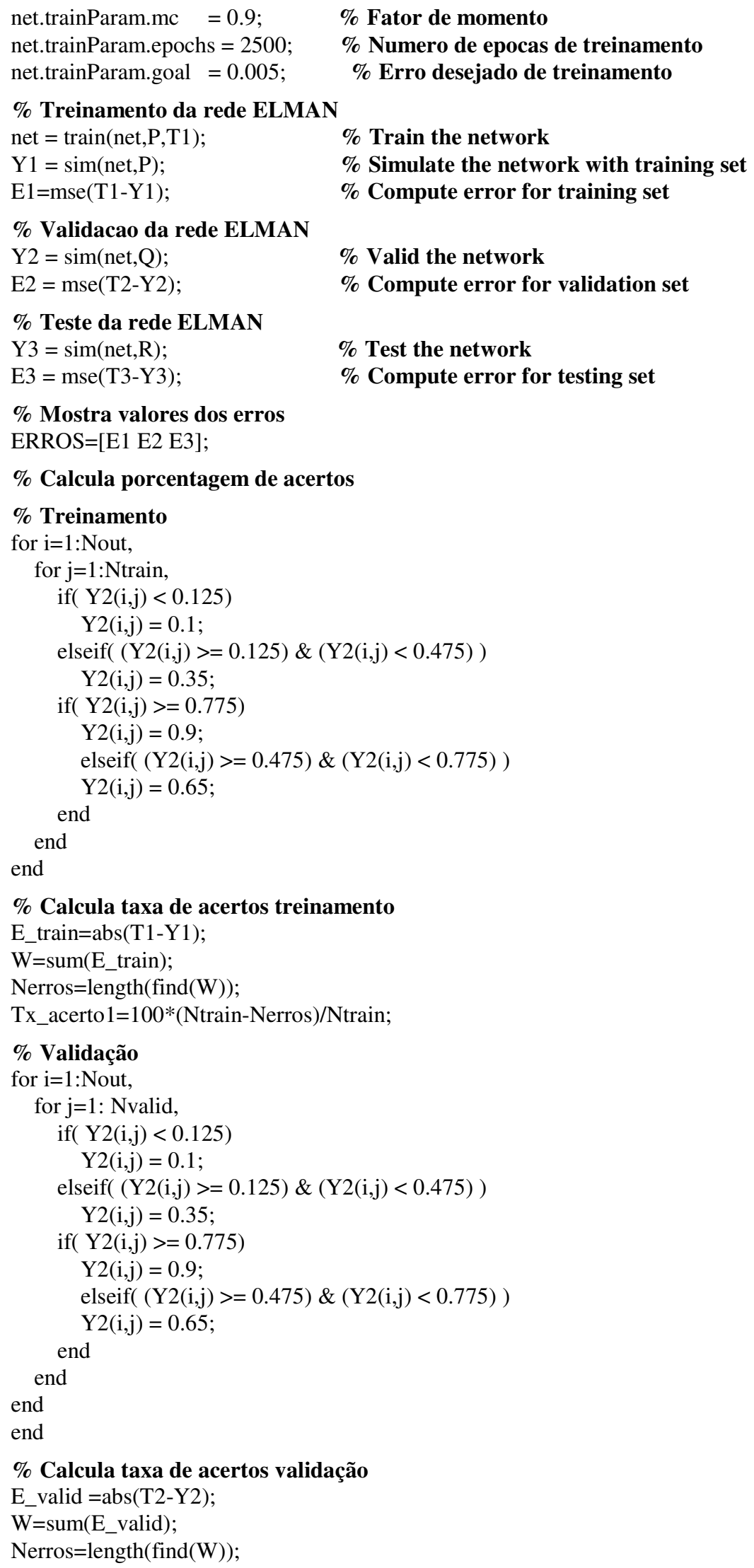


Tx_acerto $2=100 *($ Nvalid-Nerros $) /$ Nvalid;

$\%$ Teste

for $\mathrm{i}=1$ :Nout,

for $\mathrm{j}=1$ : Ntest,

if $(Y 3(i, j)<0.125)$

$\mathrm{Y} 3(\mathrm{i}, \mathrm{j})=0.1$;

$\operatorname{elseif}((\mathrm{Y} 3(\mathrm{i}, \mathrm{j})>=0.125) \&(\mathrm{Y} 3(\mathrm{i}, \mathrm{j})<0.475))$

$\mathrm{Y} 3(\mathrm{i}, \mathrm{j})=0.35$

if $(Y 3(i, j)>=0.775)$

$\mathrm{Y} 3(\mathrm{i}, \mathrm{j})=0.9$;

elseif( (Y3(i,j) >= 0.475) \& (Y3(i,j)<0.775) )

$\mathrm{Y} 3(\mathrm{i}, \mathrm{j})=0.65$;

end

end

end

end

\% Calcula taxa de acertos teste

E_test $=$ abs(T3-Y3);

$\mathrm{W}=$ sum(E_test);

Nerros=length(find(W));

Tx_acerto3 $=100 *($ Ntest - Nerros $) /$ Ntest;

$\%$ Mostra as taxas de acertos

Taxas=[Tx_acerto1 Tx_acerto2 Tx_acerto3]

\% Salva os arquivos de Teste

size(T3);

R3 = T3';

dlmwrite ('tsaida_e3756b.txt',R3,' ',0,0)

size(Y3);

D3 = Y3';

dlmwrite ('ysaida_e3756b.txt',D3,' ',0,0)

\% FIM 


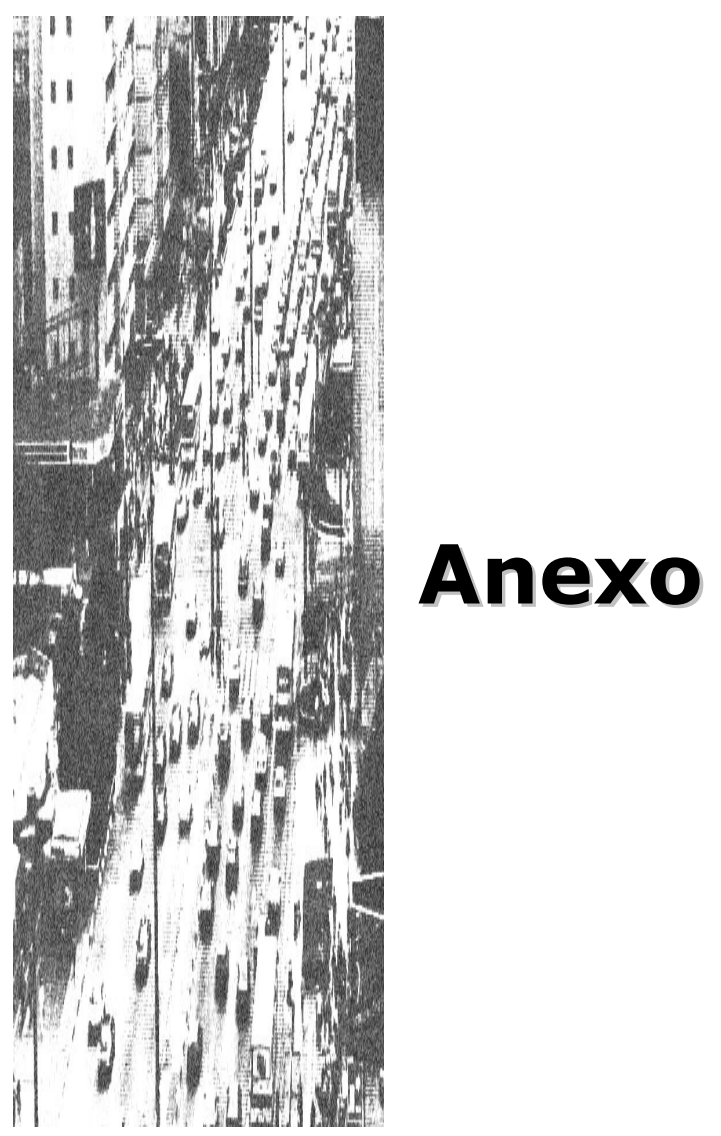

"Bienaventurado el varón que soporta la prueba; porque una vez aprobado, recibirá la corona de vida, que el Señor

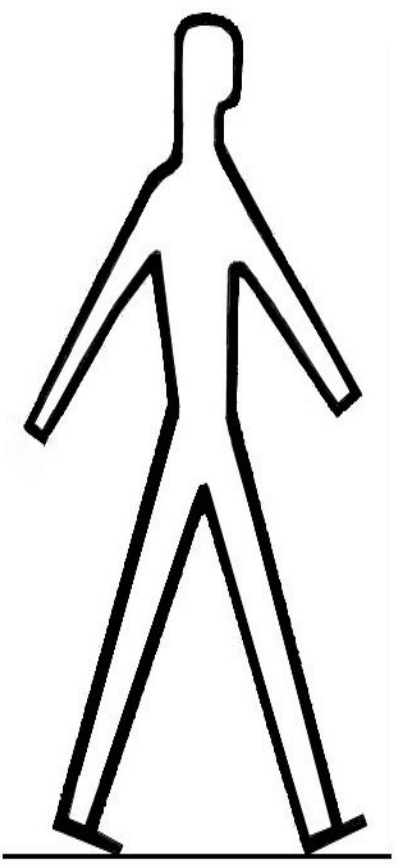
ha prometido a los que le aman" 


\begin{tabular}{|c|c|c|c|}
\hline \multicolumn{4}{|c|}{ CONFIGURACAO DA FITA JUNCAO DA PESQUISA OD / 1987} \\
\hline \multicolumn{4}{|c|}{ DADOS GERAIS } \\
\hline $\mathrm{N}$ & CAMPO & byts & CONTEUDO \\
\hline 1 & zona & 3 & zona de residência de 1 a 204 \\
\hline 2 & macro zona & 2 & macro zona de residência de 1 a 16 \\
\hline 3 & faixa & 1 & número da faixa de 1 a 4 \\
\hline 4 & livros / faixa (LFx) & 3 & total de livros da faixa \\
\hline 5 & livros pesquisados / faixa (LpFx) & 2 & total de livros pesquisados para a faixa em questão \\
\hline 6 & $\begin{array}{l}\text { fator de correção da } \\
\text { populacao (Fat_Cor) }\end{array}$ & 6 & $\begin{array}{l}\text { corrige população do universo, isto e, o número de domicílios / faixa } \\
\text { do cadastro da ELETROPAULO ( } 6 \text { dígitos, } 4 \text { casas decimais })\end{array}$ \\
\hline 7 & lote & 2 & lote (cadastro ELETROPAULO) \\
\hline 8 & distrito & 3 & distrito (cadastro ELETROPAULO) \\
\hline 9 & livro & 5 & livro (cadastro ELETROPAULO) \\
\hline 10 & domicílios / livro (DLv) & 6 & total de domicílios para o livro \\
\hline 11 & domicílios pesquisados / livro (DpLv) & 2 & total de domicílios pesquisados para o livro em questão \\
\hline 12 & $\begin{array}{l}\text { total de famílias } \\
\text { amostradas / livro (FaDm) }\end{array}$ & 6 & $\begin{array}{l}\text { somatória do número total de famílias encontradas } \\
\text { nos domicílios amostrados do livro }\end{array}$ \\
\hline 13 & famílias pesquisadas / livro (FpDm) & 3 & total de famílias pesquisadas no livro \\
\hline \multicolumn{4}{|c|}{ DADOS DO DOMICILIO } \\
\hline 14 & identifica domicilio & 1 & se 1o_registro domic. (1), senão (0) \\
\hline 15 & fator de expan. do domic (FE_D) & 6 & FE_D $=(\mathrm{LFx} / \mathrm{LpFx})^{*}(\mathrm{DLv} / \mathrm{DpLv}) *$ Fat_Cor \\
\hline 16 & domicilio & 4 & número do domicilio pesquisado \\
\hline 17 & sub zona (seqüencial) & 4 & de 1 a 1012 identificando a subzona com numeração seqüencial \\
\hline 18 & sub zona / zona & 1 & de 0 a 9 identificando a subzona da zona que pertence o domicilio \\
\hline 19 & tipo de domicilio & 1 & (1) individual; (2) coletivo \\
\hline 20 & famílias / domicilio & 2 & total de famílias que moram no domicilio amostrado \\
\hline 21 & famílias pesquisadas / domicilio & 1 & total de famílias pesquisadas do domicilio amostrado \\
\hline \multicolumn{4}{|c|}{ DADOS DA FAMÍLIAS } \\
\hline 22 & identifica família & 1 & se $1^{\circ}{ }_{2}$ registro famílias $(1)$, senão $(0)$ \\
\hline 23 & $\begin{array}{l}\text { fator de expan. dados familiar } \\
\text { (FE_F) }\end{array}$ & 6 & fator de expansão dados da famílias $\mathrm{FE} \_\mathrm{F}=(\mathrm{FaDm} / \mathrm{FpDm}) * \mathrm{FE} \_\mathrm{D}$ \\
\hline 24 & Família & 2 & número da famílias no domicilio \\
\hline 25 & data da entrevista ( ddmmaa ) & 6 & data em que a famílias foi entrevistada \\
\hline 26 & código da entrevista & 1 & $\begin{array}{ll}\text { (1) recusa total de informações } & \text { (4) incompleta } \\
\text { (2) moradores ausentes } & \text { (5) completa sem viagem } \\
\text { (3) domicilio vago } & \text { (6) completa com viagem } \\
\end{array}$ \\
\hline 27 & tempo de residência & 2 & anos de residência ( 0 se menor que 1$)$ \\
\hline 28 & código do aluguel & 1 & (1) não se aplica, (2) não respondeu, (3) sim, (4) casa própria \\
\hline 29 & aluguel (SM) & 3 & valor do aluguel $(\mathrm{SM}),(\mathrm{SM}=\mathrm{Cz} \$ 2062$, salário mínimo set/87) \\
\hline 30 & $\begin{array}{l}\text { grau de } \\
\text { instrução do } \\
\text { chefe da famílias } \\
\end{array}$ & 1 & $\begin{array}{ll}\text { (1) analfabeto } / 1^{\mathrm{o}} \text { grau ate } 4^{\mathrm{a}} \text { serie } & \text { (4) colegial concluído } \\
\text { (2) } 1^{\mathrm{o}} \text { grau ate } 4^{\mathrm{a}} \text {. serie concluído } & \text { (5) superior concluído } \\
\text { (3) } 1^{\mathrm{o}} \text { grau concluído } & \end{array}$ \\
\hline 31 & Televisores & 1 & número de televisores; (4) se possui mais que 3 televisores \\
\hline 32 & Rádios & 1 & idem ao campo TELEVISORES \\
\hline 33 & Banheiros & 1 & idem ao campo TELEVISORES \\
\hline 34 & Automóveis & 1 & idem ao campo TELEVISORES \\
\hline 35 & Empregados & 1 & idem ao campo TELEVISORES \\
\hline 36 & aspiradores de pó & 1 & idem ao campo TELEVISORES \\
\hline 37 & maquinas de lavar & 1 & idem ao campo TELEVISORES \\
\hline 38 & $\begin{array}{l}\text { classificação sócio_econômica } \\
\text { ABA - APIMEPE }\end{array}$ & 1 & $\begin{array}{l}\text { criterio ABA - ABIPEME } \\
\text { (1) classe A; (2) classe B; (3) classe C; (4) classe D; (5) classe E }\end{array}$ \\
\hline 39 & código de renda familiar & 1 & (1) não tem rend; (2) rend famili incompleta; (3) rend familiar completa \\
\hline 40 & renda familiar $(\mathrm{SM} * 10)$ & 4 & renda familiar $(\mathrm{SM}) \quad(\mathrm{SM}=\mathrm{Cz} \$ 2062$, salário mínimo set/87) \\
\hline 41 & faixa de renda media familiar & 1 & $\begin{array}{l}\text { (SM= Cz\$ 2062, salário mínimo set/87) } \\
\text { (0) não declarou }\end{array}$ \\
\hline
\end{tabular}




\begin{tabular}{|c|c|c|c|}
\hline & & & $\begin{array}{l}\text { (4) } 15-30(\mathrm{SM}) \\
(5)+\text { que } 30(\mathrm{SM})\end{array}$ \\
\hline 42 & tot. pessoas famílias & 2 & total de pessoas da famílias \\
\hline 43 & tot. viagens famílias & 2 & total de viagens da famílias \\
\hline \multicolumn{4}{|c|}{ DADOS DA PESSOA } \\
\hline 44 & identifica pessoa & 1 & se 1o. registro pessoa (1), senão (0) \\
\hline 45 & fator de expan. dados pessoa (FE_P) & 6 & FE_P $=$ FE_F ( 6 dígitos, 2 casas decimais $)$ \\
\hline 46 & Pessoa & 2 & número da pessoa dentro do domicilio \\
\hline 47 & Sexo & 1 & (1) masculino, (2) feminino \\
\hline 48 & situação familiar & 1 & (1) chefe; (2) cônjuge; (3) filho; (4) outro \\
\hline 49 & Idade & 2 & idade da pessoa \\
\hline 50 & grau de instrução & 1 & $\begin{array}{l}\text { (1) analfabeto/ 1o. grau ate 4a.serie (4) colegial concluído } \\
\begin{array}{ll}\text { (2) } 1 \text { o. grau ate } 4^{\text {a }} \text {. serie concluído } & \text { (5) superior concluído } \\
\text { (3) } 1 \text { lo. grau concluído } & \end{array}\end{array}$ \\
\hline 51 & estuda atualmente? & 1 & (1) sim; (2) não \\
\hline 52 & código de renda & 1 & (1) sem renda; (2) não informou; (3) declarou \\
\hline 53 & salário médio & 4 & salário individual $(\mathrm{SM})(\mathrm{SM}=\mathrm{Cz} \$ 2062$, salário mínimo set/87) \\
\hline 54 & faixa de renda individual & 2 & 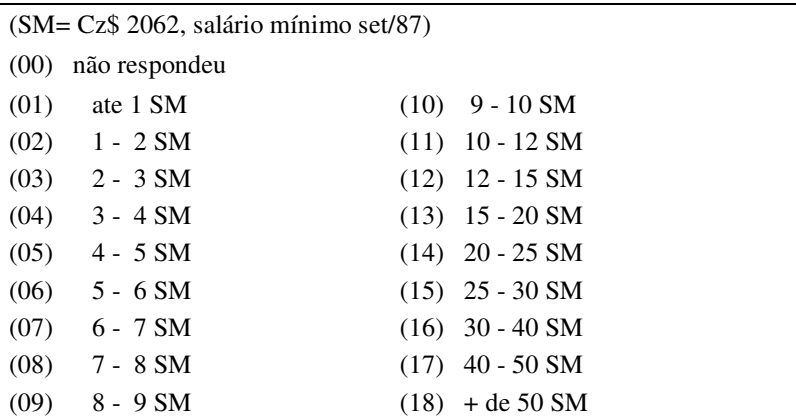 \\
\hline 55 & $\begin{array}{l}\text { classe de } \\
\text { atividade da } \\
\text { empresa na } \\
\text { qual trabalha }\end{array}$ & 2 & $\begin{array}{ll}\text { (01) agrícola } & (06) \text { serviços de transporte } \\
(02) \text { construção civil } & (07) \text { empresa de serviços } \\
(03) \text { industrial } & (08) \text { serviços autônomos } \\
\text { (04) comercial } & (09) \text { outros } \\
(05) \text { funcionalismo publico } & (10) \text { não se aplica } \\
\end{array}$ \\
\hline 56 & $\begin{array}{l}\text { Ocupação } \\
\text { Principal }\end{array}$ & 2 & 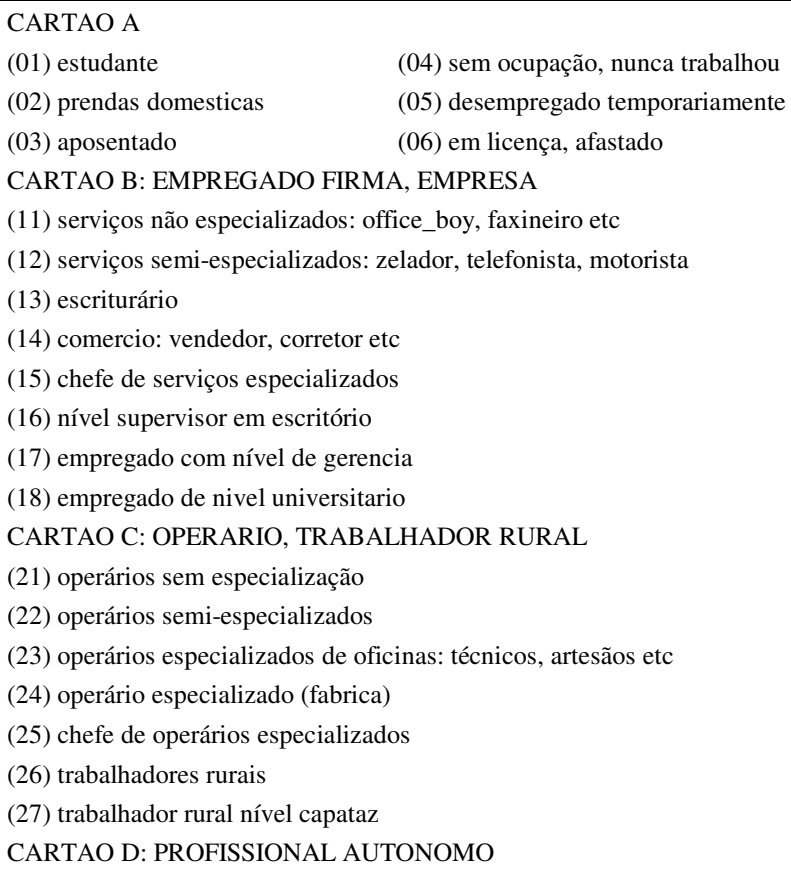 \\
\hline
\end{tabular}




\begin{tabular}{|c|c|c|c|}
\hline & & & 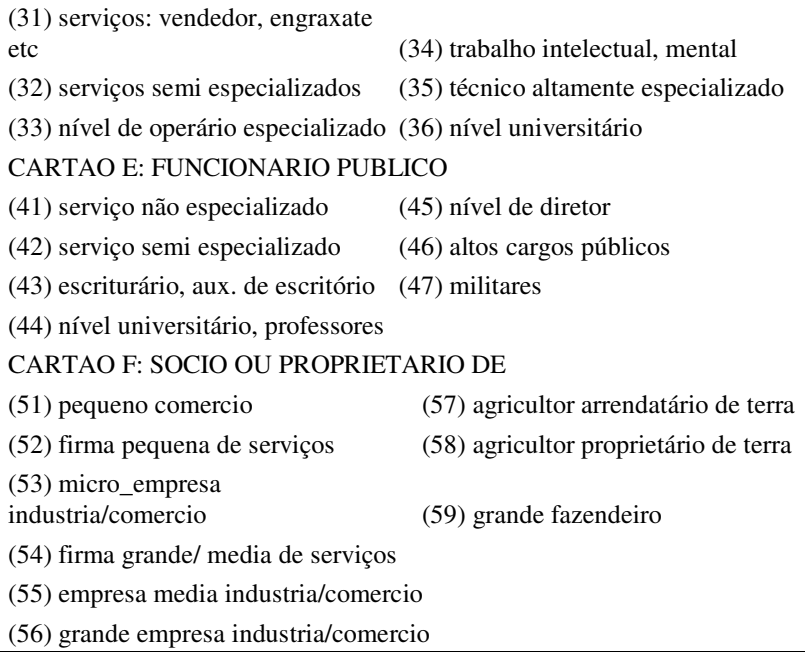 \\
\hline 57 & zona_escola & 3 & zona da escola de 1 a 254 \\
\hline 58 & macrozona_escola & 2 & macro zona da escola de 1 a 16 \\
\hline 59 & subzona_escola (seqüencial) & 4 & de 1 a 1012 identifica subzona_escola com numeração seqüencial \\
\hline 60 & subzona_escola ( por zona ) & 1 & de 1 a 9 identifica a subzona da zona que pertence a escola \\
\hline 61 & zona_1o.trabalho & 3 & zona do 1 o. trabalho de 1 a 254 \\
\hline 62 & macrozona_1o.trab. & 2 & macro zona do 1o. trabalho de 1 a 16 \\
\hline 63 & subzona_1o. Trabalho (seqüencial) & 4 & de 1 a 1012 identifica subzona do 1o. trabalho (numeração seqüencial) \\
\hline 64 & subzona_1o. Trabalho ( por zona) & 1 & de 1 a 9 identifica a subzona da zona que pertence a 10 . Trabalho \\
\hline 65 & zona_2o. trabalho & 3 & zona do 20 . trabalho de 1 a 254 \\
\hline 66 & macrozona_2o.trab & 2 & macro zona do 2 o. trabalho de 1 a 16 \\
\hline 67 & subzona_2o. Trabalho (seqüencial) & 4 & de 1 a 1012 identifica subzona do 2o. trabalho (numeração seqüencial) \\
\hline 68 & subzona_2o. Trabalho ( por zona) & 1 & de 1 a 9 identifica a subzona da zona que pertence a 20 . Trabalho \\
\hline 69 & tot. viagens pessoa & 2 & número de viagens da pessoa \\
\hline \multicolumn{4}{|c|}{ DADOS DA VIAGEM } \\
\hline 70 & dado de viagem & 1 & se existe dado viagem $(1)$, senão $(0)$ \\
\hline 71 & fator de expan. dados viagem (FE_V) & 6 & FE_V=FE_P $* 1,091$ \\
\hline 72 & dia da semana & 1 & (2) segunda; (3) terça; (4) quarta; (5) quinta; (6) sexta \\
\hline 73 & zona_origem & 3 & zona de origem de 1 a 254 \\
\hline 74 & macro zona_origem & 2 & macro zona de origem de 1 a 16 \\
\hline 75 & subzona_origem (seqüencial) & 4 & de 1 a 1012 identifica subzona de origem (numeração seqüencial) \\
\hline 76 & subzona_origem ( por zona ) & 1 & de 0 a 9 identificando a subzona da zona de origem \\
\hline 77 & zona_destino & 3 & zona de destino de 1 a 254 \\
\hline 78 & macro zona_destino & 2 & macro zona de destino de 1 a 16 \\
\hline 79 & subzona_destino (seqüencial) & 4 & de 1 a 1012 identifica subzona de destino (numeração seqüencial) \\
\hline 80 & subzona_destino ( por zona ) & 1 & de 0 a 9 identificando a subzona da zona de destino \\
\hline 81 & motivo_origem & 1 & $\begin{array}{l}\text { (1) trabalho na industria } \\
\text { (2) trabalho no comercio } \\
\text { (3) trabalho em serviços } \\
\text { (4) escola ou educação } \\
\text { (5) compras }\end{array}$ \\
\hline 82 & motivo_destino & 1 & igual ao anterior \\
\hline 83 & 10. modo da viagem & 2 & $\begin{array}{l}\text { (01) ônibus diesel } \\
(02) \text { troleibus } \\
\text { (03) ônibus fretado } \\
\text { (04) escolar } \\
\text { (05) dirigindo automóvel } \\
\text { (06) passageiro de automóvel } \\
\text { (07) táxi }\end{array}$ \\
\hline
\end{tabular}




\begin{tabular}{|c|c|c|c|c|}
\hline & & & (08) lotação & \\
\hline 84 & 2o. modo da viagem & 2 & idem ao anterior & \\
\hline 85 & 3o. modo da viagem & 2 & idem ao anterior & \\
\hline 86 & horario_saida & 4 & horario do inicio da viagem $(\mathrm{HHmm})$ & \\
\hline 87 & horario_chegada & 4 & horario do fim da viagem $(\mathrm{HHmm})$ & \\
\hline 88 & andando na origem & 2 & tempo andando na origem em minutos & \\
\hline 89 & andando no destino & 2 & tempo andando no destino em minutos & \\
\hline 90 & tipo de estacionamento & 1 & $\begin{array}{l}\text { (1) zona azul / parquimetro } \\
\text { (2) estacionamento particular } \\
\text { (3) estacionamento próprio }\end{array}$ & $\begin{array}{l}\text { (4) estacionamento patrocinado } \\
\text { (5) meio fio } \\
\text { (6) não estacionou }\end{array}$ \\
\hline 91 & tempo de duração & 3 & tempo de duração da viagem (min) & \\
\hline 92 & modo principal & 2 & $\begin{array}{l}\text { modo principal e o que caracteriza a via } \\
\text { (09) metro } \\
\text { (10) trêm } \\
\text { (02) troleibus } \\
\text { (03) ônibus fretado } \\
\text { (04) escolar } \\
\text { (01) ônibus diesel } \\
(08) \text { lotação } \\
\text { (07) táxi }\end{array}$ & $\begin{array}{l}\text { fem segundo critério de prioridade } \\
\text { (05) dirigindo automóvel } \\
\text { (06) passageiro automóvel } \\
\text { (14) caminhão } \\
\text { (11) moto } \\
\text { (12) bicicleta } \\
\text { (15) outros } \\
\text { (13) a pé }\end{array}$ \\
\hline 93 & modo individual / coletivo & 1 & $\begin{array}{l}\text { classificação do modo principal: } \\
\text { (0) a pé } \\
\text { (1) transporte individual } \\
\text { - táxi } \\
\text { - motorista de automóvel } \\
\text { - passageiro de automóvel } \\
\text { - caminhão } \\
\text { - moto } \\
\text { - bicicleta } \\
\text { - outros }\end{array}$ & $\begin{array}{l} \\
\text { (2) transporte coletivo } \\
\text { - trêm } \\
\text { - metrô } \\
\text { - troleibus } \\
\text { - ônibus fretado } \\
\text { - escolar } \\
\text { - ônibus diesel } \\
\text { - lotação }\end{array}$ \\
\hline 94 & campo unitário & 1 & contem sempre o valor 1 & \\
\hline
\end{tabular}

